
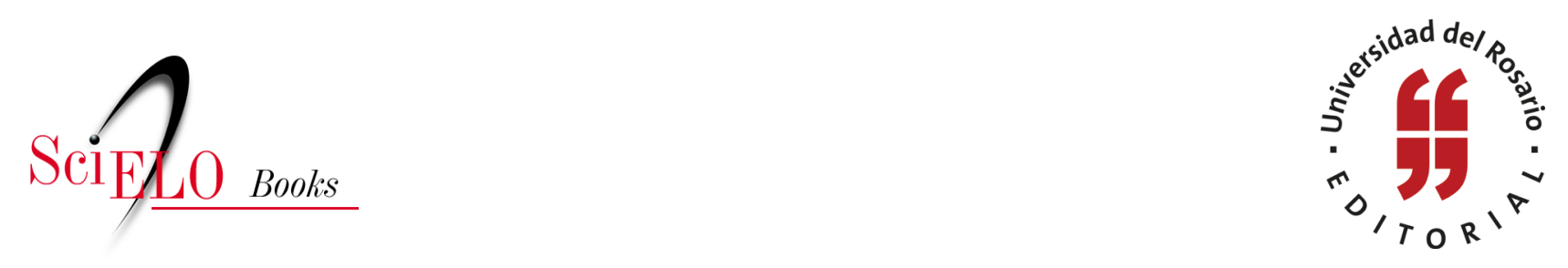

\title{
Adultos mayores privados de la libertad en Colombia
}

\author{
Carol Iván Abaunza Forero \\ Mónica Alexandra Mendoza Molina \\ Paola Bustos Benítez \\ Giovanny Paredes Álvarez \\ Karla Vanessa Enriquez Wilches \\ Andrea Carolina Padilla Muñoz
}

\section{SciELO Books / SciELO Livros / SciELO Libros}

ABAUNZA FORERO, C.I., MENDOZA MOLINA, M.A., BUSTOS BENÍTEZ, P., PAREDES ÁlVAREZ, G., ENRIQUEZ WILCHES, K.V., and PADILHA MUÑOZ, A.C. Adultos mayores privados de la libertad en Colombia [online]. Bogotá: Editorial Universidad del Rosario, Instituto Rosarista de Acción Social - SERES, 2014, 274 p. ISBN 978-958-738-532-8.

https://doi.org/10.7476/9789587385328.

All the contents of this work, except where otherwise noted, is licensed under a Creative Commons Attribution 4.0 International license.

Todo o conteúdo deste trabalho, exceto quando houver ressalva, é publicado sob a licença Creative Commons Atribição $\underline{4.0}$.

Todo el contenido de esta obra, excepto donde se indique lo contrario, está bajo licencia de la licencia Creative Commons $\underline{\text { Reconocimento } 4.0 .}$. 
UR
UR 


\title{
Adultos mayores privados de la libertad en Colombia
}

\author{
Carol Iván Abaunza Forero \\ Mónica Alexandra Mendoza Molina \\ Paola Bustos Benítez \\ Giovanny Paredes Álvarez \\ Karla Vanessa Enriquez Wilches \\ Andrea Carolina Padilla Muñoz
}




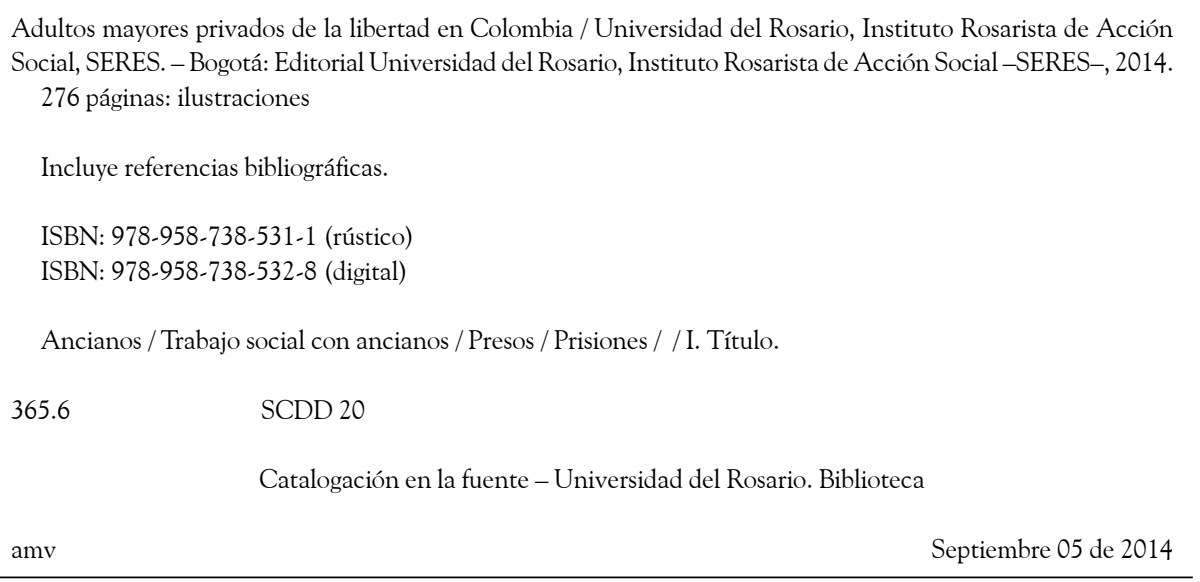

Hecho el depósito legal que marca el Decreto 460 de 1995

(c) 2014 Editorial Universidad del Rosario

(C) 2014 Universidad del Rosario, Instituto Rosarista de Acción Social -SERESGrupo de Investigación en Derechos Humanos

Editorial Universidad del Rosario

Carrera 7 № 12B-41, oficina 501 • Teléfono 2970200

http://editorial.urosario.edu.co
Primera edición: Bogotá D.C., octubre de 2014

ISBN: 978-958-738-531-1 (rústico)

ISBN: 978-958-738-532-8 (digital)

Coordinación editorial: Editorial Universidad del Rosario Corrección de estilo: Irina Florián

Diseño de cubierta: Miguel Rámirez, Kilka DG

Diagramación: Precolombi EU-David Reyes

Impresión: Xpress. Estudio Gráfico y Digital S.A.

Impreso y hecho en Colombia

Printed and made in Colombia

\section{LIBRO RESULTADO DE INVESTIGACIÓN}

Fecha de evaluación: 11 de marzo de 2014

Fecha de aprobación: 5 de junio de 2014

Todos los derechos reservados. Esta obra no puede ser reproducida sin el permiso previo por escrito de la Editorial Universidad del Rosario. 


\section{Índice}

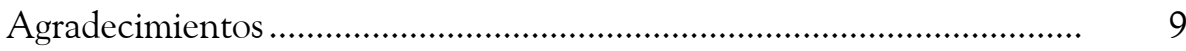

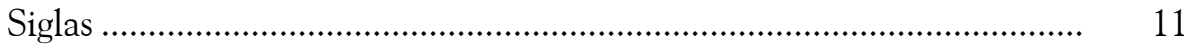

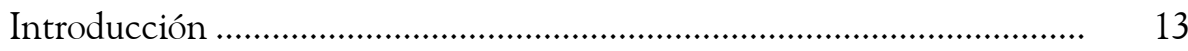

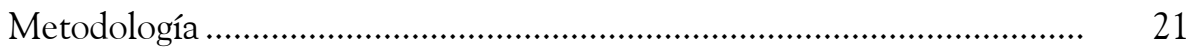

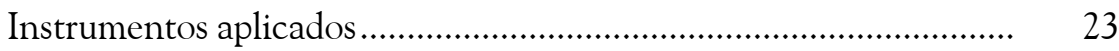

Formato de priorización de derechos fundamentales.................. 23

Lista de chequeo de 90 síntomas-revisado. SCL-90 R ................ 24

Neuropsi-Batería Neuropsicológica breve en español ................ 24

Guía para grupos focales............................................................. 25

Guía semiestructurada de visita penitenciaria ............................ 25

Principios fundantes del estado social de derecho en relación

con los adultos mayores privados de la libertad .................................. 27

Principios de solidaridad y dignidad ................................................... 28

Marco normativo de las poblaciones excepcionales .................................... 35

Los derechos constitucionales ..................................................... 36

Tratados, acuerdos y resoluciones ratificados por Colombia .............. 38

Normatividad desarrollada en Colombia sobre los adultos mayores $\quad 40$

Decretos ............................................................................ 41

Acuerdos y proyectos de acuerdo ................................................... 41

Los derechos humanos en el colectivo de los adultos mayores........... $\quad 43$ 
Panorama de las poblaciones excepcionales etarias frente

a la responsabilidad penal ........................................................... 47

Infancia y adolescencia ........................................................... 48

Adulto mayor....................................................................... 52

Pautas de atención penitenciaria a poblaciones excepcionales ............... 57

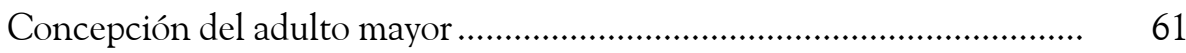

Generalidades ......................................................................... 62

El concepto del adulto mayor desde diversas disciplinas................. 71

Perspectiva jurídica del adulto mayor........................................... 71

La vejez desde las teorías psicológicas............................................ 74

Pensamientos ............................................................................. 76

Pensamientos acerca de la edad en tiempo .............................. 77

Pensamientos acerca de la edad como estado mental ............... $\quad 77$

Otras características para describir al adulto mayor ................. 78

Indicadores psicológicos de vejez................................................... 78

Capacidad/incapacidad en actividades .................................. 79

Dependencia ........................................................................ 79

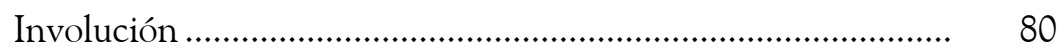

Envejecimiento como proceso................................................... 80

Cambios esperables ................................................................ 81

Reconocimiento del estado o de la edad ................................ 81

Proceso de envejecimiento .......................................................... 82

Condiciones ambientales .................................................... 82

Trato diferencial....................................................................... 84

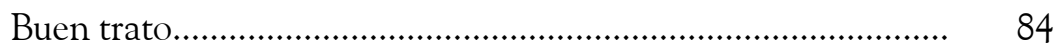

Atención médica ................................................................... 85

Exclusión ................................................................................. 85

Aspectos económicos de los adultos mayores.................................. 86

Aspectos sociológicos del adulto mayor ......................................... 88

Edad................................................................................... 94

Capacidad.......................................................................... 94

Vulnerabilidad ..................................................................... 94

Disminución de las capacidades físicas .................................... 95

Palabras otorgadas al concepto ............................................. 95

Limitación de acceso al trabajo ............................................. 96 
Aspectos positivos .................................................................... 96

Enfoque diferencial .................................................................. 97

Actitud personal y social ............................................................... 97

Caracterización de los adultos mayores privados de la libertad .................. 101

Derechos humanos y fundamentales de los adultos mayores

privados de la libertad ............................................................. 102

El derecho a la atención en salud, el más vulnerado................... 106

Incredulidad ante el sistema judicial, la normatividad................ 108

Discriminación y no igualdad ........................................................ 108

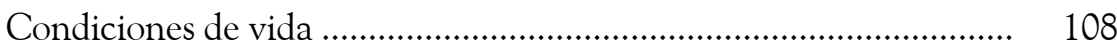

Discriminación en la población de adultos mayores privados

de la libertad ...................................................................... 110

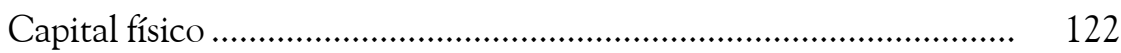

Capital humano ……................................................................... 130

Condiciones de salud de los adultos mayores privados

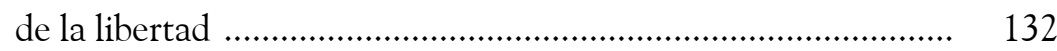

Esperanza de vida (longevidad) .................................................. 133

Estado de salud física............................................................... 134

Caracterización psicológica ..................................................... 137

Funciones cognitivas ............................................................. 139

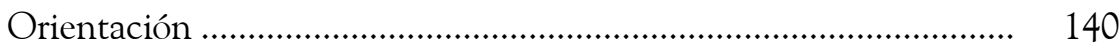

Atención y concentración .................................................................. 141

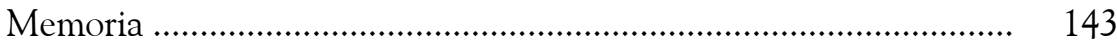

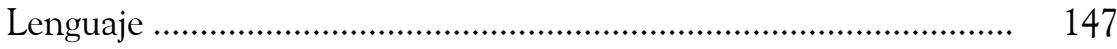

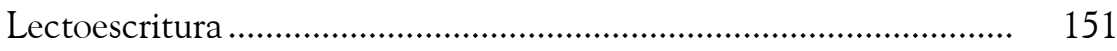

Función ejecutiva ......................................................................... 152

Condiciones psicopatológicas.................................................... 158

Percepción de enfermedad mental o psicológica

de los adultos mayores privados de la libertad ..................... 163

Necesidad de atención integral .................................................. 168

Percepción de cambios experimentados en prisión ...................... 169

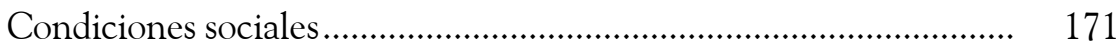

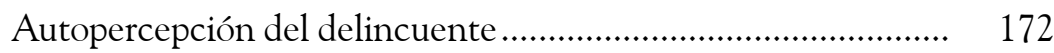

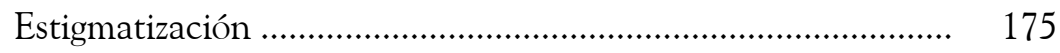

Expectativas de vida................................................................ 178

Imaginario social del delincuente............................................... 183 


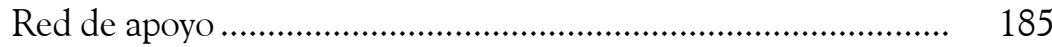

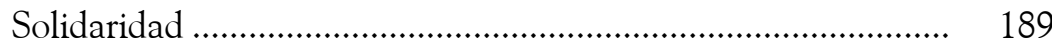

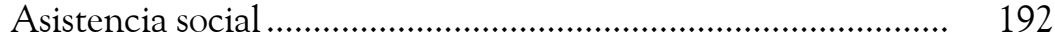

Aprendizajes en prisión ............................................................... 193

Aspectos sociales de los delitos sexuales ...................................... 195

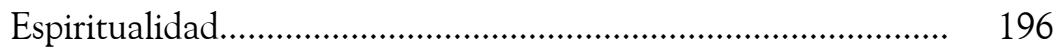

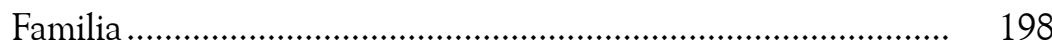

Significado otorgado a prisión ........................................................ 204

Condiciones económicas.......................................................... 205

Condiciones jurídicas ................................................................ 209

Capacidad criminal .................................................................................. 219

Razones por las cuales los adultos mayores cometen delitos ............. 221

Razones para la reincidencia .......................................................... $\quad 228$

Tratamiento penitenciario .............................................................. 231

Política criminal con enfoque diferencial en relación con el adulto mayor ..................................................................... 241

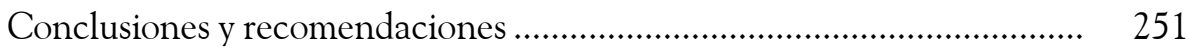

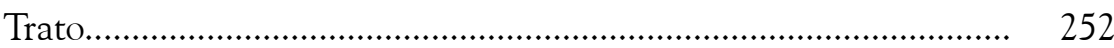

Política penitenciaria para el adulto mayor privado

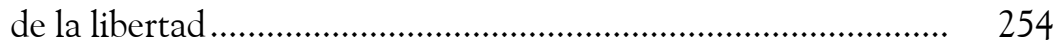

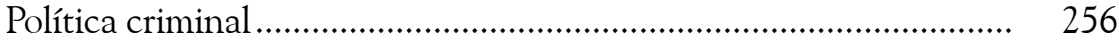

Atención y tratamiento …………………………............................ 256

Condiciones jurídicas .................................................................... 257

Condiciones de vida del adulto mayor privado de la libertad............ 259

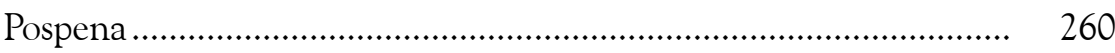

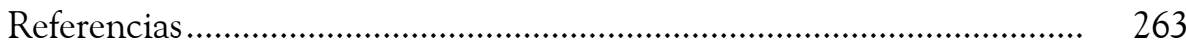




\section{Agradecimientos}

Esta investigación fue posible gracias al apoyo y la disposición prestados por el Instituto Nacional Penitenciario y Carcelario (INPEC) a los establecimientos: EPMSC Medellín, Complejo Carcelario y Penitenciario Metropolitano de Cúcuta, EPMSC Bucaramanga (ERE), Complejo Penitenciario y Carcelario de Jamundí, EPMSC Cali (ERE), Complejo Carcelario y Penitenciario de Ibagué-Picaleña, complejo Carcelario y Penitenciario Metropolitano de Bogotá, EPMSC Acacias, Reclusión de Mujeres Bogotá y Reclusión de Mujeres Medellín.

Agradecemos también al doctor Mauricio Plazas Vega, director del Instituto Seres, por su asesoría y apoyo; a los becarios y becarias del Instituto Seres; a Marcela Corredor Clavijo, por su apoyo administrativo; a Indira Velásquez Hernández, coordinadora de Acción Social del Instituto Seres, por su participación y apoyo en el trabajo de campo de la investigación, y muy especialmente a las personas privadas de la libertad, que voluntariamente decidieron compartir con nosotros muchas de sus experiencias, aportes y opiniones. 


\title{
Siglas
}

\author{
AM: adulto mayor \\ AMPL: adulto mayor privado de la libertad \\ CN: Constitución Nacional \\ CP: Código Penal \\ CPP: Código de Procedimiento Penal \\ EPC: Establecimiento Penitenciario y Carcelario \\ Inpec: Instituto Nacional Penitenciario y Carcelario \\ PPL: persona privada de la libertad \\ SPCC: sistema penitenciario y carcelario colombiano
}




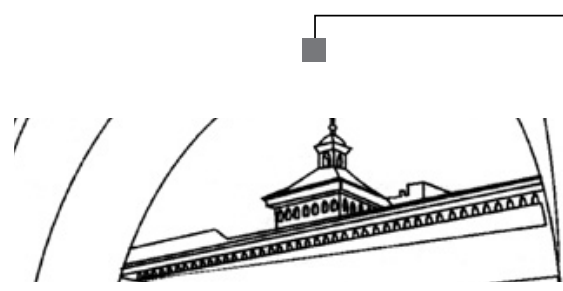




\section{Introducción}


La edad es uno de los aspectos de la vida que intriga el desarrollo humano. En las numerosas etapas que una persona tiene a lo largo de su existencia, enfrenta diversos desafíos y presenta perspectivas que se asocian a diferentes comportamientos, pero una en particular es la que, curiosamente, se anhela como la cúspide de la vida, y también se le teme: llegar a ser adulto mayor (AM).

La tendencia demográfica mundial evidencia proyecciones crecientes sobre el aumento de la población, las cuales inciden directamente en la dinámica de envejecimiento, al aumentar la esperanza de vida (Banco Mundial, 2013). De acuerdo con las Naciones Unidas (United Nations, Department of Economic and Social Affairs, Population Division, 2013), cerca del $12 \%$ de la población mundial tiene 60 años o más, y se estima que en menos de 40 años llegará a representar más del 20\%, algo que ya es una realidad en los países desarrollados. Este crecimiento de la población de AM conduce a enfrentar una realidad y a que surjan cuestionamientos sobre lo que la sociedad en su conjunto se encuentra realizando para este grupo de personas. Las decisiones que se toman parten desde el mismo concepto que se tiene del AM, las características de la población y, sobre todo, la condición que enfrentan.

Precisamente, frente a los factores y las perspectivas determinantes de la condición de los AM, se elabora el presente texto, pero con una notable particularidad de esta población, su privación de la libertad. El desafío es, entonces, analizar la realidad de los adultos mayores privados de la libertad (AMPL) para, con ello, presentar un panorama de sus características, capacidades y fundamentos, que sea relevante y apropiado para realizar recomendaciones al sistema penitenciario y carcelario colombiano (SPCC), con una perspectiva interdisciplinar que va más allá de un ejercicio ideológico y pretende ser pragmática, que se evidenció con un trabajo de campo investigativo que interrelacionó las diversas teorías y las normas con la realidad que viven los AMPL.

La Constitución Nacional de Colombia (CN), en su artículo 46, ordena que el Estado, la sociedad y la familia concurrirán para la protección y la asistencia de las personas de la tercera edad, promoviendo su integración a la vida activa y comunitaria, y garantizándoles los servicios de seguridad 
social y el subsidio alimentario en caso de indigencia. Este mandato, sin lugar a dudas, reconoce la condición de vulnerabilidad que afecta o puede afectar a este sector de la población, dentro de la cual no se exceptúan o pueden exceptuar a las personas privadas de la libertad (PPL).

La Declaración Americana de los Derechos y Deberes del Hombre, uno de los instrumentos internacionales a los que se ha adherido Colombia, establece en su artículo I que todo ser humano tiene derecho a la vida, la libertad y la seguridad de su persona; en el artículo XXV instituye que todo individuo que haya sido privado de su libertad tiene derecho a un tratamiento humano, y en el artículo XXVI establece que toda persona acusada de delito tiene derecho a que no se le impongan penas crueles, infamantes o inusitadas (Conferencia Internacional Americana, 1948).

Sin embargo, el bloque de constitucionalidad que conforman esas normas de rango superior no ha generado ni desarrollado una normativa apropiada y coherente con la que se pueda abordar y tratar de manera eficiente la condición de vulnerabilidad del AM, menos aún de aquellos que se encuentran privados de la libertad.

Pareciera entonces que las personas que por su edad se encuentran en la última fase de la vida, en otras palabras, en ese inexorable proceso de envejecimiento que solo se interrumpirá con la muerte no merecieran la atención y el cuidado que su reconocida condición demanda; no se les dispensan los mecanismos legales adecuados para hacer efectivas las garantías de sus derechos, como sí ocurre con otros grupos como el de los menores.

De allí la necesidad de una búsqueda y una revisión de la normatividad que existe a nivel internacional y nacional acerca del tema en mención, con el fin de abarcar, de manera general, el tema del AM y poder realizar, a partir de su caracterización, algunas recomendaciones de política criminal en relación con el enfoque diferencial basado en la edad, y acerca del tratamiento penitenciario que en nuestro país se le debería dar a esta población. Esta fase investigativa está acompañada de un componente metodológico de corte cualitativo y cuantitativo, aplicado en las visitas a centros penitenciarios en diferentes regiones del país.

Al respecto, el presente texto titulado Adultos mayores privados de la libertad en Colombia intenta responder a diversas inquietudes, desde los 
ámbitos jurídico, social, psicológico y económico sobre esta población. Para tal fin, se estructuró una metodología de análisis que combina de manera interdisciplinar lo teórico con lo práctico, lo cualitativo con lo cuantitativo, las fuentes secundarias con las primarias, que permite ilustrar lo que ocurre en los establecimientos penitenciarios y carcelarios (EPC), y contribuye, en alguna medida, al mejoramiento de las políticas públicas desarrolladas por las autoridades que orientan el poder judicial.

A nivel teórico-jurídico, se trabajan de manera complementaria las áreas del derecho penal con énfasis en los derechos humanos por el hecho de tratarse de una población que pertenece, como se mencionó, a un grupo sujeto a una especial protección constitucional; con lo que se pretende, de manera intencionada, que en el momento de plasmar dicho enfoque, no se vean las áreas escogidas para el trabajo de forma separada, sino que realmente se obtenga una lectura unificada, con la capacidad de influenciar de manera convincente sobre las recomendaciones de mejora que se hagan a la política criminal vigente.

Socialmente, el envejecimiento no se puede definir únicamente en términos de edad, sino que se deben considerar para su estudio otras variables como los estilos y los hábitos de vida, la condición socioeconómica, la ocupación, la salud, etc., de allí que los imaginarios sobre la vejez varíen en cada contexto y tipo de sociedad. En el ámbito penitenciario, muchos de estos imaginarios frente a la vejez, por lo general negativos, se mantienen y se suman a ellos otras condiciones particulares que permiten la construcción del sujeto AMPL. Sociológicamente, se aborda este concepto desde la perspectiva de los roles, los imaginarios y la dicotomía normal-anormal, a través de las categorías emergentes en el trabajo de campo.

En este proceso de investigación, desde la disciplina psicológica, se integran cuatro corrientes conceptuales que fueron articuladas con los aportes realizados por AMPL con el fin de fundamentar el concepto de AM, caracterizar esta población y analizar la capacidad criminal en esta: una mirada propuesta por Cristófalo (1991) en la que se asocia el envejecimiento con la disminución para responder de manera funcional a las variaciones del ambiente, con un incremento de la vulnerabilidad a enfermedades y la mortalidad de las personas; una propuesta basada en los conceptos de la 
Organización Mundial de la Salud (OMS), envejecimiento como proceso y proceso de envejecimiento; la tercera está relacionada con la psicología evolutiva en la que el concepto de vejez está ligado al proceso del desarrollo que tiene lugar a lo largo de la vida, como una etapa complementaria a la adultez y está principalmente caracterizado por el deterioro en diversas funciones físicas, psicológicas y sociales del ser y, por último, una integración de las teorías explicativas del delito expuestas por Garrido, Stangeland y Redondo (2001).

Las particularidades de la población AMPL se describen por medio de una caracterización cualitativa que se respalda con datos cuantitativos oficiales y recolectados en las diferentes visitas a los EPC, los cuales son analizados de manera interdisciplinar y muestran las condiciones de calidad o estándar de vida desde una perspectiva constitutiva y de bienestar desarrollada por Sen (1998), y que se simplifica, para un mejor entendimiento, en condiciones relacionadas con el capital físico y el capital humano que enfrentan los AM, quienes son ignorados prácticamente por la teoría económica y son asociados a su capacidad productiva, lo que conduce a que existan miradas diferenciales que invitan a analizar las condiciones de vida frente a diferentes tipos de discriminación, encontradas en los AMPL. Asimismo, se analizan las condiciones de salud, sociales, económicas y jurídicas que enfrenta esta población, lo que lleva, necesariamente, a un mejor entendimiento de lo que ocurre en los EPC con los AMPL.

Este texto está dividido en nueve partes. La primera presenta las generalidades de la metodología utilizada por el equipo investigador para el desarrollo y el análisis del trabajo realizado. En la segunda parte se muestran los principios dentro de un estado social de derecho que fundamentan lo que se esperaría fueran aspectos de aplicación en los AM; se describen, principalmente, la solidaridad y la dignidad. La tercera parte analiza el marco normativo de los AM; presenta la perspectiva jurídica desde el ámbito de los derechos humanos y fundamentales, junto con la normatividad internacional ratificada por Colombia y desarrollada por el país. La cuarta parte presenta un completo panorama de las poblaciones excepcionales frente a la responsabilidad penal, y se centra, por el mismo alcance de la presente investigación, en los AM. 
La quinta parte aborda el concepto de AM e incluye una mirada desde diversas disciplinas sobre lo que se concibe como envejecimiento. La sexta parte es un complemento de las anteriores partes, e incluye una caracterización de los AMPL; se evidencian, dentro de los EPC, sus derechos, las condiciones de vida que enfrentan y las características de esta población en Colombia. El análisis de estas características permite dar claridad a los hacedores de políticas públicas y a los funcionarios que elaboran programas de tratamiento para redireccionar sus proyectos presentes o futuros.

La séptima parte indaga sobre un tema que puede generar controversia y es el relativo a la capacidad criminal de los AM, el perfil delictivo, el potencial que tienen de reincidir y su tratamiento. Se pretende considerar un equilibrio entre lo que podría ser o no un AM antes, durante o después de estar privado de la libertad. Frente a ello, se finaliza, en una octava parte, con las diversas perspectivas político-criminales que se tienen frente a los AM, se analizan las reformas recientes y sus implicaciones.

Los capítulos incluyen fundamentos conceptuales que se contrastan con los resultados del trabajo de campo, junto con el análisis de datos, que facilitan el entendimiento de la teoría mencionada a lo largo del texto y que es corroborada con lo encontrado en los diversos EPC. En la novena y última parte los investigadores proponen recomendaciones, no como verdades absolutas, sino como fruto de la interacción con los AMPL, con los funcionarios del Instituto Nacional Penitenciario y Carcelario (Inpec), con las diversas miradas teóricas y con las experiencias de los investigadores en diferentes escenarios, entre ellos, el Congreso Internacional de Política Criminal y Libertad, desarrollado a finales del año 2013 en la Universidad Externado de Colombia, y donde tuvo lugar una ponencia en la que se ratificó y enriqueció la visión del documento; se hicieron más claros, aún, los planteamientos que finalmente quedaron desarrollados y que son presentados a lo largo del presente libro. 


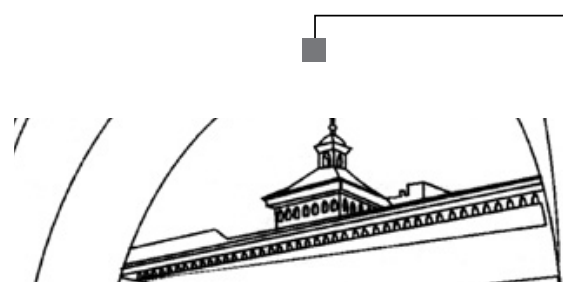


Metodología 
Por medio del trabajo de campo, se pretende entender la situación del AM en las cárceles para proveer unas recomendaciones que repercutan en la política criminal carcelaria y penitenciaria bajo un enfoque diferencial. El método cualitativo permitió contextualizar teóricamente el tema del AMPL desde diferentes disciplinas: jurídicas, psicológicas, sociales y económicas, lo que dio lugar a la categorización y el diseño de las preguntas orientadoras para la realización de 26 grupos focales de AM, en diferentes sitios geográficos de Colombia. Estos lugares fueron seleccionados de acuerdo con el reporte estadístico del Inpec, con corte a mayo del 2013; se escogieron los que mayor número de AM albergaban. Así, los establecimientos seleccionados fueron: el Complejo Carcelario y Penitenciario de Ibagué-Picaleña, el Complejo Carcelario y Penitenciario Metropolitano de Cúcuta, el Establecimiento Penitenciario de Mediana Seguridad y Carcelario (EPMSC) de Medellín, la Reclusión de Mujeres de Medellín, el EPMSC de Bucaramanga (ERE), el Complejo Penitenciario y Carcelario de Jamundí, el EPMSC de Cali (ERE), el Complejo Carcelario y Penitenciario Metropolitano de Bogotá y la Reclusión de Mujeres de Bogotá.

Los grupos focales se planearon con suficiente anticipación teniendo en cuenta la disposición de visitas reguladas por el Inpec; se solicitó que estuvieran integrados por internos de 60 años de edad o más; sin embargo, algunos participantes de menos edad fueron incluidos en la medida en que el Inpec, por sus características, los consideró como AM. En total, participaron 169 hombres y 52 mujeres, entre los 55 y 84 años. Previo a ello, con los insumos disponibles, se realizó, en la ciudad de Bogotá, una prueba piloto que permitió el ajuste de los instrumentos.

Antes de dar inicio a los grupos de discusión, se contextualizó la actividad, luego se procedió a solicitar el consentimiento informado de los participantes, que incluyó la autorización de grabación de las sesiones. Los grupos focales estuvieron conformados, en promedio, por 8 personas y tuvieron una duración aproximada de 2 horas; se cumplió con los tiempos establecidos para las actividades correspondientes para cada EPC. Las preguntas se dividieron en los ejes temáticos económico, psicológico, sociológico y jurídico. 
Una vez terminadas las visitas, se procedió a su transcripción en un documento de Word para ser procesadas y analizadas bajo el programa Atlas TI. Al analizar la información obtenida en los 26 grupos focales efectuados, se encontraron referencias y asociaciones a diversos aspectos que, a su vez, se desglosan en múltiples dimensiones. La descripción de la relación entre cada categoría y sus dimensiones se desarrolla a lo largo del texto, en el apartado pertinente. Igualmente, se exponen las relaciones entre categorías y entre dimensiones, lo que ofrece un amplio contexto de las condiciones y los procesos psicosociales de los AM que se encuentran privados de la libertad en Colombia.

\section{Instrumentos aplicados}

\section{Formato de priorización de derechos fundamentales}

Se diseñó un formato en el que se escogieron algunos derechos fundamentales, teniendo en cuenta aquellos que emergieron del estudio de Abaunza et al. (2011) y de la prueba piloto aplicada en el establecimiento carcelario (EC) de Bogotá La Modelo, como los más relevantes para las PPL, el derecho a la salud, a la vida, a la libertad de culto, al debido proceso y a la familia, entre otros, y que, a su vez, podrían considerarse como vulnerados para dicho colectivo.

Los derechos fueron ubicados en recuadros, los cuales, una vez leídos, se calificaron individualmente por los entrevistados para luego priorizar cada derecho secuencialmente de 1 al 7, de acuerdo con la relevancia adjudicada durante la privación de su libertad. La segunda pregunta se relacionaba con aquellos derechos que, según los participantes, no se les había respetado durante su reclusión. Por último, se incluyó un recuadro vacío para que el entrevistado indicara el derecho que, sin estar en el listado, era considerado como fundamental. 


\section{Lista de chequeo de 90 síntomas-revisado. SCL-90 R}

El cuestionario multidimensional explora nueve dimensiones o perfiles psicopatológicos: somatización, obsesión-compulsión, sensibilidad interpersonal, depresión, ansiedad, ira-hostilidad, ansiedad fóbica, ideación paranoide y psicoticismo, a partir del planteamiento de noventa afirmaciones relacionadas con molestias físicas y psíquicas (Derogatis, 2002). La forma de aplicación es autoadministrada y el evaluado tiene que seleccionar mediante una escala tipo Likert de cinco grados ( 0 : no lo ha molestado en absoluto y 4: le ha molestado de manera extrema) hasta qué punto se ha sentido molesto durante los últimos siete días en relación con la afirmación planteada.

\section{Neuropsi-Batería Neuropsicológica breve en español}

Es un instrumento de tamizaje que permite indagar un amplio espectro de funciones cognoscitivas en individuos psiquiátricos, geriátricos, neurológicos o pacientes con diversos problemas médicos. Explora nueve áreas: orientación, atención/concentración, lenguaje, memoria, funciones ejecutivas, procesamiento viso-espacial, lectura, escritura y cálculo. Cada una de estas áreas incluyen varias subpruebas que cubren distintos aspectos de cada dominio cognitivo; de este modo, la evaluación de la atención incluye el nivel de alerta, la eficiencia de la vigilancia y concentración y la atención selectiva. La evaluación de las funciones ejecutivas comprende la formación de conceptos, la flexibilidad, la inhibición y la programación de pruebas motoras. La memoria, por su parte, abarca la evocación inmediata y demorada de información verbal (por ejemplo, aprendizaje de listas de palabras que contienen 12 ítems pertenecientes a 3 categorías semánticas de alta frecuencia en el español: animales, frutas y partes del cuerpo), y no verbal. El recuerdo demorado de la información verbal incluye la evocación libre de la información y el recuerdo por claves semánticas y reconocimiento (Ostrosky et al., 2010). 


\section{Guía para grupos focales}

Guía semiestructurada de preguntas que se basa en las categorías del concepto de AM, la atención y el tratamiento penitenciario, las condiciones psicosociales, de vida y delictivas.

\section{Guía semiestructurada de visita penitenciaria}

Guía que, mediante criterios previamente establecidos, orientó, de forma flexible, la recolección de información relacionada con condiciones físicas y dinámicas penitenciarias durante la visita a los EPC. Los resultados fueron integrados a lo largo del texto. 


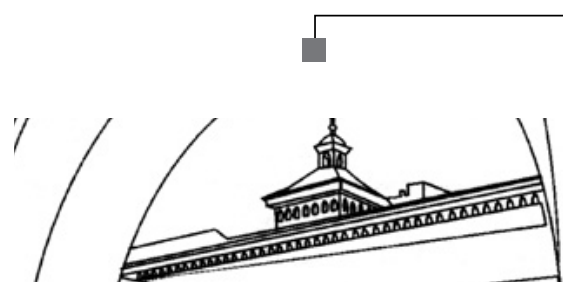




\section{Principios fundantes del estado social de derecho en relación con los adultos mayores privados de la libertad}




\section{Principios de solidaridad y dignidad}

La solidaridad es un principio que se debe garantizar a la población carcelaria; se considera como "el reconocimiento práctico de la obligación natural que tienen los individuos y los grupos humanos de contribuir al bienestar de los que tienen que ver con ellos, especialmente de los que tienen mayor necesidad" (Sebastián, 2000, p. 11), o también se entiende "como la oportunidad que tiene un individuo de colaborar con el bienestar de sus congéneres, en especial de los que se encuentran necesitados de ayuda o en situación apremiante, gracias a lo cual la persona solidaria engrandece su dignidad humana y contribuye a respetar los derechos de quien ha acudido en su ayuda o necesitado de su auxilio" (Sebastián, 2000, p. 11).

De hecho, resulta patente que la fraternidad se debe interpretar a partir de la solidaridad; la doctrina ha considerado que es una cualidad inherente en el ser humano y la sociedad como tal. Se ha afirmado que el ser humano no puede escapar de la solidaridad en el momento de auxiliar a un tercero en necesidad: "La fraternidad también sigue siendo un concepto vigente; un concepto de importancia fundamental en un mundo que ha atravesado por tan tremendas luchas internacionales e internas. [...] Es un hecho real que existe la solidaridad entre los hombres para el bien y para el mal" (Rawls, s. f., p. 138).

La solidaridad puede surgir de una necesidad personal o colectiva, en aras de preservar la salubridad pública o la propia. Además, es relevante hacer mención en el hecho de que el mundo se ha urbanizado y, por lo tanto, tenemos que convivir en una sociedad solidaria, fundada en el interés común.

De lo anterior existen varios ejemplos dentro de los ámbitos tanto jurídico como de propiedad, que por esencia tienen una función social que se antepone al interés particular; así las cosas, la propiedad debe ceder al interés público siempre que sea necesario, restringiendo de este modo el derecho a la propiedad privada.

Cede al interés público, cuando este se encuentre en conflicto con el particular; por lo tanto, en desarrollo de la función social y ecológica, se 
pueden decretar expropiaciones por motivos de utilidad pública o interés social, mediante sentencia judicial, indemnización previa y por motivos expresamente señalados por el legislador. (Corte Constitucional, 2002)

De igual forma y a escala internacional, esto se repite, nadie puede vivir aislado, y si se es parte de una sociedad, debe haber una solidaridad mínima para que la convivencia pueda ser garantizada. Rawls (s. f.) menciona que si la especie humana es solidaria, esta debe brindar un trato fraternal a los demás, siempre desde un punto de vista de colaboración y acercamiento, ya que "las medidas que se desprenden del hecho de la solidaridad no deben ser egoístas, frías, sino que tienen que estar alimentadas por el calor humano, por el amor a los semejantes" (Rawls, s. f., p. 138).

El principio de solidaridad es fundante en nuestro ordenamiento jurídico; está consagrado en la Carta Política, y ha sido tratado en copiosa jurisprudencia a lo largo de los años. Al respecto, Escamilla afirma que el concepto de solidaridad ha sufrido mucho para poder ser tenido en cuenta como fundamental; desde un punto de vista sociológico y normativo, este deber ser fue incluido en la Carta Política de 1991 y "de igual forma, su presencia se tiene como fundamento de diversas instituciones jurídicas" (Escamilla, 2004, p. 606).

Desde la esfera del ámbito penal, podemos ver que el principio de solidaridad está presente cuando se castiga la conducta de omisión, como una clara manifestación contraria a este principio. Esta relevancia quedó registrada en la exposición de motivos del Código Penal (CP) de 2000, dada su importancia y trascendencia (Escamilla, 2004). Escamilla también indica que la relación entre el deber de solidaridad y los delitos de omisión es, por supuesto, coherente, ya que solo se puede incurrir en una conducta punible de este tipo - omisión - cuando se tiene un deber jurídico de actuar, y esa infracción está estipulada expresamente en la normatividad.

También se puede observar que la solidaridad está presente en otras ramas del derecho en que las personas deben asumir una carga que las afecta económicamente; deben realizar, periódicamente, un pago en beneficio de la sociedad, los comúnmente llamados impuestos. Por otro lado, y análogo al aspecto carcelario, no se puede pasar por alto el importante rol que 
tienen los abogados defensores de oficio en los procesos penales; al respecto, la Corte Constitucional ha mencionado que ese tipo de profesionales del derecho contribuyen, de manera directa, con el desarrollo del principio de solidaridad en nuestra sociedad, al ser designados sin contraprestación económica alguna.

La Organización de las Naciones Unidas (ONU) también se ha referido a la solidaridad, que, de hecho, se deriva en muchos casos de la dignidad para el AM. Cuando existe solidaridad, la dignidad de las personas que han entrado a la vejez puede ser garantizada y, por esta razón, la ONU la declara como un principio básico, mediante la Resolución 46/91, a partir de la cual se establecen los principios de las Naciones Unidas en favor de las personas de edad (ONU, 1991). Por lo tanto, se le debe garantizar al AM una protección especial en aras de la garantía de sus derechos, a partir de la consideración de su condición de vulnerabilidad.

Tanto es así que se ha desarrollado un claro precedente jurisprudencial en el que se protegen los derechos de las personas que se encuentran en la vejez y que, posiblemente, están inmersas en un estado de debilidad manifiesta que atenta especialmente contra el derecho a la vida digna y otros derechos conexos, para que sean protegidas a través del mecanismo de la acción de tutela, así existan otras acciones judiciales disímiles a las que pueden acudir.

Que existiendo fundamento fáctico para otorgar el amparo, si el medio de defensa judicial común no es eficaz, idóneo o expedito para lograr la protección y esta llegaría tarde, encontrándose la persona en una circunstancia de debilidad manifiesta, o en insubsanable apremio en su mínimo vital, la tutela puede tener procedencia. (Corte Constitucional, 2011)

El concepto de debilidad manifiesta cobra una especial importancia en el momento de evaluar si una acción jurídica puede no ser lo suficientemente célere para proteger los intereses de los AM y, por esta razón, el papel de la tutela cobra tal importancia. La condición de debilidad mani- 
fiesta suele ser inherente en el AM; sin embargo, dicha situación se puede agravar en un escenario adverso donde difícilmente pueda ser garantizado un ambiente digno, como la cárcel. Por eso, el derecho penal consagra que la dignidad humana es sustantiva, sobre todo para las PPL (Código Penal).

El Estado tiene deberes especiales para con los reclusos, con miras a que estos puedan ejercer plenamente los derechos fundamentales que no les han sido suspendidos, y parcialmente aquellos que les han sido restringidos. Y estos deberes no implican simplemente que el Estado no debe interferir en la esfera de desarrollo de estos derechos - como ocurriría en el caso de la libertad religiosa-, sino también -y de manera especial- que el Estado debe ponerse en acción para garantizarle a los internos el pleno goce de otros derechos, tales como la dignidad, la salud, la alimentación, el trabajo, etc. Esta conclusión se deriva de la misma relación especial de sujeción de los penados frente al Estado, y del hecho de que las condiciones que se imponen a los reclusos les impide que puedan satisfacer por cuenta propia una serie de necesidades mínimas, cuya atención garantiza la posibilidad de llevar una vida digna. (Corte Constitucional, 1998)

El Estado, frente a las PPL en los EPC, tiene la obligación de respetar y velar por la dignidad humana, y por esta razón deberá siempre de abstenerse de obligar a un detenido a soportar una carga que no esté en la obligación de sobrellevar, o a darle un trato desigual que atente contra su dignidad: "Es deber del Estado tratar a los presos justamente y respetar su dignidad humana, por lo que debe resguardarse de ponerlos en condiciones de desigualdad entre sí. Garantizar los derechos del privado de libertad colabora con su reintegración a la sociedad una vez cumplida la condena" (Castro et al., 2010, p. 19). El Estado ostenta una obligación de resultado, máxime cuando se trata de un AM, quien debe ser protegido de manera especial; debe tratar de manera semejante a los iguales y de forma desigual a los que se encuentran en situaciones disímiles, como es el caso de una persona de la tercera edad en comparación con el resto de la población carcelaria. 
La Sala ha reiterado que frente a los retenidos la obligación que tiene el Estado de respetar y garantizar su vida e integridad personal y síquica es de resultado. El Estado asume una obligación específica de protección y seguridad, en virtud de la cual se hace responsable de los perjuicios que sufren las personas. Es el caso de los retenidos, quienes por encontrarse en una situación de particular sujeción frente al Estado en virtud de la cual ven limitados sus derechos y libertades y la autonomía para responder por su propia integridad, deben gozar del pleno amparo de las autoridades frente a los posibles daños y peligros que los amenacen. (Consejo de Estado, 1998)

En el momento en que una PPL sufra un perjuicio derivado de un daño en concreto, sobre todo cuando se trata de una persona que se encuentra en estado de debilidad manifiesta y que, por lo tanto, debe recibir una protección especial, se configura de manera aún más clara una falla en el servicio. Cuando esto se presenta, el Estado puede estar sujeto a una responsabilidad civil extracontractual, tratándose tanto de la PPL como de su familia cercana. Y es que un perjuicio contra la dignidad humana de cualquier PPL conlleva una serie de daños que deben ser resarcidos mediante una compensación monetaria a cargo del Estado, el cual no fue diligente en su accionar e incumplió con las obligaciones constitucionales que le eran atribuibles:

De acuerdo con la jurisprudencia vigente, el título de responsabilidad en los casos en los que se pretende imputar daños al Estado por la muerte o las lesiones sufridas por quienes se encuentran privados de la libertad en calidad de sindicados o condenados en los establecimientos carcelarios, corresponde al de la falla del servicio, esto es, por el incumplimiento o el cumplimiento defectuoso o tardío del servicio carcelario. (Sentencia Consejo de Estado, 2008). 


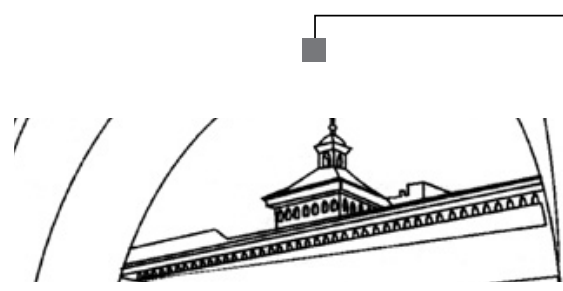




\section{Marco normativo \\ de las poblaciones excepcionales}




\section{Los derechos constitucionales}

En Colombia existen varios grupos poblacionales que se encuentran ubicados en el grupo de sujetos de especial protección constitucional como los AM, los niños, las personas con discapacidad, los sujetos privados de la libertad, los grupos étnicos, las personas en situación de desplazamiento, entre otros.

A nivel normativo, la Constitución de 1991 introduce el tema de los sujetos de especial protección constitucional, entendidos como los "grupos sociales que requieren de una protección especial para hacer efectivo el ejercicio de sus derechos fundamentales. Se trata de la consideración de edad, situación biológica, económica, o social que los colocan en situación de debilidad manifiesta, discriminación o marginación y que requieren la atención especial de las autoridades" (Cepeda \& Montealegre, 2007). ${ }^{1}$

A nivel constitucional, el artículo $46^{2}$ ampara directamente a la población objeto de estudio; sin embargo, en relación con sus derechos, están

1 Los sujetos de especial protección constitucional son las personas en situación de indigencia, con diversa orientación sexual, la mujer embarazada y cabeza de familia, los adolescentes, los trabajadores, los grupos étnicos, PPL, personas en situación de desplazamiento forzado, AM y personas con discapacidad.

2 "El Estado, la sociedad y la familia concurrirán para la protección y asistencia de las personas de la tercera edad y promoverán su integración a la vida activa y comunitaria. El Estado les garantizará los servicios de la seguridad social integral y el subsidio alimentario en caso de indigencia”. 
los artículos $1,{ }^{3} 5,{ }^{4} 13,{ }^{5} 48,{ }^{6} 49^{7}$ y $52,{ }^{8}$ los cuales, de alguna manera, se vinculan con la protección del AM como sujeto de derechos. De igual forma, el AM debe contar con el apoyo de la legislación internacional que realce su connotación y haga efectivos los derechos de este colectivo cuando el Estado colombiano no los garantice por sí solo o pretenda desconocer los compromisos internacionales con los que se comprometió.

3 "Colombia es un Estado social de derecho, organizado en forma de república unitaria; descentralizada, con autonomía de sus entidades territoriales, democrática, participativa y pluralista, fundada en el respeto a la dignidad humana, en el trabajo y la solidaridad de las personas que la integran y en prevalencia del interés general".

4 "El Estado reconoce, sin discriminación alguna, la primacía de los derechos inalienables de la persona y la familia como institución básica de la sociedad".

5 "Todas las personas nacen libres e iguales ante la ley, recibirán la misma protección y trato de las autoridades y gozarán de los mismos derechos, libertades y oportunidades sin ninguna discriminación por razones de sexo, raza, origen nacional o familiar, lengua, religión, opinión política o filosófica. El Estado promoverá las condiciones para que la igualdad sea real y efectiva, y adoptará medidas en favor de grupos discriminados o marginados. El Estado protegerá especialmente a aquellas personas que por su condición económica, física o mental, se encuentren en circunstancia de debilidad manifiesta y sancionará los abusos o maltratos que contra ellas se cometan".

6 "La Seguridad Social es un servicio público de carácter obligatorio que se prestará bajo la dirección, coordinación y control del Estado, en sujeción a los principios de eficiencia, universalidad y solidaridad, en los términos que establezca la Ley. Se garantiza a todos los habitantes el derecho irrenunciable a la Seguridad Social [...]".

7 "La atención de la salud y el saneamiento ambiental son servicios públicos a cargo del Estado. Se garantiza a todas las personas el acceso a los servicios de promoción, protección y recuperación de la salud. Corresponde al Estado organizar, dirigir y reglamentar la prestación de servicios de salud a los habitantes y de saneamiento ambiental conforme a los principios de eficiencia, universalidad y solidaridad. También, establecer las políticas para la prestación de servicios de salud por entidades privadas, y ejercer su vigilancia y control. Así mismo, establecer las competencias de la Nación, las entidades territoriales y los particulares y determinar los aportes a su cargo en los términos y condiciones señalados en la ley".

8 "Se reconoce el derecho de todas las personas a la recreación, a la práctica del deporte y al aprovechamiento del tiempo libre. El Estado fomentará estas actividades e inspeccionará las organizaciones deportivas, cuya estructura y propiedad deberán ser democráticas". 


\section{Tratados, acuerdos y resoluciones ratificados por Colombia}

Resulta oportuno recordar que los tratados y los convenios internacionales, ratificados por el Congreso, que tratan sobre los derechos humanos, prevalecen en el orden interno aun en los Estados de excepción, conforme lo establece el artículo 93 de la CN; algunos de ellos son:

- El Pacto Internacional de Derechos Civiles y Políticos. Ley 74 de 1968.

- Convención contra la Tortura y Otros Tratos o Penas Crueles, Inhumanos o Degradantes y la Discapacidad. Ley 1346 de 2009.

- Convención sobre la eliminación de todas las formas de discriminación contra la mujer. Ley 984 de 2005.

- Convención Americana sobre Derechos Humanos Pacto de San José. Ley 16 de 1972.

- Convención contra la Tortura y Otros Tratos o Penas Crueles, Inhumanos o Degradantes. Ley 70 de 1986.

- Estatuto de Roma de la Corte Penal Internacional. Ley 742 de 2002.

- Declaración sobre la Protección de Todas las Personas contra la Tortura y Otros Tratos o Penas Crueles, Inhumanos o Degradantes. Ley 70 de 1986.

- Protocolo Facultativo del Pacto Internacional de Derechos Civiles y Políticos (1966). Ley 74 de 1968.

- Convención Interamericana para Prevenir y Sancionar la Tortura. Ley 409 de 1997.

- Convención para la Prevención y la Sanción del Delito del Genocidio. Ley 28 de 1959.

- Convención Interamericana para Prevenir, Sancionar y Erradicar la Violencia contra la Mujer. Convención de Belém do Pará. Ley 248 de 1995.

- Convención sobre los Derechos Políticos de la Mujer. Ley 35 de 1986. 
- Protocolo Facultativo de la Convención sobre la Eliminación de Todas las Formas de Discriminación contra la Mujer. Ley 984 de 2005.

- Convención Interamericana sobre la Nacionalidad de la Mujer. Ley 77 de 1935.

- Convención sobre los Derechos del Niño. Ley 12 de 1991.

- Convenio sobre Aspectos Civiles del Secuestro Internacional de Niños. Ley 173 de 1994.

- Protocolo Facultativo de la Convención sobre los Derechos del Niño relativo a la Participación de Niños en los Conflictos Armados. Ley 833 de 2003.

- Protocolo Facultativo de la Convención sobre los Derechos del Niño relativo a la Venta de Niños, la Prostitución Infantil y la Utilización de Niños en la Pornografía. Ley 765 de 2002.

- Convención Interamericana sobre el Tráfico Internacional de Menores. Ley 470 de 1998.

- Convención Interamericana sobre Restitución Internacional de Menores. Ley 880 de 2004.

- Convenio OIT n. ${ }^{\circ} 138$ sobre la Edad Mínima de Admisión al Empleo. Ley 515 de 1999.

- Protocolo de San Salvador. Ley 319 de 1996. (Adulto Mayor, artículo 17).

- Declaración Americana de los Derechos y Deberes del Hombre: aprobada en la Novena Conferencia Interamericana, Bogotá, abril de 1948.

- Declaración Universal de los Derechos del Hombre y el Ciudadano, artículo 21.5.

- Protocolo de San Salvador, artículo 17.

- El Plan de Acción Intencional de Viena sobre el Envejecimiento.

- Resoluciones de la Asamblea General de las Naciones Unidas 40/30 de 1985 y 44/76 de 1989.

- Conferencia Internacional sobre Población y Desarrollo.

- Naciones Unidas. Asamblea Mundial sobre el Envejecimiento. 
- Resolución n. ${ }^{\circ}$ 4782-92. Ejecución de Plan de Acción Internacional sobre el Envejecimiento de las Personas en Desarrollo.

- Decisión 583 de la CAN. Instrumento Andino de Seguridad Social.

\section{Normatividad desarrollada en Colombia sobre los adultos mayores}

Siguiendo el orden jerárquico establecido en nuestro territorio, tenemos que no solamente se dan en relación con el tema las normas que se dejan relacionadas como integradoras del bloque de constitucionalidad, sino que existen una serie de leyes, decretos y acuerdos que tienen que ver con el AM:

- Ley 271 de 1996: "por la cual se establece el Día Nacional de las Personas de la Tercera Edad y del Pensionado".

- Ley 599 del 2000: "artículo 229: violencia intrafamiliar".

- Ley 687 de 2001: "por medio de la cual se modifica la Ley 48 de 1986, que autoriza la emisión de una estampilla pro-dotación y funcionamiento de los Centros de Bienestar del Anciano, instituciones y centros de vida para la tercera edad, se establece su destinación y se dictan otras disposiciones".

- Ley 700 de 2001: "por medio de la cual se dictan medidas tendientes a mejorar las condiciones de vida de los pensionados y se dictan otras disposiciones".

- Ley1171 de 2007: "por medio de la cual se establecen unos beneficios a las personas adultas mayores".

- Ley 1251 de 2008, acerca de la vejez en Colombia: "por la cual se dictan normas tendientes a procurar la protección, promoción y defensa de los derechos de los adultos mayores".

- Ley 1276 de 2009: "a través de la cual se modifica la Ley 687 del 15 de agosto de 2001 y se establecen nuevos criterios de atención integral del adulto mayor en los centros vida". 


\section{Decretos}

- Decreto 0303 de 1992: "celebración del Día del Abuelo".

- Decreto 0281 de 1992: "por el cual se crea el Fondo de Solidaridad y Emergencia Social”.

- Decreto 2133 de 1992: "por el cual se fusiona el Fondo Especial de la Presidencia de la República al Fondo de Solidaridad y Emergencia Social y se reestructura el Departamento Administrativo de la Presidencia de la República".

- Decreto 591 de 1994: "por medio del cual se define y regula el programa para la juventud, la mujer y la familia. Aplica para mujeres ancianas".

- Decreto 2099 de 1994: "por el cual se reorganiza el Fondo de Solidaridad y Emergencia Social de la Presidencia de la República”.

- Decreto 1135 de 1994: "por el cual se reglamentan parcialmente los artículos 257, 258, 259, 260, 261 y 262 de la Ley 100 de 1993” (auxilio para ancianos indigentes).

- Decreto 731 de 1995: "por el cual se crea la Comisión Tripartita de Concertación para el Desarrollo de Programas para la Tercera Edad, se determina su composición y se le asignan funciones".

- Decreto 1387 de 1995: "por el cual se modifica parcialmente el Decreto 1135 de 1994".

- Decreto 972 de 1997: "por el cual se reglamentan los planes de servicios y descuentos especiales en materia de turismo para la tercera edad".

- Decreto 2113 de 1999: "por el cual se reglamenta la Ley 271 de 1996".

\section{Acuerdos y proyectos de acuerdo}

Los siguientes son los acuerdos distritales y los proyectos de acuerdo que se han tramitado sobre los derechos del adulto mayor: 
- Acuerdo 27 de 1992: "por el cual se crea el Comité Interinstitucional de Bienestar Social para la Población Mayor de Santa Fe de Bogotá".

- Acuerdo 11 de 1999: "por medio del cual se promueve en el Distrito Capital la organización de los Clubes de la Tercera Edad como estrategias para impulsar el mejoramiento de la calidad de vida de los ancianos".

- Acuerdo 51 de 2001: "por el cual se dictan normas para la atención a las personas con discapacidad, la mujer en estado de embarazo y los adultos mayores en las entidades distritales y empresas prestadoras de servicios públicos".

- Acuerdo 254 de 2006 (Concejo de Bogotá): "por medio del cual se establecen los lineamientos de la política pública para el envejecimiento y las personas mayores en el Distrito Capital y se dictan otras disposiciones".

- Acuerdo n. 003 de 2005 (Consejo Distrital de Barranquilla): "por medio del cual se modifican los acuerdos 013 de agosto 10 del 2004 y el acuerdo 022 de diciembre 24 del 2004, con relación a la emisión de la estampilla para financiar programas de dotación, funcionamiento y desarrollo de programas de prevención y promoción de los centros de bienestar del anciano y centros para la tercera edad".

- Proyecto de acuerdo n. 121 de 2005 (Concejo de Bogotá): "por el cual se ordena la emisión de la estampilla en favor de la tercera edad y se dictan otras disposiciones".

- Proyecto de acuerdo n. 213 de 2005 (Concejo de Bogotá): "por el cual se autoriza la emisión de la estampilla pro-dotación y funcionamiento de los centros de bienestar del anciano, instituciones y centros de vida para la tercera edad y se dictan otras disposiciones en Bogotá Distrito Capital”.

- Proyecto de acuerdo n. 631 de 2008 (Concejo de Bogotá): "por medio del cual se garantiza el subsidio al adulto mayor en condición de desamparo, discapacidad y vulnerabilidad económica". 
- Proyecto de acuerdo n. 039 de 2008 (Concejo de Bogotá): "por medio del cual se regula el funcionamiento de los hogares geriátricos que prestan servicios a las personas mayores en el Distrito Capital, y se dictan otras disposiciones".

\section{Los derechos humanos en el colectivo de los adultos mayores}

El perjuicio que se le genere a una PPL de la tercera edad puede ocurrir por acción u omisión del Estado, representado en el Inpec, y “en consecuencia, puede concluirse que la omisión en que incurrió el Inpec fue causa eficiente y determinante en la producción del daño antijurídico sufrido por los demandantes" (Consejo de Estado, 2002). También es cierto que cuando lo anterior ocurre y se presenta un perjuicio a un interno de avanzada edad, esto atenta contra el principio de solidaridad y vida digna que el Estado debe defender.

Puede generarse una responsabilidad patrimonial del Estado, pero resulta aún más grave si esa responsabilidad se genera de la mera inoperancia y la omisión estatal de brindar una protección adecuada a los susodichos internos: "La falla en el servicio, indudablemente, corresponde al régimen de responsabilidad subjetiva, en donde prima la culpa de la administración por el retardo en el cumplimiento de obligaciones, bien sea por cumplir dichas obligaciones tardía o defectuosamente, o el simple incumplimiento de las obligaciones que le competen al Estado" (Ruiz-Orjuela, 2010, p. 2).

El Inpec no puede garantizar el derecho a una vida digna para los reclusos, y mucho menos para quienes se encuentran en estado de debilidad manifiesta cuando existe una sobrepoblación carcelaria. Las condiciones mínimas para que haya una vida digna dentro de las cárceles se tornan inalcanzables, en algunos casos; por lo que se acude al mecanismo de la improvisación y al sometimiento de los reclusos a tratos crueles e inhumanos, en especial en lo que tiene que ver con el derecho a la vida e integridad personal de quienes no ostentan las mismas herramientas ni capacidades para sobrevivir en un ambiente hostil como es el de las cárceles colombianas: 
En efecto, tanto el derecho a la dignidad como el de no recibir tratos o penas crueles, inhumanos o degradantes se ven quebrantados por el hacinamiento y las malas condiciones de la estructura física y de servicios públicos que se encuentra en los centros de reclusión; los derechos a la vida y la integridad física son vulnerados o amenazados de manera inminente por el mismo hacinamiento, por la mixtura de todas las categorías de reclusos y por la carencia de los efectivos de guardia requeridos; el derecho a la familia es quebrantado por la sobrepoblación carcelaria y las deficiencias administrativas, condiciones estas que implican que los visitantes de los reclusos han de soportar prolongadas esperas, bajo las inclemencias del clima, para poder ingresar al centro, y que dificultan en grado extremo las visitas conyugales y familiares; el derecho a la salud se conculca dadas las carencias infraestructurales de las áreas sanitarias, la congestión carcelaria, la deficiencia de los servicios de agua y alcantarillado y la escasez de guardia para cumplir con las remisiones a los centros hospitalarios; los derechos al trabajo y a la educación son violados, como quiera que un altísimo porcentaje de los reclusos no obtiene oportunidades de trabajo o de educación y que el acceso a estos derechos está condicionado por la extorsión y la corrupción; el derecho a la presunción de inocencia se quebranta en la medida en que se mezcla a los sindicados con los condenados y en que no se establecen condiciones especiales, más benévolas, para la reclusión de los primeros, etc. (Corte Constitucional, 1998)

Ahora, por supuesto este tipo de condiciones atentan contra la integridad de los internos y su derecho a la dignidad, pero también contrarían el bloque de constitucionalidad de manera flagrante ya que "toda persona privada de libertad será tratada humanamente y con el respeto debido a la dignidad inherente al ser humano" (ONU, 1976). Y no solo transgreden el bloque de constitucionalidad ratificado por Colombia, sino que representan una conculcación a la base del ordenamiento jurídico, ya que de manera expresa están proscritos los tratos crueles, inhumanos y degradantes, por lo que de manera directa se viola la dignidad humana: 
La Constitución de manera explícita hace referencia a esta idea en su artículo 12 cuando establece que "Nadie será sometido a desaparición forzada, a torturas ni a tratos o penas crueles, inhumanos o degradantes". De acuerdo con esto, toda pena, independientemente del delito del cual provenga, debe respetar unas reglas mínimas relativas al tratamiento de los reclusos, que se encuentran ligadas de manera esencial, al concepto de dignidad humana y al principio según el cual la pena no tiene por objeto el infligir sufrimiento corporal. (Corte Constitucional, 1992)

A partir de lo anterior, podemos ver que los principios de dignidad y de solidaridad se encuentran íntimamente relacionados, cuando no se permite que los reclusos en estado de debilidad manifiesta y con necesidad de especial protección puedan cumplir con la pena impuesta o la medida cautelar sin unas condiciones mínimas que garanticen su integridad mientras permanezcan privados de la libertad.

El estado de cosas inconstitucional que da cuenta la Corte Constitucional, en las sentencias mencionadas - que en extenso fueron igualmente consideradas en Abaunza et al. (2011) -, según se establece en dicho estudio, no fue superado ni lo ha sido hasta la fecha en el SPCC, prueba de ello es el hacinamiento que hoy reportan la cifras oficiales, que se detallarán posteriormente; así como la declaración del Estado de emergencia penitenciaria y carcelaria que dio lugar al Decreto 1505 del 31 de mayo de 2013, situación que condujo, precisamente, a otra rama del poder público, en este caso, al legislador, a asumir la reforma del Código Penitenciario y del CP en lo que tiene que ver principalmente con la detención y la prisión domiciliaria, los subrogados penales de la condena de ejecución y libertad condicional, y otros beneficios; lo que, igualmente, se analizará más adelante, al abordar la Ley 1709 de 2014. 


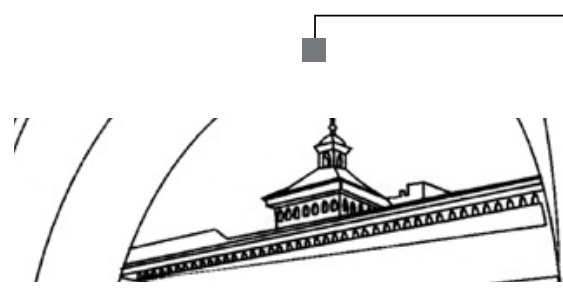




\section{Panorama de las poblaciones excepcionales etarias frente a la responsabilidad penal}


La responsabilidad es la consecuencia del delito a través de la cual se tiene al autor, cómplice o auxiliador como destinatario de la sanción prevista en la norma penal, una vez se describe el comportamiento delictivo. Nuestro estatuto represor (CP) exige que para que haya responsabilidad, el comportamiento delictivo debe ser típico, antijurídico y culpable. ${ }^{1}$

Doctrinariamente, se convalida lo anterior cuando algunos tratadistas expresan que el tema de la responsabilidad supone dos cosas: la culpabilidad del autor y, además, la necesidad de la pena desde el punto de vista preventivo, general y especial (Roxin, 2000). La pena es una reacción ante la infracción de una norma (Jakobs, 1995).

\section{Infancia y adolescencia}

No obstante que el Código de la Infancia y la Adolescencia, Ley 1098 de 2006, busca acogerse a la doctrina de la protección integral como principio rector de la Convención de los Derechos del Niño (CDN) de 1989, con el fin de instituir al adolescente como sujeto de deberes y derechos, en realidad prioriza sus derechos, así se considere la reparación del daño causado por parte de sus padres o representantes legales, tal como lo reconoce la Ley 12 de 1991 (Congreso de Colombia, 1991), que también propende por la expedición de la política pública relacionada al respecto.

Tal como lo establece la Carta Fundamental, al consagrar el derecho prevalente que le asiste al adolescente, buscando proteger no solamente su vida actual, sino también futura en sociedad, resulta esencial que la persona en sus inicios de existencia cuente con toda la atención de la familia y del Estado para alcanzar, en las mejores condiciones posibles, el estatus de persona adulta. En cuanto a su sanción, advierte expresamente que los menores de 14 años no serán juzgados, declarados penalmente responsables ni privados de la libertad por delito alguno, y en relación con las conductas delictivas de los adolescentes en que proceda la privación de la libertad, la sanción solo podrá darse en establecimientos de atención especializada en 
programas del Sistema Nacional de Bienestar Familiar, siempre y cuando estén separados de los adultos. Incluso cuando no existan establecimientos con dichas condiciones y características, se procederá a la libertad, todo ello en sintonía con la CDN, de conformidad con el artículo 49, Tratado Internacional de Naciones Unidas por el que los Estados reconocen a los niños y las niñas como sujetos de derechos.

Sin embargo, como se verá, no es equiparable ni proporcional la legislación del AM que se produce en relación con la de menores, especialmente en lo que tiene que ver con el respeto, la protección y la garantía de sus derechos. Así las cosas, el sistema de responsabilidad penal para menores contiene una serie de garantías y objetivos diferenciales que se presentan a continuación (figura 1), con base en la Ley 1068 de infancia y adolescencia, que debe tenerse como marco referente para una efectiva protección y alcance normativo para la guarda de los derechos de los AM.

La participación de los actores que se dan a conocer en la figura 2 es vital y debe ser articulada; se pretende emular esta misma coordinación para la protección de los AMPL. Las sanciones a las que pueden ser sometidos los niños, las niñas y los adolescentes declarados penalmente responsables, según el Código de la Infancia y la Adolescencia, son: la amonestación, reglas de conducta, prestación de servicios a la comunidad, libertad asistida, internación en un medio semicerrado y privación de la libertad en un centro de atención especializado. ${ }^{2}$ La privación de la libertad solo se aplica de manera excepcional, ${ }^{3}$ extremo sancionatorio que cuenta con un procedimiento especial, la intervención de una serie de funcionarios expertos y unos establecimientos, de igual manera, especializados.

La privación de la libertad solo se da hasta por 5 años para delitos graves y 8 años para delitos gravísimos como el homicidio, el secuestro y la extorsión; entre 16 y 18 años solo hay restricción de la libertad; si la infracción está castigada con más de 6 años, sumado todo ello al déficit de cupos que se presenta en los centros de reclusión, la persona adquiriría la

2 Artículo 177 de la Ley 1098 de 2006 (Código de la Infancia y la Adolescencia), modificado por el artículo 89 de la Ley 1453 de 2011.

3 Artículo 161 de la Ley 1098 de 2006 (Código de la Infancia y la Adolescencia). 
Figura 1. Sistema de responsabilidad penal para adolescentes

\author{
Es el conjunto de principios, normas, procedimientos, autoridades judiciales \\ especializadas y entes administrativos que intervienen en la investigación y el \\ juzgamiento de los delitos cometidos por personas que tengan entre 14 y 18 años. \\ Ley de infancia y adolescencia.
}

\section{Objetivo}

El Código busca establecer medidas de carácter pedagógico, privilegiando el interés superior del niño y garantizando la justicia restaurativa, la verdad y la reparación del daño.

Derechos en la privación de la libertad

- Permanecer internado en la misma localidad, municipio o distrito más próximo al domicilio de sus padres, representantes o responsables.

- Garantizar al adolescente un lugar con condiciones de higiene, seguridad y salubridad y acceso a los servicios públicos.

- Ser examinado por un médico inmediatamente después de su ingreso al programa de atención especializada.

- Continuar con su proceso educativo.
Recibir información sobre el reglamento interno de la institución donde cumplirá su sanción.

- No ser trasladado arbitrariamente del programa donde cumple la sanción.

- No ser sometido a ningún tipo de aislamiento.

- Mantener correspondencia y comunicación con sus familiares y amigos, recibir entrevistas por lo menos una vez a la semana.

- Tener acceso a la información de los medios de comunicación.
Derechos. Ser citados como testigos en los procesos penales que se adelantan contra los adultos. Su declaración solo podrá ser tomada por el defensor de familia.

La provación de la libertad es excepcional y solo podrá definirse hasta por 5 años para delitos graves y 8 años para delitos gravísimos (homisidio doloso, secuestro o extorsión).

- Derecho al debido proceso penal y sus garantías como presunción de inocencia, asesoramiento, presencia de sus padres o tutores.

- No podrá ser investigado, acusado ni juzgado por acto u omisión, en el momento de la ejecución del delito que no esté previamente definido en la ley penal vigente.

- Solo podrá ser sancionado con la imposición de las medidas definidas en el Código de la Infancia y la Adolescencia.

Fuente: elaboración propia.

libertad o la sustitución de la medida, si no hay cupo disponible para hacerla efectiva. ${ }^{4}$ Ello considerando que el menor no solamente delinque cuando es utilizado por el crimen organizado, sino que en muchas ocasiones la decisión de trasgredir la ley obedece a una decisión autónoma sin ninguna clase de presión social o familiar.

Tan exclusivo resulta el tratamiento penal de los adolescentes que se sigue pensado que es un sistema que continúa salpicado de impunidad, frente a ese cúmulo de garantías y protecciones, precisamente por el trato que la ley les da cuando se determina su autoría y responsabilidad en la co-

4 Artículo 162 de la Ley 1098 de 2006 (Código de la Infancia y la Adolescencia). 
Figura 2. Algunos actores del sistema

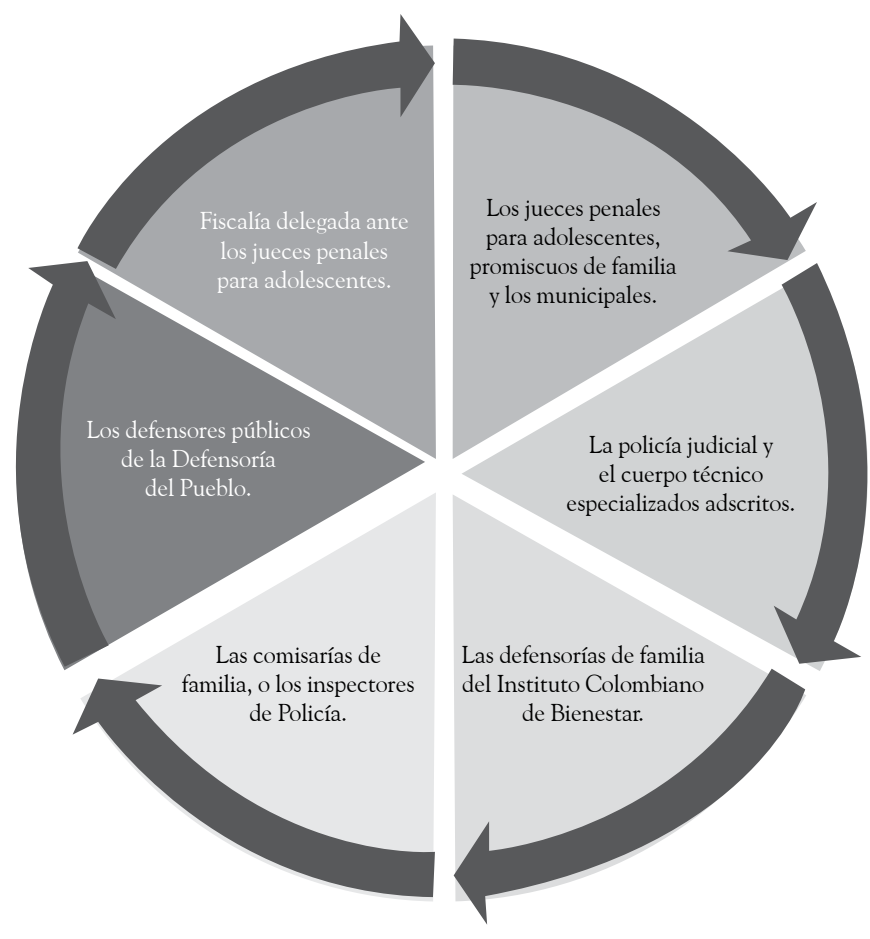

Fuente: elaboración propia.

misión de hechos delictivos, y esta es una de las causas de la reincidencia en el delincuente adolescente; de allí que no sea un tema pacífico por tratar en el ámbito de la política criminal y penitenciaria, en el que en ocasiones se reclama una respuesta más enérgica para con el delincuente menor de edad, toda vez que se superpone en este caso el derecho penal de autor al derecho penal de acto.

Ciertamente, resulta como causa eficiente de la manifestación delincuencial de menores adolescentes la propia conducta del sujeto, muchas veces desposeída de principios y valores, de la crisis del núcleo familiar de donde proviene, de las falencias que genera el modelo educativo nacional, lo que se aúna a un Estado carente de un sistema penal adecuado y desarrollado para su corrección y tratamiento (Álvarez et al., 2008). 


\section{Adulto mayor}

Si bien el menor debe contar con todas las garantías procesales, llama la atención que esa situación no se generalice o se comparta con grupos en igual o acrecentada condición de debilidad, específicamente como ocurre con el AM, quien debe contar con un sistema o pautas de responsabilidad penal especial, como ocurre con el adolescente; es decir, con unas garantías mínimas relativas a establecer las condiciones físicas, psíquicas y sociales de dicho sujeto activo, que pudieran haber tenido incidencia en la conducta imputada, toda vez que su sola condición de AM, en términos de razonabilidad, proporcionalidad y de cara a la administración de justicia, aminora en forma grave sus derechos fundamentales, como el acceso a la justicia, el debido proceso, el derecho a la defensa, entre otros, por lo que tendría que ser extraído de los parámetros generales de investigación y juzgamiento, como en efecto acontece con el adolescente, dado su estado de limitación e indefensión; estado procurado, en la mayoría de las veces, por sus circunstancias endémicas, económicas, sociales, culturales e incluso políticas, que lo hacen propenso a la discapacidad, la pobreza, la marginación, factores que maximizan su situación de dependencia, dado que no está en igualdad de condiciones que los demás (Dueñas, 2011).

Lo anterior por cuanto no existe una regulación normativa que reconozca ese estado de vulnerabilidad en relación con el derecho penal colombiano, considerando que la responsabilidad penal es el sometimiento de una persona que vulnera la norma impuesta por el derecho penal, conducta que la hace merecedora y destinataria de las consecuencias que le impone la misma ley, vale decir, la pena, según lo mencionado. Así las cosas, frente a la responsabilidad declarada por el Estado a través del aparato jurisdiccional, surge la necesidad de considerar especialmente la persona destinataria de la pena, como es obvio, para efectos de buscar su resocialización o reinserción social positiva.

El sistema penal colombiano, respecto de los AM, solo exige como presupuesto de sanción sobre responsabilidad penal —así haga alusión a conductas dolosas o culposas - los mismos parámetros que rigen para cualquier sujeto activo del delito, sin ninguna consideración especial, como sî 
sucede con los adolescentes, para quienes contempla especiales condiciones para su procesamiento y sanción.

Sin embargo, resulta obvio que ese presupuesto de responsabilidad penal en la persona mayor no es equitativo ni ponderado, y se toma como un elemento generalizado de investigación y juzgamiento, como ocurre en la actualidad. De allí que la persona mayor debe ser considerada como un sujeto activo especial de delito, no para vestirlo con un ropaje de impunidad o presumirlo inimputable - lo que llevaría a extremos, aunque en ocasiones pueda llegar a serlo-, sino con el fin de que sea concebido como un sujeto personal y socialmente merecedor de un trato especial, de un acompañamiento exclusivo, de un tratamiento diferente, que le permita como sujeto de derechos alcanzar la rehabilitación y la socialización, lo que se supone justifica la pena, así se encuentre en las postrimerías de su existencia, por cuanto sigue siendo persona y poseedor de sueños y esperanzas; al respecto, resulta consecuente invocar a Luigi Ferralloli, al tratar sobre el principio de la pena mínima necesaria y el respeto a la persona, cuando manifiesta que "un Estado que mata, que tortura, que humilla a un ciudadano no solo pierde cualquier legitimidad, sino contradice su razón de ser, poniéndose al nivel de los mismos delincuentes" (1997).

De igual manera que sucede con el adolescente infractor, resultaría necesario dar al infractor AM un trato especial dado que la respuesta institucional que se da en relación con la investigación, el juzgamiento y la sanción no contempla tratos diferenciales de mayor envergadura, como se puede corroborar a través de las distintas instituciones procesales. Los eximentes de responsabilidad que consagra el artículo 32 del CP no hacen alusión a situaciones relativas a la condición de AM, predicables por la vulnerabilidad a la que está expuesto, como se dijo anteriormente; tampoco, como lo revela el artículo 55 del CP, en relación con las circunstancias de menor punibilidad, salvo las referentes a las condiciones de inferioridad psíquicas determinadas por la edad a las que se refiere en su numeral 9 , pero no se alude específicamente a la edad.

Cuando se inicia la judicialización del AM, tampoco se establecen señalamientos específicos en relación con dicha circunstancia, a excepción de la posibilidad de sustituir la detención preventiva que se refiere en el artículo 
54

314.2 de la Ley 906 de 2004, modificado por el artículo 27 de la Ley 1142 de 2007, cuando el imputado o acusado es mayor de 65 años, siempre que su personalidad, la naturaleza y modalidad del delito hagan aconsejable su reclusión en el lugar de residencia. 


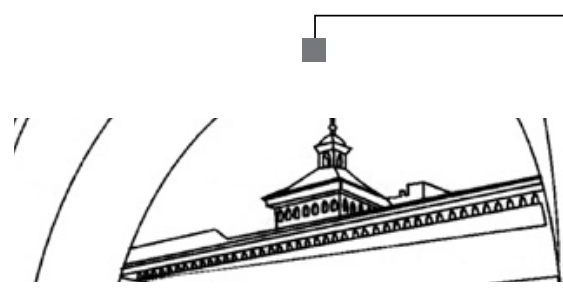




\section{Pautas de atención penitenciaria a poblaciones excepcionales}


El Inpec ha diseñado pautas de integración social dirigidas a grupos con condiciones excepcionales, que optan por la inclusión y la solución a necesidades culturales a través de la participación (tabla 1).

Tabla 1. Pautas de atención para poblaciones excepcionales

\begin{tabular}{|c|c|}
\hline $\begin{array}{l}\text { Población } \\
\text { excepcional }\end{array}$ & Pautas de atención \\
\hline Madres gestantes & $\begin{array}{l}\text { - Control prenatal. } \\
\text { - Culminación adecuada del embarazo, involucrando a la familia. } \\
\text { - Coordinación de programas pedagógicos con instituciones pú- } \\
\text { blicas y privadas. }\end{array}$ \\
\hline Madres lactantes & $\begin{array}{l}\text { - Control posparto. } \\
\text { - Control de crecimiento y desarrollo. } \\
\text { - Coordinar con el ICBF la atención integral de madres e hijos/hijas. } \\
\text { - Promover la lactancia materna. }\end{array}$ \\
\hline Indígenas & $\begin{array}{l}\text { - Certificar con la autoridad indígena competente la pertenencia } \\
\text { - Pel recluso a su comunidad. } \\
\text { de origen. } \\
\text { - Prevenir el desarraigo cultural, facilitando el contacto con la } \\
\text { familia y la comunidad. } \\
\text { - Coordinar la provisión de gastos de transporte al lugar de origen, } \\
\text { - en caso de otorgarse la libertad. } \\
\text { - Apoyar presupuestalmente las acciones adelantadas por las or- } \\
\text { - Apoyarion las actividades de asistencia y acompañamiento empren- } \\
\text { - didas por las autoridades indígenas. } \\
\text { - } \text { establecer convenios de cooperación entre el Inpec y entidades } \\
\text { - Ajustarse al marco de referencia que rige para pueblos indígenas. }\end{array}$ \\
\hline Afrocolombianos & $\begin{array}{l}\text { - Prevenir el desarraigo cultural, facilitando el contacto con la } \\
\text { familia y la comunidad. } \\
\text { - Apoyar las actividades de asistencia y acompañamiento empren- } \\
\text { didas por las comunidades negras. } \\
\text { - Establecer convenios de cooperación entre el Inpec y entidades } \\
\text { públicas y privadas para brindar apoyo a esta población. }\end{array}$ \\
\hline
\end{tabular}




\begin{tabular}{|l|l|}
\hline \multirow{4}{*}{ Adultos mayores } & $\begin{array}{l}\text { - Facilitar el acceso a los programas de promoción y prevención. } \\
\text { - Considerar factores de riesgo físico, psicológico o social, que impi- } \\
\text { dan el adecuado desenvolvimiento en las actividades cotidianas. } \\
\text { - Fomentar la colaboración de organismos nacionales e interna- } \\
\text { cionales que trabajen en pro de los AMPL. }\end{array}$ \\
\hline Extranjeros & $\begin{array}{l}\text { - Facilitar el contacto con las autoridades consulares de su país. } \\
\text { - Propender por hacer la inducción al establecimiento en el idioma } \\
\text { - Prevenir el desarraigo cultural, facilitando el contacto con auto- } \\
\text { ridades consulares y la familia. } \\
\text { - Fomentar la colaboración de organismos nacionales e interna- } \\
\text { cionales que trabajen en pro de los reclusos extranjeros. }\end{array}$ \\
\hline Personas con disca- & $\begin{array}{l}\text { Velar por que la ubicación física del interno responda a sus limi- } \\
\text { taciones y locomoción. }\end{array}$ \\
pacidad & $\begin{array}{l}\text { Considerar factores de riesgo o necesidad de acondicionamiento } \\
\text { Gestionar el suministro de ayudas técnicas o tecnológicas para } \\
\text { su desempeño autónomo. } \\
\text { Fomentar la colaboración de organismos nacionales e interna- } \\
\text { cionales que trabajen en pro de las personas con discapacidad en } \\
\text { reclusión. }\end{array}$ \\
\hline
\end{tabular}

Fuente: información tomada del Programa de Integración Social para Personas con Condiciones Excepcionales. Elaboración propia.

Este programa, sin embargo, no se consolida como una directriz estructurada de tratamiento diferencial ni establece parámetros claros para cada población; por el contrario, y muy posiblemente por la escasez de recursos con los que cuenta el Inpec, se limita a proponer una serie de acuerdos de cooperación con organismos externos, que puedan aportar a la integración de estas poblaciones, como parte de su objeto misional. De esta manera, es posible afirmar que en la actualidad el Inpec no cuenta con una política clara de tratamiento diferencial, aunque se reconoce la conciencia de la institución sobre esta problemática particular. 


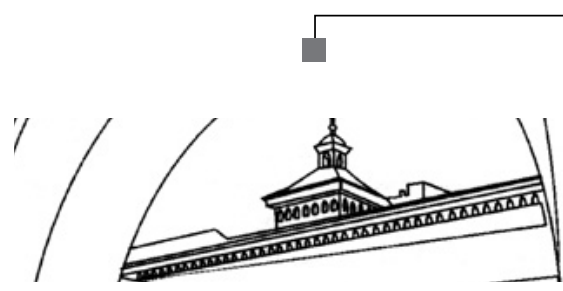




\section{Concepción del adulto mayor}




\section{Generalidades}

El término AM es un eufemismo para disimular la realidad de la vejez, considerada, de por sí, como un estigma, un estamento costoso e inútil (Gainzo Vicente, 2009). No obstante, a través de los siglos se ha valorado como una etapa de respeto y de sabiduría que merece más que consideración.

Desde la perspectiva jurídica, se puede afirmar que es la propia ley, como su intérprete autorizada, la que busca definir al AM (Corte Contitucional, 2010), sin que su conceptualización relativa a la tercera edad resulte forzosamente clara y aceptable, por lo que también se considera que las personas que por sus características fisiológicas, psicológicas y mentales, que no necesariamente convergen en una edad determinada, son las que revelan una disminución en la integridad de su ser, condición que demanda asistencia, cuidado, consideración, protección y solidaridad no solo de sus semejantes, sino de manera especial del Estado a través de la ley. Los jubilados y no jubilados deben contar con estilos de vida adecuados y con la garantía de políticas que opten por mejorar su calidad de vida, disminuir efectivamente los gastos en salud pública y renovar las relaciones familiares y el entorno comunitario. El AM requiere que se le asigne un rol en la sociedad; el final del tiempo no puede ser un espacio exclusivo para la desocupación, el dolor, la enfermedad, la angustia y la orfandad, en espera de la muerte. Si el menor no se puede autosostener, requiere de protección y cuidado frente a su condición de vulnerabilidad; la misma protección y cuidado se le debe dispensar al AM que se encuentre en la misma situación.

Se estipula que los AM son aquellas personas que, debido al proceso de los años, se hallan en una etapa de cambios a nivel físico y psicológico, y dentro de la comunidad se les debe dar condiciones y garantías para la efectividad de los derechos económicos y sociales, ya que requieren de cuidados especiales durante el proceso de envejecimiento (Dueñas, 2011). Así las cosas, se debe propender por el reconocimiento del AM como un eje fundamental de la sociedad en la relación con el Estado, la familia, la educación, el bienestar, la recreación, el trabajo, y comprender que sus cambios obedecen a una etapa natural e inevitable que no debe ser burlada y que no puede ser excusa para discriminarlos o desarraigarlos de su entorno, familia, 
trabajo y hasta del mismo Estado, pues por un lado se legisla a favor de esta población, pero, por otro lado, son excluidos y eliminados del conjunto de la fuerza de producción, de trabajo o de la población considerada como "útil".

Establecer en la actualidad un término que identifique lo que comúnmente conocemos como viejo, anciano o persona de edad, nos remite necesariamente a los logros conceptuales que desde diversas disciplinas como las llamadas ciencias médicas y las ciencias sociales se han construido. La determinación en relación con la edad, tiene diversos componentes que van desde consideraciones según el nivel de bienestar de la población, hasta los avances médicos y de participación social. [...] Los organismos mundiales, ubican a esta población entre los 60 o más años. [...] En abril de 1994 la Organización Panamericana de la Salud decidió emplear el término adulto mayor, que abarca una visión integral, interdisciplinaria y holística. (Universidad Libre, s. f.)

Si bien concordamos en que el envejecimiento no se puede definir en términos de edad, puesto que en él influyen diversidad de variables como el estilo de vida, la condición socioeconómica, los hábitos de vida saludables, la ocupación y las condiciones de salud, entre otras, y que por tal motivo es difícil establecer una edad única para hablar de AM, en esta investigación se abordó la población de 60 años y más, clasificación que ha sido aceptada por la OMS.

La vejez no es definible exclusivamente con la cronología sino más bien por la suma de las condiciones físicas, funcionales, mentales y de salud de las personas analizadas. Hablamos de la edad fisiológica según el envejecimiento de órganos y funciones. De la edad psíquica o mental, según el grado de madurez, envejecimiento psicológico. Y existe otra edad, la subjetiva según el envejecimiento que experimenta la propia persona. Por tanto, la ancianidad es un concepto dinámico, pues hay que tener en cuenta que la edad biológica puede diferir marcadamente de la cronológica, y ambas de la subjetiva. (Olmos, 2009, p. 8) 
Esta nueva concepción, sin duda, propende por superar el imaginario, bastante manejado por las ciencias económicas, que define la vejez solo en términos de edad. Al respecto, hablar de una concepción del AM, desde las ciencias económicas, no resulta sencillo, debido a que las dimensiones que se manejan desde la economía privilegian el criterio de la edad como orientador principal, lo cual está acompañado por el proceso de envejecimiento fisiológico y de productividad, determinado por las actitudes y las conductas que se tienen con respecto a la edad (Comisión Económica para América Latina y el Caribe [Cepal], 2011).

La primera asociación al concepto de AM se configura por la definición cronológica, que es un criterio que difiere por las diferentes legislaciones y culturas, por lo que es difícil de determinar de manera específica. Sin embargo, la mayoría de los países, principalmente los países en vías de desarrollo, coinciden en que esta etapa de la vida inicia a los 60 años, criterio que marca, en algunas legislaciones de América Latina, la edad de jubilación. ${ }^{1}$ Esta concepción desde la edad cronológica se relaciona con la pérdida de productividad, debido a la disminución que las personas sufren de las capacidades funcionales que les permiten mantenerse autónomas, independientes y con la capacidad de producir para ellas y otras.

Otra concepción hace referencia a la fisiología; en este caso, la vejez, además de estar enmarcada en la edad cronológica, se determina por la pérdida de capacidad física (a nivel muscular y de fuerza) que tienen las personas, lo que las lleva a un deterioro "natural" físico o mental-de forma separada o en forma conjunta-, que les impide tener una vida social independiente (Centro Latinoamericano y Caribeño de Demografía [Celade], 2001).

$1 \quad$ En Colombia, al igual que en Venezuela, las personas se jubilan más jóvenes con una pensión completa: 55 años, para las mujeres, y 60 años, para los hombres. En el resto del mundo nos igualan las Islas Fiji, Costa de Marfil, Ruanda y la mayoría de los países de Medio Oriente y norte de África, entre otros. Aunque se tiene previsto que a partir del 1 de enero de 2014 la edad de jubilación para mujeres será de 57 años y para hombres, de 62 años. El único país que está por debajo de Colombia es Turquía, donde las mujeres dejan de trabajar a los 44 años y los hombres a los 47. Colombia está por debajo de países como Argentina, Brasil y Chile, donde los hombres deben cumplir 65 años para pensionarse, y en países como Estados Unidos, Australia y el Reino Unido se requiere tener más de 67, tanto para hombres como para mujeres. 
Finalmente, los dos anteriores aspectos conducen a una relación directa e intrínseca con la productividad; el término AM se refiere, así, a una etapa donde los procesos de producción, las tendencias de consumo y la generación de tributación disminuyen, con motivo del retiro de la "actividad laboral" que es reemplazada por actividades de diversión, disfrute y placer (Cepal, 2011).

Sin embargo, el cese de la actividad laboral no necesariamente representa cambios positivos, es común encontrar AM que se ven obligados a afrontar la desprotección y la marginalización. Un ejemplo bastante ilustrador de esta situación es el caso de los ancianos japoneses, para quienes la cárcel se ha vuelto en el último refugio, al punto de que

roban para ir a la cárcel y huir de una sociedad individualista que los ignora. La pequeña delincuencia protagonizada por la tercera edad es un fenómeno en alza en Japón, el último informe anual sobre delincuencia de la policía japonesa ha sembrado la inquietud. Las estadísticas muestran que uno de cada cuatro japoneses detenidos por robar en el 2010 era mayor de 65 años. En 1986, cuando se empezó a confeccionar este tipo de estadísticas, solo uno de cada veinte japoneses detenido por hurto era mayor de 65. (La Vanguardia, 2013)

Esta situación demuestra la ruptura de la tradición ancestral nipona de reunir bajo un mismo techo a tres generaciones de la misma familia. En la cárcel, los AM tienen techo, comida caliente y compañía; cuentan con espacios especiales y tienen que trabajar 6 horas diarias, 2 horas menos que los demás internos. Este tratamiento diferencial y especial, sin embargo, no es la norma en los EPC de todos los países; por el contrario, la privación de la libertad representa para muchos AM un evento desafortunado y hostil. Al respecto, se encuentra la siguiente declaración, en relación con la experiencia en España:

La ancianidad se acompaña de un mayor número de padecimientos que muchas veces coexisten a la vez. Existe con alta frecuencia procesos degenerativos, como deterioro cognitivo, enfermedades cardiovascu- 
lares, limitaciones del aparato locomotor, cáncer. Sin olvidar que una buena parte de nuestros pacientes por su historial de abusos de sustancias tóxicas agravan su situación y presentan todavía más deterioro que la población no reclusa. Estos procesos degenerativos establecidos de forma crónica y perenne, junto con la presencia de caídas, accidentes o alteraciones de los sentidos llevan a un final común que es la Invalidez y la Dependencia. Y una marcada pérdida de funcionalidad. (Ministerio del Interior del Gobierno de España, Secretaría General de Instituciones Penitenciarias, s. f.)

Es común, entonces, encontrar una relación directa entre la adultez mayor y la enfermedad, el deterioro físico y la improductividad, entre otros aspectos, lo cual posiblemente responde a entender la vejez como una etapa específica y no como un proceso. Arango y Ruiz (2001) afirman, en relación con el tema del envejecimiento y la vejez, que se refieren al "conjunto de modificaciones morfológicas y fisiológicas que aparecen desde el mismo momento del nacimiento, se incrementa con el paso del tiempo e involucra a todos los seres vivos. Es un proceso biológico, social y psicológico, como resultado de la interacción de la herencia, el ambiente y la conducta y va delineando la última etapa de la vida: la vejez" (Arango \& Ruiz, 2001). Una población se considera envejecida en la medida en que el $7 \%$ está conformado por personas de 60 años o más. ${ }^{2}$ En el caso de América Latina se cuenta con el siguiente panorama (tabla 2).

2 El índice de envejecimiento es un indicador del proceso que muestra la relación existente entre la cantidad de personas mayores de 60 años y la de niños y jóvenes menores de 15 años; cuando está por debajo de 100, existen menos personas de 60 años que menores de 15 años, y se encuentra por encima de 100 cuando el número de personas mayores de 60 años supera al de niños y adolescentes. 
Tabla 2. Índice de envejecimiento de la población 1950-2050 en América Latina

\begin{tabular}{|c|c|c|c|c|c|}
\hline País/Country & 1950 & 1975 & 2000 & 2025 & 2050 \\
\hline Argentina & 23,1 & 39,0 & 48,1 & 75,5 & 135,6 \\
\hline Bolivia & 13,6 & 12,9 & 16,1 & 31,0 & 82,1 \\
\hline Brasil/Brazil & 11,7 & 15,0 & 27,3 & 73,8 & 146,6 \\
\hline Chile & 18,7 & 21,4 & 35,8 & 82,2 & 131,9 \\
\hline Colombia & 11,7 & 12,9 & 20,9 & 55,2 & 116,1 \\
\hline Costa Rica & 19,8 & 16,7 & 23,8 & 74,0 & 155,9 \\
\hline Cuba & 20,4 & 26,5 & 64,3 & 156,5 & 221,1 \\
\hline Ecuador & 20,6 & 14,0 & 20,5 & 53,1 & 124,1 \\
\hline El Salvador & 11,1 & 10,4 & 20,2 & 41,0 & 106,9 \\
\hline Guatemala & 9,7 & 9,7 & 12,1 & 21,5 & 65,6 \\
\hline Haití & 22,3 & 17,1 & 14,1 & 26,9 & 74,3 \\
\hline Honduras & 8,7 & 8,7 & 12,4 & 30,4 & 85,6 \\
\hline México & 16,9 & 12,2 & 20,9 & 58,2 & 143,4 \\
\hline Nicaragua & 9,3 & 8,3 & 10,7 & 25,6 & 79,7 \\
\hline Panamá & 16,1 & 15,2 & 24,9 & 58,0 & 118,4 \\
\hline Paraguay & 22,9 & 16,5 & 13,5 & 30,6 & 76,0 \\
\hline Perú & 13,7 & 12,9 & 20,5 & 51,5 & 119,6 \\
\hline $\begin{array}{l}\text { República Dominicana/ } \\
\text { Dominican Republic }\end{array}$ & 11,6 & 10,4 & 19,8 & 52,5 & 116,9 \\
\hline Uruguay & 42,3 & 51,0 & 69,2 & 93,4 & 144,5 \\
\hline Venezuela & 7,9 & 11,4 & 19,4 & 54,6 & 120,3 \\
\hline
\end{tabular}

Fuente: Cepal-Celade.

De acuerdo con esto, Colombia se encuentra, al igual que el resto de países de América Latina, en un acelerado proceso de envejecimiento; el aumento de los Am frente a las tasas de fecundidad ubica al país en un proceso de envejecimiento moderado, ${ }^{3}$ frente a otros países de Latinoamérica.

3 El envejecimiento se ha clasificado demográficamente en cinco grandes categorías (Celade, 2010): 
Ante esto, la concepción de AM cada día cobrará mayor importancia en la media en que el peso relativo del total de la población siga en aumento.

Tabla 3. Índice de envejecimiento vs. tasa global de fecundidad en América Latina

\begin{tabular}{|c|c|c|c|}
\hline Etapas & Países & $\begin{array}{c}\text { Índice de } \\
\text { envejecimiento }\end{array}$ & $\begin{array}{c}\text { Tasa global de } \\
\text { fecundidad }\end{array}$ \\
\hline \multirow{18}{*}{$\begin{array}{l}\text { Envejecimiento } \\
\text { incipiente }\end{array}$} & Belice & 16,7 & 2,8 \\
\hline & Bolivia (Est. Plur. de) & 20,1 & 3,3 \\
\hline & Guatemala & 15,1 & 3,9 \\
\hline & Guayana Francesa & 19,5 & 3,1 \\
\hline & Haití & 18,0 & 3,4 \\
\hline & Honduras & 16,8 & 3,1 \\
\hline & Nicaragua & 18,1 & 2,7 \\
\hline & Paraguay & 22,8 & 3,0 \\
\hline & Colombia & 29,8 & 2,2 \\
\hline & Ecuador & 30,9 & 2,5 \\
\hline & El Salvador & 32,2 & 2,3 \\
\hline & Guyana & 32,4 & 2,3 \\
\hline & Jamaica & 37,0 & 2,3 \\
\hline & Panamá & 33,6 & 2,5 \\
\hline & Perú & 29,1 & 2,5 \\
\hline & República Dominicana & 27,6 & 2,6 \\
\hline & Suriname & 32,7 & 2,4 \\
\hline & Venezuela (República Bolivariana de) & 29,3 & 2,5 \\
\hline
\end{tabular}

a) Envejecimiento incipiente: cuenta con una tasa de fecundidad de más de 3,3 hijos, frente a 23 AM por cada 100 menores.

b) Envejecimiento moderado: cuenta con una tasa de fecundidad de entre 2,7 y 2,3 hijos, frente a AM que representan entre el $27,6 \%$ y el $37 \%$ por cada 100 menores.

c) Envejecimiento moderado avanzando: cuenta con una tasa de fecundidad de entre 2,1 y 1,8 hijos, frente a AM que representan entre el $33 \%$ y el $42 \%$ por cada 100 menores.

d) Envejecimiento avanzando: cuenta con una tasa de fecundidad entre 1,8 y 2,1 hijos, frente a AM que representan entre el $51 \%$ y el $82 \%$ por cada 100 menores.

e) Envejecimiento muy avanzado: cuenta con una tasa de fecundidad entre 1,5 y 1,9 hijos, frente a AM que representan entre el $91 \%$ y el $100 \%$ por cada 100 menores. 


\begin{tabular}{|c|c|c|c|}
\hline Etapas & Países & $\begin{array}{c}\text { Índice de } \\
\text { envejecimiento }\end{array}$ & $\begin{array}{c}\text { Tasa global de } \\
\text { fecundidad }\end{array}$ \\
\hline \multirow{5}{*}{$\begin{array}{l}\text { Envejecimiento } \\
\text { moderadamen- } \\
\text { te avanzado }\end{array}$} & Bahamas & 41,3 & 2,0 \\
\hline & Brasil & 39,8 & 1,8 \\
\hline & Costa Rica & 37,3 & 2,0 \\
\hline & México & 33,9 & 2,1 \\
\hline & Santa Lucía & 38,6 & 2,0 \\
\hline \multirow{6}{*}{$\begin{array}{l}\text { Envejecimiento } \\
\text { avanzado }\end{array}$} & Antillas Neerlandesas & 75,6 & 1,9 \\
\hline & Argentina & 58,1 & 2,3 \\
\hline & Chile & 58,1 & 1,9 \\
\hline & Guadalupe & 62,1 & 2,1 \\
\hline & Trinidad y Tobago & 51,5 & 1,7 \\
\hline & Uruguay & 81,7 & 2,1 \\
\hline \multirow{4}{*}{$\begin{array}{l}\text { Envejecimiento } \\
\text { muy avanzado }\end{array}$} & Barbados & 90,0 & 1,6 \\
\hline & Cuba & 100,0 & 1,5 \\
\hline & Martinica & 97,5 & 1,9 \\
\hline & Puerto Rico & 97,8 & 1,8 \\
\hline
\end{tabular}

Fuente: Celade (2010).

En los EPC, aunque no se cuenta con los datos de la tasa global de fecundidad, lo que permitiría evidenciar la categoría de envejecimiento en la que se encuentra su población, el aumento de las penas hace prever que, independientemente de la situación jurídica definida, los internos vienen envejeciendo y la población de AMPL continúa con una tendencia al alza, y, literalmente, esta población tiene como única esperanza concluir su vida encarcelada (figura 3). Curiosamente, aunque no existe cadena perpetua en Colombia, el aumento de las penas, junto con el incremento de la esperanza de vida, la longevidad y los índices de envejecimiento permiten suponer que implícitamente esta pena es una realidad en el país. 
Figura 3a. Número de adultos mayores privados de la libertad 2009-2013 (comportamiento de edad y sexo)

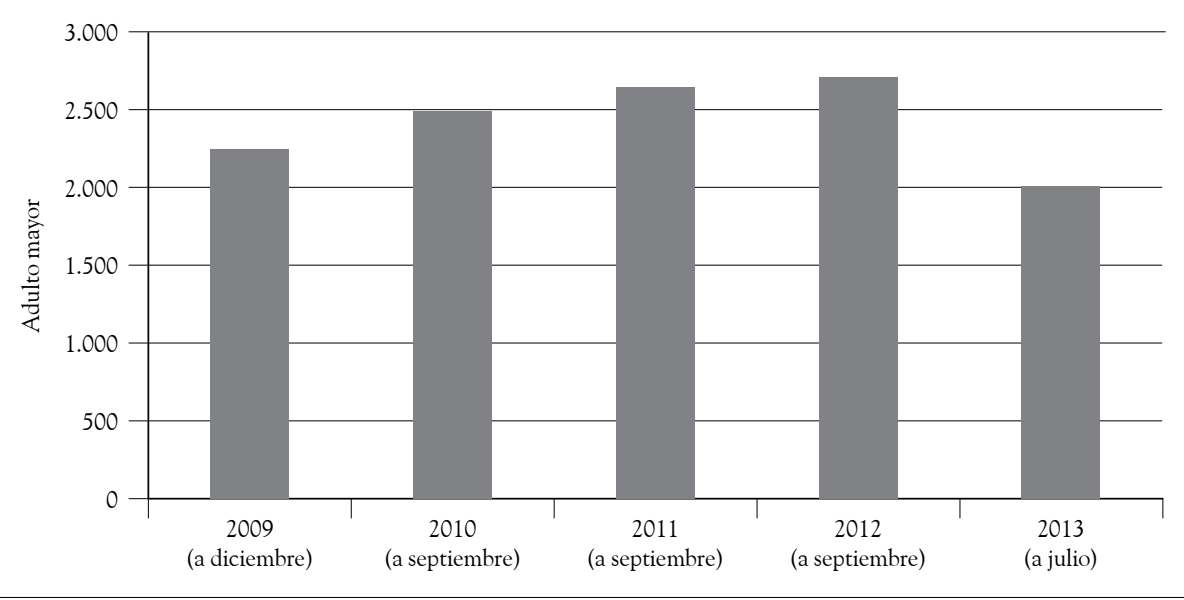

Figura 3b. Adultos mayores privados de la libertad

(distribución por de edad y sexo)

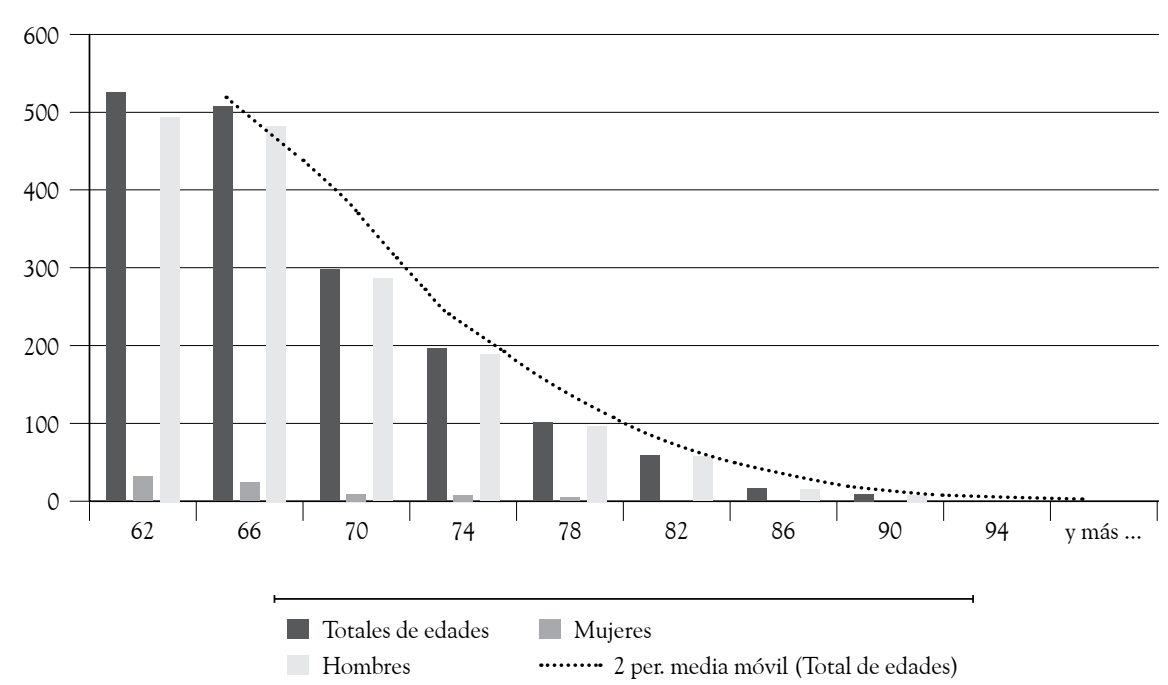

Fuente: plan de compras del Inpec para cada vigencia, y censo de condiciones excepcionales, 31 de julio de 2013 del Sisipec Web. Cálculos de los autores. 


\section{El concepto del adulto mayor desde diversas disciplinas}

En el presente apartado se abordan las diferentes concepciones sobre el AM, acogidas y desarrolladas desde las ciencias jurídicas, la psicología, la economía y la sociología, y contrastadas con la información empírica. Hacer referencia a las temáticas relacionadas con el AM en prisión se convierte en un reto que invita al análisis de cada uno de los términos que se utilicen con el fin de mostrar realidades encontradas en esta población.

Lo anterior, permite entender por qué se elige el término "concepción" como el "conjunto de ideas que se tienen sobre alguna cosa" (Real Academia Española [RAE], 2013); no como parte del entramado de fríos conceptos que se exponen de manera sistemática, secuencial y cronológica con el fin de lograr ilustrar algo, sino como el conjunto de ideas acompañadas de preguntas que son el vehículo que permite aproximarse a la manera como se llega a concebir la imagen que se tiene de algo.

\section{Perspectiva jurídica del adulto mayor}

Tanto la CN, en su artículo 46, como la ley hacen referencia al concepto de adulto mayor; la primera lo señala como persona de la tercera edad, mientras que la ley lo define como aquella persona que cuenta con sesenta (60) años de edad o más. Este último criterio se enfatiza en la Ley 1251 de 2008, artículo 3, normatividad que, además, incluye las definiciones de vejez: "Ciclo vital de la persona con ciertas características propias que se producen por el paso del tiempo en el individuo" (Congreso de Colombia, 2008), y de envejecimiento: "Conjunto de modificaciones que el paso del tiempo ocasiona de forma irreversible en los seres vivos" (Congreso de Colombia, 2008).

De manera semejante, el anterior criterio es reiterado por la Ley 1276 de 2009, artículo 7, literal b, cuando señala: "Adulto Mayor es aquella persona que cuenta con sesenta (60) años de edad o más. A criterio de los especialistas de los centros vida, una persona podrá ser clasificada dentro de este rango, siendo menor de 60 años y mayor de 55, cuando sus condi- 
ciones de desgaste físico, vital y psicológico así lo determinen" (Congreso de Colombia, 2009).

Pareciera, entonces, que desde el punto de vista legal, el concepto de adulto mayor principalmente está atado al de la edad, que es considerada para la jubilación y, a través del requisito pensional, se pretende armonizar y generalizar su definición, puesto que apenas la Ley 1276 muy tímidamente se atreve a incluir otras características relativas a lo físico, lo vital y lo psicológico.

Lo anterior, nos conduce a asumir o adentrarnos en el campo de la seguridad social, por ser la línea conductora y reguladora del adulto mayor en Colombia. A partir de un recuento histórico en cuanto a asistencia y seguridad social del AM, Arenas-Monsalve (2007) describe cinco etapas en la historia de la seguridad social en Colombia: desde el nacimiento de la República hasta 1945, un periodo de organización desde 1945 hasta 1967, un periodo de expansión desde 1967 hasta 1977, un periodo de cambios y crisis desde 1977 hasta 1990 y un periodo de reformas estructurales a partir de 1990.

En la primera etapa se percibe una desatención por parte del Estado, por lo que se le delegaba a la caridad la obligación frente al particular. Posteriormente, gracias a Rafael Uribe Uribe, se implementa, aunque solo hasta 1936, el programa Socialismo de Estado, que buscaba vincular al Estado con el tema de la seguridad social. Con la Ley 90 de 1946 se implementa un modelo de seguridad social que vela por la protección de los trabajadores y, en adelante, se formula otra normatividad, como el Decreto 1824 de 1965, la Ley 4 de 1976 o la Ley 1650 de 1977, que propendió por definir los aspectos concernientes a la seguridad social y velar por su cumplimiento (Ciprián-Carvajal, 2011).

Otro aspecto importante es que, previo al inicio de la década de los setenta, se crea, por medio de la Ley 75 de 1968, el Instituto Colombiano de Bienestar Familiar, encargado de prestar asistencia por enfermedad, invalidez o calamidad a los que se encontraran afiliados. Posteriormente, se expide la Ley 29 de 1975, a través de la cual se crea la protección a la ancianidad, y surge el Fondo Nacional de la Ancianidad Desprotegida para favorecer a las personas que tengan más de 60 años y que se encuentren en estado de indefensión, pobreza y quebrantos de salud (Congreso de Colombia, 1975). 
En la década de los ochenta surge la Ley 48 de 1986, "por la cual se autoriza la emisión de una estampilla pro-construcción, dotación y funcionamiento de los centros de bienestar del anciano, se establece su destinación y se dictan otras disposiciones" (Congreso de Colombia, 1986); se invoca esta ley como antecedente de una intención más para la protección del AM en ese momento histórico.

En la década de los noventa, se señala el Día de la Tercera Edad y el Pensionado, en la Ley 271 de 1996, y se hace alusión al principio de dignidad, sin que se haya desarrollado una política pública seria al respecto. Con la Constitución del 91 se expidió la Ley 100 de 1993, que, como se sabe, constituyó el hito más importante en la materia, fue el objeto de algunas reformas y, en la actualidad, se tiene la perspectiva de modificarla.

El hecho de que legalmente no se fortalezca la concepción del AM a nivel nacional conduce a la poca importancia que se le sigue dando al tema y a que no exista claridad sobre quiénes son, tanto desde el punto de vista del Estado a través de sus diferentes servidores, los que tendrían que dispensar su cuidado y protección, como desde la arista de quiénes lo necesitan; al punto de que dicho vacío, contrario a lo que pasa con los menores, quienes cuentan con todo un código al respecto, ha generado una reacción puntual sobre el tema, como es el caso del Distrito Capital, que aventaja en dichas políticas a lo nacional.

En cuanto a los hallazgos de campo, es común encontrar entre las opiniones de los participantes que el concepto de AM se vincula inmediatamente con la edad, lo que guarda coherencia con lo planteado en la legislación nacional; de esta manera, se afirma reiterativamente que "un adulto mayor es una persona que está por encima de los 60 años" (grupo focal, Comeb, julio de 2013, Bogotá). En cuanto a la seguridad social, se encontró que aunque son pocos, algunos de los participantes se encuentran cubiertos por el régimen pensional, aunque la prisión se vuelva una limitante para el goce efectivo de este derecho. "Yo soy pensionado y aquí me atiende mi EPS, pero cuando mi familia me pide una cita, no me llevan, me la cancelan, y luego piden otra cita, y me hacen perder las citas... me han hecho perder 3 citas donde los especialistas, donde los cirujanos [...]" (grupo focal, EPMSC, julio de 2013, Medellín). 


\section{La vejez desde las teorías psicológicas}

Antes de profundizar en las variables psicológicas específicas que se tuvieron en cuenta para el estudio, es necesario retomar algunos aportes que ayudan en la comprensión del concepto vejez. Al tener en cuenta que el trascurrir de la vida implica el "uso" de las funciones psicofisiológicas de manera continuada, se entiende que en el desarrollo del proceso de envejecimiento se observen cambios en el cuerpo que son producto de las modificaciones en su química: baja de la masa muscular, además de la "disminución para responder de manera funcional a las variaciones del ambiente, incremento en la vulnerabilidad a enfermedades y mortalidad de las personas", entre otros (Cristófalo, 1991); luego, el envejecimiento se asocia con el desgaste, la disminución, la mengua. En una línea muy similar, la OMs (citado en Gión et al., 2011) se ha centrado en diferenciar los conceptos de envejecimiento como proceso y proceso de envejecimiento, así como de la promoción de la idea de envejecimiento activo, descritos así:

Tabla 4. El envejecimiento según la Organización Mundial de la Salud

\begin{tabular}{|l|l|l|}
\hline \multicolumn{1}{|c|}{ Envejecimiento como proceso } & Proceso de envejecimiento & \multicolumn{1}{c|}{ Envejecimiento activo } \\
\hline $\begin{array}{l}\text { También llamado envejecimien- } \\
\text { to normal, en el que se hace } \\
\text { referencia a los cambios bioló- }\end{array}$ & $\begin{array}{l}\text { Este concepto tiene rela- } \\
\text { ción con factores ambien- } \\
\text { tales, de estilo de vida y y } \\
\text { gicos esperables relacionados } \\
\text { enfermedades que pueden } \\
\text { con la edad, sin afectación por } \\
\text { causo de hacerse mayor sin } \\
\text { envejecer mediante el de- } \\
\text { estar vinculadas con el en- } \\
\text { conficiones del entorno. }\end{array}$ & $\begin{array}{l}\text { sarollo continuado de ac- } \\
\text { tividades físicas, sociales } \\
\text { vejecimiento, pero no se } \\
\text { y espirituales a lo largo de } \\
\text { toda la vida". }\end{array}$ \\
\hline
\end{tabular}

Fuente: OMS (citado en Gión et al., 2011).

Es notorio que existe una preocupación por diferenciar las consecuencias propias del envejecimiento de las que son producto de factores que si bien tienen relación con este, aparecen como causas externas necesariamente vinculadas a estilos de vida y condiciones del entorno que pueden ser o no elección del individuo. Finalmente, aparece una estrategia que busca hacer frente al proceso de envejecimiento, que consiste en preparase para el envejecimiento normal durante toda la vida. 
Además de los anteriores, se encuentran los conceptos de envejecimiento primario, que implica cambios que inevitablemente se presentarán con la edad, y envejecimiento secundario, referente a los cambios causados por afecciones que no son resultado de la edad (Moreno, 2004). Estos se han adoptado para intentar explicar el envejecimiento únicamente desde el aspecto físico, y están enmarcados en la teoría de la preprogramación genética que afirma la reproducción de las células solo hasta una cierta edad, y las teorías del desgaste según las cuales las funciones mecánicas del cuerpo dejan de trabajar de manera idónea (Berger \& Thompson, 2009). Las ideas expuestas hasta el momento muestran unos puntos de encuentro entre las diferentes posturas:

1. Se observa el envejecimiento como parte de un proceso que se da a lo largo de la vida y no como un episodio estático o apartado de esta.

2. Se entiende que existe un acuerdo entre algunas características deseables relacionadas con la preparación que debe hacer cada individuo para enfrentar la vejez.

3. Presencia del deterioro que da lugar a la exigencia de realizar ajustes para lograr la adaptación funcional en diversas esferas.

Estos postulados se convierten en un marco de referencia inicial que sirve para sentar las bases con respecto del término AM; por tanto, no pretenden convertirse en definiciones estandarizadas ni son aplicables a toda esta población. Como referencia inicial, admiten vinculaciones de diversas categorías de análisis con el ánimo de lograr el mayor acercamiento posible a lo que sería la definición desde el punto de vista que integra posturas psicológicas y percepciones de los protagonistas de esta investigación. Ese ánimo conlleva la inclusión de percepciones, ideas, pensamientos o juicios de internos que participaron en grupos focales, desarrollados en EPC del país. El resultado que se obtuvo fue un concepto de AM desde lo psicológico que se interpreta a partir de algunas categorías previamente mencionadas y otras que emergen producto de la participación e interacción con los que 
se consideran principales actores de este trabajo investigativo, los AMPL. En la tabla 5 se puede visualizar la matriz de codificación utilizada.

Tabla 5. Dimensiones del concepto adulto mayor

\begin{tabular}{|c|c|c|c|c|c|}
\hline 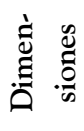 & Pensamientos & $\begin{array}{l}\text { Indicadores } \\
\text { psicológicos } \\
\text { de vejez }\end{array}$ & $\begin{array}{l}\text { Envejecimiento } \\
\text { como proceso }\end{array}$ & $\begin{array}{c}\text { Proceso de } \\
\text { envejecimiento }\end{array}$ & $\begin{array}{c}\text { Trato } \\
\text { diferencial }\end{array}$ \\
\hline \multirow{3}{*}{ 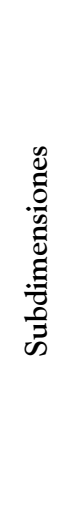 } & $\begin{array}{l}\text { Pensamiento } \\
\text { acerca de la } \\
\text { edad en tiempo. }\end{array}$ & $\begin{array}{l}\text { Capacidad/inca- } \\
\text { pacidad en acti- } \\
\text { vidades. }\end{array}$ & $\begin{array}{l}\text { Cambios } \\
\text { esperables. }\end{array}$ & $\begin{array}{l}\text { Condiciones } \\
\text { ambientales. }\end{array}$ & $\begin{array}{l}\text { Buen } \\
\text { trato. }\end{array}$ \\
\hline & $\begin{array}{l}\text { Pensamientos } \\
\text { acerca de la } \\
\text { edad como } \\
\text { estado mental. }\end{array}$ & Dependencia. & $\begin{array}{l}\text { Reconoci- } \\
\text { miento del } \\
\text { estado o de la } \\
\text { edad. }\end{array}$ & & $\begin{array}{l}\text { Atención } \\
\text { médica. }\end{array}$ \\
\hline & $\begin{array}{l}\text { Otras carac- } \\
\text { terísticas para } \\
\text { describir al AM. }\end{array}$ & Involución. & & & $\begin{array}{l}\text { Exclu- } \\
\text { sión. }\end{array}$ \\
\hline
\end{tabular}

Fuente: elaboración propia.

\section{Pensamientos}

El pensamiento como producto cognitivo no puede ser medido directamente, sino mediante la observación de su materialización en acciones, y tiene una influencia determinante en las representaciones del individuo acerca de lo que conoce, por cuanto su fin se constituye en encontrar soluciones a los problemas o mantenerse en una constante búsqueda de estas. En coherencia con esta definición, existe una estructura propuesta por Ericsson y Hastie (1994) que permite ubicar como principales funciones del pensamiento las de categorizar, razonar, decidir, solucionar problemas e inventar. A partir de esta propuesta, se encuentra que los AM participantes establecen categorías para el concepto de AM que agrupadas se refieren a la edad, un estado mental y otras características. 


\section{Pensamientos acerca de la edad en tiempo}

Cuando se habla del paso del tiempo, es obligatorio tocar el tema de la edad; al respecto, la población ubica la adultez mayor a partir de los 60 años de edad, lo que guarda coherencia con lo establecido en el ordenamiento legal (Congreso de Colombia, 2008). Otra idea relacionada con la edad es la tendencia a realizar una comparación retrospectiva que refleja el sentimiento de estar más jóvenes, entre los 25 a los 30 años, etapa de la vida que algunos autores consideran como la más productiva y, que al parecer, los participantes perciben de la misma manera: "Pero nosotros podemos ser más jóvenes mentalmente que un muchacho de 25" (grupo focal, EPMSC, julio de 2013, Medellín), "el cuerpo, que uno no tenga ningún, como se llama, dolor que lo domine a uno, es decir que uno se sienta como de 30 años. Yo me siento así, como de 30 años de juventud" (grupo focal, Comeb, julio de 2013, Bogotá).

\section{Pensamientos acerca de la edad como estado mental}

Para establecer el significado de la expresión estado mental, se toma como referencia a Lubrano (citado en Mora, et al., 2004), en cuanto a que en términos generales el estado mental denota el funcionamiento de áreas como la conciencia, el estado de ánimo, el afecto, el pensamiento, la conducta, entre otros; es decir, permite describir si estas funciones se están desarrollando de forma correcta o incorrecta.

Análoga a esta definición, está la referencia que hacen los participantes al término estado mental para representar positivamente cómo se perciben con respecto de su edad. Tal vez por eso, para ellos la vejez no está asociada al paso del tiempo o al número de años que tienen, sino a un conjunto de pensamientos que la constituyen, como algo que se lleva en la mente y, por lo tanto, se puede cambiar. En ese sentido, han convertido la edad en una experiencia subjetiva que no se circunscribe a medidas de tiempo por cuanto no es considerada como la principal característica que los describa: "Es un estado mental, el que se cree viejo, es viejo" (grupo focal, EPMSC ERE, julio de 2013, Cali), "pues yo creo que la edad la tiene uno en la mente. 
Uno es joven lo que se sienta de joven. Si uno a los 90 años se siente joven, es joven" (grupo focal, Comeb, julio de 2013, Bogotá). En consecuencia, el estado mental que se refleja en los pensamientos, las actitudes, las acciones o las percepciones se puede enmarcar dentro de lo positivo o lo negativo, y de esta forma influir y reflejar cómo se asume la vejez frente a la vida.

\section{Otras características para describir al adulto mayor}

La utilización de conceptos permite realizar asociaciones por características que dan como resultado nuevos términos con los que podemos describir objetos o personas. En este sentido, Murphy (citado en Limón, 2005), los define como un pegamento que tiene como función conectar experiencias del pasado con las interacciones que en la actualidad se están teniendo con el mundo. Esta capacidad permite a los individuos designar particularidades para hablar de algo o de alguien sin tener que mencionarlo y, para el caso de los entrevistados, específicamente, han conseguido conceptualizar al AM mediante la asignación de atributos como la sabiduría, la conciencia de los actos, la responsabilidad, de los cuales resaltan que son adquiridos por el paso del tiempo y la suma de experiencias. Un análisis tentativo puede indicar que estos atributos solo llegan a darse por la conjugación de la edad, y asumir un estado mental positivo que los posiciona sobre las personas más jóvenes: "Es decir, el AM es el que tiene conciencia de sus actos en toda su palabra" (grupo focal, Comeb Bogotá, julio 2013).

\section{Indicadores psicológicos de vejez}

Los participantes en los grupos focales no se limitaron a la simple construcción de un significado, sino que hicieron referencia a una serie de aptitudes o recursos con los que cuentan para el desarrollo de actividades. Estas acepciones se interpretan como indicadores de vejez que acompañan este concepto. En otras palabras, se constituyen en características atribuibles a esta etapa, ya no en términos de pensamiento, sino de acciones. 


\section{Capacidad/incapacidad en actividades}

El primer indicador planteado consiste en reconocer si, como AM, cuenta o no con los recursos personales para desempeñar una actividad. En términos expresados por los participantes, esto se relaciona con la palabra "capacidad". En este sentido, al percibirse con capacidades, se afirman en la idea de mantenerse al margen del envejecimiento. "Mire, acá hay capacidad laboral que no la tiene la juventud, aquí en este momento, nos la pasamos laborando, haciendo dibujos, manualidad, que una cosa que la otra" (grupo focal, EPMSC ERE Cúcuta, julio de 2013). No obstante, tienen presente que la capacidad se puede perder, y, si aún la conservan, puede ser debido al estado mental o la actitud, que se mencionaron anteriormente. Luego, este parámetro surge para identificarse positivamente.

En oposición, surgieron afirmaciones con las que se evaluaron negativamente, en las que se atribuía que la experiencia de envejecer era la ausencia total de capacidades, producto del paso de los años. "Ya uno tanta edad, iya qué! Ya no es capaz uno de nada” (grupo focal, Coiba Ibagué, junio de 2013). Aquí vale la pena detenerse un momento para analizar que si este es un parámetro bajo el cual se ha de medir la vejez desde una óptica negativa, es casi imposible que lleguen a considerarse viejos, en cuanto el deterioro que implicaría la incapacidad de hacer cualquier cosa; aunque puede aparecer, no es frecuente para esta población.

Esta polarización, igual que la edad asociada al estado mental y no al tiempo, prevé una situación gana-gana en el AM, porque lo ubica siempre cerca de cumplir los indicadores positivos y muy lejano de los negativos, toda vez que las circunstancias de incapacidad total son poco probables.

\section{Dependencia}

Es evidente que el cúmulo de tiempo tiene consecuencias contrarias a las deseadas, una de estas hace alusión a la dependencia, la cual fue descrita en situaciones en las que se requiere de otros para hacer cosas que regularmente los AM hacían solos. Esto se refleja en el malestar de tener que necesitar de 
alguien y, por ende, se puede entender como la pérdida de autonomía, si se considera que consiste en mantener la propia individualidad y la libertad personal, relacionadas con la autodeterminación (Ortiz \& Castro, 2009). "Empecé a ser vieja, por ejemplo, cuando me tocó valerme por medio de mi hija porque yo ya no" (grupo focal, Complejo Carcelario y Penitenciario de Medellín Pedregal [Coped], julio de 2013).

\section{Involución}

El término hace referencia a la posibilidad de volver a estados anteriores, en cuanto a tener necesidades específicas, lo que es producto del avanzado deterioro de las funciones físicas y cognitivas, y su impacto en lo social. En este sentido, el hecho de tener que depender del cuidado de los demás en actividades básicas es equiparable a estar viejo, y ese envejecimiento conduce a que los AM se perciban en estados de indefensión en los que necesitan de mayor atención, a tal punto que, paradójicamente, al percibirse como viejos, dicen que necesitan ser atendidos como niños. "Porque está como un niño ya que requiere de muchos tratamientos, de mucha compasión, creo que será eso" (grupo focal, EPMSC Bucaramanga, julio de 2013). Puede ser que la referencia al niño encierre un significado despectivo respecto de la forma en que les gustaría ser atendidos en sus necesidades especiales.

Hasta el momento, se han mostrado las consideraciones que influyen en los participantes en cuanto al concepto de AM. En primera instancia, se contemplaron los pensamientos referentes a la edad en términos de tiempo; la edad y la vejez como estado mental, y otras características emergentes que se atribuyen al AM como indicadoras de esta etapa, enmarcadas en la capacidad y la dependencia, como la pérdida de autonomía y la involución.

\section{Envejecimiento como proceso}

La OMS (citado en Gión et al., 2011) contempla un envejecimiento normal con cambios a nivel biológico asociados a la edad, que excluye la influencia 
de factores patológicos o ambientales; bajo esta perspectiva, se encontraron descripciones de algunos cambios significativos y que conscientemente son reconocidos por los participantes como parte del proceso (figura 5).

\section{Cambios esperables}

La tabla 6 hace referencia a los cambios físicos y biológicos manifestados en "enfermedades" y "dolencias" que se describieron en cuanto al concepto de AM.

Tabla 6. Cambios físicos y biológicos manifestados

por los adultos mayores privados de libertad

\begin{tabular}{|l|l|}
\hline Condición biológica & \multicolumn{1}{c|}{ Cita } \\
\hline Aspecto físico & $\begin{array}{l}\text { "Se le van notando las arrugas a uno, la pata de gallina, icómo que } \\
\text { no? Uno no puede decir: no, es que no estoy". }\end{array}$ \\
\hline Visión & $\begin{array}{l}\text { "La visibilidad se va perdiendo". } \\
\text { "La vista, yo entre aquí sin gafas y aquí me dieron estas gafas". }\end{array}$ \\
\hline Condición motora & $\begin{array}{l}\text { "Unos pasamanos porque entonces ya empiezo a perder el equilibrio, } \\
\text { "Que disminuimos nuestro caminar". }\end{array}$ \\
\hline $\begin{array}{l}\text { Enfermedades } \\
\text { gastrointestinales }\end{array}$ & $\begin{array}{l}\text { "La mayoría, a esta edad entramos casi todos enfermos, yo por lo } \\
\text { menos tengo gastritis crónica, tengo úlceras, tengo hernias, tengo } \\
\text { de todo eso". }\end{array}$ \\
\hline $\begin{array}{l}\text { Enfermedades } \\
\text { crónicas }\end{array}$ & $\begin{array}{l}\text { "La mayoría tenemos enfermedades crónicas, por ejemplo yo soy } \\
\text { hipertenso, hay diabéticos, a veces aquí a uno le dan tratamiento, } \\
\text { no es que sea malo del todo. También tengo problemas cardiacos". }\end{array}$ \\
\hline
\end{tabular}

Fuente: elaboración propia.

\section{Reconocimiento del estado o de la edad}

La capacidad del ser humano de estar consciente de las acciones, los sentimientos, las emociones, el dolor, entre otros, le permite comprender la experiencia en relación consigo mismo y con el entorno. La autoaceptación 
es uno de los criterios del bienestar psicológico expuesto por Ryff (citado en Ortiz \& Castro, 2009), y tiene relación con experimentar una actitud positiva hacia sí mismo y hacia la vida pasada. Desde esta perspectiva, el proyectar o vivir la vejez requiere de un ejercicio consciente de aceptar los cambios o las nuevas formas en las que se represente la existencia.

A partir de la anterior afirmación, los grupos aceptaron la condición de AM como aquella que está enmarcada en una fase de la vida determinada por la edad, en la capacidad de asimilar lo que están viviendo (limitaciones) y los roles que se asumen: "que somos abuelos"; además, promueven la premisa del equilibrio que debe existir para enfrentar las situaciones de la mejor manera. "Es un estado mental, el que se cree viejo es viejo. Pero, perdón, pero sin perder tampoco la perspectiva, el tiempo en que estamos ni la situación que estamos, porque tampoco con sesenta, setenta u ochenta años tampoco me voy a creer que puedo hacer muchísimas cosas, se debe ser equilibrado dentro de un sistema, pero tampoco me voy a poner a hacer cosas que yo sé que no puedo hacer" (grupo focal, EPMSC ERE CALI, julio de 2013).

\section{Proceso de envejecimiento}

Entre los aportes que dan cuenta de las consecuencias no deseables del envejecimiento, se destacan los que son producto de factores que, si bien pueden tener relación con este, aparecen como causas externas necesariamente vinculadas a estilos de vida y condiciones del entorno que difícilmente para los AMPL son su elección (figura 6).

\section{Condiciones ambientales}

En el contexto de la prisión convergen una serie de factores ambientales que son adversos para el desarrollo psicosocial de quienes se encuentran allí. Como marco, se puede considerar lo expresado en la Sentencia T-153 de 1998: 
En efecto, tanto el derecho a la dignidad como el de no recibir tratos o penas crueles, inhumanos o degradantes se ven quebrantados por el hacinamiento y las malas condiciones de la estructura física y de servicios públicos que se encuentra en los centros de reclusión; los derechos a la vida y la integridad física son vulnerados o amenazados de manera inminente por el mismo hacinamiento, por la mixtura de todas las categorías de reclusos y por la carencia de los efectivos de guardia requeridos. (Corte Constitucional de Colombia, 1998)

Estos factores, junto con las enfermedades vinculadas al envejecimiento, las prácticas del estilo de vida en la cárcel y las necesidades de un trato diferencial, han sido claramente expresados por los AM y no les es difícil establecer la relación con el deterioro en la salud tanto mental como física. En la tabla 7 se muestra cómo se agruparon los aspectos institucionales que determinan las condiciones ambientales percibidas por los internos y las participaciones en las que relacionaron las condiciones con su estado de salud en referencia con el AM.

Tabla 7. Condiciones ambientales en el proceso de envejecimiento

\begin{tabular}{|l|l|}
\hline \multicolumn{1}{|c|}{ Condiciones } & \multicolumn{1}{c|}{ Cita } \\
\hline $\begin{array}{l}\text { Reglamento } \\
\text { régimen } \\
\text { interno }\end{array}$ & $\begin{array}{l}\text { "Tengo } 74 \text { años cumplidos y yo si me siento mal, ya no oigo y ya no veo y } \\
\text { aquí desafortunadamente en esta cárcel no tengo compasión de nadie, } \\
\text { aquí se monta uno por encima del otro a la hora de la comida, eso no } \\
\text { les interesa nada a ellos, entonces qué pasa aquí, no hay protección". }\end{array}$ \\
\hline Hacinamiento & $\begin{array}{l}\text { "Los dormitorios, estamos en un hacinamiento casi del 50\%, según } \\
\text { nosotros tenemos entendido que somos 52 y la capacidad de cada patio, } \\
\text { pero nosotros también entendemos que hay un hacinamiento, que hay } \\
\text { una superpoblación carcelaria que los del Inpec no tienen la culpa". }\end{array}$ \\
\hline Alimentación & $\begin{array}{l}\text { "La cuestión de la alimentación es precaria, yo soy hipertenso; no tengo } \\
\text { lo uno, los medicamentos, no nos los dan, eso era catapril y labrotadina, } \\
\text { elimento bajo de grasa, cero sodio y dieta blanca... y yo no sé qué, bajo } \\
\text { no estamos comiendo regularmente a una sola hora... entonces, eso } \\
\text { parece que altera mucho la cuestión digestiva y hasta la salud anímica } \\
\text { de nosotros". }\end{array}$ \\
\hline
\end{tabular}

Fuente: grupos focales en los EPC visitados. 
Los internos exponen que la experiencia de la adultez mayor en la cárcel se convierte en una carga que deben sobrellevar, experimentando la incomodidad, las amenazas de otros internos, la sensación de no contar con protección ni privilegios, como un lugar específico o dietas especialmente diseñadas. Observan la necesidad de ser ubicados como un grupo etario especial, en un espacio en el que los factores ambientales no sean los que determinen actividades tan básicas como la recepción del alimento o el descanso. "Que nos aíslen por allí en el ERON, pero que sea bien" (grupo focal, EPMSC ERE Cúcuta, julio de 2013).

\section{Trato diferencial}

El sometimiento a condiciones extremas, como las que exteriorizaron los internos AMPL en el apartado anterior, determina que las ideas de ser tratados de manera diferente están fijadas por las condiciones del contexto inmediato, más que por su condición de grupo etario que amerita una serie de acciones específicas enmarcadas, entre otras, en la Ley 1251 de 2008. "Debe de haber un privilegio para uno al llegar a cierta edad porque ya uno se exime de tantas cosas, entonces la mayoría no tiene ese sentimiento propio de pensar que uno tenga un privilegio" (EC de Bogotá, julio de 2013). En este sentido, no manifestaron la necesidad de ser tratados como un grupo con necesidades especiales como un derecho constituido, sino como un privilegio que se han ganado con la edad.

\section{Buen trato}

La petición de amabilidad como parte del respeto o la cortesía fue agrupada en la subdimensión de buen trato: "Yo sí pienso distinto a la señora, por ejemplo, si a mí usted o una de las niñas me dice como con rabia yo lo voy a tomar a mal, pero si me dice viejita linda mi cariño, yo se lo voy a aceptar" (grupo focal, Coped Mujeres Medellín, julio de 2013). Esto facilita las relaciones amables con los demás y, por norma social o etiqueta, son mínimas 
en la interacción cotidiana. En los aportes realizados por los AM, reclaman constantemente estos elementos como parte de la diferencia con la que piensan deben ser atendidos.

\section{Atención médica}

Para los integrantes de los grupos focales, esta es una necesidad prioritaria y lo que permite enmarcarla como trato diferencial es que, en las condiciones actuales, pareciera que no existen enfermedades asociadas al envejecimiento, sino a condiciones del ambiente, lo que implica que ya no pueden ser abordadas desde lo preventivo. Con respecto de esto, un interno comenta: "En la tercera edad que es indispensable que tengamos ese apoyo médico prioritario... para poder salir urgentemente al médico, es que uno se esté muriendo o herido" (grupo focal, EC de Bogotá, julio de 2013).

\section{Exclusión}

Existen percepciones de los internos relacionadas con el rechazo de otros o con la sensación de no ocupar el lugar que en determinado momento de su vida ocuparon. Las verbalizaciones muestran elementos con los que ellos han configurado un componente de exclusión al sentir el trato de los internos más jóvenes. Este se da desde la utilización de términos peyorativos para dirigirse a ellos: "Por qué a nosotros los abuelitos nos miran como un agüero" (grupo focal, EPMSC ERE Bucaramanga, julio de 2013) hasta la utilización de los delitos como justificadores de los malos tratos: "Nos miran como una basura. Nos llaman violos".

En conclusión, los participantes tienen claridad acerca de la edad legal a partir de la cual se considera al AM, pero esta no se concibe como un obstáculo para el desarrollo de diferentes actividades, y tomarla de esa manera les ayuda a asumir efectivamente las situaciones que se les presentan en su cotidianidad. A esto se le puede sumar la asignación de términos positivos para describir al AM asociados a la edad y las experiencias de vida, lo cual proporciona la sensación de ir un paso más adelante que los adul- 
tos más jóvenes. En este mismo orden, se encontró que asignan un gran valor a la posibilidad de poder ejecutar labores como una forma de percibir y hacer ver que son funcionales. También se distinguen casos en los que experimentan deterioro en la salud dentro de lo esperado en el proceso de envejecimiento, y en ellos, parece existir un equilibrio entre la aceptación de las consecuencias del paso del tiempo, el momento actual y los roles que les corresponden, que les ayuda a enfrentar con actitud positiva este momento. En consecuencia, identifican la dependencia como un determinante de la vejez, que ejemplifican realizando paralelos entre el cuidado que necesita un AM y el que necesita un niño.

Por último, se encuentra que anteponen la edad cuando manifiestan la necesidad de ser tratados como un grupo con necesidades especiales, dentro de las que se encuentran el buen trato, la atención médica y la posibilidad de contar con espacios exclusivos adaptados a sus condiciones y características. Todo esto, sumado a estilos de vida precedentes al encarcelamiento que son desfavorables para el desarrollo del envejecimiento, son los principales factores que representan riesgo y que deben ser intervenidos con el fin de mejorar las condiciones en las que se encuentran los AMPL.

\section{Aspectos económicos de los adultos mayores}

La población de AM en el mundo entero tiende a aumentar. Resulta importante contextualizar este desarrollo debido a que las proyecciones muestran que existe un acelerado envejecimiento demográfico de la población con edad igual o mayor a los 60 años, frente a la población total. En América Latina, el fenómeno genera mayor preocupación si se tiene en cuenta que cerca del $30 \%$ de esa población se encuentra por debajo de la línea de pobreza; incluso se considera que una proporción de ese porcentaje - cerca del $40 \%$ - se encuentra en estado de indigencia (Celade, 2010). Al respecto, es importante mencionar lo planteado por Gainzo Vicente en relación con la "emergencia" del envejecimiento: 
A pesar de ser el envejecimiento individual un proceso que ha estado presente en toda la historia de la humanidad, no es hasta el Siglo XX, que comienza a convertirse en un fenómeno social, tanto para los países con alto desarrollo económico, como para los países en desarrollo. Según datos de Naciones Unidas, en 1950 existían en el mundo 200 millones de personas mayores de 60 años, en 1975 aumentó a 350 millones, pronosticándose para el año 2020, la cifra de más de mil millones. (2009)

En este sentido, resulta contradictorio que una de las características para definir al AM sea su salida de la actividad laboral o productiva, cuando la carencia de ingresos en esa etapa de la vida es una situación que afecta a más de la mitad de estas personas en Colombia, ${ }^{4}$ y la posibilidad de que estén incluidas en el mercado laboral es muy baja, lo que trae como consecuencia la poca cobertura de la seguridad social. Al respecto, algunos AMPL mencionan que efectivamente encontraron algunas barreras para el acceso al trabajo cuando se encontraban en libertad, pero, además, mencionan un aspecto muy interesante y es el de la capacidad para seguir trabajando pese a su edad: "Yo lo que quiero es seguir trabajando hasta que sea capaz, hasta ya lo último" (grupo focal, EPMSC Bucaramanga, julio de 2013). Este deseo de continuar laborando no resulta contradictorio frente a la realidad de América Latina, donde la participación económica de las personas mayores es más elevada, sobre todo en los países más pobres, aunque sea precaria e informal en la mayoría de los casos (Cepal, 2009) (figura 7).

Esta situación que enfrentan los AM que se encuentran fuera de los EPC en sí ya es grave, pero cuando se suma el hecho de estar privados de la libertad, la situación se vuelve aún más crítica porque las instituciones creadas para la protección de esta población no se han adaptado, ni lo vienen haciendo, para dar respuesta a la tendencia de envejecimiento demográfico, y más aún cuando la esperanza de vida se encuentra en aumento.

4 De acuerdo con los datos de la Cepal, en Colombia luego de los 50 años, progresivamente se perciben $40 \%$ menos ingresos, la principal fuente de ellos son los aportes familiares y, en un menor porcentaje, la anhelada pensión o jubilación. 
Figura 7. América Latina (países seleccionados): población de 60 años y más, según fuente de ingreso, zonas urbanas

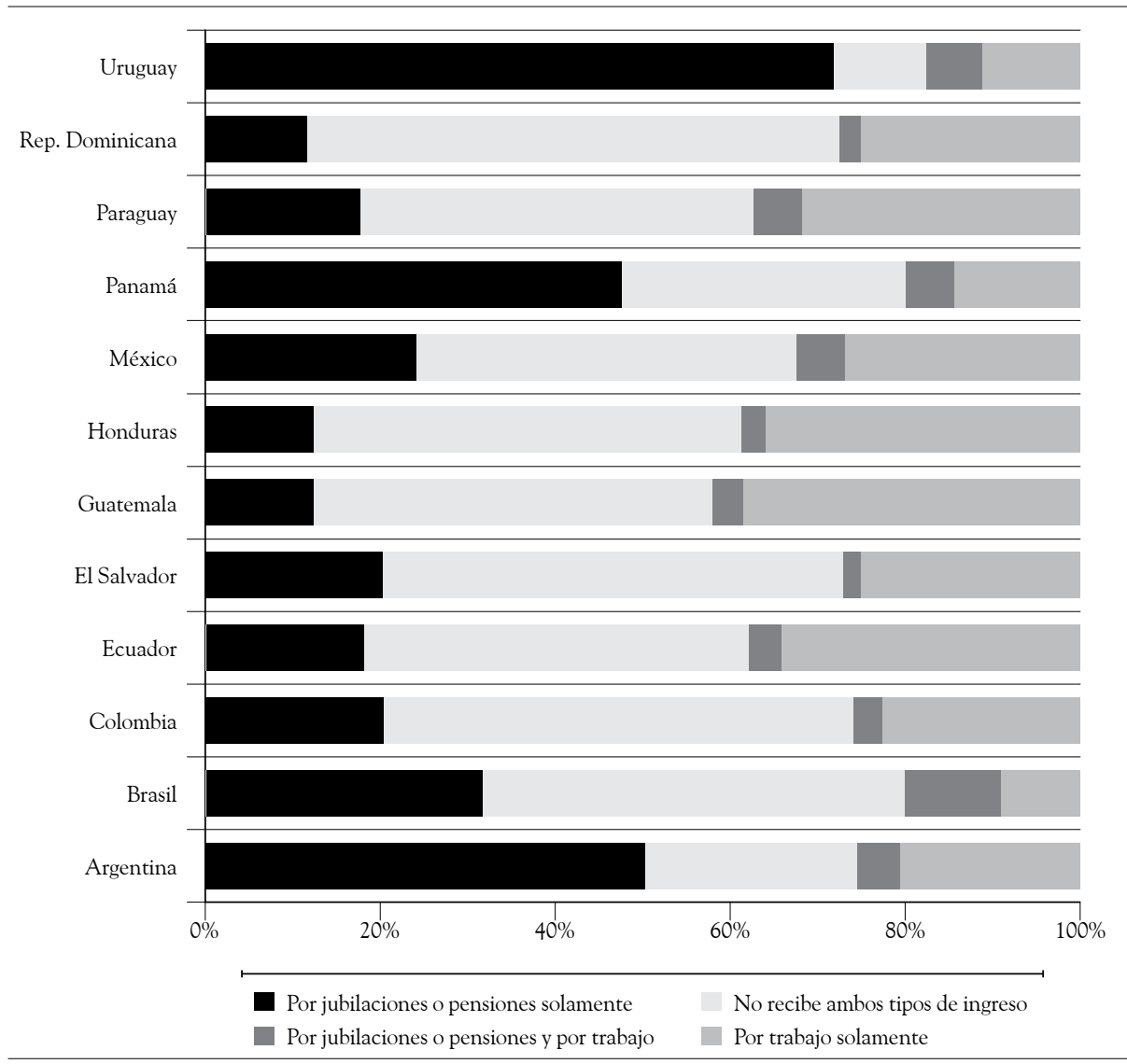

Fuente: Cepal, sobre la base de tabulaciones especiales de las encuestas de hogares de los respectivos países (Celade, 2010).

\section{Aspectos sociológicos del adulto mayor}

La construcción de las representaciones sobre la vejez varía de acuerdo con los contextos y los grupos humanos; así, se suele adjudicar cierto rol de importancia a los ancianos pertenecientes a "sociedades simples" y cierto rol de inutilidad a los ancianos en las sociedades industriales y postindustriales. Sin embargo, gracias a múltiples estudios, se ha determinado que, en todos los tiempos han habido posiciones y prácticas frente a los AM, que 
van desde la eliminación física hasta la gerontocracia (Alba, 1992). De esta manera, culturalmente se ha significado a este colectivo que, sin embargo, puede presentar como único rasgo común la edad.

Es habitual, entonces, encontrar en las sociedades primitivas la figura del patriarca, representado por el viejo de la familia, quien, en razón de su experiencia y sabiduría, era venerado y respetado. También se solía adjudicar a los más viejos ciertos poderes asociados con la magia y lo sobrenatural. En otros casos, por el contrario, como en algunas tribus nómadas, era común el exterminio de los ancianos, por considerarlos una carga difícil de llevar. Esta práctica puede asociarse también con la ocurrencia de infanticidios y la eliminación de personas con discapacidad. En Grecia y Roma la vejez se asocia a la prudencia y la sabiduría, de allí la institución del Senado. Durante la Edad Media, se impone más bien, permeada por los principios del cristianismo, la práctica de la caridad y la benevolencia hacia los ancianos desvalidos (Alba, 1992). De esta manera, no hay una concepción única sobre la vejez, ni temporal ni espacial; cada contexto desarrolló y continúa desarrollando formas de entender y abordar esta etapa de la vida.

Desde el punto de vista sociológico, para este estudio se aborda la ancianidad en términos de roles, de las representaciones sociales que se construyen a su alrededor y de la dicotomía normal-anormal. En ese sentido, se realiza un análisis de lo que socialmente se espera de un anciano, de la forma como debe comportarse y de los significados que se le atribuyen, en otras palabras, del cumplimiento de la expectativa social. Todo ello, partiendo de la hipótesis de que el AMPL es considerado dos veces "anormal": en razón de su edad, por salir del ámbito de la productividad y estar asociado a la enfermedad y la discapacidad, y en relación con la ley, por la comisión del delito.

En el primer caso, el anciano deja de producir recursos económicos porque se jubila, porque sus condiciones físicas decrecen o porque no cumple con los requisitos establecidos para el cumplimiento de ciertos trabajos; por tal motivo, es marginado y estigmatizado como un ser no productivo, "inútil" y, por tanto, prescindible. 
Este tipo de segregación cultural está en relación con la obsesión productivista propia de la "modernización" capitalista: si, como sucede en la cultura del capitalismo, a los viejos se les considera más como "jubilados" que como personas, entonces no es raro que la sociedad "adulta" segregue hacia ellos una actitud estigmatizadora y dirigista. Retiro e inutilidad quedan emparentados al ser definidos socialmente, y así, que el primero signifique también carencia en una mayoría de ocasiones resulta algo enteramente lógico. (Rodríguez-Ibañez, 1979, p. 78)

Tal vez lo más preocupante de esta segregación es la pérdida del rol o los roles que el individuo tenía anteriormente, al ser considerado como un ser improductivo y engorroso; el AM debe resignarse a una especie de muerte social, que le impide seguir desarrollándose y poner sus conocimientos y habilidades al servicio de la sociedad. Al respecto, Gainzo Vicente afirma:

Socialmente se ha considerado el rol del jubilado como un rol sin rol, por no haberle reconocido la sociedad contemporánea un papel social como lo hacían muchas sociedades primitivas o la medieval, donde el final de la actividad guerrera o artesanal no suponía la pérdida del status social. Dichas sociedades eran más eficaces en la utilización de los recursos humanos que las contemporáneas, ya que los mayores cuando dejaban una actividad encontraban otra sustitutiva, relevante para ellos y útil para la comunidad. (2009)

Sin embargo, la situación del AM varía considerablemente de acuerdo con el contexto socioeconómico en el que se desenvuelve. De esta manera, lejos de pensar en su jubilación, muchos AM deben seguir pensando en conseguir su sustento y el de su familia. Al respecto, es importante mencionar los testimonios de algunos AMPL que participaron en los grupos focales y que afirmaron vivir muy preocupados al pensar que sus familias ya no contaban con el soporte económico que ellos representaban. Al respecto, uno de ellos menciona: "Un aspecto importante con relación al AM es la falta que hay para dar una asistencia, o sea, de pronto a la familia, por ejemplo la esposa, en caso de nietos pequeños que dependen de ese AM que está detenido, 
entonces eso no lo hace una entidad, ver como este señor está aquí, pero ver también cómo está su familia afuera" (grupo focal, establecimiento EC Bogotá, La Modelo, mayo de 2013).

En este sentido, es común encontrar que en distintas sociedades, "los ancianos y las ancianas que no acceden a los beneficios de pensiones y/o jubilaciones continúan realizando actividades que desempeñaron desde jóvenes, a pesar de limitaciones físicas o del deterioro de su salud al ser muchos de ellos portadores de conocidas enfermedades endémicas" (Martínez et al., 2008, p. 79), lo que es profundamente contrastable con un hallazgo de campo, relacionado con las expectativas de vida de los internos AM, tanto hombres como mujeres, quienes -la gran mayoría- afirman que quieren salir de prisión para continuar trabajando como lo hacían antes.

Por su parte, el imaginario de enfermedad que se asocia a la adultez mayor es muy fuerte y, asimismo, la apariencia y la condición física del anciano no corresponden al estereotipo impuesto socialmente. En las sociedades actuales, nadie quiere envejecer, todo el mercado apunta a la prolongación de la juventud, lo cual se evidencia en la sobreoferta de productos como cremas antiarrugas, cirugías estéticas, gimnasios, tratamientos adelgazantes, etc. De esta manera, en razón de su edad, el anciano incumple las normas asociadas a la productividad y la estética; es, por tanto, un individuo anormal. Por otro lado, la relación entre adultez mayor y discapacidad es muy estrecha; de acuerdo con las cifras de la OMS, cerca del 15\% de la población mundial tiene algún tipo de discapacidad:

En los años futuros, la discapacidad será un motivo de preocupación aun mayor, pues su prevalencia está aumentando. Ello se debe a que la población está envejeciendo y el riesgo de discapacidad es superior entre los adultos mayores, y también el aumento mundial de enfermedades crónicas como la diabetes, las enfermedades cardiovasculares, el cáncer y los trastornos de la salud mental. (OMS, 2014)

Este vínculo entre vejez y discapacidad se asocia, a nuestro modo de ver, con el paradigma de la prescindencia desarrollado en torno a esta última, que afirma que la persona con discapacidad es innecesaria, toda 
vez que no representa mayor contribución a la sociedad. Igualmente, este paradigma abarca el modelo eugenésico, que ensalza la perfección corporal y el modelo de la marginación, lo que indica que la persona con discapacidad es objeto de exclusión, caridad y beneficencia (Velásquez, 2009, p. 8).

De esta manera, se consolida el AM como un individuo "anormal", definido desde su incapacidad productiva y desde la "imperfección" corporal. En el segundo caso planteado, es evidente que el AMPL no solo falta a la norma, sino que directamente quebranta la ley; en ese sentido e independientemente de los móviles que lo impulsan, también es un sujeto "anormal".

La violación de la ley, esta acción concreta, es de tal importancia que pone en movimiento toda la maquinaria del Estado y decide en detalle casi todo lo que ocurrirá subsecuentemente. El factor decisivo es el crimen o el delito (el pecado), no los deseos de la víctima, no las características individuales del culpable, no las circunstancias particulares de la sociedad local. (Christie, 1984, p. 60)

Así, el AMPL se consolida como un sujeto doblemente "anormal" frente a los ojos de la sociedad. Frente a la anormalidad surge una tendencia a la normalización, que ha sido denominada por Foucault como proyecto normativo (2000), y que está destinada a corregir lo imperfecto y a poner en cauce lo que se ha descarriado, en el marco de los parámetros estipulados por los discursos hegemónicos, producto de una ciencia única, reconocida y validada.

La forma en que se vincula en este estudio el concepto de AM con la anormalidad se relaciona con un discurso de corte social y económico, que se refiere principalmente a pautas físico-corporales y a la capacidad de producción. El estereotipo físico impuesto deja por fuera a las personas viejas, quienes, a causa del deterioro propio de los años, incumplen la norma y se vuelven indeseables. Por su parte, las relaciones propias del sistema económico y político en el que nos desenvolvemos, mediadas esencialmente por la producción, marginan al AM, quien ya no puede producir o no produce 
a la velocidad y con la calidad exigida, lo que lo convierte, de igual manera, en un individuo indeseable.

En este sentido, el caso del AM se ajusta también, a nuestro modo de ver, a un proyecto normativo que, en ocasiones, incluso se soluciona con el encierro (ancianatos, asilos o instituciones geriátricas). Para Arle Hochschild, este aislamiento responde a factores políticos, económicos y sociales: "El aislamiento de los ancianos se debe fundamentalmente a tres factores: su 'declive en el rendimiento laboral', la consolidación de un 'sistema de estratificación basado en la edad' y 'el relativo debilitamiento de los vínculos de parentesco' a nivel general" (citado en Rodríguez-Ibañez, 1979 , p. 81). Al indagar por el concepto de AM en los grupos focales, se encontraron las siguientes asociaciones, que en general guardan coherencia con los elementos planteados en este capítulo (tabla 8):

Tabla 8. Características asociadas al concepto de adulto mayor

\begin{tabular}{|l|l|}
\hline \multicolumn{1}{|c|}{ Concepto } & \multicolumn{1}{c|}{ Características } \\
\hline & Edad. \\
\cline { 2 - 3 } & Capacidad. \\
\cline { 2 - 3 } Adulto mayor & Vulnerabilidad. \\
\cline { 2 - 3 } & Disminución de las capacidades físicas. \\
\cline { 2 - 3 } & Ealabras otorgadas al concepto. \\
\cline { 2 - 3 } & Limitación de acceso al trabajo. \\
\cline { 2 - 3 } & Aspectos positivos. \\
\cline { 2 - 3 } & Enfoque diferencial. \\
\cline { 2 - 3 } & Actitud personal. \\
\cline { 2 - 3 } & Actitud social \\
\hline
\end{tabular}

Fuente: elaboración propia. 


\section{Edad}

La edad es la asociación inmediata que se hace al concepto de AM, casi sin excepción. AM es para los participantes una persona que ha pasado cierta edad o que tiene más de 60 o 65 años.

\section{Capacidad}

Igualmente, se hace referencia al concepto de capacidad para denotar que pese a su edad, el AM tiene plena capacidad para realizar cualquier tipo de trabajo o labor que se le encomiende: "A mí si me ponen a hacer un trabajo, yo lo hago" (grupo focal, EPMSC Acacias, mayo de 2013). Este aspecto contrasta con el imaginario de improductividad que se adjudica al AM, pues muchos de ellos manifiestan poder continuar con las labores que venían desarrollando o iniciar unas nuevas.

\section{Vulnerabilidad}

Un gran número de participantes reconocen que la edad avanzada y las condiciones que la acompañan generan vulnerabilidad; es decir, la necesidad de cuidados especiales, dependencia y desprotección. Específicamente, en el ámbito carcelario, es importante resaltar que muchos participantes afirman no ser peligrosos, precisamente por su vulnerabilidad y reclaman, por tanto, un castigo diferente a la prisión, donde se les facilite la prestación de cuidados especiales que requieren por su edad.

Al respecto, a partir de los hallazgos en campo y de otras evidencias previamente documentadas, se puede afirmar que los roles adjudicados a los ancianos pueden estar asociados al cuidado, pero en doble vía; es decir, no solo los ancianos demandan cuidados, muchas veces son ellos mismos quienes se ocupan del cuidado de otros miembros de la comunidad. 
Cuando estos (los viejos) no pueden autoabastecerse completamente, requieren el apoyo de los "nuevos" para su subsistencia. En este sentido, la solidaridad y la reciprocidad hacia los ancianos constituyen una pauta generalizada, lo que se vincularía tal vez con el protagonismo que adquieren en determinadas instancias de la crianza, socialización y cuidado de la salud de los miembros de la comunidad, no solo de los niños. (Martínez, Morgante, \& Remorini, 2008, pp. 76-77)

\section{Disminución de las capacidades físicas}

Muchos participantes reconocen una disminución de las capacidades físicas y afirman que la vejez está acompañada de achaques, limitaciones, enfermedades del cuerpo y de la mente, decaimiento y problemas de memoria, lo que implica una mayor y oportuna atención médica.

\section{Palabras otorgadas al concepto}

Los internos reconocen algunas nominaciones o palabras otorgadas al concepto de AM, como cucho o abuelo. En el ámbito carcelario, también se desarrollan apelativos como los violos, el escuadrón de la muerte o los que tienen la lápida pegada en la cola: "Nos llaman el escuadrón de la muerte... menospreciando todo el tiempo" (grupo focal, EPMSC Bucaramanga, julio de 2013). Estas palabras o apelativos se enmarcan en el ámbito de la estigmatización y se vinculan con características como chocho, caprichoso, inútil, incapaz, discapacitado e inválido: "Prácticamente uno es un inválido más que un discapacitado" (grupo focal, EC de Bogotá, La Modelo, mayo de 2013).

Realizando un comparativo, se encuentra que estas connotaciones son bastante generalizables y corresponden a sociedades industriales o postindustriales, mediadas por relaciones de tipo capitalista, en las que el viejo es considerado un demandante de servicios y, por tanto, una carga para la sociedad. 
Asociada a una idea de decadencia, de ocaso, la vejez, lejos de desearse o ponderarse, se previene. De este modo, no se procura desarrollar capacidades propias de una etapa de la vida sino desalentarla, en cuanto es negativamente considerada (soledad, incapacidad, vulnerabilidad, pérdidas, etc.). Este modelo occidental de viejo y de vejez -acompañado de una segregación etaria basada en el rechazo de alcanzar tal condición- contribuye a aumentar una imagen de los viejos demandante, como carga económica. (Martínez et al., 2008, p. 85)

\section{Limitación de acceso al trabajo}

Los estigmas traen consigo consecuencias evidentes que se materializan de diversas formas, una de ellas es la limitación de acceso al trabajo. De acuerdo con lo observado en campo, el trabajo es uno de los aspectos de la vida más importante para los AMPL, de allí que una de las preocupaciones propias de su edad radica en que son conscientes de que las oportunidades laborales disminuyen con los años y, en su caso, con el atenuante de haber estado en prisión: "Ya nos prohíben trabajar, no tenemos derecho al trabajo, que ya no nos pueden ocupar en ninguna clase de trabajo, aquí hay un código que yo lo tengo, donde dice que personas de la tercera edad, que pasen de los 60 años, no se pueden ocupar en ninguna clase de oficio pesado" (grupo focal, EPMSC Acacias, mayo de 2013).

\section{Aspectos positivos}

Sin embargo, no todas las características asociadas al concepto son negativas, algunos participantes reconocen las ventajas y los aspectos positivos de ser AM, y relacionan esta edad con el respeto, la madurez, la ejemplaridad, la experiencia, la responsabilidad y la sabiduría: "Son los que saben qué es lo que están haciendo y qué es lo que deben hacer... que tienen responsabilidad consigo mismos y con sus familias" (grupo focal de mujeres, Complejo Carcelario y Penitenciario de Jamundí, julio de 2013). Es muy interesante 
encontrar en la caracterización planteada por los participantes el aspecto de ejemplaridad, que por supuesto sería inmediatamente cuestionado por un tercero, al tratarse de los AMPL, quienes han infringido la ley o, al menos, son sospechosos de haberlo hecho. Efectivamente, en algunas sociedades, los viejos son los conocedores de la norma y, por tanto, los responsables de transmitirla a las nuevas generaciones:

Los viejos son portadores de la norma justificada que rige el orden social [...] Esta supremacía en el saber confiere a los ancianos un papel fundamental en el plano educativo, dado que transmiten a los más jóvenes la historia del grupo y las reglas sociales de que son depositarios (Martínez et al., 2008, p. 82)

\section{Enfoque diferencial}

Por otro lado, aparece el aspecto de enfoque diferencial, que es fundamental porque no hace referencia únicamente al concepto de AM, sino también a la privación de la libertad; los internos reconocen que por el hecho de tener cierta edad y estar en prisión requieren de un tratamiento especial que se adapte a sus condiciones particulares. De esta manera, se menciona constantemente la necesidad de que estos tengan un patio especial para estar aislados de las revueltas, el vicio, los abusos y el peligro; también se habla de las diferencias entre los jóvenes y los viejos, lo que dificulta la convivencia, y de la necesidad de una atención prioritaria en salud.

\section{Actitud personal y social}

Para algunos participantes, como se anotaba en los aspectos psicológicos de la vejez, esta es una cuestión mental o de actitud, independientemente de la edad que se posea, de allí que se vinculen al concepto los aspectos de actitud personal y actitud social. Respecto a esta última, los participantes afirman haber sido discriminados en razón de su edad; por este motivo, la 
vejez significa soledad, aislamiento, desprecio y rechazo. La discriminación se vive tanto fuera como dentro de la cárcel: "De pronto vienen unos artistas que cantan, pero a nosotros los viejitos no nos sacan, somos un estorbo, dicen pa' qué si esos se quedan dormidos, entonces solo sacan a los jovencitos" (grupo focal, Complejo Carcelario y Penitenciario de Jamundí, julio de 2013).

De esta manera, las definiciones y las características otorgadas al concepto de AM, en el marco de los grupos focales, se pueden ubicar, de una u otra manera, en la tipología de estrategias de acomodación a la ancianidad (Ibañez, 1979, p. 90), planteada por Suzanne Reichard, Florine Linson y Paul G. Petersen, y que establece cinco posibilidades:

- Constructividad: caracterizada por la actividad y la lucha contra el deterioro físico e intelectual.

- Dependencia: caracterizada por la pasividad y el aislamiento.

- Defensividad: caracterizada por el rechazo a la propia edad.

- Hostilidad: caracterizada por el miedo y la exaltación de la juventud.

- Odio hacia uno mismo: caracterizada por el pesimismo, la depresión y la aceptación de la muerte como alivio.

Como se puede apreciar, algunas de estas atribuciones al concepto de AM hacen referencia a la autopercepción que se tiene de la condición y otras se refieren a la percepción que tienen los otros. Surgen, así, conceptos bastante objetivos como la edad o la disminución de capacidades físicas, que se contrastan con las actitudes personales o sociales, las imputaciones prevalentemente negativas de la vejez y el reconocimiento de una condición especial. 


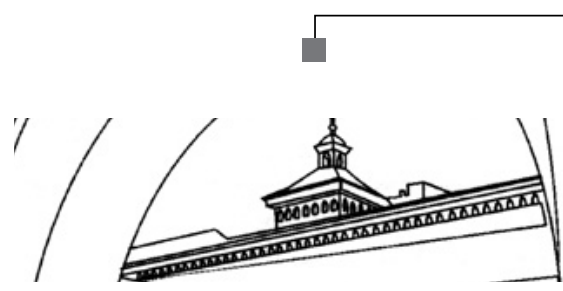




\section{Caracterización de los adultos mayores privados de la libertad}


Este capítulo se centra en describir los atributos particulares de la población AMPL. La caracterización realizada parte de una descripción cualitativa que se soporta con datos cuantitativos oficiales y recolectados en las diferentes visitas por medio de instrumentos utilizados por el equipo investigador, lo que permite profundizar de manera estructurada en las características de los AMPL. Dentro de una fase descriptiva, se identificó y contrastó la información conceptual que se tenía con lo evidenciado en las visitas a los diferentes EPC, a partir de lo cual se establecieron las características de los internos frente a sus derechos, y a sus condiciones de vida, psicológicas, sociales, económicas y jurídicas.

\section{Derechos humanos y fundamentales de los adultos mayores privados de la libertad}

A través del formato de priorización de derechos fundamentales, se recogió la percepción de los AMPL en cuanto a los derechos humanos; al respecto, se solicitó a los participantes que priorizaran de 1 a 7 , según su propia percepción de valoración, algunos de los derechos fundamentales que se encuentran consagrados en la Constitución Política de Colombia, que consideraban eran los más importantes, que se deberían respetar durante la reclusión y que habían sido vulnerados. En las figuras 8 y 9 se dan a conocer los derechos fundamentales ${ }^{1}$ que debían ser priorizados.

La información obtenida indica que se perciben como más vulnerados los siguientes derechos: salud (36\%), protección y asistencia (16\%), educación (15\%), familia (13\%), defensa (8\%), libertad de culto (7\%) y vida $(5 \%)$.

Cada participante tenía que colocar un número (del 1 al 7) con el fin de valorar el derecho que consideraba más importante; luego, con un círculo debía resaltar el derecho que, según su percepción, no se le había respetado durante su reclusión. En el cuadrado vacío el AMPL podía escribir algún derecho que consideraba fundamental y que no había sido incluido. 
Figura 8. Formato de priorización de derechos fundamentales

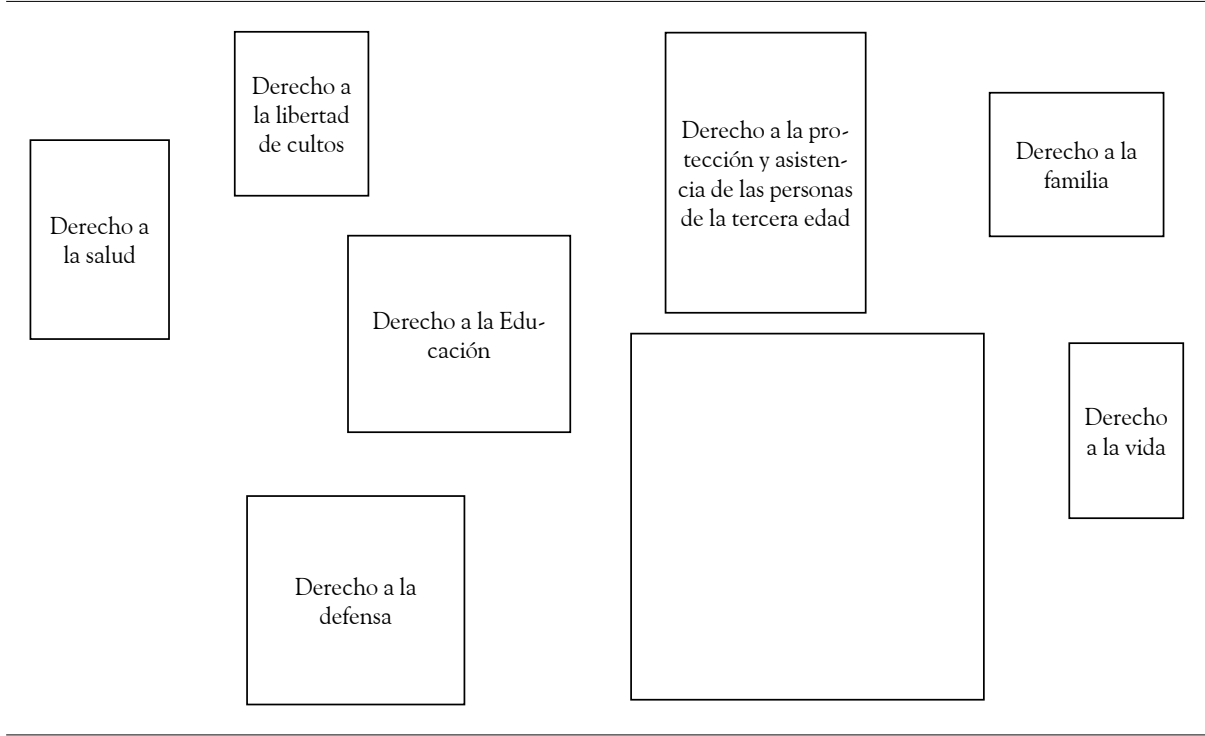

Fuente: elaboración propia.

Figura 9. Derechos humanos vulnerados

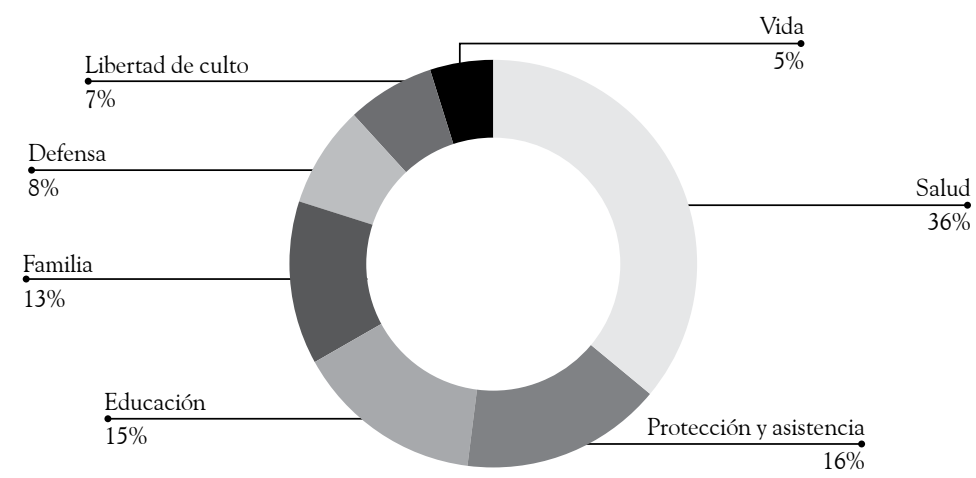

Fuente: grupos focales en los EPC visitados. Cálculo de los autores.

Los resultados encontrados son congruentes con lo que habitualmente se expone en los medios de comunicación, acerca del abandono en cuanto a la atención en salud, y la protección y la asistencia para esta población. En tercera instancia, hacen referencia a la educación, con un $15 \%$, lo que indica la necesidad de mejorar aspectos en este ámbito, que es, a nuestro parecer, primordial para una resocialización. 
Por otra parte, un $13 \%$ de los AMPL encuestados perciben que su derecho a tener cercanía con su familia está siendo vulnerado, lo cual tiene sentido por las limitaciones que existen para las visitas u otro tipo de interacciones. En materia de salud, por presentar patologías propias de la edad o padecimientos crónicos, requieren de una atención diferenciada, que incluya especialistas en salud mental, condiciones de salubridad óptimas, barandas en sitios específicos, pasillos, escaleras y rampas que se adapten a sus particularidades.

Junto con los derechos humanos fundamentales que, según los AMPL, son vulnerados, existen otros derechos que no fueron considerados en el formato, pero que se mencionaron como fundamentales y se considera que deberían haber sido incluidos; al respecto, el 72 \% de la población agregó uno más a la lista, de la que resultaron otros derechos fundamentales vulnerados (figura 10).

Figura 10. Otros derechos fundamentales vulnerados

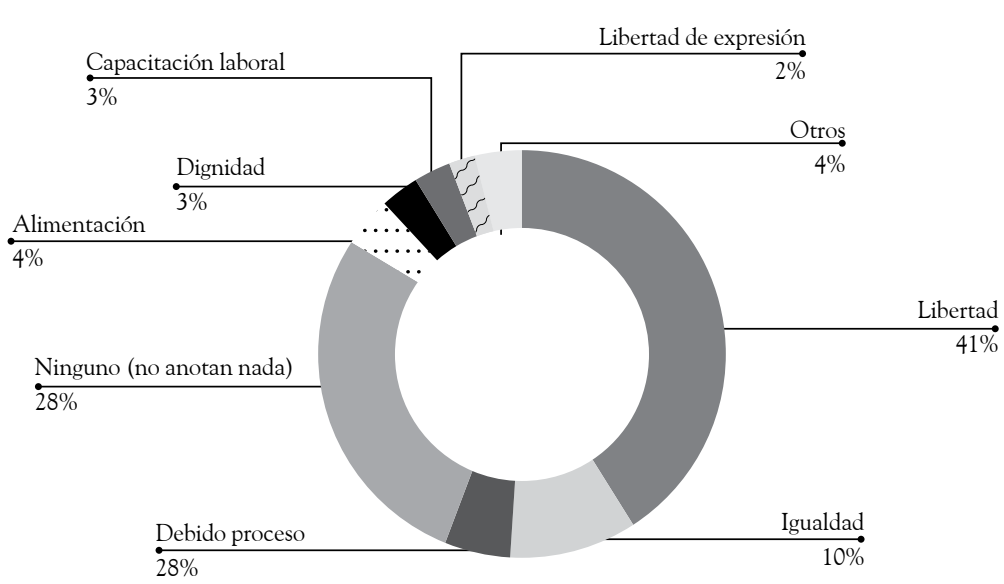

Fuente: grupos focales en los EPC visitados. Cálculo de los autores.

De estos derechos, el $41 \%$ corresponde a la libertad, lo cual sin duda responde a su situación; el 10\%, a la igualdad, y el 5\%, al debido proceso. Otros derechos nombrados por menos del $4 \%$ de los reclusos fueron: la alimentación, la dignidad, la capacitación laboral, la libertad de expresión y otros. Resulta interesante observar que el $28 \%$ de los reclusos no perciben 
ningún otro derecho fundamental que les haya sido vulnerado, lo que se podría interpretar como un desconocimiento de sus derechos.

Con estos resultados globales, se puede observar cómo los AMPL perciben varios de los derechos fundamentales vulnerados y, en relación con este aspecto, la sociedad y las ciencias jurídicas tendrían que realizar intervenciones efectivas que vayan en consononacia con las funciones resocializadoras que tienen los EPC. De igual forma, nos pueden sugerir alguna discrepancia entre la vulneración de los derechos que se perciben desde fuera de los EPC, contrastados con la realidad que enfrentan los hombres y las mujeres AMPL, sujetos de especial protección constitucional y que, en razón de sus relatos y respuestas, no se sienten incluidos dentro de esta categoría. Ahora bien, los resultados sobre los derechos que se consideran más vulnerados son concordantes con aquellos que los AMPL consideran más importantes (figura 11).

Figura 11. Derechos en orden de importancia

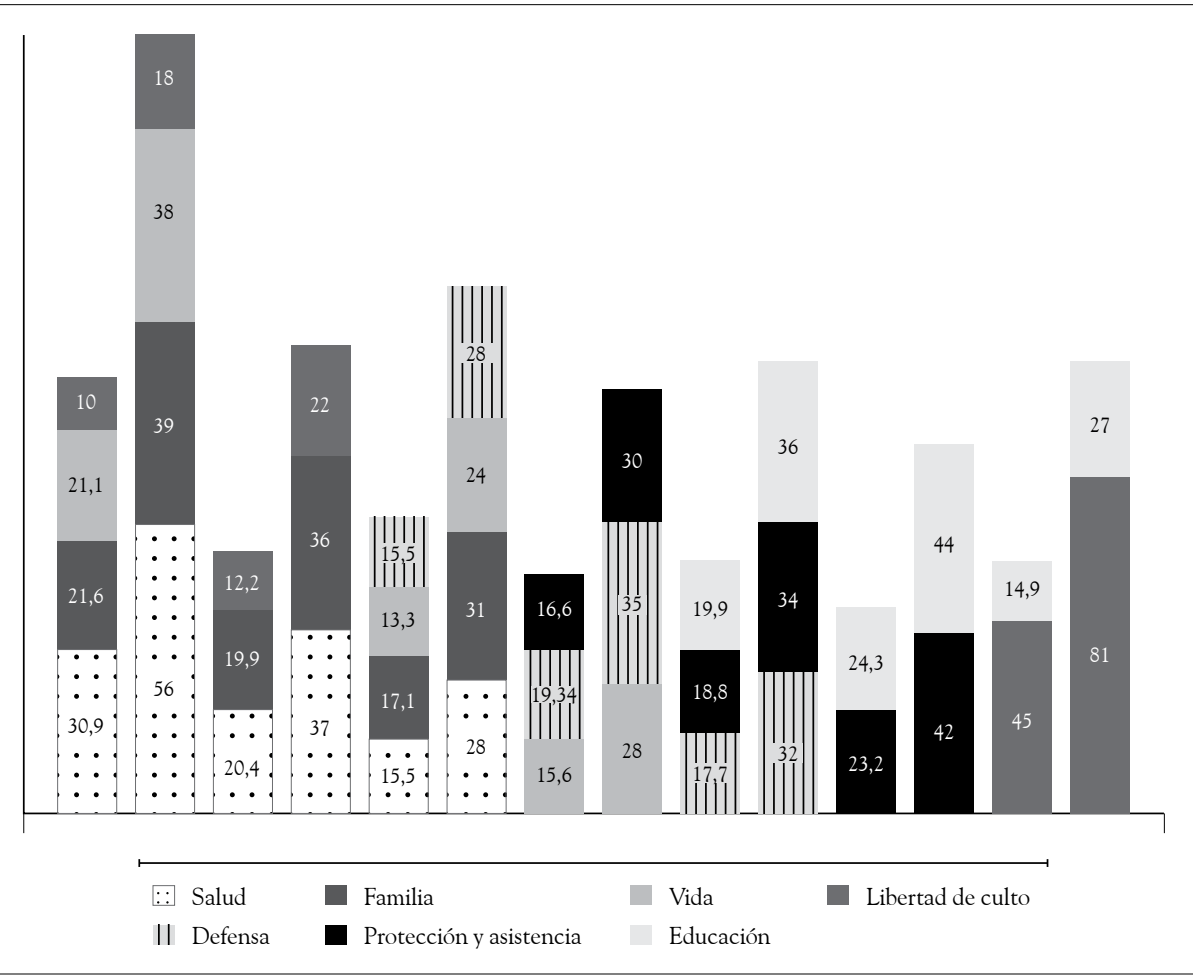

Fuente: grupos focales en los EPC visitados. Cálculo de los autores. 
El derecho que tiene una mayor importancia para los AMPL, con el $30,9 \%$, es el de la salud; seguido por el derecho a reunirse con la familia, con el 21,6 \%; el derecho a la vida, con el 21,1 \%, y el derecho a la libertad de culto, con el $10 \%$.

\section{El derecho a la atención en salud, el más vulnerado}

Durante los grupos focales salió a relucir, de forma repetitiva, la reclamación por la precaria o nula atención médica, categoría que se denominó como la prestación del servicio de salud, que, para el grupo de AMPL, se define como la dificultad para ser atendidos en sus dolencias relacionadas con la salud. Los problemas de salud son atribuidos, por los participantes, a factores como el hacinamiento, la mala alimentación y la falta de salubridad.

Al contrastar algunos estándares internacionales relacionados con este derecho con la percepción que tienen los AMPL, se encontró que una cosa es lo que se debería hacer, de acuerdo con las reglas mínimas para el tratamiento de los reclusos (Oficina del Alto Comisionado de las Naciones Unidas para los Derechos Humanos, 2002, pp. 172-187), y otra muy diferente es lo que mencionan los AMPL en los grupos focales (tabla 9).

Tabla 9. Estándares internacionales vs. opinión de los adultos mayores privados de la libertad

\begin{tabular}{|c|c|}
\hline Reglas mínimas para el tratamiento de los reclusos & Lo que manifiestan los AMPL \\
\hline $\begin{array}{l}\text { "El médico estará a cargo de velar por la salud } \\
\text { física y mental de los reclusos. Deberá visitar } \\
\text { diariamente a todos los reclusos enfermos, a } \\
\text { todos los que se quejen de estar enfermos y } \\
\text { a todos aquellos sobre los cuales se llame su } \\
\text { atención". }\end{array}$ & $\begin{array}{l}\text { "Aquí no hay ni servicio médico, aquí no } \\
\text { hay nada, va uno allí al puesto de salud, } \\
\text { a la enfermería y no hay una pasta que } \\
\text { le den a uno, le dan una fórmula y dura } \\
\text { por ahí tres cuatro meses que le den la } \\
\text { droga". }\end{array}$ \\
\hline $\begin{array}{l}\text { "El médico presentará un informe al director } \\
\text { cada vez que estime que la salud física o mental } \\
\text { de un recluso haya sido o pueda ser afectada } \\
\text { por la prolongación, o por una modalidad cual- } \\
\text { quiera de la reclusión". }\end{array}$ & $\begin{array}{l}\text { "Tengo } 74 \text { años cumplidos y yo sí me } \\
\text { siento mal, ya no oigo y ya no veo, aquí } \\
\text { me hicieron unos exámenes que para } \\
\text { darme gafas y firmamos la factura y esas } \\
\text { gafas nunca aparecieron”. }\end{array}$ \\
\hline
\end{tabular}




\begin{tabular}{|l|l|}
\hline Reglas mínimas para el tratamiento de los reclusos & Lo que manifiestan los AMPL \\
\hline "El médico hará inspecciones regulares y ase- & \\
sorará al director respecto a: & \\
a) la cantidad, calidad, preparación y distribu- & "Incluso aquí nos dan accesorios de aseo \\
ción de los alimentos; & cada 3 meses, y ahorita ya van 6 meses y \\
b) la higiene y el aseo de los establecimientos & nada, no nos dan es nada, ya hay mucha \\
y de los reclusos; & gente, mucho viejo". \\
c) las condiciones sanitarias; & \\
d) la calidad y el aseo de las ropas y de la cama & \\
de los reclusos". & \\
\hline
\end{tabular}

Fuente: grupos focales en los EPC visitados.

Es evidente que, a partir de los comentarios realizados, existe no solo una apreciación negativa en relación con la atención de la salud, sino también una incredulidad absoluta en cuanto al mismo sistema. Teniendo en cuenta las edades que en este grupo se representan, es claro que existe un riesgo mayor de adquirir problemas de salud. Asimismo, la omisión en la atención a la salud puede desencadenar casos que conduzcan a una discapacidad, lo que haría que no solo se reforzara el estatus de un sujeto como miembro de un grupo de especial protección constitucional, como lo es una persona AMPL, sino que además ahora se encontraría en condición de discapacidad, lo que aumentaría su vulnerabilidad.

Resulta interesante observar que el manejo de los aspectos de la salud, para los AMPL, se encuentra íntimamente relacionado con el trato digno que requiere la persona: "Refiriéndonos al aspecto carcelario, ya nosotros de avanzada edad, nos afecta la bulla, algunos alimentos, ciertas anomalías que no están en el círculo de nosotros, pero yo diría que si hablamos de la población a nivel nacional, claro, los niños deben tener un trato especial, su atención si hay un abandono de la niñez [...]" (grupo focal, Coiba Ibagué, junio de 2013). La dignidad es una categoría transversal a la atención en salud, así como a la no discriminación e igualdad; se puede afirmar, única y exclusivamente bajo el contexto de la presente investigación, que el trato no digno de la PPL está relacionado con una falencia en el enfoque diferencial. 


\section{Incredulidad ante el sistema judicial, la normatividad}

Teniendo en cuenta las vivencias en la privación de la libertad, llama la atención la reflexión que "internamente" se tiene con respecto a las normas y la justicia, siendo más relevante en la medida en que estas son herramientas de defensa. Los AMPL ven las normas, los derechos y el sistema en general como un ente administrativo que genera desconfianza y cuyos componentes fallan: "Hoy el sistema carcelario tiende a hacerse en ocasiones muy oportunista con relación a si la persona condenada tiene dinero, si está en disposición de colaborar con la justicia, de un poco de cosas que entre otras podrían llevar a una discriminación" (grupo focal, Coiba Ibagué, junio de 2013).

\section{Discriminación y no igualdad}

Junto con lo mencionado anteriormente, los AMPL consideran que no tienen las mismas oportunidades que otras personas que se encuentran en igual condición: "Que sea un trato más digno, más humano porque debe haber igualdad para todos, entonces, ¿qué sucede?, que nos quieren tratar lo mismo que a un muchacho, somos seres humanos y todos somos iguales, pero ya uno viejo merece el trato digno para la tercera edad" (grupo focal, Coiba Ibagué, junio de 2013). La no discriminación y el trato diferencial que deberían tener los AMPL se acentúan, categóricamente, en las condiciones de vida, que sin lugar a dudas exigen una respuesta necesaria, adecuada y proporcional a esta población, considerando aspectos de infraestructura, limitaciones físicas y condiciones psicológicas, que involucren personal especializado en el manejo de la edad geriátrica.

\section{Condiciones de vida}

Analizar condiciones de calidad o estándares de vida para una población es un asunto complejo, pero de gran importancia, pues se procura mejorar 
su forma de vivir, independientemente de la situación por la que esté pasando. Las diferentes perspectivas sobre las condiciones de vida responden al esfuerzo teórico de diversos autores, que explican el mejoramiento o empeoramiento de estas, basados en su entendimiento. Así, por ejemplo, la perspectiva de la libertad humana, vista como la última meta de la vida económica y como el medio más eficiente para lograr el bienestar (Sen, 1998), plantea que el mejoramiento en las condiciones de vida se debe entender como el conjunto de todas aquellas características materiales o no que facilitan tener determinado tipo de vida. Bajo esa perspectiva, las diferentes acciones que se emprenden deberían apuntar a mejorar tanto las características materiales como las que no lo son.

El mejorar las condiciones o el estándar de vida de las personas debe valorarse desde una perspectiva que involucra aspectos como el contexto o el ambiente donde se encuentran las personas, y aspectos sobre el modo de vida en sí mismo en ese entorno. Diversos estudios plantean formas de asumir las condiciones de vida, pero se pueden sintetizar desde dos perspectivas plurales: la competitiva y la constitutiva (Casas et al., 2001). La primera perspectiva privilegia el logro de condiciones personales sobre las demás, por lo tanto, cualquier medición de estándar de vida es entendida desde una visual utilitarista de bienestar como una elección de la persona según los satisfactores a sus deseos; por ello, el estándar lo establece el sujeto de acuerdo con sus satisfactores de bienestar en su vida. Esta perspectiva no resulta práctica para los AMPL porque el logro de los satisfactores se encuentra predeterminado por las oportunidades de decisión que tiene una persona en libertad, al poder elegir las condiciones o estándar de vida que desea tener.

Por otra parte, las condiciones de medición del estándar de vida, que es asumido para los AMPL, se toman desde la perspectiva constitutiva (Bliss, 1996; Seabright, 1996; Gamboa et al., 2000), que se caracteriza por establecer factores o variables que se han adaptado a las situaciones que están viviendo los AMPL, y que pueden simplificarse para un mejor entendimiento, en condiciones relacionadas con el capital físico y el capital humano.

Los profesionales y los directivos de la Subdirección de Tratamiento y Desarrollo-División de Desarrollo Social, hoy Subdirección de Reinserción Social-Grupo de Desarrollo Humano, con el fin de asumir una 
posición científica frente al contexto penitenciario, que tuviera en cuenta los factores criminológicos y penitenciarios, plantearon y desarrollaron la investigación Caracterización y perfilación criminológica y penitenciaria de la población condenada y privada de la libertad en los EPC del Inpec y propuesta para el direccionamiento del tratamiento penitenciario en Colombia, con el fin de conocer directamente la población condenada, caracterizarla, establecer los perfiles criminológicos y penitenciarios, y así proponer lineamientos en el diseño de programas de atención e intervención penitenciaria, teniendo en cuenta la perspectiva de género, los tipos de internos, así como también los tipos delictivos (Inpec \& Ministerio del Interior y de Justicia, 2011).

A partir de esta caracterización, se evidenció que la población AMPL debía tenerse en cuenta en el momento de formular un trato diferencial, acorde con las necesidades, el tratamiento y el proyecto de vida de estas personas, porque la pena no puede privar al ser humano de tener un crecimiento integral, a fin de desarrollarse dentro del mismo centro y estar preparado para salir.

Por ello, antes de establecer la características agrupadas en los tipos de capital mencionados, se plantea que la falta de condiciones adecuadas que fortalezcan a esta población hace que aumente, potencialmente, la probabilidad de discriminación; esto es más grave en las mujeres adultas mayores, pues la teoría económica y las políticas públicas prácticamente las omiten (Huenchuan, 2010) y, por esto, se plantea dentro de las condiciones de vida la discriminación en los AMPL como parte de estas políticas.

\section{Discriminación en la población de adultos mayores privados de la libertad}

La discriminación puede observarse desde diferentes definiciones que permiten entender argumentos que orientan de forma conceptual la manera como se puede evidenciar lo encontrado en la población de AM, y facilitan ver la efectividad de la política que se aplica en estas circunstancias.

Usualmente, cuando se habla de discriminación, esta se observa desde una perspectiva jurídica relacionada con la igualdad, entendida ante la 
ley como el "principio que reconoce a todos los ciudadanos la capacidad para los mismos derechos" (Real Academia Española, 2001), por lo que se podría pensar que todo lo que no cumpla esa igualdad, es un acto de discriminación, que requeriría un trato preferencial y una exigencia a la no discriminación, independientemente de la normatividad que lo acompañe. Sin embargo, el concepto de discriminación evidencia diversos sentidos e intenciones.

Desde el sentido léxico, el verbo discriminar no tiene una equivalencia negativa, debido a que se refiere a "separar, distinguir, diferenciar una cosa de otra" (Real Academia Española, 2001); por ello, discriminar no tendría valoración alguna de rechazo, sencillamente se discrimina cuando se distingue una cosa de otra, y esto es vital para la vida humana, tanto así que desde el preescolar, se enseña a discriminar por colores, tamaños, formas, etc., sin que se considere que una cosa es superior a otra, mucho menos se desprecia esa acción; al contrario, se valora que se pueda discriminar de forma correcta, como parte necesaria del proceso de aprendizaje. Es importante señalar este aspecto porque se utiliza la palabra discriminar como un elemento humillante, para argumentar acciones u omisiones sin ningún fundamento axiológico.

Sin embargo, también desde el léxico, el mismo diccionario da una definición con componentes sociales, al decir que discriminar es "dar trato de inferioridad a una persona o colectividad por motivos raciales, religiosos, políticos, etc." (Real Academia Española, 2001); esta es la definición más común en nuestra sociedad, en la que se le da un sentido valorativo a lo que es superior e inferior, y cuando una persona se encuentra en la segunda condición, es discriminada y estigmatizada por las características que no resultan interesantes para quien discrimina. Esa concepción y uso del término oculta el verdadero valor que se le da a una persona o población, y genera una conducta moral sobre ella con una valoración cultural.

Así, por ejemplo, una persona por su edad, AM, puede ser juzgada por una sociedad, que se basa en los prejuicios o estigmas que se tienen frente a ella, lo que implica que se da un valor humano menor a quien es juzgado, y se le niegan intencionalmente -aunque puede no ser explícitamente-derechos fundamentales, bien sea porque no se le permite directamente acceder 
a ellos o porque se generan mecanismos o acciones que indirectamente se lo impiden. Para subsanar esto, se busca "adoptar" medidas que protejan a estas personas; para ello, se formulan leyes y políticas públicas que impulsen la no discriminación (Rodríguez Zepeda, 2006) ${ }^{2}$ de esta población con condiciones excepcionales. ${ }^{3}$

Dentro de esas políticas de no discriminación, el Inpec cuenta con un Programa de Integración Social de Grupos con Condiciones Excepcionales donde se busca, entre otras cosas, "poner en conocimiento de las instancias competentes dentro del EPC, las solicitudes hechas por los(as) internos(as) Adultos(as) Mayores, en relación con posibles factores de riesgo de tipo físico, psicológico o social que afecten su adecuado desenvolvimiento en las actividades cotidianas, a fin de que se tomen las medidas correspondientes" (Inpec, 2012). Esas actividades cotidianas se encuentran asociadas a las capacidades físicas y mentales, las cuales se suelen relacionar, de manera común, con la disminución, debido al proceso de envejecimiento.

2 Dentro de las diferentes concepciones generales de lo que es "discriminación" y lo que es "no discriminación", Jesús Rodríguez Zepeda menciona que "la discriminación es una conducta, culturalmente fundada, y sistemática y socialmente extendida, de desprecio contra una persona o grupo de personas sobre la base de un prejuicio negativo o un estigma relacionado con una desventaja inmerecida, y que tiene por efecto (intencional o no) dañar sus derechos y libertades fundamentales" (2006) y que "la no discriminación es el derecho de toda persona a ser tratada de manera homogénea, sin exclusión, distinción o restricción arbitraria, de tal modo que se le haga posible el aprovechamiento de sus derechos y libertades fundamentales y el libre acceso a las oportunidades socialmente disponibles" (Rodríguez Zepeda, 2006). Asimismo, desde una lógica argumental del principio rawlsiano, se fundamenta la no discriminación como: "el derecho de toda persona a ser tratada de manera homogénea sin exclusión, distinción o restricción arbitraria, de tal modo que se le haga posible el aprovechamiento de sus derechos y libertades fundamentales y el libre acceso a las oportunidades socialmente disponibles; siempre y cuando un tratamiento preferencial temporal hacia ella o hacia su grupo de adscripción no sea necesario para reponer o compensar el daño histórico y la situación de debilidad y vulnerabilidad actuales causada por prácticas discriminatorias previas contra su grupo" (Rodríguez Zepeda, 2006).

3 La Constitución Política de Colombia de 1991, en su artículo 46, previendo lo que podría ocurrir con esta población, señala que: "El Estado, la sociedad y la familia concurrirán para la protección y la asistencia de las personas de la tercera edad y promoverán su integración a la vida activa y comunitaria. El Estado les garantizará los servicios de la seguridad social integral y el subsidio alimentario en caso de indigencia”. Basado en ese mismo artículo, se realiza una legislación que busca garantizar al adulto mayor el pleno ejercicio de sus derechos. Cfr. la Ley 1251 de 2008. Dentro de esa ley se menciona, en su artículo $4^{\circ}$ como principio rector la no discriminación, entendida como la "supresión de todo trato discriminatorio en razón de la raza, la edad, el sexo, la condición económica o la discapacidad (cursivas de los autores). 
Desde el escenario económico, las capacidades físicas y mentales se asocian a la capacidad productiva de un individuo. Al considerarse de manera generalizada que la persona que llega a ser $\mathrm{AM}^{4}$ se ve disminuida por el proceso de envejecimiento, esto hace que sufra de un trato diferenciado, lo que, a la luz de lo esbozado, se referiría a la discriminación, que es planteada, desde la economía, cuando una de dos personas con la misma capacidad productiva, pero que difieren por alguna característica personal (en este caso, la edad), recibe un trato inferior en cuanto a las posibilidades de acceder al empleo o la educación. Esa discriminación, usualmente, se da más por género, hay un desbalance entre hombres y mujeres, pero también por edad, por estrato o por niveles educativos; la sumatoria de todo lo anterior agudiza, aún más, la discriminación.

$\mathrm{Si}$ a ese escenario se le adiciona otro factor, el estar recluido en un EPC en diversas condiciones, la discriminación tiende a aumentar. Desde la economía se han desarrollado diversas teorías para tratar de explicar los tratos diferenciales, especialmente a nivel laboral, que no se justifican por la capacidad productiva, sino por características personales. Siendo este el caso, la discriminación se estudió, con el fin de evidenciarla, de diversas maneras en el trabajo de campo por el equipo investigador, y se llegó a una clasificación que, independientemente de la tipología, resulta importante mencionarla, debido a que la discriminación genera pérdidas tanto económicas como sociales, y reduce sustancialmente las posibilidades de desarrollo de las personas y, sobre todo, el mejoramiento del SPCC. Los tipos de discriminación observados y analizados fueron:

a) Discriminación por género: de acuerdo con este tipo de discriminación, las desigualdades no siempre se dan por diferentes niveles de productividad; aun cuando se tienen los mismos niveles, los hombres ganan mayores beneficios que las mujeres. A nivel teórico, esto se conoce como el modelo de poder de mercado (Robison,

4 La definición de adulto mayor es la tomada de la Ley 1276 de 2009, que en su artículo $7^{\circ}$, literal b), dice que: "Adulto Mayor. Es aquella persona que cuenta con sesenta (60) años de edad o más. A criterio de los especialistas de los centros vida, una persona podrá ser clasificada dentro de este rango, siendo menor de 60 años y mayor de 55 , cuando sus condiciones de desgaste físico, vital y psicológico así lo determinen" (cursivas de los autores). 
1965), donde se plantea que aunque los dos géneros pueden tener capacidades productivas, se supone que los hombres tienen mayor movilidad geográfica que las mujeres; en otras palabras, los hombres ven menos inconvenientes que las mujeres a desplazarse hacia otro sitio con mejores oportunidades. Asimismo, las mujeres tienen menor posibilidad de asociación en grupos de poder de negociación (ejemplo: sindicatos) que los hombres, lo que hace que sean controladas más fácilmente.

En cuanto a esta discriminación en los EPC visitados, esta no resulta evidente, no porque no exista como tal, sino porque la mayor parte de la población carcelaria es masculina; ${ }^{5}$ existen establecimientos especiales para mujeres, lo que evita una competencia por género relacionada directamente con ello (tabla 10).

Tabla 10. Población reclusa por género en Colombia

\begin{tabular}{|c|c|c|c|}
\hline \multirow{2}{*}{ Regional } & \multirow{2}{*}{ Población } & \multicolumn{2}{|c|}{ Género } \\
\hline & & Masculino & Femenino \\
\hline Central & 37.593 & 34.572 & 3.021 \\
\hline Occidental & 23.986 & 22.106 & 1.880 \\
\hline Norte & 13.338 & 12.899 & 439 \\
\hline Oriente & 12.470 & 11.530 & 840 \\
\hline Noreste & 15.918 & 14.536 & 1382 \\
\hline Viejo Caldas & 14.896 & 13.513 & 1383 \\
\hline Total & 118.201 & 109.158 & 9245 \\
\hline
\end{tabular}

Fuente: Sisipec Web, julio de 2013.

Lo anterior se apoya teóricamente (Blau et al., 1998) y se refuerza con la evidencia, que es casi inexistente, de la discriminación por género (masculino, femenino) en los EPC, al encontrar ocupaciones aplicables en sitios específicos, es decir, al existir división de establecimientos por género, las ocupaciones también se encuen-

5 De acuerdo con el Inpec, a julio de 2013, el 92,3\% de la población carcelaria estaba constituida por hombres, mientras que el 7,7\%, por mujeres (Inpec, 2013, p. 13). 
tran divididas, por lo que hay oportunidades para ambos géneros. Sin embargo, en el ámbito social, el hecho de que más del 92\% sean hombres -proporción similar con los AMPL-, genera una dificultad en las unidades familiares porque se generan menores posibilidades de ingreso y una disminución de la calidad de vida. Socialmente, el impacto familiar es diferente cuando termina en la cárcel un hombre y no una mujer.

b) Discriminación por edad: los AM, al pasar de la actividad económica a la aparente inactividad, se encuentran con barreras por su edad, lo que hace que estas personas tengan largos periodos sin actividad o tengan que ocuparse en aquellas labores que el resto de la población no desea realizar.

Al respecto, se evidencia aún más la discriminación hacia los AMPL, incluso cuando el mismo Inpec censa a esa población por debajo de lo que establecen los organismos internacionales y la propia legislación colombiana, ${ }^{6}$ lo que refleja la desocupación y la difícil entrada a los programas tanto educativos como laborales que sufre esta población; esto disminuye la productividad potencial entre 10 y 7 años antes de lo previsto, y se desperdician las capacidades que estas personas pueden tener por su experiencia. Curiosamente, este retroceso en el cálculo de la edad se da cuando la esperanza de vida estimada en Colombia va en aumento (Banco Mundial, 2013), y llega a los 74 años de edad. En varios establecimientos, pero no es la generalidad, existen AMPL con cierto grado de conocimientos y experiencias, y que sienten el

6 Aunque la definición de adulto mayor la reconoce el mismo Inpec en su documento Pautas Programas Grupo Desarrollo Humano 2012 (2012, p. 24), y menciona que se encuentra establecida en la Ley 65 de 1993, artículo 29; el informe de la Segunda Asamblea Mundial sobre Envejecimiento, de abril de 2002; la Política Nacional de Envejecimiento y Vejez 2007-2019 (2007), Ministerio Protección Social; la Declaración de Brasilia, Naciones Unidas, 2007; la Ley 1251 de 1996, que establece el 7 de marzo como el Día Nacional de las Personas de la Tercera Edad; la Ley 1251 del 27 de noviembre de 2008, por la cual se dictan normas tendientes a la protección y defensa de los derechos de los AM, toda esta legislación menciona que AM es aquella persona que cuenta con sesenta (60) años de edad o más; el Inpec en su propio censo modificó la edad para hombres, los reconoce como AM cuando tienen 53 años o más, y las mujeres cuando tienen 50 años o más (cursivas de los autores). 
efecto discriminatorio por su edad; esta discriminación los hace no productivos dentro de los propios EPC cuando afuera, probablemente, sí lo eran:

¿Qué hace uno acá estando encerrado todo el tiempo comiendo y durmiendo? Y uno sin trabajo...Yo por ejemplo a mi edad son setenta y pico de años pero yo todavía trabajo, que me permitan pasar materiales para trabajar la odontología o la farmacia o la medicina para ver enfermos, que en realidad uno si se ha especializado en ver en enfermos porque mi estudio fue práctica en los hospitales, yo atendía ortopedia, neurocirugía y órganos. Tres salones y estudié mucho la medicina, tengo buena vocación para ver a los enfermos pero acá estamos amarrados porque no tenemos derecho de nada. (Grupo focal, EPMSC, Bucaramanga (ERE), julio de 2013)

Al respecto, la desocupación de los AM que no están en EPC en sí ya es un fenómeno importante, que viene en aumento y se refleja con total claridad cuando están en la cárcel.

c) Discriminación de costo psíquico: la discriminación como preferencia o gusto (Becker, 1957) se conoce como el modelo del gusto por la discriminación, y plantea que a cierto grupo de personas se les hace difícil tolerar la presencia de otras con características diferentes a las propias, por lo que ejercen sobre ellas una especie de "costo psíquico" que se traduce en discriminación realizada por gusto. En los EPC existe un estigma marcado de los AM, de forma generalizada; la mayoría son distinguidos como los "violos"; cuanto mayor es la discriminación, mayor es el aislamiento que se genera en la población. Sin embargo, como lo plantea Arrow (1972), el gusto por la discriminación depende de cómo se encuentra compuesto un lugar. En relación con este aspecto, se observó mayor discriminación en aquellos EPC donde no existía una diferenciación de la población, ni se contaba con pabellones especiales - sin afirmar que la existencia de pabellones especiales para los AMPL en los EPC evita la discriminación porque, como sugieren Marshall (1974) y 
Thurow (1975), la "aversión" hacia cierta clase de personas puede depender más de una "distancia social" y no de una "distancia física"; el estigma generado hacia esta población hace que con pabellón especial o sin él esta sea discriminada.

d) Discriminación estadística: partiendo de la teoría asociada a la discriminación estadística (Phelps, 1973), se evidencia que los programas de integración social de grupos en condiciones excepcionales, incluyendo los relacionados con los AMPL, toman como punto de referencia las características promedio de los distintos grupos y no las individuales, lo cual, hasta cierto punto, tiene lógica; al contar con escasa información sobre las habilidades de cada individuo, es más práctico (o al menos eso se cree) tener un grupo promedio sobre el cual se prefiere asumir el riesgo de generar programas sobre condiciones especiales. De acuerdo con el Inpec (2013), el $8,6 \%$ de los internos del país pertenecen a la población reclusa en condiciones excepcionales, de ellos, el 28,5\% corresponden a la tercera edad (tabla 11).

Tabla 11. Población reclusa en condiciones excepcionales

\begin{tabular}{|l|r|r|r|r|r|r|r|r|r|}
\hline \multicolumn{1}{|c|}{ Regional } & $\begin{array}{c}\text { Indí- } \\
\text { genes }\end{array}$ & $\begin{array}{c}\text { Afroco- } \\
\text { lombianos }\end{array}$ & $\begin{array}{c}\text { Extran- } \\
\text { jeros }\end{array}$ & $\begin{array}{c}\text { Tercera } \\
\text { edad }\end{array}$ & $\begin{array}{c}\text { Madres } \\
\text { lactantes }\end{array}$ & $\begin{array}{c}\text { Madres } \\
\text { gestantes }\end{array}$ & $\begin{array}{c}\text { Discapa- } \\
\text { citados }\end{array}$ & $\begin{array}{c}\text { Inimpu- } \\
\text { tados }\end{array}$ & Total \\
\hline Central & 201 & 573 & 408 & 1080 & 12 & 53 & 253 & 5 & 2585 \\
\hline Occidente & 502 & 2412 & 140 & 554 & 13 & 18 & 187 & 10 & 3836 \\
\hline Norte & 121 & 152 & 108 & 248 & 2 & 12 & 69 & 5 & 717 \\
\hline Oriente & 20 & 167 & 123 & 323 & 0 & 12 & 136 & 6 & 787 \\
\hline Noroeste & 51 & 733 & 55 & 310 & 2 & 19 & 172 & 2 & 1344 \\
\hline Viejo Caldas & 118 & 233 & 35 & 390 & 3 & 19 & 132 & 1 & 931 \\
\hline Total & 1013 & 4270 & 869 & 2905 & 32 & 133 & 949 & 29 & 10.200 \\
\hline
\end{tabular}

Fuente: Sisipec Web, julio de 2013.

Sin embargo, al tomar estrictamente la edad cronológica, que legalmente se encuentra establecida en la definición de AM, es decir 60 años, se encuentra que a julio de 2013, el total de AMPL era de 1719 internos, distribuidos como se muestra en la tabla 12. 
Tabla 12. Población de adultos mayores privados de libertad

\begin{tabular}{|l|c|c|c|}
\hline \multicolumn{1}{|c|}{ Regional } & Mujeres & Hombres & Total \\
\hline Central & 15 & 661 & 676 \\
\hline Occidente & 15 & 267 & 282 \\
\hline Norte & 11 & 181 & 192 \\
\hline Oriente & 10 & 202 & 212 \\
\hline Noroeste & 11 & 197 & 208 \\
\hline Viejo Caldas & 19 & 130 & 149 \\
\hline Total & 81 & 1638 & 1719 \\
\hline
\end{tabular}

Fuente: Sisipec Web, censo de condiciones excepcionales, 31 de julio de 2013. Cálculos de los autores.

Con base en ello, se tendría que el 1,45 \% del total de la población de los EPC estaría ocupado por AM, con edad igual o superior a los 60 años. Por otra parte, el ser extranjero y AM podría aumentar una condición que genera un sesgo discriminatorio adicional; aunque son pocos los casos encontrados, resulta importante referenciar los 10 casos en hombres (figura 12).

Figura 12. Población de adultos mayores privados de la libertad extranjeros

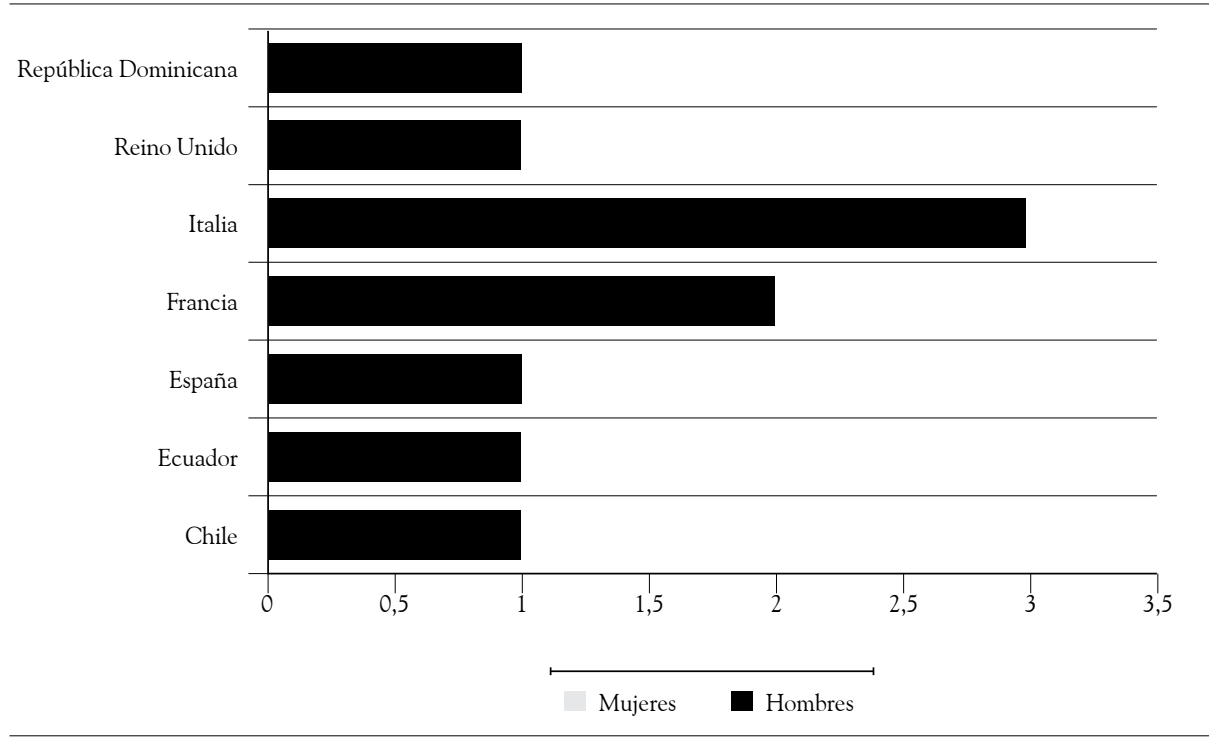

Fuente: Sisipec Web, 31 de julio de 2013. Cálculos de los autores. 
Aunque es posible que el Inpec se equivoque al no diferenciar la población de manera individualizada ni asumir su edad establecida, sino tomarla por promedios comunes, esta discriminación estadística lo beneficia y también a los EPC debido a que conocer la información más específica, como saber cuántos AMPL son personas con discapacidad y afrocolombianos e imputables, demandaría grandes recursos que el Instituto no posee; por lo que considerar características promedio observadas en la población demanda menos recursos e implica un menor riesgo en el momento de realizar programas de integración social, sin que deje de existir cierto grado de incertidumbre sobre lo que se puede y se debe hacer, y realmente sobre lo que se hace con cada población en condiciones excepcionales.

e) Discriminación ocupacional: junto con lo anterior, existe una teoría relacionada en cierta forma con la discriminación estadística y es el modelo de la concentración: la segregación ocupacional (Bergmann, 1974), donde se evidencia que al existir cierto grupo de personas limitadas por características estadísticas, se reduce el número de ocupaciones que estas personas pueden llegar a realizar, lo que induce a que los tomadores de decisiones -pueden ser los mismos directores de los EPC- las aparten o segreguen de distintas actividades, considerando, sin razón o con ella, que estos grupos pueden tener una productividad menor que la de otros internos. Básicamente, la conclusión de esta teoría (al realizar su aplicación en la población excepcional, de forma general) es que los internos que no se encuentran dentro de la población con condiciones excepcionales reciben mejores condiciones ocupacionales, lo que limita el campo de acción de las poblaciones excepcionales, sobre todo de los AMPL.

Si se eliminara el concepto de poblaciones con condiciones excepcionales, la discriminación a nivel ocupacional desaparecería, por lo que los AMPL se beneficiarían de las mismas ocupaciones que los demás internos. Se supone que estas poblaciones actualmente tienen acceso a las mismas ocupaciones, pero en realidad esto no 
es cierto; cuando no se es parte de estas, el beneficio para acceder a ellas resulta mejor, "uno ya mayor de 65 años... la cárcel es para los pobres que no tenemos plata y los que no tenemos estudio y que no podemos pagar, porque los grandes de cuello blanco, ellos sí tienen todos los beneficios y tienen todo a la perfección y el pobre campesino sobre todo que no tiene recursos de ninguna clase, a ese sí le va mal, le toca luchársela para que lo pongan a hacer algo" (grupo focal, EPMSC Acacias, junio de 2013). La asignación ocupacional en los EPC es selectiva; de acuerdo con los datos del Inpec (2013), el 66,68\% del total de la población reclusa se encuentra en trabajo, estudio y enseñanza, incluyendo a hombres y mujeres.

Teniendo en cuenta que del total de la población reclusa a julio de 2013, el 2,45\% corresponde a AM, y suponiendo que en el mismo porcentaje esa población tiene acceso a las diferentes ocupaciones, se podría concluir que cerca de 1931 internos estarían ocupados, siendo más notable esto en las mujeres que en los hombres; sin embargo, si esto fuera cierto, se estaría afirmando que el 95,93\% de la población condenada accede a trabajo, estudio y enseñanza, algo que normalmente no se puede presentar por la misma capacidad que tienen los EPC en el país (tabla 13).

Tabla 13. Población reclusa en trabajo, estudio y enseñanza

\begin{tabular}{|l|r|r|r|r|r|r|r|r|r|}
\hline \multirow{2}{*}{ Regionales } & \multicolumn{2}{|c|}{ Trabajo } & \multicolumn{2}{|c|}{ Estudio } & \multicolumn{2}{|c|}{ Enseñanza } & $\begin{array}{c}\text { Total } \\
\text { hombre }\end{array}$ & $\begin{array}{c}\text { Total } \\
\text { mujer }\end{array}$ & $\begin{array}{c}\text { Total } \\
\text { TEE }\end{array}$ \\
\cline { 2 - 10 } Combre & Mujer & Hombre & Mujer & Hombre & Mujer & & \\
\hline Central & 12.825 & 806 & 13.796 & 1216 & 542 & 45 & 27.163 & 2067 & 29.320 \\
\hline Occidente & 5728 & 666 & 6751 & 702 & 209 & 20 & 12.688 & 1388 & 14.076 \\
\hline Norte & 3016 & 175 & 3845 & 95 & 165 & 7 & 7026 & 277 & 7303 \\
\hline Oriente & 3575 & 489 & 4104 & 365 & 122 & 33 & 7801 & 887 & 8688 \\
\hline Noroeste & 3039 & 426 & 4415 & 504 & 128 & 16 & 7582 & 946 & 8528 \\
\hline Viejo Caldas & 4402 & 460 & 5187 & 777 & 151 & 23 & 9740 & 1260 & 11.000 \\
\hline Total & 32.585 & 3022 & 38.098 & 3659 & 1317 & 144 & 72.000 & 6825 & 78.825 \\
\hline
\end{tabular}


Indudablemente, una de las principales causas del problema de la desocupación de la población carcelaria ha sido el rápido crecimiento de internos en las cárceles; solo durante el último año hubo un incremento cercano al 7\%, se pasó de 111.005 (julio de 2012) a 118.201 (julio de 2013); en promedio, cada día ingresaron 20 personas a los EPC. Por lógica, solo este fenómeno tiene un impacto sobre las oportunidades de acceder a las actividades ocupacionales; la entrada de nuevos internos, bajo la misma capacidad de recursos con los que cuentan los EPC para atender a la población, disminuye significativamente la posibilidad ocupacional, principalmente de una población excepcional, como son los AMPL, cuyas posibilidades de libertad son casi inexistentes, y como las actividades ocupacionales apuntan a una resocialización para una probable salida, al ser ese escenario bajo, desestimula tanto a los internos como a los EPC en invertir recursos en esta población.

f) Discriminación de elegibilidad para la inversión en capital humano: teniendo presente lo mencionado sobre los tipos de discriminación y las diferentes teorías que se han desarrollado al respecto, es importante mencionar que elegir invertir en los AMPL termina siendo un asunto de eficiencia económica.

Para el Inpec, destinar recursos a una población que representa menos del $3 \%$ del total de la población reclusa, que cuenta con escasas posibilidades de resocialización y que por su edad productiva, económicamente hablando, no tiene probabilidades de volver al mercado laboral, lastimosamente, no es eficiente, al ser una inversión en capital humano que no posee un retorno, sin que el riesgo sea alto, y al serlo, el costo termina siendo mayor. De igual manera, la eficiencia proviene del mismo grupo discriminado, los AMPL; frente a la situación a la que se hizo referencia, y al ser conscientes de que son víctimas directas de perjuicios, tradiciones sociales, desplazamientos por la edad, su desmotivación aumenta, lo que genera una disminución de su esfuerzo productivo; esto impone costos de mantenimiento mayores (por enfermedad física o psicológica) al SPCC y al Estado en su conjunto; ante ello, 
la reacción es aumentar la discriminación y deteriorar aún más las condiciones que se les pueden generar; se crea así un círculo vicioso donde el sistema discrimina por eficiencia, pero esa misma eficiencia hace que se creen brechas de bienestar y baja productividad en la destinación de los recursos, lo que genera mayores costos en el sistema.

Es indudable que otra situación de discriminación que se presenta sobre los AMPL es la deficiente distribución entre las ocupaciones en los diferentes EPC; al respecto, no existe unidad de criterio, sino que el acceso a la ocupación que permita el mejoramiento de capital humano en este o cualquier tipo de población está más determinado por los contactos, las influencias o la dirección de turno existente en el establecimiento, lo que implica que no en todos los EPC se valora la inversión en los AMPL de manera idónea, y se traduce en una pérdida de eficiencia.

Teniendo presente estos diferentes tipos de discriminación observados y analizados en el entorno de los EPC con los AMPL, a continuación se establecen las condiciones de vida que tiene esta población, mediante una valoración que se definió con información que fue corroborada en las visitas de campo y que consideró ciertas características o factores de condiciones de vida que se agruparon en dos tipos de capital: capital físico y capital humano, los cuales se evaluaron desde su funcionamiento y capacidad en los EPC.

\section{Capital físico}

Las características físicas de los EPC explican ciertas variables que muestran los recursos y las condiciones de los internos; se aísla la percepción, que casi siempre es subjetiva, que ellos tienen y hay un sustento en la evidencia encontrada. El premio de paz Nelson Mandela dijo en su autobiografía: "Suele decirse que nadie conoce realmente cómo es una nación hasta haber estado en una de sus cárceles" (Mandela, 2010). El recorrido que hizo el grupo de 
investigadores en los diferentes EPC evidenció lo que es de conocimiento público y que comenzó con una prueba piloto en el establecimiento penitenciario La Modelo (grupo focal, EPMSC, La Modelo, mayo de 2013), aspecto que los mismos medios de comunicación han documentado (El Tiempo, 2013), y que se refiere a una nueva declaratoria de emergencia carcelaria decretada a finales del mes de mayo de 2013 por el gobierno Santos.

El primer factor analizado en los aspectos relacionados con el capital físico de los EPC tiene que ver con la capacidad de infraestructura que tiene el Inpec para atender a los internos que se encuentran a su cargo. A julio de 2013, los EPC tenían una capacidad para cubrir a 75.726 internos, la cual, frente al total de la población existente, conduce a un permanente desbordamiento. El SPCC cuenta con más internos que los cupos que físicamente posee (tabla 14).

Tabla 14. Capacidad de infraestructura en las direcciones regionales del Inpec

\begin{tabular}{|l|c|c|c|c|}
\hline \multicolumn{1}{|c|}{ Regional } & Departamentos & $\begin{array}{c}\text { Municipios que } \\
\text { agrupa }\end{array}$ & Cantidad ERON & $\begin{array}{c}\text { Capacidad } \\
\text { ERON }\end{array}$ \\
\hline Central & 8 & 39 & 42 & 28.481 \\
\hline Occidente & 4 & 23 & 24 & 14.414 \\
\hline Norte & 8 & 14 & 16 & 7180 \\
\hline Oriente & 4 & 13 & 14 & 7142 \\
\hline Noreste $^{*}$ & 2 & 21 & 21 & 8414 \\
\hline Viejo Caldas $^{* *}$ & 5 & 18 & 21 & 10.095 \\
\hline \multicolumn{2}{|r|}{ Total } & 128 & 138 & 75.726 \\
\hline
\end{tabular}

*Administrativamente, el establecimiento penitenciario de mediana seguridad y carcelario de Aguachica corresponde a la regional Oriente.

** Administrativamente, los establecimientos penitenciarios de mediana seguridad y carcelario de Puerto Boyacá (Boyacá), Armero-Guayabal, Fresno, Líbano y el Complejo de Picaleña (Tolima) están adscritos a la regional Viejo Caldas.

Fuente: Sisipec Web, julio de 2013.

Actualmente, existen 118.201 internos en el país, por lo que, frente a la capacidad física de los EPC, hay un hacinamiento del 56,1\%. El Observatorio de Seguridad Ciudadana de la Organización de los Estados Americanos (OEA) (2013) muestra que Colombia no ha logrado superar 
el número de espacios disponibles para atender a los internos recluidos en sus EPC, superando la capacidad en más de la mitad; la relación muestra que por cada 100 cupos que existen, hay en promedio 156 internos (figura 13). Una información preocupante que permite evidenciar la imposibilidad institucional por atender el exceso de demanda que prevalece, lo que hace que la situación sea estructural, sin tener novedades ni perspectivas de mejoramiento real.

Figura 13. Comportamiento del número de internos por cada 100 cupos

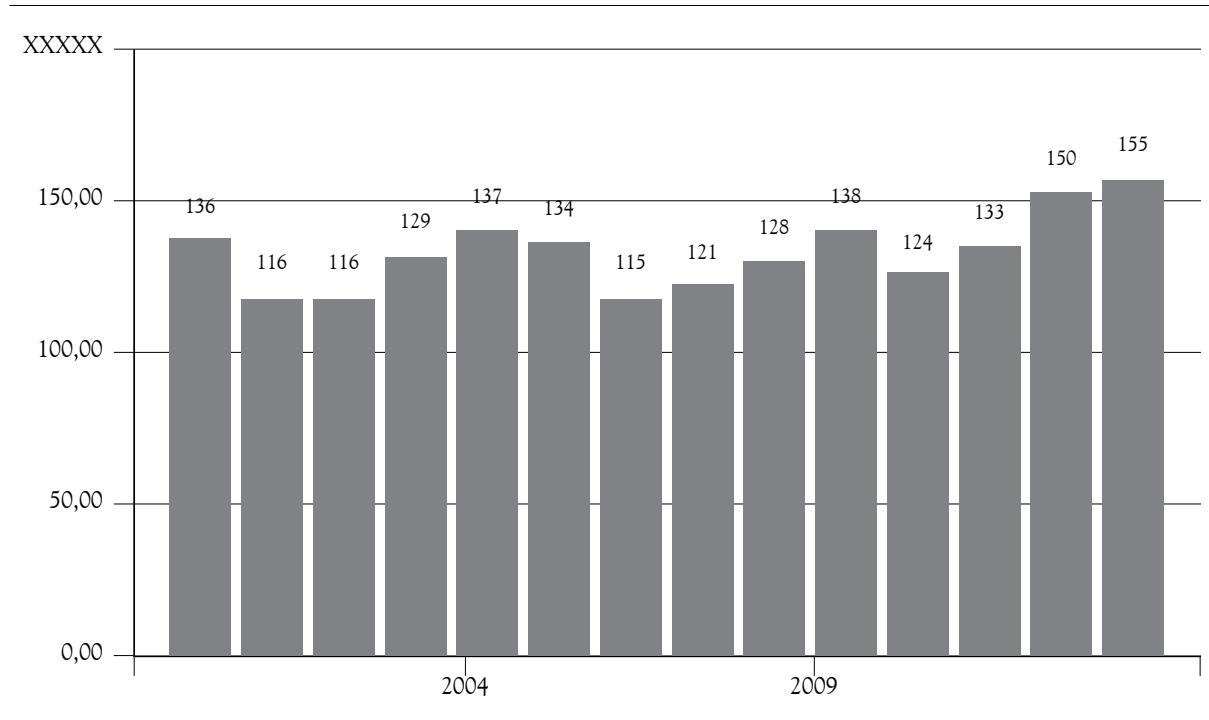

Fuente: Ministerio de Justicia y Derecho Instituto Nacional Penitenciario y Carcelario (Inpec). Departamento para la Prosperidad Social, Instituto Colombiano de Bienestar Familiar Cecilia de la Fuente de Lleras.

Cifras analizadas con anterioridad (Abaunza et al., 2011) evidencian la imposibilidad del Estado por otorgar una capacidad adecuada para la población existente en los EPC, lo que se suma a la precaria aplicación de justicia que existe en Colombia. El actual ministro de Justicia, Alfonso Gómez Méndez, ha mencionado la incapacidad estatal por hacer cumplir las propias normas que crea: "Como no cumplimos la ley entonces cambiémosla [...] Hemos caído no solo en el populismo punitivo si no que hemos padecido de otro mal que es el fetichismo normativo: creer que cambiando las normas se cambia la realidad" (Revista Semana, 2014). 
En el caso de los AMPL, la situación es aún más crítica porque dependiendo de los niveles de hacinamiento en cada EPC, deben ocupar el mismo espacio que los demás internos, sin tener ninguna diferencia por ser población en condiciones excepcionales, no porque el Inpec lo desee, sino porque la capacidad del establecimiento no lo permite. Uno de esos casos donde la situación es crítica es en el EPC de Medellín Bellavista, donde sus instalaciones fueron diseñadas con una capacidad para atender a 2424 personas y se encontraron 7500 internos, por lo que las cifras de hacinamiento son superiores al 200\%, lo cual se refleja en lo que los mismos AMPL manifiestan: "Dormimos en el suelo, imagínese doctor, unos durmiendo en los baños. Varias noches así, 80 y pico en un calabozo, es el colmo. Un día 9 nos tuvimos que tirar al baño", "iUstedes creen que es justo que haya un solo sanitario para todos los que aquí estamos?" (Grupo focal, EPMSC Medellín, Bellavista, julio de 2013). En este establecimiento no existe un pabellón exclusivo para los AMPL debido al mismo hacinamiento que se presenta; sería un ideal, pero físicamente es imposible.

Otros EPC que sufren problemas de hacinamiento han flexibilizado el uso de las instalaciones, dándoles cierta libertad a los internos, facilitando la movilidad en sus lugares de reclusión, haciendo que se perciban, por parte de los AMPL, condiciones diferentes, especialmente en los pabellones de mujeres: "Aquí nosotras tenemos las habitaciones, las celdas abiertas [...] Yo lo digo, tenemos muchos privilegios que en otras cárceles, porque yo estuve en el patio 12 y es muy bueno todo, lo que pasa es que como todo tiene sus cosas [...] hay internas de demasiada mala convivencia, como todo. Pero como le explicaba ahorita tenemos desayuno, almuerzo y comida gratis [...] aquí nos lavan la ropa, hasta lavandería nos tienen" (grupo focal de mujeres, Coped, Pedregral de Medellín, julio de 2013).

La situación de hacinamiento es más grave en la reclusión de hombres que en la de mujeres; en Coped se evidencia que aún no existe, de forma marcada, el problema de hacinamiento, pero no hay planes de contingencia para cuando esto ocurra. Independientemente del grado de hacinamiento que exista entre un establecimiento y otro, la situación real que sufren los EPC y la dotación con la que ellos cuentan, la gestión administrativa que se realiza es vital, y esta hace que pueda aumentar o disminuir la percepción de 
condiciones físicas del establecimiento. Así, por ejemplo, en Villahermosa la sensación del pabellón de AMPL es de estar en un hogar geriátrico, donde incluso no existen las celdas, sino que son puertas de madera donde se coloca el número de habitación y residen los internos; existe autorregulación en el uso de las instalaciones y la administración del mismo pabellón. Los mismos internos hablan de sus condiciones de vida en este sitio y describen un día allá así:

A las $5 \mathrm{a} . \mathrm{m}$. algunos se levantan a hacer ejercicios, a bañarnos, a esperar el desayuno a las 6:30 a. m. o 7:00 a. m. Otros se la pasan jugando billar, jugando parqués, dominó, otros se la pasan viendo televisión todo el día y no los levantan ni con una grúa jejeje... Pero hay algo mucho más importante y es que eso que quede registrado allí, en este patio, aquí no se cobra ni un peso al preso por nada, aquí llega el preso y tiene que hacer carrera para ocupar una celda, todos tienen esa opción así no tengo cinco centavos porque la gran mayoría es gente demasiado pobre, no es como otros patios donde son exclusivos de la gente de dinero, aquí la mayoría de gente no tienen recursos, pero viven en condiciones un poquito digámoslo entre comillas, un poquito más dignas, debido a que aquí no se les cobra cinco centavos, los que entre comillas administran el patio o internos de este patio donde está el presidente y estoy yo, no se les cobra cinco centavos a nadie por ni siquiera por hacerle un memorial, aquí la solidaridad es absoluta. (Grupo focal, EPAMSC Cali-ERE-, Villahermosa, julio de 2013)

Al tener en cuenta lo anterior, la percepción de las personas sobre la situación que afrontan en su diario vivir, frente a las condiciones físicas reales, está sujeta a tres factores que potencializan unas mejores o peores condiciones de vida de los AMPL. El primero de ellos consiste en tener un espacio físico exclusivo para este tipo de población. En los EPC donde esto ocurre, el trato entre iguales hace que se genere una dinámica homogénea, que difiere de donde deben estar compartiendo con personas de otras edades, sobre todo en el caso de los hombres. 
El segundo tiene que ver con la dotación de los EPC; al respecto, no hay diferencia alguna frente a otros pabellones; los AMPL, por sus condiciones físicas, requieren que las instalaciones se encuentren adecuadas a nivel de espacios, baños y demás, para que su salud no se deteriore aún más; sin embargo, en los EPC visitados, desafortunadamente, esto no ocurre, y mucho menos en los que carecen de pabellones especiales para esta población.

El tercer factor que involucra el capital físico del establecimiento es tener presente el padecimiento de alguna enfermedad (física o psicológica), lo que es fundamental para evaluar el estándar de vida de los AMPL; en la medida en que se presente una enfermedad, la infraestructura debe ser la adecuada para su atención, por el bienestar de quien la padece, pero también por los demás que pueden ser afectados directa o indirectamente.

Por todo lo mencionado, se puede concluir que el capital físico, como una condición de medición del estándar de vida, actualmente es un factor crítico que no solamente afecta a los AMPL -donde se agrava aún más-, sino que sigue siendo una falencia del SPCC, cuya solución no se observa en el corto ni en el mediano plazo, mientras este aspecto se continúe manejando con anuncios gubernamentales, cuya única visual sea la ampliación de cupos -algo necesario, pero nunca suficiente-, y se pierda la perspectiva humana; si no se reconoce con hechos que allí hay personas que, independientemente de la situación por la que están sindicadas o condenadas, deben mantener una mínimas condiciones físicas que les garanticen un estándar de vida, la privación de la libertad puede constituir una forma de tortura o un trato inhumano y degradante, ${ }^{7}$ como actualmente ocurre (Oficina del Alto Comisionado de las Naciones Unidas para los Derechos Humanos, 1996), y esta es aún más grave si se tiene presente que las deficientes condiciones físicas de los establecimientos con sobrepoblación en

7 La Declaración sobre Protección de Todas las Personas contra la Tortura y Otros Tratos o Penas Crueles, Inhumanos o Degradantes, adaptada por la Asamblea General de las Naciones Unidas en su resolución 3452 del 9 de diciembre de 1975, menciona en su artículo 2: "Todo acto de tortura u otro trato o pena cruel, inhumano o degradante constituye una ofensa a la dignidad humana y será condenado como violación de los propósitos de la Carta de las Naciones Unidas y de los derechos humanos y libertades fundamentales proclamados en la Declaración Universal de Derechos Humanos". 
lugar de disminuir, aumentan, ${ }^{8}$ a un ritmo mayor que lo hace la capacidad de los EPC; un ejemplo de ello se evidencia al observar el segundo semestre del 2013 (Inpec, 2014) (tabla 15).

Tabla 15. Capacidad, población, sobrepoblación y hacinamiento, segundo semestre de 2013

\begin{tabular}{|l|r|r|r|r|r|r|r|}
\hline \multicolumn{1}{|c|}{ Concepto } & \multicolumn{1}{c|}{ Julio } & \multicolumn{1}{c|}{ Agosto } & Septiembre & Octubre & Noviembre & Diciembre & $\begin{array}{r}\text { Promedio } \\
\text { mensual }\end{array}$ \\
\hline Capacidad & 75.726 & 75.726 & 75.895 & 75.895 & 75.895 & 76.066 & 75.867 \\
\hline Población & 118.201 & 118.478 & 119.350 & 120.038 & 120.310 & 120.032 & 119.402 \\
\hline Soprepoblación & 42.475 & 42.752 & 43.455 & 44.143 & 44.415 & 43.966 & 43.534 \\
\hline Hacinamiento & $56,1 \%$ & $56,5 \%$ & $57,3 \%$ & $58,2 \%$ & $58,5 \%$ & $57,8 \%$ & $57,4 \%$ \\
\hline
\end{tabular}

Fuente: Sisipec Web, diciembre de 2013.

Esta situación hace que las medidas que se toman ${ }^{9}$ reiteren el incumplimiento repetitivo de lo que internacionalmente se definió hace años en cuanto a los "locales destinados a los reclusos" (Oficina del Alto Comisionado de las Naciones Unidas para los Derechos Humanos, 1996-2012) en el Primer Congreso de las Naciones Unidas sobre Prevención del Delito y Tratamiento del Delincuente, celebrado en Ginebra en 1955, y aprobado por el Consejo Económico y Social en sus resoluciones 663C (XXIV) del 31 de julio de 1957 y 2076 (LXII) del 13 de mayo de 1977, donde se establecieron las reglas de aplicación general sobre las instalaciones:

1. Las celdas o cuartos destinados al aislamiento nocturno no deberán ser ocupados más que por un solo recluso. ${ }^{10} \mathrm{Si}$ por razones especiales,

8 En los EPC están ingresando en promedio 92 nuevos internos diariamente, 2760 internos mensuales, mientras que se le otorga libertad a 1000 cada mes; ese desbalance ayuda a que los niveles de hacinamiento sigan en aumento y comiencen a llegar al 60\% (El Tiempo, 2013).

9 La última medida tomada recientemente por el Gobierno fue la aprobación de la Ley 1709 de 201; al respecto: "La suspensión de la pena es una de las medidas contra el hacinamiento, prevista en el nuevo Código Penitenciario [...] Los presos están hacinados en las cárceles de Colombia y la solución que el gobierno le quiere dar a ese problema es dejar libres a 9000 reclusos que cumplen con ciertas condiciones" (Revista Semana, 2014).

10 Corroborando el trabajo de campo realizado en los EPC visitados, lo mencionado por el juez 
como el exceso temporal de población carcelaria, resultara indispensable que la administración penitenciaria central hiciera excepciones a esta regla, se deberá evitar que se alojen dos reclusos en cada celda o cuarto individual. Cuando se recurra a dormitorios, estos deberán ser ocupados por reclusos cuidadosamente seleccionados y reconocidos como aptos para ser alojados en estas condiciones. Por la noche, estarán sometidos a una vigilancia regular, adaptada al tipo de establecimiento de que se trate.

2. Los locales destinados a los reclusos y especialmente a aquellos que se destinan al alojamiento de los reclusos durante la noche, deberán satisfacer las exigencias de la higiene, habida cuenta del clima, particularmente en lo que concierne al volumen de aire, superficie mínima, alumbrado, calefacción y ventilación.

3. En todo local donde los reclusos tengan que vivir o trabajar: a) Las ventanas tendrán que ser suficientemente grandes para que el recluso pueda leer y trabajar con luz natural; y deberán estar dispuestas de manera que pueda entrar aire fresco, haya o no ventilación artificial; b) La luz artificial tendrá que ser suficiente para que el recluso pueda leer y trabajar sin perjuicio de su vista.

4. Las instalaciones sanitarias deberán ser adecuadas para que el recluso pueda satisfacer sus necesidades naturales en el momento oportuno, en forma aseada y decente.

5. Las instalaciones de baño y de ducha deberán ser adecuadas para que cada recluso pueda y sea requerido a tomar un baño o ducha a una temperatura adaptada al clima y con la frecuencia que requiera la higiene general según la estación y la región geográfica, pero por lo menos una vez por semana en clima templado.

Pedro Uribe Pérez, quien realizó una inspección judicial el 5 de agosto de 2013, en una pequeña cárcel en Facatativá, apoya lo encontrado en la investigación y refleja que la situación de las instalaciones no tiene lugar excluyente. "Duermen en el piso, pegados los unos a los otros, debajo de los camarotes, en rincones de 40 centímetros y en los techos hay cobijas colgadas a manera de hamacas. Incluso, en uno de los dormitorios existe un solo baño que comparten casi cien personas" (El Tiempo, 2013). 
6. Todos los locales frecuentados regularmente por los reclusos deberán ser mantenidos en debido estado y limpios. (Oficina del Alto Comisionado de las Naciones Unidas para los Derechos Humanos, 1996-2012, cursivas de los autores)

La comparación del capital físico actual como uno de los factores del estándar de vida para los AMPL en los EPC permite determinar que las variables de espacios disponibles, baños, hacinamiento, etc., presentan un estado deficitario en cuanto a las condiciones de detención; violan las normas de derecho internacional humanitario (DIH) y otros estándares del mínimo vital establecidos a nivel internacional, lo cual necesariamente termina afectando e incidiendo en la salud, la higiene y el acceso al agua, y los más afectados son los internos más vulnerables, como los AMPL, más aún si tienen enfermedades crónicas.

\section{Capital humano}

Si solo se tuviera en cuenta el capital físico en las condiciones de vida, se trataría de un enfoque utilitarista, omitiendo el valioso aporte teórico de Amartya Sen (1998), que incluye las potencialidades, las capacidades y las aptitudes de las personas, y que están relacionadas al capital humano.

El capital humano presente y potencial en los EPC está relacionado, directamente, con la población objeto de estudio, los internos; en este caso, los AMPL. Este aspecto es esencial en el momento de evaluar los logros actuales y futuros de un establecimiento o de forma conjunta del SPCC frente a la gestión que se realiza con esta población en particular. Dentro del análisis a los AMPL, se incluyeron variables de acuerdo con el enfoque básico de necesidades que los AM presentan (Pérez Ortiz, 1997), y que se adaptan a lo que existe en el interior de los EPC.

La visual económica de las sociedades capitalistas muestra la existencia de los AM como un grupo inferior a los demás debido a su dependencia y el marginamiento al que se ven sometidos, por lo que se trata de un capital humano en una condición "subsidiaria" al resto de la sociedad, 
que demanda beneficios en forma de salud, servicios sociales, educativos y, a cambio, no compensa con nada. Para determinar esas características del capital humano en los AM, se tienen en cuenta algunas posiciones en las que se coincide desde diversas perspectivas teóricas que agrupa la División de Población de la Cepal, como:

a) La pobreza, la dependencia, la enfermedad o la incapacidad no se deben considerar inherentes a la vejez, sino que son condiciones que pueden ser explicadas por variables sociales, económicas y/o culturales diferentes a la edad.

b) $\mathrm{Al}$ igual que cualquier persona, los Am pueden lograr un estado de bienestar y aspirar a uno superior, aunque existen unos riesgos, no se puede suponer la imposibilidad del bienestar en esta población.

c) Los AM, al igual que cualquier persona, pueden mantener y desarrollar actividades sociales determinadas por tres factores o variables: Condiciones de salud, situación económica y apoyo social recibido. Así, la edad por sí sola no debería impedir el desarrollo social, exceptuando que por circunstancias puntuales las variables mencionadas presenten un deterioro.

d) Se debe tener presente que existen parámetros sociales sobre las edades, y que marcan pautas para los AM en cuanto a comportamientos, expectativas, roles, etc., y van marcado la última etapa del ciclo de vida que se encuentra definido histórica y socialmente. (Celade, 2001)

Esas perspectivas fundamentan un desarrollo conceptual más profundo del sentido que se le da a las condiciones de vida o la calidad de vida que se relacionan directamente con el concepto de bienestar, cuyo significado aún es tema de debate según el pensamiento económico que se utilice y el alcance que desde allí se le dé (Schumpeter, 1994).

Para poder operacionalizar los diversos conceptos, y aunque las características de condiciones de vida dependen del contexto en el que se manejen -incluso pueden diferir entre EPC-, en el caso de los AMPL, para 
analizar el capital humano, se agruparon diversas categorías que caracterizan las condiciones de vida con las que se analizan los AMPL (tabla 16).

Tabla 16. Categorías para el análisis de las condiciones de vida

\begin{tabular}{|c|c|}
\hline Condiciones de vida & Caracterizaciones o categorías \\
\hline \multirow{3}{*}{ Condiciones de salud } & Esperanza de vida. \\
\hline & Salud física. \\
\hline & Psicológicas. \\
\hline \multirow{12}{*}{ Condiciones sociales } & Autopercepción. \\
\hline & Estigmatización. \\
\hline & Expectativa de vida. \\
\hline & Imaginarios sociales del delincuente. \\
\hline & Red de apoyo. \\
\hline & Solidaridad. \\
\hline & Asistencia social. \\
\hline & Aprendizaje en prisión. \\
\hline & Aspectos sociales de los delitos sexuales. \\
\hline & Espiritualidad. \\
\hline & Familia. \\
\hline & Significado otorgado a prisión. \\
\hline Condiciones económicas & Disponibilidad de ingresos. \\
\hline \multirow{2}{*}{ Condiciones jurídicas } & Sindicados e imputados. \\
\hline & Condenados. \\
\hline
\end{tabular}

Fuente: elaboración propia.

\section{Condiciones de salud de los adultos mayores privados de la libertad}

En cuanto a las condiciones de vida mencionadas del capital humano, que permitieron la caracterización de los AMPL, se encuentran, en primera 
instancia, las condiciones de salud que se enmarcan dentro de tres caracterizaciones: esperanza de vida, salud física y psicológica de los internos.

\section{Esperanza de vida (longevidad)}

De acuerdo con el Banco Mundial (2013), la esperanza de vida en Colombia es, en promedio, de 74 años, con una tendencia a que se alargue aún más en la próxima década, según las mismas estadísticas que maneja el Departamento Administrativo Nacional de Estadística (DANE); esta es más larga en las mujeres, quienes, se estima, viven en promedio 77 años frente a los hombres, quienes viven, aproximadamente, 73 años (figura 14).

Figura 14. Esperanza de vida

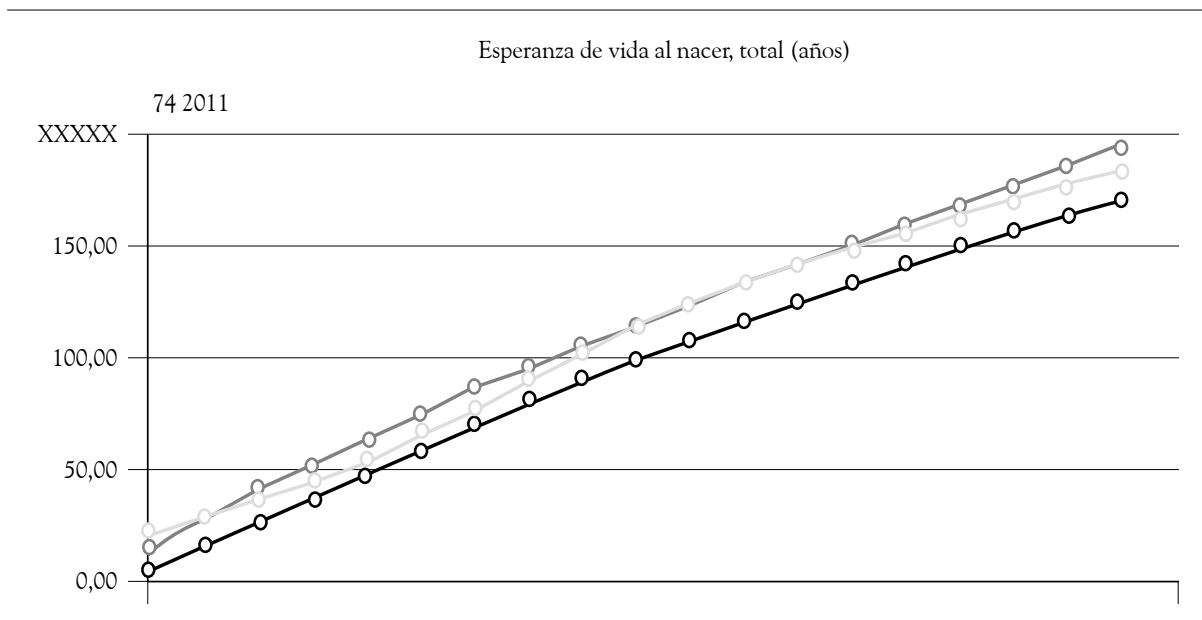

Fuente: datos del Banco Mundial.

Frente a la esperanza de vida en Colombia, y observando la edad actual de los AMPL, se encuentra que la mayoría de ellos cuentan con una edad 12 años por debajo de ese indicador; 62 años es la edad más frecuente, tanto en hombres como en mujeres. De ellos, la edad de las mujeres oscila entre los 62 y los 82 años, y la de los hombres entre los 62 y los 94 años (figura 15). 
Figura 15. Longevidad de los adultos mayores privados de la libertad

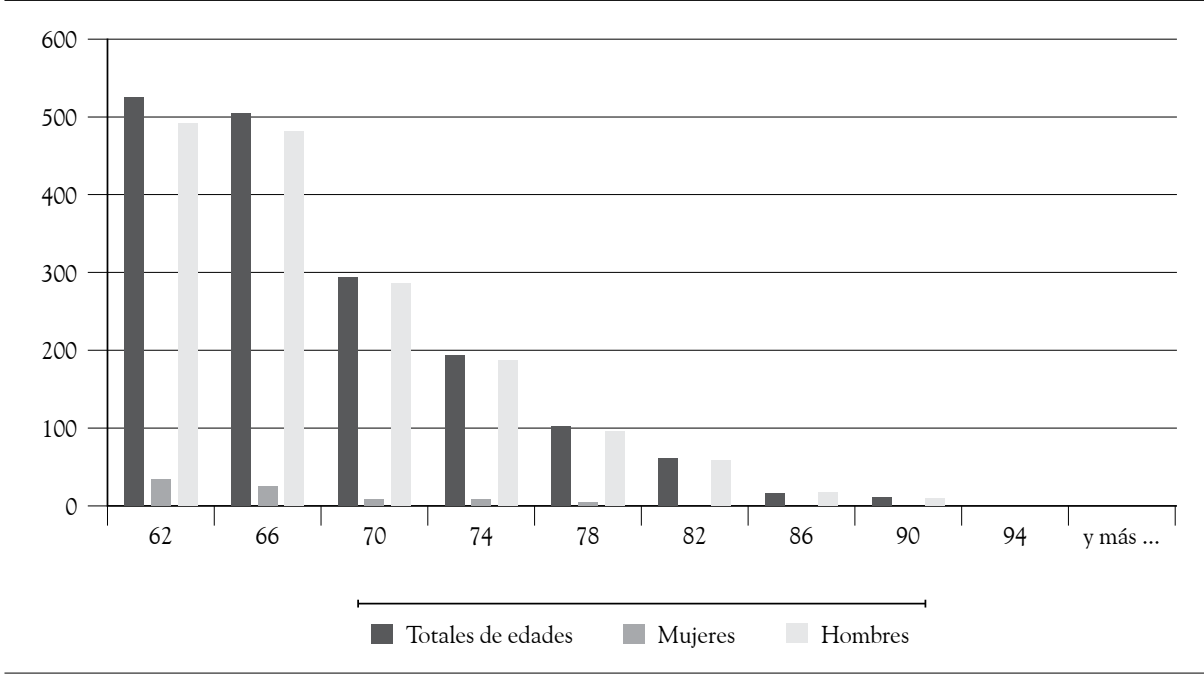

Fuente: Sisipec Web, 31 de julio de 2013. Cálculos de los autores.

Esta condición de longevidad de los AMPL frente a la esperanza de vida invita a reflexionar hasta qué punto una persona que está por debajo de la línea de esperanza de vida en Colombia podría cumplir condenas hasta ese límite, o qué sentido tiene tener a un AM que ha sobrepasado los límites de esperanza de vida en un EPC. Asimismo, invita a reflexionar sobre la funcionalidad de los programas dirigidos a esta población para una eventual resocialización debido al estado de salud que a esa edad presenta.

\section{Estado de salud física}

Al buscar cifras oficiales sobre la salud física o mental de los AMPL, para sorpresa, el Inpec no cuenta con esos datos correlacionados con la edad, lo que ratifica la percepción de los internos frente a la vulneración de su derecho a la salud. Sin embargo, al observar las discapacidades, se tiene que el $96 \%$ carecen de cualquier tipo de ellas, el $4 \%$ tienen discapacidad en sus funciones y solo el $2 \%$ presentan discapacidad en estructuras (figura 16). 
Figura 16. Discapacidades en adultos mayores privados de libertad

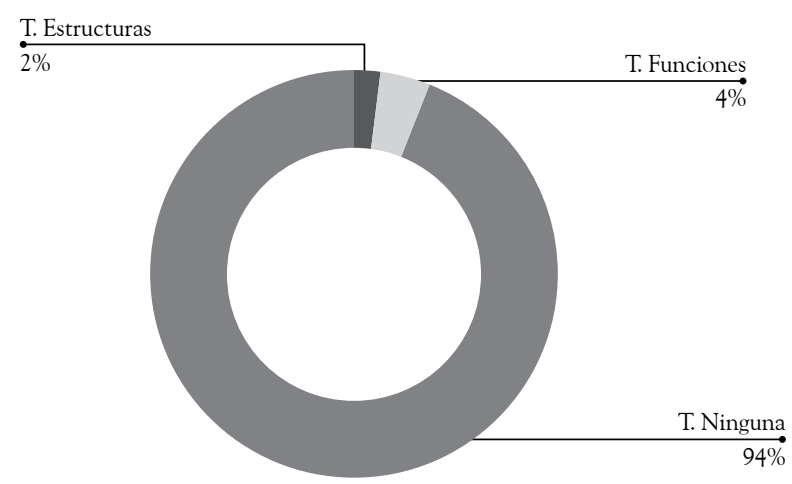

Fuente: Sisipec Web, 31 de julio de 2013. Cálculos de los autores.

Frente a esto, al indagar sobre las enfermedades físicas que los AMPL asocian a su estadía en prisión, se pudo evidenciar que este tema es de interés en la población; de hecho, fue uno de los temas que mayor espacio generó para discusión dentro de los grupos focales. De esta forma, se logró agrupar el cúmulo de enfermedades descritas en sus narraciones (tabla 17).

Tabla 17. Enfermedades físicas asociadas a la prisión según los adultos mayores privados de la libertad

\begin{tabular}{|l|l|}
\hline \multicolumn{1}{|c|}{ Enfermedad } & \multicolumn{1}{c|}{ Referencia de los internos } \\
\hline Cardiovascular & $\begin{array}{l}\text { Hipertensión, tensión alta, sufrir del corazón, problemas } \\
\text { cardiacos. }\end{array}$ \\
\hline Viral & Gripa, viH. \\
\hline Bacteriana & Tuberculosis, sífilis. \\
\hline Úlceras & Úlcera gástrica, úlceras en la piel. \\
\hline Trastornos metabólicos & Diabetes. \\
\hline Alergias & Granos, enfermedades de la piel. \\
\hline Cáncer & De colon, de próstata. \\
\hline Pulmonar & Afecciones pulmonares, neumonía. \\
\hline Reumatológica & Artritis. \\
\hline Sistema óseo & $\begin{array}{l}\text { Osteoporosis, problemas de columna vertebral, dolor en los } \\
\text { huesos. }\end{array}$ \\
\hline
\end{tabular}




\begin{tabular}{|l|l|}
\hline \multicolumn{1}{|c|}{ Enfermedad } & \multicolumn{1}{c|}{ Referencia de los internos } \\
\hline Visión & Disminución de la visión. \\
\hline Auditiva & Por ruidos, escándalo, mucha bulla. \\
\hline Otras & $\begin{array}{l}\text { Colesterol, próstata, triglicéridos, la vesícula, migraña, diálisis, } \\
\text { gastritis, dermatitis. }\end{array}$ \\
\hline
\end{tabular}

Fuente: grupos focales en los EPC visitados.

$\mathrm{Al}$ analizar estos resultados, es claro que se encuentran diversos síntomas y enfermedades, que aunque son atribuidos al estar "encarcelados", son comunes en este grupo etario a nivel general en el país, según la Encuesta Nacional de Demografía y Salud (Profamilia, 2010). Esto puede responder a lo planteado por Arango y Ruiz (2008), en cuanto a que la vejez se ha equiparado con la enfermedad, y a partir de ahí resulta que la mayoría de los AM interpretan su salud como mala.

Sin embargo, vale la pena decir que la gravedad de la enfermedad puede aumentar a causa de las condiciones en prisión. Al respecto, una de las atribuciones a la generación de enfermedad está relacionada con la habitabilidad, la cual está dada por las características físicas del establecimiento: "Aquí se enferman de este baldosín frío, de acostarse ahí uno se llena los calambres" (grupo focal, EPMSC ERE Bucaramanga, julio de 2013), "De frío le da a uno dolor de huesos y la gripa" (grupo focal, EPMSC Medellín, julio de 2013), "La parte auditiva se pierde muchísimo, los ruidos son un escándalo y una bulla que los señores que están en reclusión es mucho el escándalo" (grupo focal Comeb, Cúcuta, julio de 2013). De otro lado, estas enfermedades se encuentran relacionadas con las de visión, las gastrointestinales o crónicas, que fueron asociadas a la dinámica carcelaria e ilustradas en el capítulo de la fundamentación del concepto.

El acceso limitado al sistema de salud también puede ampliar la percepción de gravedad de la enfermedad, ya que las personas manifiestan dilación en los procesos de atención tanto de urgencias como de tratamientos a las dolencias que padecen, lo que genera ansiedad, incertidumbre y preocupación constante por su estado de salud, al conocer y proyectar un resultado negativo o poco satisfactorio. Al respecto, Koch, Cravero y Farre (citados en Londoño \& Chaparro, 2011) indican que el estado de salud 
puede observarse como unipersonal y multideterminado, y la posibilidad de acceder a los servicios médicos es una de las medidas para establecer satisfacción de necesidades. Desde esta perspectiva, se vería en riesgo la condición de salud física de los AMPL.

\section{Caracterización psicológica}

En este apartado se expondrán las características psicológicas relacionadas con las funciones cognitivas y las condiciones psicopatológicas observadas en los AMPL. La idea es aproximarse a esta realidad para proyectar, en alguna medida y a manera de propuesta, acciones para la atención acordes con la población. Para Bonilla et al. (2009), la caracterización es una fase descriptiva cuyo fin es identificar, entre otros aspectos, los componentes, los acontecimientos, los actores, los procesos y el contexto de una experiencia, un hecho o un proceso. Partiendo de esta afirmación, se realizó un análisis psicológico de la información recolectada mediante la aplicación de los instrumentos Neuropsi, SCL 90R y grupos focales, en los que se preguntó a los AMPL acerca de las enfermedades psicológicas o los cambios experimentados en prisión. La aplicación de instrumentos se describe en las siguientes fases y se explica a profundidad en el desarrollo del texto.

Se presenta la descripción de las funciones cognitivas de 21 participantes con quienes se llevó a cabo la aplicación de 2 instrumentos de screening con el fin de observar el funcionamiento mental y psicológico en relación con el tiempo de internamiento. Este ejercicio se desarrolló en paralelo con la ejecución de los grupos focales. Los primeros instrumentos aplicados a estos 21 internos fueron el Neuropsi, que permite indagar un amplio espectro de funciones cognoscitivas, y el SCL-90, el cual establece 9 dimensiones psicopatológicas; asimismo, se recolectaron datos sociodemográficos exclusivos a los 21 participantes.

Los criterios para la selección de los participantes en el estudio fueron: ser mayor de 60 años, estar condenado, participar voluntariamente, y haber diligenciado el consentimiento informado y en tiempos específicos de internamiento (el internamiento menor para un periodo de reclusión 
entre 9 y 49 meses, el internamiento intermedio comprendido entre 50 y 90 meses y el internamiento prolongado a partir de 91 y hasta 132 meses). Inicialmente, se proyectaron 3 internos por cada intervalo de tiempo, pero se observó que el desarrollo de las pruebas era complejo para algunos de ellos, situación que contrastó con el poco tiempo disponible asignado. De esta forma, se tomó 1 interno por cada lapso de tiempo; es decir, 3 por establecimiento o ciudad. El tipo de estudio elegido para el desarrollo de la investigación no permite interpretar que los resultados obtenidos sean generalizables a toda la población, por cuanto se tomó solo como indicador de lo que ocurre a los internos participantes, específicamente. Sin embargo, puede interpretarse como una primera aproximación al funcionamiento cognitivo y psicopatológico de los AMPL (tabla 18).

Tabla 18. Participantes por establecimiento en la descripción de funciones cognitivas

\begin{tabular}{|l|l|c|}
\hline \multicolumn{1}{|c|}{ Establecimiento } & \multicolumn{1}{c|}{ Ciudad } & Participantes \\
\hline EPMSC & Acacias & 3 \\
\hline Coiba & Ibagué & 3 \\
\hline EPMSC & Medellín & 3 \\
\hline EPMSCERE & Bucaramanga & 3 \\
\hline EPMSCERE & Cúcuta & 2 \\
\hline Comeb & Bogotá & 2 \\
\hline EPMSCERE & Cali & 3 \\
\hline EPC Cojam & Jamundí & 2 \\
\hline \multicolumn{2}{|c|}{} \\
\hline
\end{tabular}

Fuente: grupos focales en los EPC visitados.

Respecto a las condiciones sociodemográficas, se encontró que la edad mínima de los participantes era de 60 años y la edad máxima, de 74 años, con una media en edad de 65 años. En cuanto al nivel de escolaridad, se encontró que el 14,3\% (3 sujetos) no cuentan con un nivel de educación. De los que cuentan con educación, se halló que el mayor número de participantes (el 33,3\%) (7 sujetos) se encuentran en el nivel de 
básica incompleta, seguidos de los que se encuentran en la media incompleta, con el 19\% (4 sujetos), y el 14,3\% (3 sujetos) han terminado alguna profesión.

Desde la perspectiva jurídica, los participantes manifestaron estar privados de la libertad por haber cometido delitos de homicidio (con el 42,9\%, 9 sujetos), seguidos de delitos sexuales (con el 33,3\%, 7 sujetos). Vale la pena mencionar que estos datos son subjetivos en la medida en que no fueron contrastados con el expediente para su verificación, de hecho se cree que pudieron ser más delitos sexuales ya que la estigmatización sobre estos impide que sean revelados.

Respecto a los tiempos de condena, se encontró que la más baja fue de 41 meses y la máxima de 420 meses, la media para esta condición fue de 211,42 meses. El tiempo que llevaban privados de la libertad en el momento de la evaluación estuvo en un mínimo de 9 meses y un máximo de 132 meses, con una condena media de 68,62 meses.

Dentro de las actividades que actualmente desempeñan en prisión, se encontró que, a excepción de 2 participantes, realizaban alguna actividad al interior de los EPC; las que más se presentaron fueron las relacionadas con los trabajos manuales o artesanías, seguidas de las actividades de aseo; no obstante, manifestaron desempeñar múltiples actividades que no están dentro de las válidas como redención de pena, como lavar ropa.

\section{Funciones cognitivas}

Las funciones cognitivas, como se mencionó anteriormente, fueron evaluadas a los 21 participantes seleccionados para la aplicación del instrumento Neuropsi, que los autores describen como breve, confiable y objetivo, y funciona adecuadamente en pacientes psiquiátricos, geriátricos, neurológicos y con diversos problemas médicos (Ostrosky et al., 2010). A continuación, en la tabla 19, se dan a conocer las características esenciales del instrumento. 
Tabla 19. Características esenciales del instrumento Neuropsi

\begin{tabular}{|c|c|}
\hline $\begin{array}{l}\text { Áreas cognitivas } \\
\text { evaluadas/subáreas }\end{array}$ & $\begin{array}{l}\text { Orientación: tiempo, lugar y persona. } \\
\text { Atención y concentración: dígitos, 20-3. } \\
\text { Memoria: palabras, evocación espontánea, por categorías, reco- } \\
\text { nocimiento. } \\
\text { Lenguaje: denominación, repetición, comprensión. } \\
\text { Procesos visoconstructivos: figura semicompleja. } \\
\text { Funciones ejecutivas: semejanzas, cálculo, secuencias, mano dere- } \\
\text { cha, mano izquierda, movimientos alternos, reacciones opuestas. } \\
\text { Lectura, escritura y cálculo: dictado, copia, lectura. }\end{array}$ \\
\hline Normas & $\begin{array}{l}\text { Estandarizada en una muestra de } 800 \text { sujetos normales hispano- } \\
\text { hablantes entre los } 16 \text { y los } 85 \text { años, la muestra se estratificó de } \\
\text { acuerdo con edades agrupadas en: } 16 \text { a } 30,31 \text { a } 50,51 \text { a } 65 \text { y } 66 \\
\text { a } 85 \text { años; y en cada rango de edad se incluyeron cuatro niveles } \\
\text { educativos: 0; } 1 \text { a 4; } 5 \text { a } 9 \text { y más de } 10 \text { años de estudio. }\end{array}$ \\
\hline Calificación & $\begin{array}{l}\text { Con los datos independientes de cada habilidad cognoscitiva, se } \\
\text { obtiene un perfil individual que señala las habilidades e inhabilida- } \\
\text { des del sujeto en cada una de las áreas evaluadas. Los parámetros } \\
\text { de estandarización permiten obtener un grado o nivel de alteración } \\
\text { que clasifica en: normal, alteraciones moderadas y alteraciones severas. }\end{array}$ \\
\hline Áreas de aplicación & $\begin{array}{l}\text { Útil como instrumento de tamizaje o para ayudar a determinar si } \\
\text { se necesita una evaluación neuropsicológica completa. }\end{array}$ \\
\hline
\end{tabular}

Fuente: elaboración propia.

Los resultados que muestran de manera general el funcionamiento cognitivo de los AMPL se exponen de acuerdo con el orden de las áreas y subáreas del instrumento. En el análisis de los resultados, se centró la atención en las puntuaciones que dejaron ver algún nivel de afectación, por cuanto la mayoría de evaluados se ubicaron dentro de lo normal o esperado para el nivel educativo y la edad.

\section{Orientación}

En esta área, se observó que todos los participantes demostraron ubicación global en tiempo, espacio y estado de activación óptimo, en el momento de 
la aplicación del instrumento, por lo que se puede afirmar que esta área se conserva, contrariamente a la edad y el tiempo de internamiento.

\section{Atención y concentración}

La atención permite la integración de estímulos, agrupándolos o alternándolos, seleccionando y activando los procesos cognitivos en actividades de interés. En los AM puede aparecer disminución en la atención sostenida debido a que las señales recibidas mediante los sentidos están siendo filtradas de manera irregular. En este sentido, en la compilación realizada por Losadas (2003) y López et al. (2001) (citados en Sánchez \& Pérez, 2008) se afirma que como producto del envejecimiento se presenta la disminución progresiva en el grado de vigilancia, que se manifiesta en tareas para mantener la atención (figura 17).

Figura 17. Atención y concentración

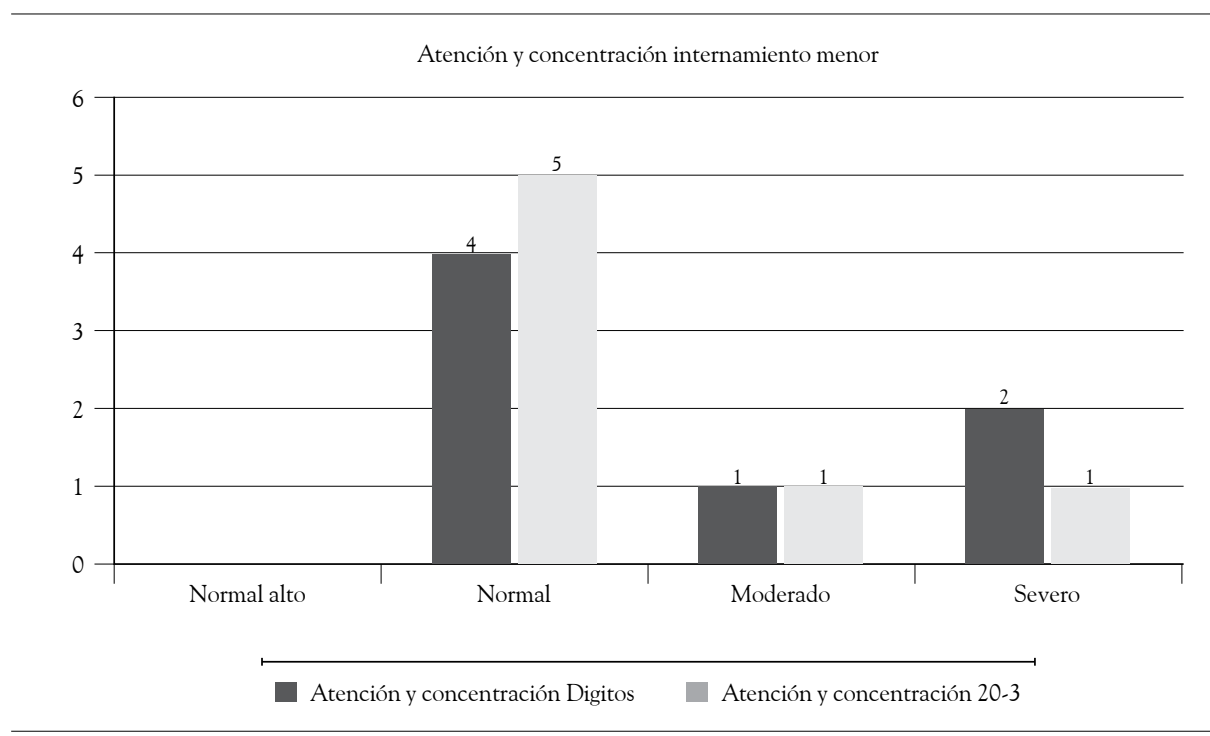


Atención y concentración internamiento intermedio
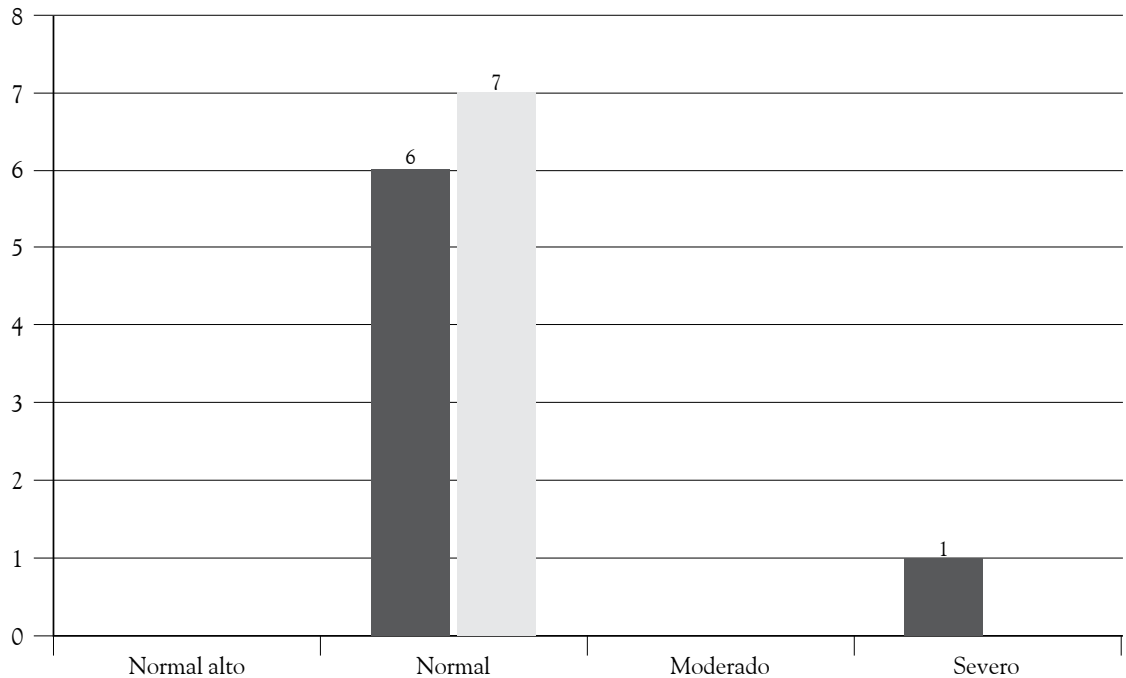

Atención y concentración Digitos

Atención y concentración 20-3

Atención y concentración internamiento prolongado

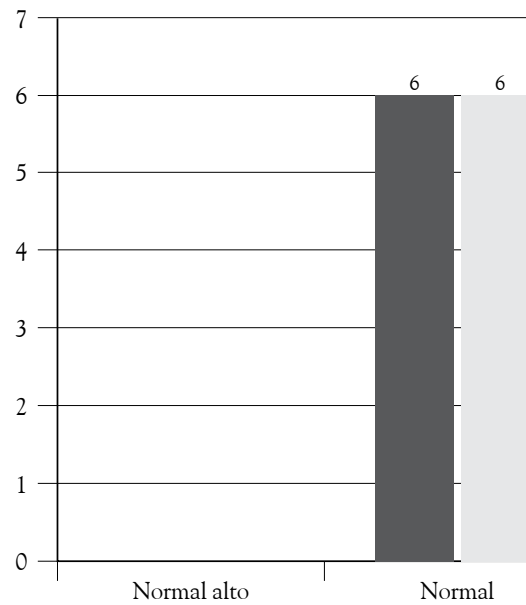

6

Atención y concentración Digitos

Atención y concentración 20-3

Fuente: elaboración propia.

En los AMPL evaluados, las tareas señaladas por el instrumento que implicaban la repetición o regresión numérica sucesiva enmarcaron las funciones de atención y concentración. De esta manera, la mayoría de ellos se ubicaron en el margen de la normalidad, en los 3 intervalos de tiempo, es 
decir que lograron realizar la actividad adecuadamente. No obstante, en el internamiento menor, 3 de 7 evaluados presentaron alteración severa en esta área, mientras que con afectación moderada se encontraron solo 2 internos. Entre tanto, en los AMPL del grupo de evaluados, con un periodo de internamiento intermedio, solo aparece un participante con indicador de daño severo. Finalmente, en un interno se presentan los niveles de alteración moderado y severo, en este proceso, en el internamiento prologado.

$\mathrm{Al}$ analizar los resultados, se infiere que la capacidad de mantener la atención para realizar tareas que implican secuencias de actividades en orden progresivo de selección de estímulos en los procesos cognitivos se vio más alterada en los sujetos participantes con menor tiempo de internamiento. Este hallazgo es consistente con los resultados de López, Calero y Navarro (2013), en cuanto que la atención sostenida y la capacidad de aprendizaje o plasticidad cognitiva son, por este orden, las variables que mejor explican los cambios experimentados por las personas mayores. Ahora, si se analiza esta función en relación con las consecuencias y las exigencias de adaptación al contexto carcelario, es claro que la cantidad de estímulos percibidos como nuevos en prisión altera la selección y la discriminación de los procesos de atención por un tiempo. Por la reiteración, estos estímulos se convierten en los únicos percibidos, lo que genera baja en esta función y tiene como consecuencia una mayor atención para estímulos nuevos o novedosos.

De ser así, podría decidirse que para los internos seleccionados en el nivel de internamiento inicial, será necesario establecer actividades con instrucciones que se desarrollen progresivamente y sin mayor exigencia de atención por largos periodos de tiempo. Y para los que participaron en el grupo de mayor tiempo de internamiento, sería la oportunidad de brindar nuevos y varios estímulos dentro del proceso de atención y tratamiento, ya que esta función estaría conservada.

\section{Memoria}

Se hará especial énfasis en esta área por ser una de las más evaluadas en el instrumento y porque está fuertemente asociada al proceso de enveje- 
cimiento. En la comprensión de este concepto, Schacter y Tulving (1994) (citados en Dixon et al., 2013) indican que la memoria es un conjunto de procesos que relacionan mecanismos cerebrales, el procesamiento de la información y los principios operacionales. Este proceso se puede ver afectado por los cambios que se dan en el curso de la vida, especialmente cuando se está en la etapa de la vejez. Al respecto, Dixon et al. (2012) plantean que la memoria es una herramienta esencial que indica que el proceso del desarrollo en la persona es exitoso, es decir, gozar de "buena memoria" se ha convertido en el imaginario común, en indicador que no se está presentando deterioro producto del envejecimiento. Esta tendencia se puede ver reforzada por lo habitual, que es escuchar lamentaciones acerca de los olvidos que muchos AM permanentemente manifiestan, y basta con pensar en la posibilidad de perderla para comprender que una de las implicaciones del envejecimiento más temida es que aparezcan signos que indiquen la pérdida de la memoria (Dixon et al., 2012).

Dos procesos asociados al adecuado y normal funcionamiento de la memoria son las funciones de codificación y evocación; en cuanto a la primera, Etchepareborda y Abad-Mas (2005) expresan que la información puede codificarse en imágenes, sonidos, experiencias, acontecimientos o ideas significativas, y que el entorno o las situaciones son determinantes para que el estímulo se procese adecuada o inadecuadamente. Esto resalta la importancia de la atención, la concentración y las condiciones emocionales de la persona en el ordenamiento de la información para su posterior recuperación. La segunda función, la de evocación, hace referencia al proceso de recuperación de la información previamente almacenada y codificada; es decir, ofrece la posibilidad de recordar.

Existen investigaciones centradas en los procesos de recordar eventos o información experimentados o adquiridos con anterioridad, y en los cambios que este proceso tiene con la edad o las condiciones en que se presentan. Al respecto, las investigaciones de Baltes y Strunder (1996), Dixon et al. (2012), Moulin et al. (2010), Herlitz y Rehnman (2008) mostraron que factores como la vulnerabilidad neuronal, el estado de salud, la vitalidad, el estilo de vida, la educación, el género y el medio ambiente pueden agravar o modular estos cambios; los resultados mostraron bajos puntajes en 
la población AM en comparación con los más jóvenes, y gradualidad en el deterioro, es decir, a pesar de las condiciones del entorno, este no sucederá de manera espontánea.

Respecto a esta área, el presente estudio evidenció diferencias de los evaluados en función del tiempo. En el internamiento menor, se observó afectación moderada en 2 de 7 internos, en las subáreas de seriación de palabras y memoria por claves (recordar palabras retenidas según categorías previamente establecidas). Asimismo, en las áreas de codificación mediante memoria verbal espontánea (recordar sin un orden previamente establecido), procesos visoespaciales y memoria por reconocimiento, se encontró solo 1 de los internos por cada área valorada. En cuanto a las subescalas que mostraron afectación severa, se encontraron 2 internos afectados en los procesos de evocación por claves, y en memoria verbal espontánea, un interno (figura 18).

Figura 18. Memoria internamiento menor

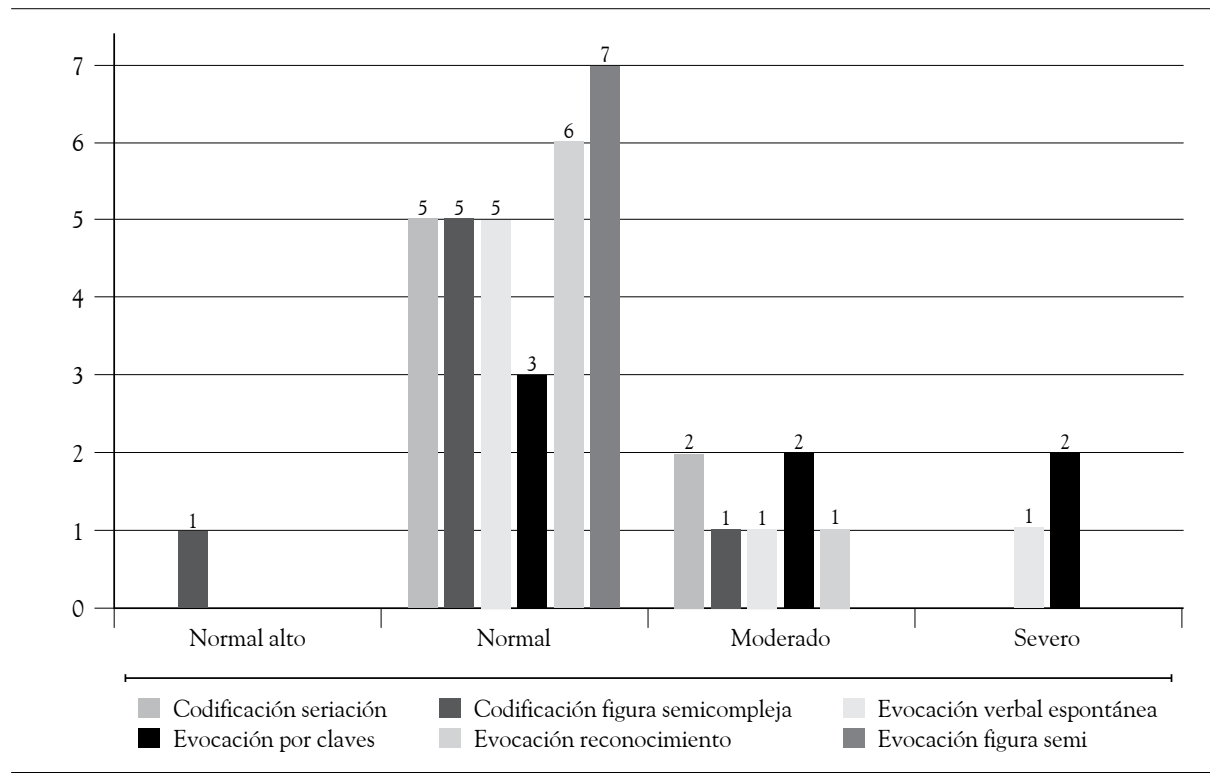

Fuente: elaboración propia.

Respecto al internamiento intermedio, se observó, en relación con el internamiento menor, aumento en cuatro internos con afectación moderada en la función de evocación por claves. Y con posible deterioro severo, apare- 
cen las funciones de codificación mediante proceso visoespacial, evocación verbal espontánea, por claves y por reconocimiento en 2 internos para cada una y un interno con deterioro con evocación por memoria visoespacial.

Figura 19. Memoria internamiento intermedio

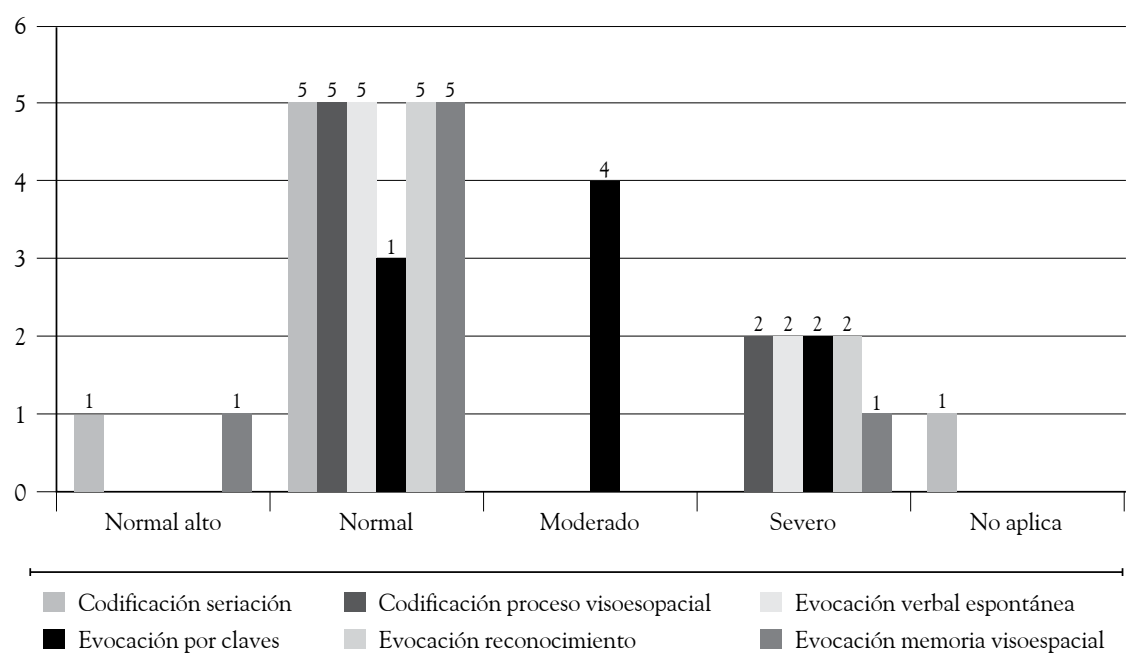

Fuente: elaboración propia.

Finalmente, para el grupo de internos evaluados con periodo prolongado de encarcelamiento, aparecen alteradas con intensidad moderada las funciones de evocación por reconocimiento y verbal espontánea en 2 internos, y nuevamente la evocación por claves en 1 de los participantes. Se destaca para deterioro severo la función de evocación por claves en 5 de los 7 participantes.

En resumen, se tiene que los resultados expuestos dan cuenta de que los AMPL afectados presentan dificultades para evocar a partir de datos organizados de manera metódica como la categorización que aparentemente se acentúa con el internamiento prolongado. Esto tiene relación con los estudios de Park y Reuter-Lorenz (2009) que demuestran que la velocidad con que se procesa la información en los sistemas de memoria operativa o de trabajo y memoria a largo plazo en el subsistema de memoria episódica disminuye de manera vertiginosa con la edad. Por otra parte, al parecer, en compensación con las limitaciones que implican los deterioros menciona- 
Figura 20. Memoria internamiento prologando

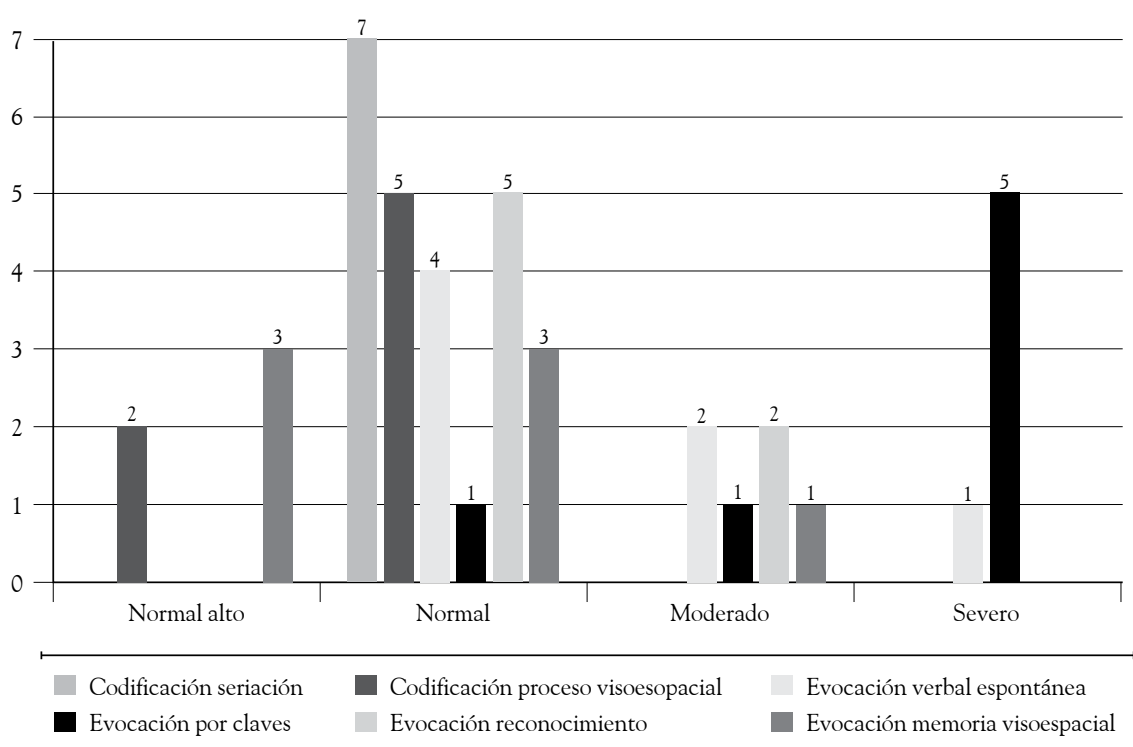

Fuente: elaboración propia.

dos, los AMPL evaluados tienen facilidades en la función de codificación de la información mediante registros visuales y, de igual manera, la evocación mediante la memoria visoespacial; esto es coherente con Etchepareborda y Abad-Mas (2005), para quienes si la experiencia ha sido bien almacenada y clasificada, será más fácil localizarla y utilizarla en el momento en que se solicita.

\section{Lenguaje}

Este es definido por Portellano (2005) como un sistema de comunicación simbólico que se manifiesta a través de las palabras y la escritura; implica la complejización de todos los procesos cognitivos, incluido el de pensamiento, mediante la utilización de las manos, los pies y el aparato fonatorio para la producción de elementos simbólicos que representan o reproducen ideas, deseos, estados anímicos y demás; permite establecer un contacto entre la mente y el mundo. 
Para que se produzca el lenguaje, es necesaria la articulación de los sentidos y, para ilustrarlo, se hace un recorrido muy elemental del curso que sigue en su producción. En el caso de la escucha, los estímulos son captados por los órganos del sistema auditivo y son trasmitidos al cerebro, donde entran en juego los sistemas de memoria, aprendizaje y pensamiento para dar sentido o interpretar lo percibido; mientras que para la lectura, la información estimula el área visual primaria para ser integrada con los estímulos auditivos, trasmitiéndola al área de Wernicke, que es la responsable de la comprensión de lo que significan las palabras. Para el habla, se hace necesario que la información procesada con anterioridad en los sistemas de memoria sea conducida hasta las áreas del cerebro donde están ubicados los componentes que estimulan las formas como se deben producir los sonidos de manera comprensible, para finalmente articular las palabras mediante los movimientos correctos de los músculos bucofonatorios. De acuerdo con el Neuropsi, esta área observa el funcionamiento del lenguaje a partir de 6 subáreas, las cuales serán descritas en función del comportamiento de la escala en los AMPL y la observancia de necesidades de atención o intervención específica para los afectados (figura 21).

En general, los resultados de las subpruebas de lenguaje se ubicaron en la categoría de la normalidad; se descartó en los evaluados trastornos relacionados con afasias, entendidas como la afectación en el procesamiento simbólico del lenguaje, y caracterizadas por la presencia, en un grado variable, de trastornos de comprensión, expresión, denominación, fluidez y repetición (Portellano, 2005). Pero algunos afectados mostraron inhabilidad en la función de comprensión en los 3 niveles de internamiento; en el internamiento prolongado, se detectó el mayor número de internos (3 de 7) con afectación moderada en comprensión de instrucciones. Lo que se detalla en este apartado del estudio tiene relación con investigaciones citadas por Lopuzzo (2002), en las que se encontró la ocurrencia de 3 fenómenos en que se pueden agrupar las conclusiones acerca de lo que sucede con el lenguaje en AM. 
Figura 21. Lenguaje internamiento menor, intermedio y prologando

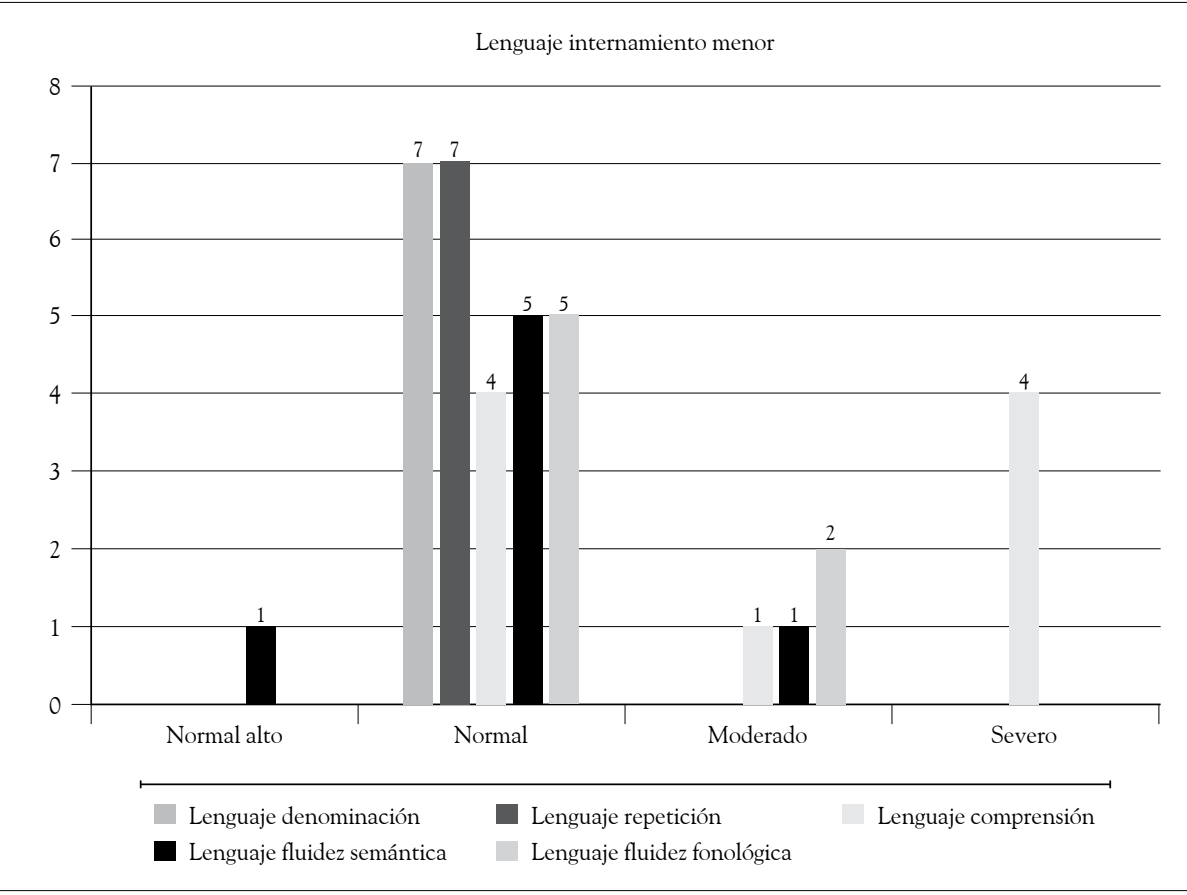

Lenguaje internamiento intermedio

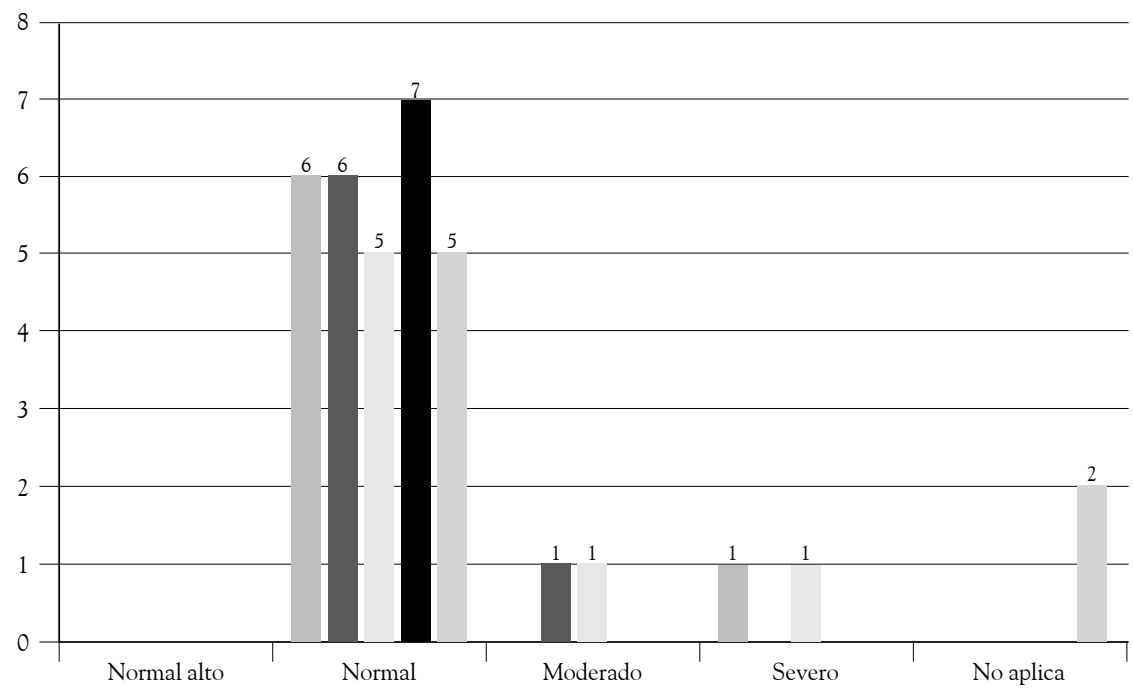

Lenguaje denominación

Lenguaje repetición

Lenguaje comprensión

Lenguaje fluidez semántica

Lenguaje fluidez fonológica 


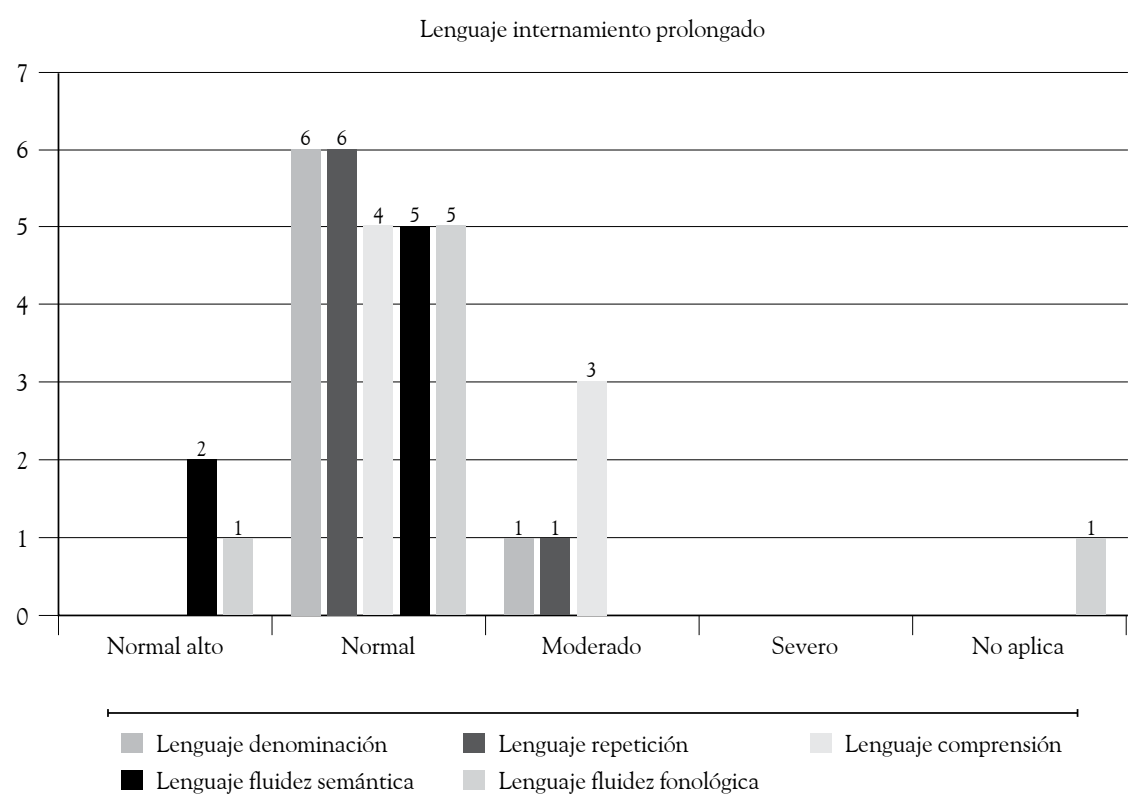

Fuente: elaboración propia.

1. El vocabulario pasivo (denominación) se mantiene.

2. Dificultades importantes en el acceso al léxico (comprensión).

3. El conocimiento conceptual no se deteriora, al parecer aumenta (fluidez fonológica, fluidez semántica).

Como conclusión, se puede decir que el lenguaje es una facultad del ser humano cuya emergencia depende de la unión de 2 componentes, descritos por Destéfano (2012): el sistema cognitivo y el sistema de ejecución (biológico). El funcionamiento de los órganos que componen el sistema de ejecución puede llegar a afectar el lenguaje no en su contenido, sino en la producción, pero una afectación en el sistema cognitivo sí perturba el lenguaje en su contenido. Es el caso de este estudio, en el que se observó que en los valorados, el lenguaje sigue funcionando, pero el nivel de comprensión de los internos que mostraron afectación no encaja en lo esperado, por cuanto se hace necesario conocer antecedentes clínicos de los AMPL que mostraron alteración moderada o severa. 


\section{Lectoescritura}

Antes de presentar el análisis de estas funciones, es necesario aclarar que 8 de los 21 participantes no presentaron una calificación de estas subescalas ya que no cumplían con el nivel académico requerido (figura 22).

Figura 22. Lectoescritura; internamiento menor, intermedio y prolongado

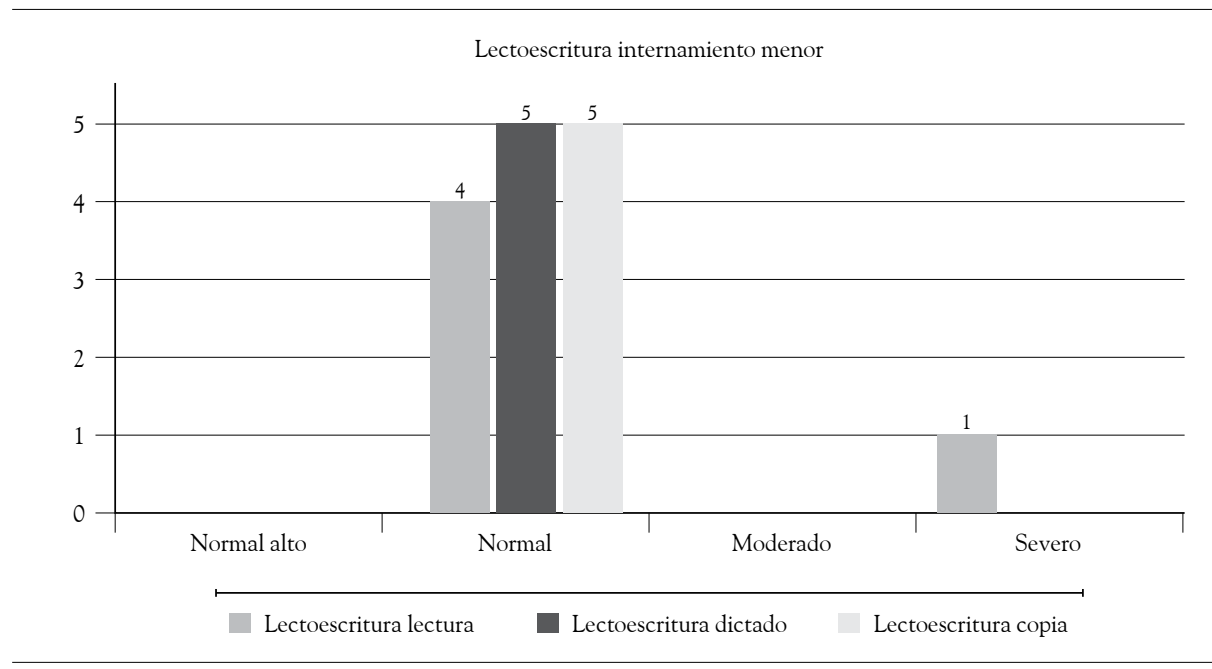

Lectoescritura internamiento intermedio

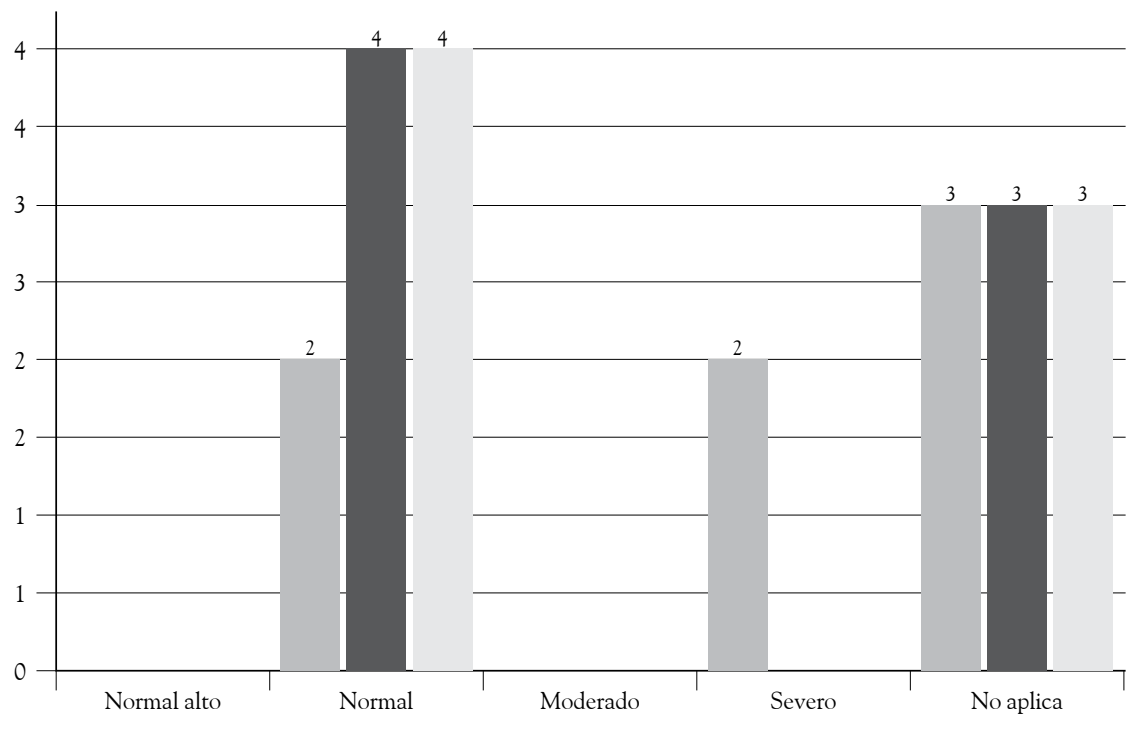




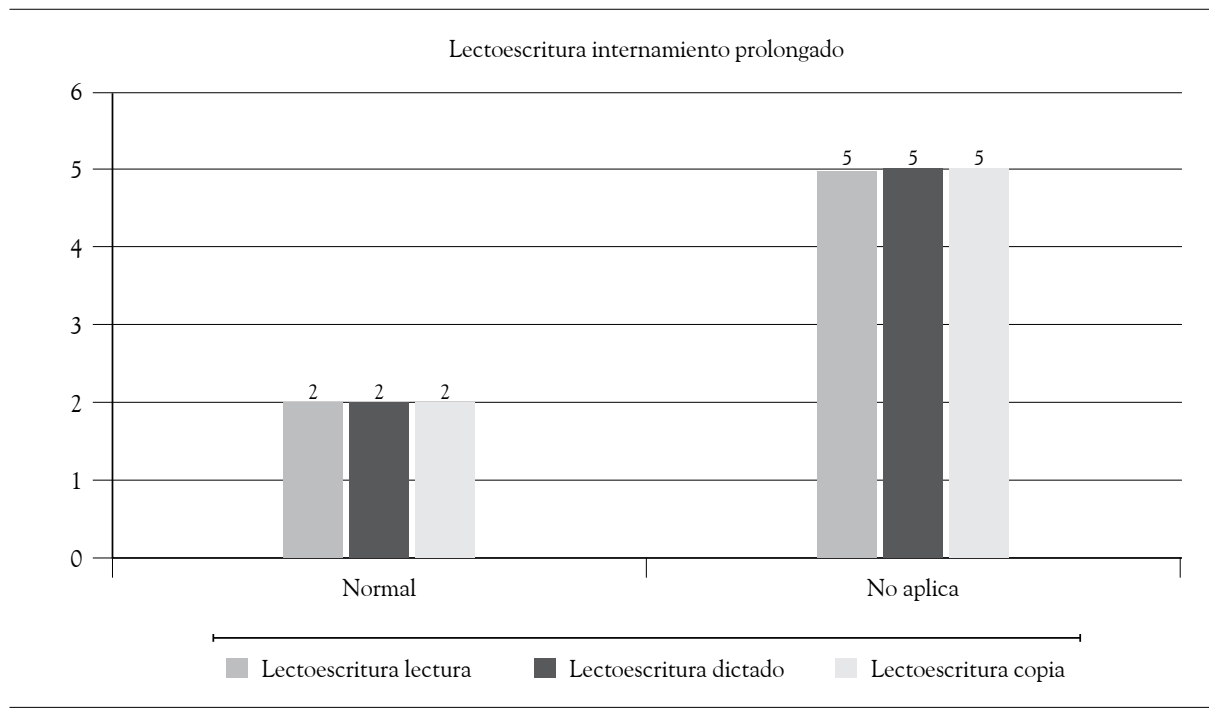

Fuente: elaboración propia.

Se registró un participante con alteración severa en lectura del grupo de internamiento menor y 2 del grupo intermedio. Estos resultados no indican que haya un déficit cognitivo en los afectados, debido a que algunos manifestaron que el deterioro de la visión les impedía leer correctamente.

\section{Función ejecutiva}

Para Verdejo y Bechara (2010), las funciones ejecutivas constituyen mecanismos de integración intermodal e intertemporal que permiten proyectar cogniciones y emociones desde el pasado hacia el futuro con el objeto de resolver situaciones novedosas y complejas. Esto implica observar cómo los participantes establecen semejanzas, hacen cálculos u observan secuencias lógicas de los acontecimientos con el fin de llevar a cabo el cumplimiento de objetivos. En el instrumento, este apartado está dividido en dos grandes grupos: las funciones conceptuales y las motoras (figura 23). 
Figura 23. Funciones ejecutivas conceptuales

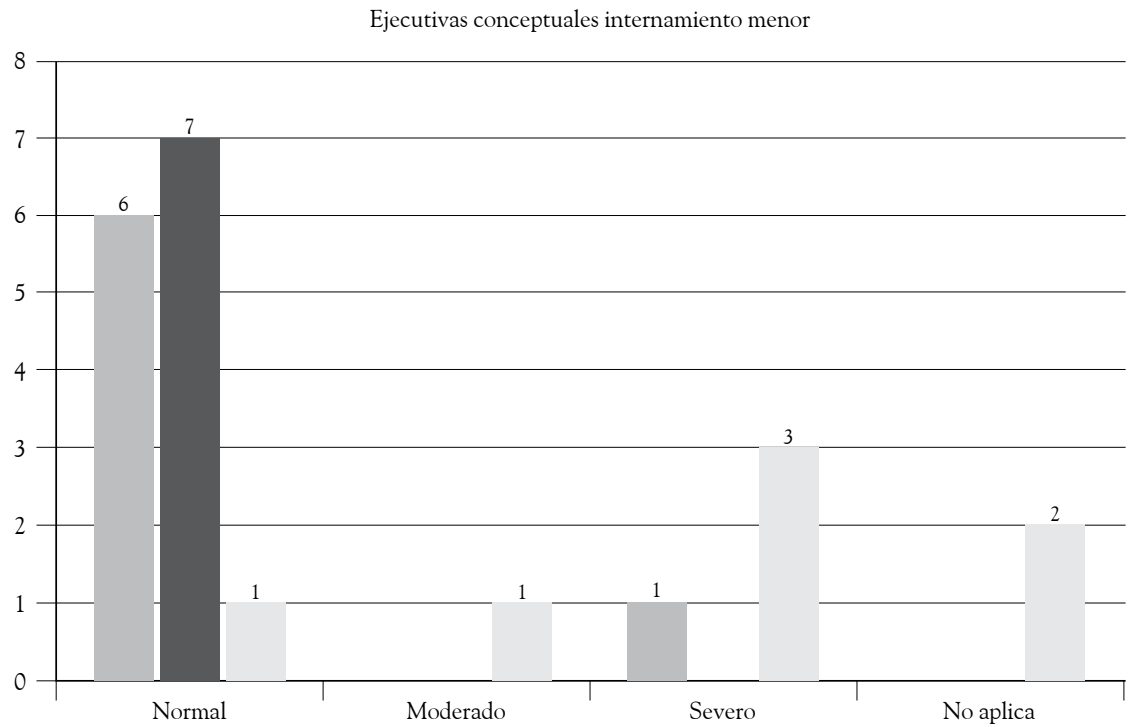

Funciones ejecutivas conceptuales semejanza

Funciones ejecutivas conceptuales cálculo

Funciones ejecutivas conceptuales secuencial

Ejecutivas conceptuales internamiento intermedio

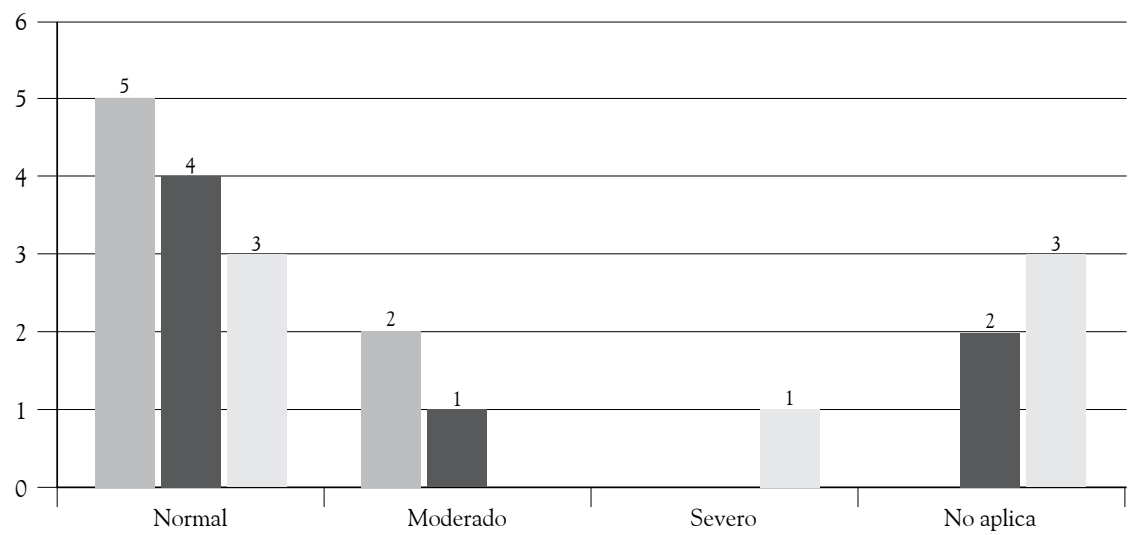

Funciones ejecutivas conceptuales semejanza

Funciones ejecutivas conceptuales cálculo

Funciones ejecutivas conceptuales secuencial 


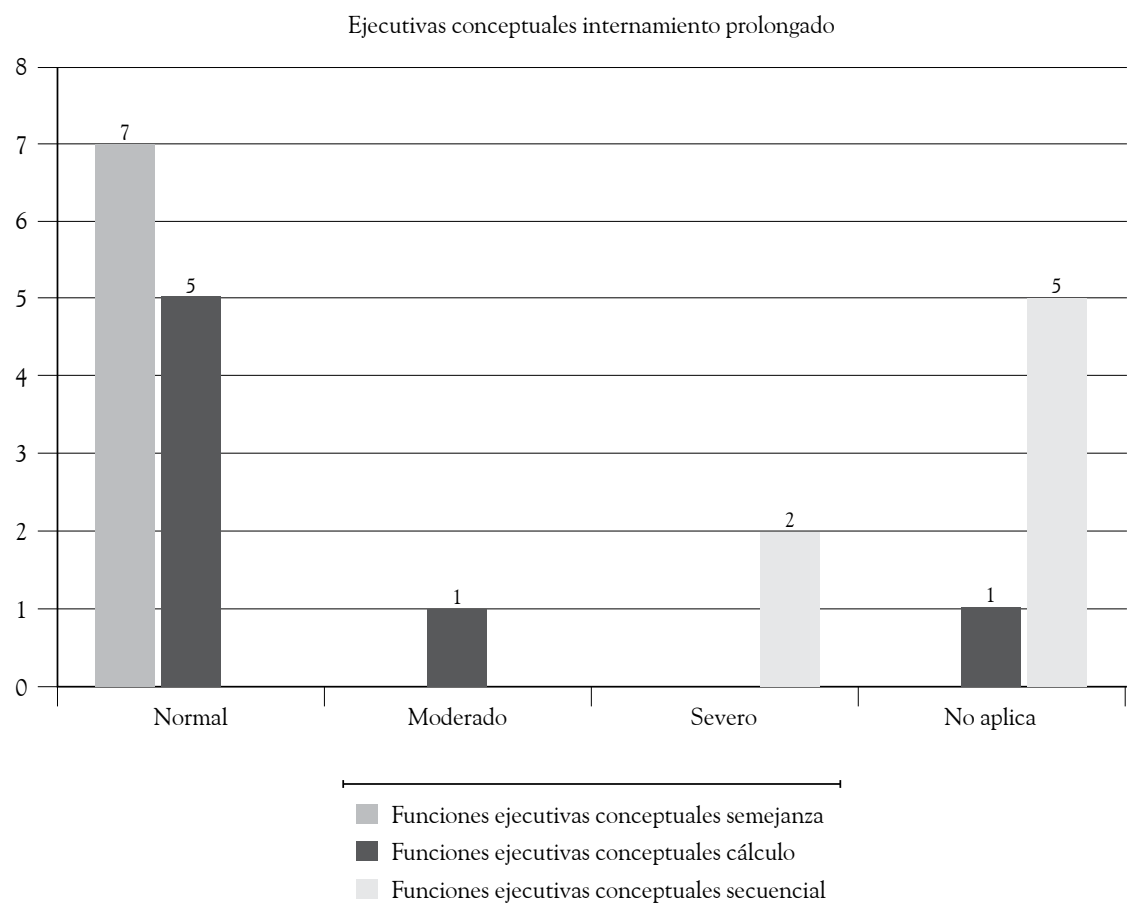

Fuente: elaboración propia.

En el internamiento menor se observó una alteración moderada en la función de secuenciación en un interno, y severa en 3 internos. Tanto en el grupo intermedio como en el prolongado la afectación severa de esta función apareció solo en un interno. En los internamientos intermedio y prolongado aparece solo un participante con alteración moderada en la función de cálculo.

La función semejanzas se encuentra asociada con el razonamiento analógico, que tiene que ver con la capacidad de entendimiento y explicación, de justificar las relaciones de semejanza, de encontrar conexiones entre los objetos y las situaciones, de poder hallar los esquemas de inferencia según la naturaleza del problema (Abregú, 2009); en otras palabras, se refiere a la capacidad de discriminar entre diferentes posibilidades que son adecuadas para cumplir un fin. En el grupo de internamiento menor, esta capacidad aparece con afectación severa en un sujeto, mientras que en el grupo intermedio, aparecieron 2 internos con alteración moderada. 
Consecuentemente con lo expuesto, se estableció que la función con mayor frecuencia de alteración fue la de secuenciación, que se encuentra directamente relacionada con la habilidad para anticipar, ensayar y ejecutar secuencias complejas de conducta en un plano prospectivo (Verdejo \& Bechara, 2010). En este sentido, los resultados mostraron que los participantes con esta afectación y menor tiempo de internamiento pueden llegar a experimentar dificultades en la planificación y la anticipación de actividades. Esta característica, en los AMPL, disminuyó en el grupo con internamiento intermedio y se elevó nuevamente en el grupo de internos detenidos por largo tiempo. Finalmente, es necesario mencionar que no se incluyeron resultados en funciones como secuenciación y cálculo, en algunos de los internos evaluados, como sucedió con la función lectoescritura (figura 24).

Figura 24. Funciones ejecutivas motoras

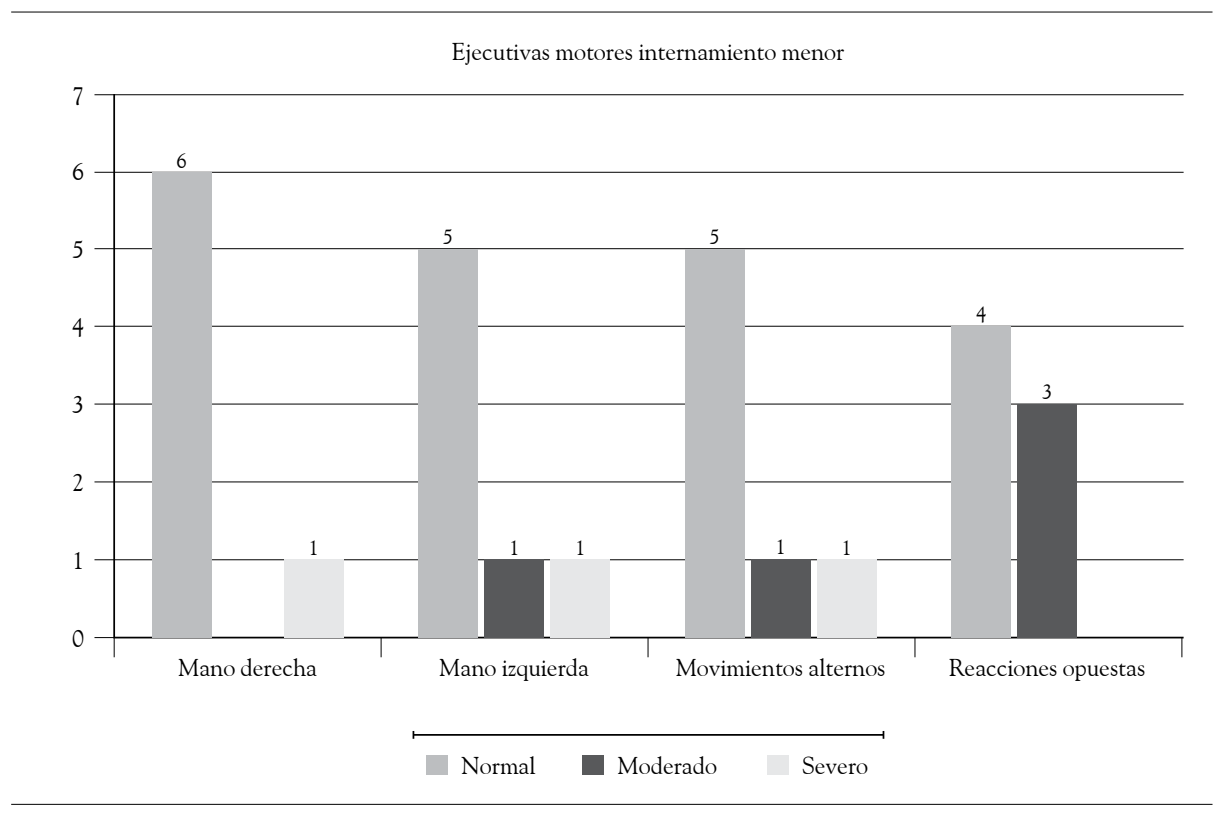




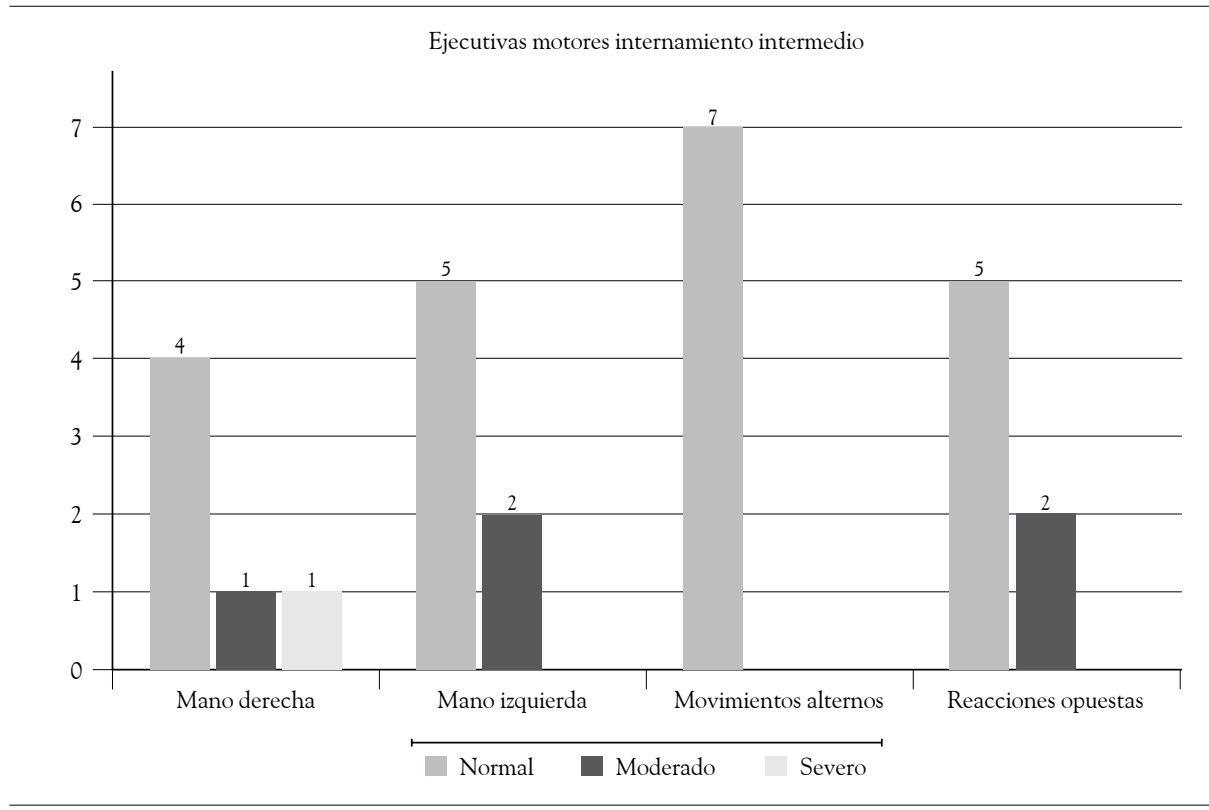

Ejecutivas motores internamiento prolongado

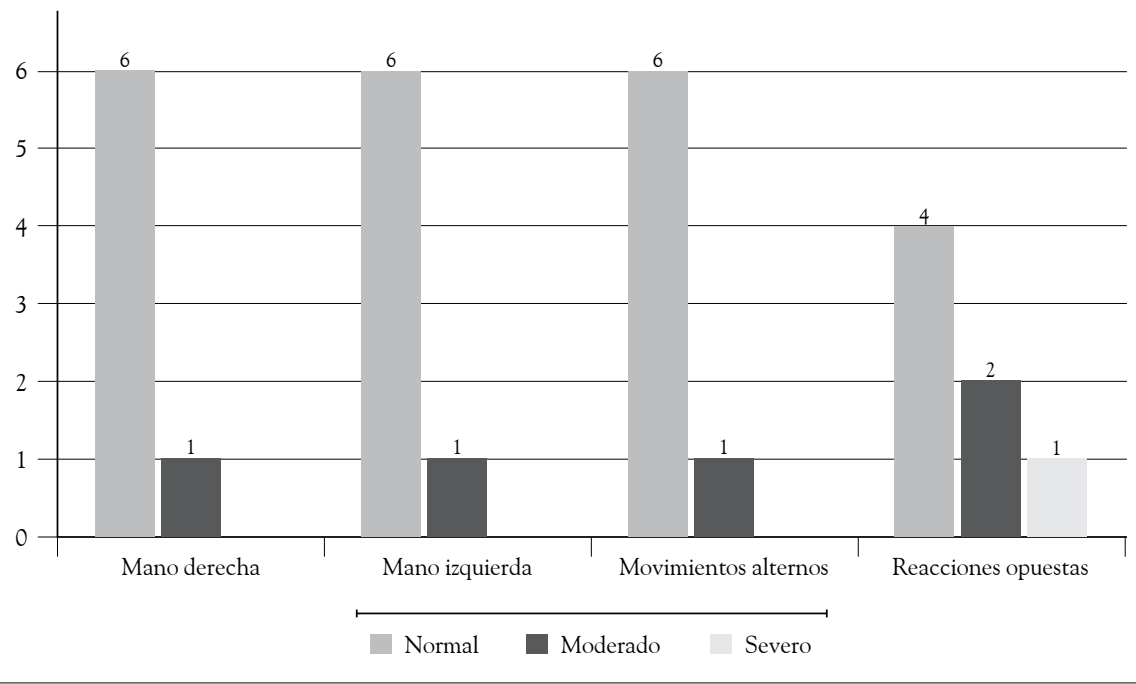

Fuente: elaboración propia.

Los resultados indicaron, en su gran mayoría, una actividad normal de los evaluados para las funciones ejecutivas motoras en todos los niveles de internamiento. Como quiera que estas se encargan de organizar y administrar la acción de todas las funciones cognitivas que se evaluaron, se puede decir que estos internos poseen la capacidad de administrar adecuadamente 
las habilidades. Sin embargo, estos resultados también mostraron que por cada 1 de los 2 primeros niveles de internamiento, se presentó un sujeto con alteración severa en la mano derecha, y un sujeto del primer momento de internamiento mostró alteración severa en el uso de la mano izquierda.

Cuando la tarea implicó el uso de las dos manos de manera alterna, se observó alteración severa en uno de los internos iniciales en prisión. En cuanto a la tarea que implicaba movimientos opuestos para cada una de las manos, se percibió una alteración moderada en 3 internos iniciales, 2 intermedios, y una alteración severa en 1 de los internos con estancia prolongada en la cárcel.

En estos sujetos en los que se presentó algún nivel de alteración se hace necesario descartar o corroborar la presencia de una lesión en la corteza premotora, que es la que permite la planeación, la organización y la ejecución secuencial de movimientos y acciones complejas (Flores \& Ostrosky, 2008).

En suma, a partir de cada una de las pruebas que componen la batería Neuropsi, y que calificaron el desempeño de los AMPL, se pudo establecer que estos se encontraban ubicados en tiempo, espacio y persona en el momento de realizar la prueba. Los internos con menor tiempo de internamiento presentaron disminución en la velocidad con que procesan, retienen y evocan la información, posiblemente porque están influenciados por las situaciones de adaptación al entorno y demás que se presentan durante el inicio del internamiento.

Por otra parte, la función memoria de los sujetos afectados presenta alteración principalmente en la evocación por categorías, en especial en el grupo con internamiento prolongado. Por contraste, la evocación por procesos visoespaciales se convierte en el recurso mediante el cual algunos de los evaluados traen al presente de nuevo lo aprendido. Además, no se observa alteración en la función lenguaje en los evaluados, que permita inferir la presencia de daños neurológicos producto del envejecimiento o lesión cerebral, y la principal alteración apareció en la dificultad para comprender instrucciones.

Las condiciones de aplicación del instrumento conllevaron la exclusión de un grupo de internos por su nivel educativo, cuando se llevó a cabo 
el apartado de lectoescritura. Es necesario aplicar instrumentos que faciliten la evaluación de estas funciones y su relación con el deterioro cognitivo y el paso del tiempo.

Existe normalidad en el ejercicio de las funciones ejecutivas de los evaluados, por cuanto los internos que obtuvieron esos resultados están en la capacidad de adaptarse a situaciones nuevas con respuestas adecuadas a las exigencias del contexto. Esto resalta la importancia de tener en cuenta a los sujetos con algún nivel de alteración en funciones motoras para valoraciones más precisas.

\section{Condiciones psicopatológicas}

Los resultados de la primera parte hacen referencia a la descripción de los datos de la muestra en general (21 participantes), de acuerdo con las dimensiones sintomáticas, la percepción de gravedad de los síntomas y la referencia de los ítems críticos que más fueron seleccionados por los participantes. En la segunda parte, se discriminan los datos por tiempo de internamiento, específicamente de las dimensiones sintomáticas.

Para la extracción de los datos, se calificaron las pruebas de acuerdo con las plantillas, y los puntajes directos se convirtieron a puntuaciones $\mathrm{T}$, de acuerdo con los baremos de población no clínica expuestos por el instrumento. De este modo, se tomaron como significativos aquellos que se encontraron por encima del T 58, donde se considera como positiva o presente la dimensión psicopatológica que se está comparando; del mismo modo ocurrió para los índices globales y para los ítems críticos.

Respecto a los resultados del total de la población, se obtuvo, dentro de las dimensiones psicopatológicas a nivel general, que la depresión fue positiva en mayor frecuencia, en este caso, en 12 participantes; seguida, en igual cantidad, por las condiciones de somatización y obsesión compulsiva, en 11 participantes. Finalmente, la ideación paranoide se registró en 10 participantes (figura 25). 
Figura 25. Dimensiones psicopatológicas generales

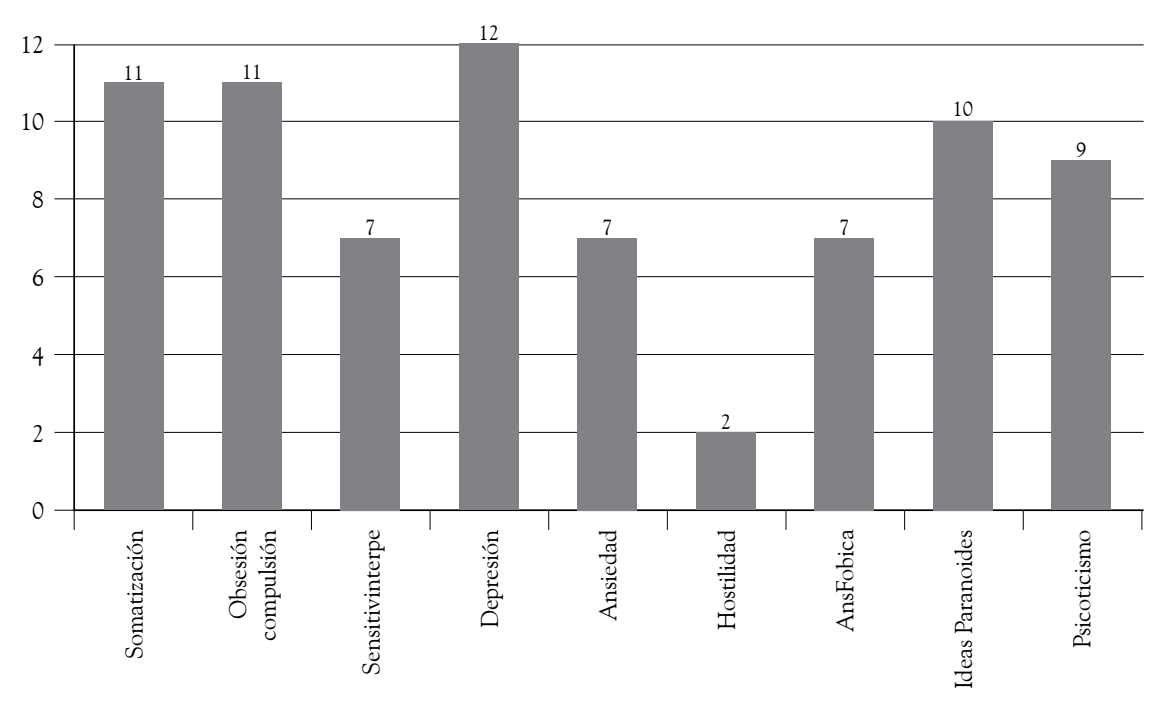

Fuente: elaboración propia.

A partir de este primer análisis de los resultados, se concluye que los internos que mostraron síntomas positivos para la depresión corresponden al $57 \%$ del total de los evaluados. Este elevado número deber ser tenido en cuenta pues si bien la muestra es pequeña, encontrar 12 personas con poco interés por las cosas, pensamientos fatalistas, sentimientos de desesperanza hacia el futuro o con la sensación de ser inútiles o no valer nada - que son algunos de los ítems que respondieron positivamente- definitivamente amerita intervención con el fin de prevenir consecuencias como el suicidio, fenómeno latente en prisión; lo cual se puede contrastar con el estudio de Mojica et al. (2009), llevado a cabo en un EPC colombiano, donde se concluyó que los reclusos que presentan riesgo suicida tienen mayores grados y niveles moderados y altos de desesperanza y de depresión, y existe una correlación positiva entre el riesgo suicida y estas 2 variables. Además, este aspecto también se corresponde con la afectación que apareció con mayor frecuencia en las participaciones de los AMPL en los grupos focales, cuando se habló acerca de la percepción de enfermedad mental o psicológica. 
En cuanto a los internos que observan síntomas positivos en somatización, se hace necesario descartar que estos indicadores no estén relacionados con una patología médica, toda vez que las preguntas indagan sobre enfermedades en los sistemas cardiovascular, respiratorio, gastrointestinal y muscular, que son percibidos, según los AMPL, como los más afectados en la cárcel, como se estableció en el apartado "Percepción de enfermedades físicas en prisión".

La obsesión-compulsión que aparece con síntomas positivos en 11 de los participantes muestra que en ellos pueden estar presentes los siguientes aspectos: la preocupación acerca del desaseo, el descuido o la desorganización; sentirse incapaces de hacer las cosas o terminar las tareas; la dificultad para tomar decisiones; entre otros. Esto es concordante con las condiciones ambientales que pueden conllevar consecuencias no deseables del envejecimiento vinculadas a estilos de vida y condiciones del entorno en la cárcel, frente a las cuales no pueden hacer nada, y que fueron expuestas por los AMPL en los grupos focales. Además, esto tiene relación con lo encontrado por Ruiz (2007), en cuanto que un mayor nivel de malestar emocional se asoció con una evaluación más negativa del clima emocional y una percepción más elevada de no poder disfrutar de las cosas.

Por otra parte, la ideación paranoide, presente en 10 de los internos, incluyó respuestas positivas en ítems como la idea de no poderse fiar de la gente, la sensación de que las otras personas lo miran o hablan mal de él, la percepción de que los otros no reconocen adecuadamente los méritos o la impresión de que los demás son los culpables de los problemas. En este sentido, existe una relación con la subdimensión exclusión y condiciones ambientales, en la que se agruparon las respuestas de los AM participantes en los grupos focales cuando hablaron de la experiencia de la adultez mayor en la cárcel, enmarcada en la sensación de no ocupar un lugar que en determinado momento de la vida tuvieron, el rechazo de otros, la percepción de incomodidad, las amenazas de otros internos, la sensación de no contar con protección ni privilegios.

Vale la pena mencionar que el índice global de severidad, es decir, el indicador del nivel actual de la severidad del malestar (Derogatis, 2002) fue positivo para 8 de los participantes, consecuentemente con los sujetos 
con mayor número de dimensiones positivas; lo que indica, de este modo, un mayor malestar psicológico, como se puede apreciar en la tabla 20.

Tabla 20. Índice global de severidad en los adultos mayores privados de la libertad

\begin{tabular}{|c|c|c|}
\hline N. ${ }^{\circ}$ de dimensiones positivas & N. $^{\circ}$ de Sujetos & Positivo IGS \\
\hline Ninguna & 4 & 0 \\
\hline 1 & 4 & 0 \\
\hline 2 & 2 & 0 \\
\hline 3 & 1 & 0 \\
\hline 4 & 2 & 0 \\
\hline 5 & 1 & 1 \\
\hline 6 & 1 & 1 \\
\hline 7 & 3 & 3 \\
\hline 8 & 2 & 1 \\
\hline 9 & 1 & \\
\hline
\end{tabular}

Fuente: elaboración propia.

Teniendo en cuenta que este índice presenta una medida de la intensidad del sufrimiento psíquico y psicosomático en general, se puede decir que en estos internos está presente la necesidad de realizar evaluaciones puntuales para establecer el nivel actual o la profundidad del trastorno y cuáles son las necesidades de atención específicas con el fin de articular acciones tendientes a la disminución de estos síntomas en los planes de tratamiento penitenciario.

Los resultados analizados en razón del tiempo de internamiento permitieron observar que en el internamiento menor, las 2 dimensiones que más se presentan en 6 sujetos son depresión y obsesivo-compulsión; en la primera se consideran signos y síntomas clínicos propios de los trastornos depresivos. De acuerdo con el manual, se incluyen aquellos relacionados con vivencias disfóricas, de desánimo, anhedonia, desesperanza, impotencia y falta de energía; así como manifestaciones cognitivas relacionadas con muerte y autodestrucción. Este mismo autor describe la segunda como 
"conductas, pensamientos e impulsos que el sujeto considera como absurdos e indeseados, que generan intensa angustia y que son difíciles de resistir, evitar o eliminar. También se relacionan con los fenómenos cognitivos de trastorno y personalidades obsesivas" (Derogatis, 2002). Asimismo, aparece como positiva, en segundo lugar, la dimensión de somatización en 5 sujetos; esto es indicador de sintomatología relacionada con vivencias desagradables frente al funcionamiento del cuerpo y, como lo describe el autor, es posible que estén mostrando una patología médica.

Figura 26. Resultados en razón del tiempo de internamiento

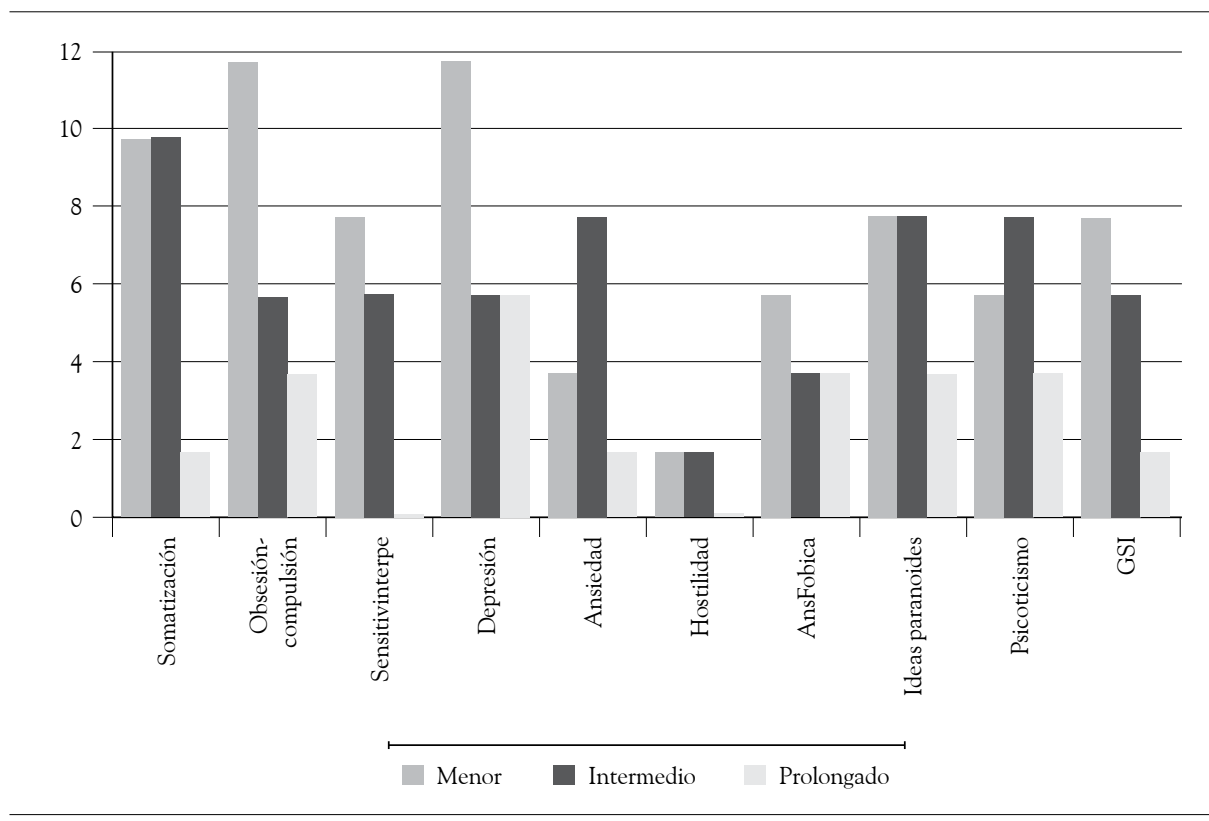

Fuente: elaboración propia.

Frente al internamiento intermedio, se evidenció que la dimensión de somatización es la que más se presenta en 5 participantes. Las dimensiones de ansiedad (signos generales de tensión emocional y manifestaciones psicosomáticas), ideación paranoide (asociada a aspectos de la conducta paranoide en especial a pensamientos proyectivos) y psicoticismo (de acuerdo con Derogatis, esta dimensión se relaciona en población no clínica, en mayor medida con alienación social) se presentan en igual proporción en 4 participantes. En este intervalo de tiempo, se puede observar que, en 
comparación con el internamiento menor, el número de participantes que presentan dimensiones sintomáticas positivas disminuye. Pero la ansiedad es la única dimensión que aumenta en comparación con los que llevan menos tiempo de internamiento. En cuanto al internamiento prolongado, se percibe que el número de dimensiones sintomáticas disminuye en relación con los anteriores intervalos de tiempo; no obstante, la depresión es la dimensión que más se presenta en 3 sujetos.

Al realizar algunas asociaciones entre variables, se observó que a mayor condena impuesta, los participantes reflejaban menores frecuencias positivas en somatización, sensitivismo interpersonal e ideación paranoide y, asimismo percibían menor malestar psicológico (GSI). En relación con la edad, se asoció que a mayor edad, se elevaba la frecuencia positiva de sensitivismo interpersonal y percibían mayor malestar psicológico. De igual manera, se percibió que los participantes que llevaban más tiempo privados de la libertad, presentaban menor frecuencia positiva en las dimensiones de somatización y sensitivismo interpersonal.

En conclusión, se puede afirmar que para los 21 participantes de esta parte del estudio, el mayor número de dimensiones positivas se presenta en el internamiento menor en comparación con los otros 2 tiempos de internamiento. En relación con el aspecto psicopatológico, existe el indicador de que a mayor tiempo de internamiento, menor número de alteraciones psicológicas presentan los AMPL. La somatización es significativa en los 2 primeros intervalos de tiempo de internamiento y la depresión es constante para los 3 intervalos. La ansiedad se presenta en más sujetos en el intervalo de tiempo intermedio. Respecto a la ideación paranoide, se mantiene homogénea en los 2 primeros tiempos de internamiento y disminuye significativamente en el internamiento prolongado.

\section{Percepción de enfermedad mental o psicológica de los adultos mayores privados de la libertad}

Para este apartado de la caracterización, la información se obtuvo a partir de las respuestas de los grupos focales. La pretensión fue observar algunas 
condiciones de enfermedad desde lo psicológico que estuvieran asociadas al internamiento, y conceptualmente se utilizó el término psicopatología para describir trastornos del funcionamiento de la vida mental.

De acuerdo con la naturaleza de los términos empleados para describir de qué se enferman mentalmente o psicológicamente los AMPL, estos se agruparon, teniendo en cuenta la sintomatología, y en ningún caso los diagnósticos, en 3 grandes categorías: estrés, depresión y, desde lo fenomenológico, los síntomas asociados con el malestar psicológico. Para presentar lo anterior, se elaboró la tabla 21 con algunas de las expresiones más representativas.

Tabla 21. Manifestación psicopatológica en los grupos focales de los adultos mayores privados de la libertad

\begin{tabular}{|c|c|c|}
\hline \multicolumn{3}{|c|}{ Manifestación psicopatológica } \\
\hline Estrés & Depresión & $\begin{array}{c}\text { Síntomas de malestar } \\
\text { psicológico }\end{array}$ \\
\hline $\begin{array}{l}\text { "Es el estrés, aquí no sabe- } \\
\text { mos que es el estrés, pero } \\
\text { hay algo que lo enferma a } \\
\text { uno más todavía, que es el } \\
\text { estrés, aquí no sabemos que } \\
\text { es el estrés, pero el estrés lo } \\
\text { mata a uno, lo enferma del } \\
\text { corazón, de muchas cosas, } \\
\text { son enfermedades adqui- } \\
\text { ridas por solo el hecho de } \\
\text { estar encerrado y uno no } \\
\text { adivina con ellas. No es que } \\
\text { tengo gripa, es que me due- } \\
\text { le esto, me duele aquello, } \\
\text { mentiras es que el estrés lo } \\
\text { mata a uno lo pone en difi- } \\
\text { cultades para poder...”. }\end{array}$ & $\begin{array}{l}\text { "La depresión hay momen- } \\
\text { tos que hay mucha depre- } \\
\text { sión, de pronto uno de pen- } \\
\text { sar la situación, uno en la } \\
\text { familia". }\end{array}$ & $\begin{array}{l}\text { “... el problema psicológico } \\
\ldots ”\end{array}$ \\
\hline
\end{tabular}




\begin{tabular}{|c|c|c|}
\hline \multicolumn{3}{|c|}{ Manifestación psicopatológica } \\
\hline Estrés & Depresión & $\begin{array}{c}\text { Síntomas de malestar } \\
\text { psicológico }\end{array}$ \\
\hline $\begin{array}{l}\text { "Yo estuve en el Ejército y } \\
\text { poco me afecta, pero lógica- } \\
\text { mente uno se estresa, llega } \\
\text { al patio y lo único que uno } \\
\text { hace es ver televisión". }\end{array}$ & $\begin{array}{l}\text { "Sí, porque uno tiene unos } \\
\text { días con mucha depresión, } \\
\text { mire yo estando aquí priva- } \\
\text { da de la libertad perdí a mi } \\
\text { hermana que me cuidaba a } \\
\text { mis hijos". }\end{array}$ & $\begin{array}{l}\text { "Hay una señora que parece } \\
\text { que fuera... pues nosotros } \\
\text { le decíamos la psiquiátrica, } \\
\text { pero esa señora estaba nor- } \\
\text { mal, normal... y estaba hasta } \\
\text { charlando, cuando dijo 'tengo } \\
\text { un mareo' y yo le dije 'recués- } \\
\text { tese'... nosotras prestándole } \\
\text { atención porque nos da ner- } \\
\text { vios... porque ella no duerme } \\
\text { en la noche, no duerme". }\end{array}$ \\
\hline $\begin{array}{l}\text { "Estrés por las peleas, por los } \\
\text { operativos porque le votan } \\
\text { todo a uno a la basura, todo } \\
\text { eso lo altera a uno". }\end{array}$ & $\begin{array}{l}\text { "En el patio llegó un señor } \\
\text { que está deprimido y vino } \\
\text { con una herida en la pierna } \\
\text { y van a tener que cortarle la } \\
\text { pierna, a la enfermera le da } \\
\text { fastidio hacerle curación, } \\
\text { mantiene con fiebre alta y } \\
\text { sicológicamente destruido } \\
\text { y hemos propuesto que este } \\
\text { señor necesita tratamiento } \\
\text { sicológico y clínico espe- } \\
\text { cial”. }\end{array}$ & $\begin{array}{l}\text { "Aquí existe una parte (in- } \\
\text { comprensible), cansancio ce- } \\
\text { rebral, enfermedad mental, } \\
\text { un tratamiento psiquiátrico, } \\
\text { un tratamiento que es perju- } \\
\text { dicial hacia la salud". }\end{array}$ \\
\hline \multirow[t]{2}{*}{$\begin{array}{l}\text { "Cómo es posible que aquí } \\
\text { se traiga gente enferma para } \\
\text { que se rehabiliten, y vengan } \\
\text { a delinquir y no salgan peor, } \\
\text { eso a uno le produce estrés". }\end{array}$} & $\begin{array}{l}\text { "Yo estoy en tratamiento de } \\
\text { depresión, acá lo único que } \\
\text { se consiguen son enferme- } \\
\text { dades". }\end{array}$ & $\begin{array}{l}\text { "Eso hace que me aparezca } \\
\text { una enfermedad que nunca } \\
\text { tenía, la droga esa... esa pa- } \\
\text { ra mantenerlo a uno dizque } \\
\text { dormido, eso es perjudicial". }\end{array}$ \\
\hline & $\begin{array}{l}\text { "La tristeza, ver el cambio, } \\
\text { el hacinamiento, revueltos } \\
\text { con otras personas de dife- } \\
\text { rente formas de proceder, } \\
\text { entonces el cambio sicoló- } \\
\text { gico es de un } 100 \% \text { más que } \\
\text { todo deprimente". }\end{array}$ & $\begin{array}{l}\text { "Si claro, su familia, sus nietos } \\
\text { - Pensar en la familia. } \\
\text { - Claro, pensar en la familia, } \\
\text { eso le trabaja el coco a uno, } \\
\text { ahí es donde vienen las en- } \\
\text { fermedades". }\end{array}$ \\
\hline
\end{tabular}




\begin{tabular}{|c|c|c|}
\hline \multicolumn{3}{|c|}{ Manifestación psicopatológica } \\
\hline Estrés & Depresión & $\begin{array}{c}\text { Síntomas de malestar } \\
\text { psicológico }\end{array}$ \\
\hline $\begin{array}{l}\text { "Aquí siempre se ha escu- } \\
\text { chado mucho más, es el es- } \\
\text { trés, el estrés de la persona". }\end{array}$ & $\begin{array}{l}\text { "La familia se afecta mucho, } \\
\text { psicológicamente las fami- } \\
\text { lias se afectan mucho... y } \\
\text { uno también". }\end{array}$ & $\begin{array}{l}\text { "Yo durante toda mi vida has- } \\
\text { ta mi vejez cometí un delito, } \\
\text { cometí un error, nada. Y venir } \\
\text { después de } 65 \text { años... eso es } \\
\text { duro. Yo los primeros días yo } \\
\text { lloraba, yo mantenía la cabe- } \\
\text { za encerrada, yo no veía para } \\
\text { dónde, ya luego uno se va } \\
\text { adaptando". }\end{array}$ \\
\hline \multirow[t]{2}{*}{$\begin{array}{l}\text { "Hay otro caso en el que los } \\
\text { mismos guardianes tienen } \\
\text { que cuidar de nosotros, nos } \\
\text { estresan mucho, hay unas } \\
\text { personas que viven muy } \\
\text { amargadas y que van a des- } \\
\text { cargar toda esa amargura } \\
\text { con nosotros". }\end{array}$} & & $\begin{array}{l}\text { "Pues nosotros siempre ve- } \\
\text { nimos enfermos, porque yo } \\
\text { tengo un problema psiquiátri- } \\
\text { co y mucho dolor de cabeza y } \\
\text { aquí no hay nadie que lo vea } \\
\text { a uno. Por más que uno llore, } \\
\text { salga y pida auxilio, no, como } \\
\text { le digo media ampolla de dipi- } \\
\text { rona y eso no alienta a nadie". }\end{array}$ \\
\hline & & $\begin{array}{l}\text { "Algunas se generan acá por } \\
\text { el encierro, las preocupacio- } \\
\text { nes. Por el hacinamiento". }\end{array}$ \\
\hline \multirow[t]{2}{*}{$\begin{array}{l}\text { "Aguante hambre. } \\
\text { Desde las } 3 \text { p. m. hasta el } \\
\text { otro día a las } 6 \text { a. m., eso } \\
\text { va artillando en el estado } \\
\text { de ánimo de uno en el... } \\
\text { en todo... ya uno se siente } \\
\text { incómodo, muchas veces } \\
\text { le da hasta rabia porque el } \\
\text { hambre da rabia". }\end{array}$} & & $\begin{array}{l}\text { "El ruido de la gente, la ha- } \\
\text { bladera, esa bulla traen pro- } \\
\text { blemas sicológicos al cerebro, } \\
\text { se siente como si la cabeza le } \\
\text { fuera a estallar". }\end{array}$ \\
\hline & & $\begin{array}{l}\text { En la sola entrada el cambio } \\
\text { es sicológico. }\end{array}$ \\
\hline
\end{tabular}

Fuente: grupos focales en los EPC visitados. 
Esta organización permitió relacionar particularidades que ameritan ser tenidas en cuenta como parte de la caracterización. En primera medida, los síntomas de estrés se asociaron con situaciones específicas del entorno que, en este caso, se refieren a las dinámicas de prisión frente a las cuales los AMPL no pueden hacer nada para modificarlas. En relación con lo anterior, se debe tener en cuenta que el estrés es una manifestación de ajuste ante un estímulo o evento considerado como negativo para el sujeto, por lo que se infiere que las dinámicas de prisión por sí mismas son fuente de estrés para esta población.

Los síntomas de depresión, por el contrario, estuvieron asociados a emociones, sentimientos y situaciones de los internos con respecto a las dificultades y la limitación de contacto con las personas cercanas o familiares. Lo anterior es relacional con el estudio de Pulido et al. (2009), el cual indica que hay una mayor cantidad de síntomas depresivos cuando los internos tienen poco contacto con sus hijos y familiares, y frente a la percepción de su propia salud. A partir de lo anterior, se percibe la importancia de desarrollar actividades que permitan el acercamiento, el restablecimiento o la creación de redes de apoyo con personas o instituciones para disminuir esos efectos de la prisión.

En la tercera columna aparecen síntomas que se relacionan con el malestar psicológico; se perciben como conductas que no se consideran normales o pensamientos y sentimientos no especificados o desagradables; se hace referencia a que el malestar psicológico es producto de la interacción cotidiana en prisión. En este mismo apartado aparecen percepciones negativas frente al tratamiento con medicación.

Es claro que los síntomas de estrés, depresión y malestar psicológico, desde la psicología, en primera instancia se pueden observar, en este contexto, como reacciones adaptativas al medio y a su condición de internamiento. No obstante, para que sean consideradas como psicopatológicas, es necesario contrastarlas con el factor tiempo, ya que se espera que a lo largo de la condena, estas sean "estabilizadas". Al respecto, en su estudio, Ruiz (2007) indica que se presentó una mayor sintomatología emocional asociada a llevar menor tiempo en prisión, enfrentar situaciones estresantes cotidianas y tener poco apoyo social. 


\section{Necesidad de atención integral}

El Código Penitenciario y Carcelario prevé que tanto la atención social como el tratamiento penitenciario deben responder a necesidades específicas de los internos. En este ejercicio investigativo, se encontraron una serie de carencias asociadas a aspectos psicológicos, físicos y de hábitos saludables, en correspondencia directa a las exigencias de atención por parte de los AMPL.

La solicitud de atención psicológica solo tiene lugar cuando se ve como necesaria, en situaciones límite como en el momento de ingreso al establecimiento o cuando hay un deterioro visible en el porte o la actitud del individuo. De otro lado, un Estado consciente de autocuidado atañe a la exigencia del desarrollo de actividades que impliquen movimiento físico, como un elemento primordial para disminuir los efectos del confinamiento. Seguidamente, los AMPL no tienen la posibilidad de modificar la alimentación de acuerdo con sus necesidades alimentarias específicas, y esto parece conjugarse con hábitos que son desfavorables para la salud. En algunos casos, da la impresión que viven una serie de restricciones alimenticias en la semana que son satisfechas en exceso los días de visita (tabla 22). En general, las 3 particularidades que se mencionan a continuación tienen un punto de encuentro: la ausencia de actividades de tipo preventivo para la salud mental y física de los AMPL.

Tabla 22. Referencias sobre necesidades de los adultos mayores privados de libertad

\begin{tabular}{|c|c|c|}
\hline $\begin{array}{l}\text { Referencias a la necesidad de } \\
\text { atención psicológica }\end{array}$ & $\begin{array}{c}\text { Referencias a la necesidad } \\
\text { de actividades de promoción } \\
\text { de la salud física }\end{array}$ & cesidades \\
\hline $\begin{array}{l}\text { "Es la parte primordial que se } \\
\text { le debe trabajar a un interno } \\
\text { cuando llega a un sitio de } \\
\text { estos, esa es la parte primor- } \\
\text { dial, la parte psicológica". } \\
\text { "No hay nada de eso acá". }\end{array}$ & $\begin{array}{l}\text { "Es que no existe de hacer } \\
\text { un ejercicio, de hacer algo } \\
\text { para el AM, nosotros que } \\
\text { necesitamos hacer ejerci- } \\
\text { cio, moverse uno el cuerpo } \\
\text { de uno". }\end{array}$ & $\begin{array}{l}\text { "Aquí la única forma para } \\
\text { que lo saquen al médico rápi- } \\
\text { do es viéndolo a uno cortán- } \\
\text { dose, aunque yo no lo haría } \\
\text { ni a palo". }\end{array}$ \\
\hline
\end{tabular}




\begin{tabular}{|l|l|l|}
\hline $\begin{array}{c}\text { Referencias a la necesidad de } \\
\text { atención psicológica }\end{array}$ & $\begin{array}{c}\text { Referencias a la necesidad } \\
\text { de actividades de promoción } \\
\text { de la salud física }\end{array}$ & \multicolumn{1}{|c|}{ Otras necesidades } \\
\hline $\begin{array}{l}\text { "Mantiene con fiebre alta y } \\
\text { sicológicamente destruido } \\
\text { y hemos propuesto que este } \\
\text { señor necesita tratamiento } \\
\text { sicológico y clínico especial". }\end{array}$ & $\begin{array}{l}\text { y se afecta la movilidad". } \\
\text { co, hos cambiado el físi- }\end{array}$ & $\begin{array}{l}\text { "Él es hipertenso, come mu- } \\
\text { cho, le gusta mucho la grasa, } \\
\text { esas carnes gordas, el domin- } \\
\text { go 3 o 4 caseros". }\end{array}$ \\
\hline & $\begin{array}{l}\text { "Acá es acumulación de gra- } \\
\text { sas. Le dan a uno una sopas } \\
\text { que lo único que le echan es } \\
\text { grasa". }\end{array}$ \\
\hline
\end{tabular}

Fuente: grupos focales en los EPC visitados.

\section{Percepción de cambios experimentados en prisión}

Los internos manifestaron cambios que se han dado durante su estadía en prisión y no todos implican desmejoramiento, sino que están relacionados con lo que Paulus, Dzindolet y Valverde (citados en Becerra, Torres \& Ruiz, 2008) han descrito como prisionización, en relación con la adopción de modos y costumbres propias del ambiente carcelario como forma de adaptación a este.

$\mathrm{Al}$ respecto, se encontró que los internos resaltan, en su mayoría, cambios que favorecen la actividad intelectual, como el aumento de la lectura y la escritura, así como acciones direccionadas al autoconocimiento. En complemento, aparece la mención de experiencias de trasformación espiritual, en las que se asocia y visibiliza un estado de libertad, inclusive desde la apariencia física. Por otro lado, destacan cambios desfavorables en lo físico, relacionados con la alimentación y las condiciones ambientales como el hacinamiento. Finalmente, solo un participante manifestó que no percibe cambios en sus comportamientos a lo largo del tiempo: "En cuanto a mi comportamiento, es el mismo, no tengo nada que decir, ha sido el mismo en los 40 años" (grupo focal, EPMSC Bucaramanga, julio de 2013). Como ejemplo de lo anterior, se da a conocer la tabla 23. 
Tabla 23. Percepciones de cambios experimentados en prisión por los adultos mayores privados de la libertad

\begin{tabular}{|c|c|c|}
\hline Psicológicos & Fisiológicos & Espirituales \\
\hline $\begin{array}{l}\text { "Yo he aprendido aquí co- } \\
\text { nocimientos mejores, mo- } \\
\text { dos de vivir, he aprendido } \\
\text { a comportarme como un } \\
\text { ser humano con capacidad } \\
\text { intelectual". }\end{array}$ & $\begin{array}{l}\text { "Cuando yo llegué aquí, yo } \\
\text { no podía leer bien y de un } \\
\text { momento a otro ya puedo } \\
\text { leer muy bien, pero de cerca. } \\
\text { Mejoré de la vista". }\end{array}$ & $\begin{array}{l}\text { "Cuando yo llegué aquí todo } \\
\text { se me derrumbó, me dije: 'yo } \\
\text { de esta no me salgo, si yo } \\
\text { no me muero, no aguanto', } \\
\text { yo le pedí tanto al señor de } \\
\text { rodillas y aquí estoy. Que día } \\
\text { vino un señor y me dijo: 'nos } \\
\text { vemos afuera' y yo le dije: } \\
\text { 'no señor, yo soy un inter- } \\
\text { no' y el señor me dijo: 'pero } \\
\text { usted parece que estuviera } \\
\text { libre' 'yo me siento libre, } \\
\text { conocí a cristo". }\end{array}$ \\
\hline $\begin{array}{l}\text { "Yo sentí el cambio, pero } \\
\text { viéndome en la oportuni- } \\
\text { dad de tener más tiempo de } \\
\text { escribir, de leer, para hacer } \\
\text { reflexiones. Se aprenden co- } \\
\text { sas para compartir con otros } \\
\text { allá afuera como referente } \\
\text { para que aprendan de algo". }\end{array}$ & $\begin{array}{l}\text { "Uno comía verduras, proteí- } \\
\text { nas, cosas que alimentan el } \\
\text { cerebro, entonces al no tener } \\
\text { uno una buena alimentación } \\
\text { no va tener una buena salud". }\end{array}$ & $\begin{array}{l}\text { "Si, lógico que sí, sobre todo } \\
\text { espiritualmente". }\end{array}$ \\
\hline $\begin{array}{l}\text { "Hay algo que se llama des- } \\
\text { pertar de la conciencia y eso } \\
\text { es un cambio muy impor- } \\
\text { tante". }\end{array}$ & $\begin{array}{l}\text { "Yo tengo osteoporosis y se } \\
\text { me ha complicado mucho la } \\
\text { situación". }\end{array}$ & \\
\hline $\begin{array}{l}\text { "Los cambios que he visto } \\
\text { son al revés, yo me sabía las } \\
\text { tablas al derecho y al revés, } \\
\text { ahora ya no coordino, he } \\
\text { perdido mucho la mente". }\end{array}$ & $\begin{array}{l}\text { "Del hacinamiento, por el } \\
\text { contacto con las demás per- } \\
\text { sonas, con los virus y las bac- } \\
\text { terias se vuelve uno más pro- } \\
\text { penso a perder defensas, en- } \\
\text { tonces cualquier enfermedad } \\
\text { lo ataca a uno más rápido". }\end{array}$ & \\
\hline
\end{tabular}

Fuente: grupos focales en los EPC visitados. 
De manera sucinta, se puede decir que existe un interés por parte de los AMPL por mostrar las necesidades que tienen con respecto a la atención en salud. Las enfermedades que asocian a su estancia en prisión son las mismas que sufren los AM en general, por lo que se confirma que la vejez se asocia a la enfermedad y, al parecer, el mal estado de salud en la cárcel aumenta por las condiciones de habitabilidad, la dificultad para el acceso a los servicios médicos y los tratamientos que se necesitan.

En cuanto al ajuste psicológico, producto de las realidades percibidas en prisión, se encuentra que el estrés, la depresión y la sintomatología psicológica son identificados por los AMPL como las principales afectaciones experimentadas. A partir de esta categorización, se analizan afirmaciones que establecen una relación causal entre estrés y situaciones propias de las dinámicas en los EPC como los horarios, la alimentación, el hacinamiento, entre otras. Entre tanto, la depresión se asocia con sentimientos generados por el alejamiento de las personas significativas, el rompimiento de relaciones o los problemas personales. No obstante, al hablar de los cambios en prisión, predomina una percepción favorable de estos, que dista de la adopción de costumbres carcelarias enmarcadas en la prisionización, y se enfocan en actividades de producción intelectual como la lectura, la escritura y otras orientadas al autoconocimiento; por lo anterior, es comprensible que siendo los síntomas de estrés y depresión constantes en la estadía en el establecimiento, solo perciben la necesidad de atención psicológica para eventos de crisis o como una forma de superar estados de estrés asociados a momentos fundamentales como el ingreso a la prisión y los cambios experimentados en todas las áreas de ajuste durante los primeros meses del internamiento.

\section{Condiciones sociales}

A continuación se describen cada uno de los elementos emergentes en las categorías sociológicas planteadas para el estudio: autopercepción del delincuente, estigmatización, expectativas de vida, imaginario social del delincuente, red de apoyo, solidaridad, asistencia social, aprendizajes 
en prisión, aspectos sociales de los delitos sexuales, espiritualidad, familia y significado otorgado a la prisión.

\section{Autopercepción del delincuente}

La autopercepción del delincuente se define en este estudio como la forma en que los AMPL entienden y conciben las personas que cometen un delito o que representan riesgo y peligro para la sociedad. Aunque en los grupos focales no se realizó una pregunta concreta sobre qué o quién es un delincuente, fue común encontrar en las respuestas a otras preguntas referencias a lo que debe y no debe considerarse como delincuencia. De esta manera, emergen los conceptos que se ilustran en la tabla 24.

Tabla 24. Aspectos asociados a la categoría autopercepción del delincuente

\begin{tabular}{|l|l|}
\hline \multicolumn{1}{|c|}{ Categoría } & \multicolumn{1}{c|}{ Aspectos asociados } \\
\hline \multirow{4}{*}{$\begin{array}{l}\text { Autopercepción } \\
\text { del delincuente }\end{array}$} & Justicia. \\
\cline { 2 - 2 } & Estigmatización. \\
\cline { 2 - 2 } & Juventud. \\
\cline { 2 - 2 } & Reincidencia. \\
\cline { 2 - 2 } & Problemática social. \\
\cline { 2 - 2 } & Gravedad del delito. \\
\cline { 2 - 2 } & Autorreconocimiento. \\
\hline
\end{tabular}

Fuente: elaboración propia.

\section{Justicia}

En cuanto a la justicia, muchos internos consideran que sus derechos han sido vulnerados, al ser condenados por un sistema de justicia que es esencialmente injusto. Se menciona, en varias oportunidades, el hecho de que hay personas que deberían estar presas y no lo están o que van a salir de prisión por beneficios que no merecen; al respecto, es recurrente la alusión a paramilitares y políticos corruptos: "Aquí la justicia es muy diferente para 
cada persona, es solo para los privilegiados de este país que matan y están allá asesorando al Gobierno" (grupo focal, EPMSC Cali, julio de 2013) . Igualmente, se afirma que delincuente no es el que delinque, sino el que se deja coger o al que se le imputa el delito. Se hace una mención especial al tema de los delitos sexuales, que son imputados en gran medida a los AM, y cuya sanción es percibida en muchos casos como injusta.

\section{Estigmatización}

Frente a la estigmatización, algunos participantes reconocen que así como ellos son estigmatizados por la sociedad, que construye falsos mitos a su alrededor, también ellos tenían una percepción negativa de las PPL antes de ingresar a prisión: "Uno tenía esa opinión de que el que iba a la cárcel era porque era muy malo" (grupo focal de mujeres, Complejo Carcelario y Penitenciario de Jamundí, julio de 2013); en ese sentido, la autopercepción del delincuente varía con el tiempo, las coyunturas y la propia experiencia. El hecho de estar en prisión no significa necesariamente ser un delincuente y el hecho de no estarlo no quiere decir no serlo.

\section{Juventud}

Por otro lado, la mayoría de los participantes establecen un vínculo entre juventud y delincuencia, lo que nuevamente demuestra que ellos no se consideran delincuentes. Se mencionan factores que favorecen este vínculo como las pautas de crianza, las necesidades, el abandono de los padres, la educación, las malas compañías y, sobre todo, la drogadicción. Para los participantes, es poco probable que un AM reincida, pero es muy probable que un joven que ha estado en prisión vuelva a estarlo en un futuro. De esta manera, la reincidencia es atribuida a los jóvenes, en mayor medida: "Lo que uno ve es mucho joven delincuente, en las cárceles hay un gran acumulado de jóvenes que no están trabajando, son delincuentes y eso es mano de obra perdida [...] y es muy difícil que se rehabiliten, porque esa población es muy joven. Hay personas de 29 años y tienen hasta cuatro entradas y ya tienen hijos y están por las mismas" (grupo focal, EPMSC Cali, julio de 2013). 
Esta relación que se establece entre juventud y delito es muy interesante para esta investigación pues, en términos de identidad, representa lo que nuestra población no es o no reconoce ser, ni en términos de grupo etario ni en términos de comisión del delito. Es importante reiterar, en este punto, la constante recurrencia a la "peligrosidad", que es imputada a la juventud y que se desliga del concepto de AM.

\section{Reincidencia}

La reincidencia también es atribuida a los jóvenes y los delincuentes. Se hace referencia permanente a los internos que tienen más de una entrada a prisión y que, por tanto, tienen una carrera delictiva. "Nosotros somos delincuentes, aunque en la calle no fuimos delincuentes, cometimos un error, más no hicimos carrera de delincuentes como hay muchos aquî" (grupo focal, Complejo Carcelario y Penitenciario de Jamundí, julio de 2013).

\section{Problemática social}

Este aspecto emergió en varias de las categorías que se establecieron, en diferentes contextos y como respuesta a lo indagado por los investigadores. Para algunos participantes, el problema no es que haya delincuentes, se reconoce que hay delincuentes y que muchos están en prisión, la cuestión radica en por qué los hay, por qué cada vez hay más y por qué hay tanta gente en prisión. "Hay una problemática, hay una superpoblación carcelaria, tenemos delincuentes en todas las cárceles y esto está reventado, hay una problemática social" (grupo focal, EPMSC Cali, julio de 2013).

\section{Gravedad del delito}

En materia de gravedad del delito, es muy recurrente, en los grupos focales, la referencia a internos que han cometido delitos graves, a gente que delinque y merece la prisión, y a la maldad. Así, se establece una especie de rango de tolerancia frente a los delitos, que en algunos casos son justificables, razonables o se pueden minimizar, mientras que hay otros sobre 
los que debe caer el peso de la ley y la sanción social. Esta relativización del delito, por lo general, apunta a que los punibles y cometidos en carne propia no contemplan una gravedad considerable, por lo que podrían ser tratados con otros mecanismos diferentes: "Hay gente que mata, pero ellos son los buenos y los 'violos' los malos" (grupo focal, Complejo Carcelario y Penitenciario de Jamundí, julio de 2013); esta situación nos lleva a pensar que al interior de la prisión también hay estigmatización por parte de los mismos internos frente al tipo de delito que se comete, la sanción y lo que se considera bueno o malo.

\section{Autorreconocimiento}

Con respecto al autorreconocimiento como delincuente, aunque son pocos los casos, algunos participantes aceptan la comisión del delito, demuestran arrepentimiento y reconocen haber violentado derechos ajenos con su accionar: "Cuando viajé con eso, sabía que no lo estaba haciendo bien, pero yo solo pensaba que era para el sustento de mi familia, pero de pronto no miré el daño que podía hacerle a otros. Ya con el tiempo va uno reflexionando y piensa... aunque le duela estar acá" (grupo focal de mujeres, Complejo Carcelario y Penitenciario de Jamundí, julio de 2013).

De esta manera, se construye dentro de los AMPL un imaginario de delincuente al que se le imputan prácticas, condicionantes y características específicas, que en general difieren de los constructos que tienen sobre sí mismos. No obstante, en algunos casos hay un reconocimiento de la comisión del delito y sus consecuencias.

\section{Estigmatización}

La categoría estigmatización se define, en este estudio, en concordancia con el planteamiento de Goffman (2006), como la serie de atributos desacreditadores impuestos a ciertas personas y que determinan las actitudes de los demás frente ellas. Se pueden mencionar 3 tipos de estigmas, notoriamente diferentes. En primer lugar, las abominaciones del cuerpo -las distintas 
deformidades físicas. Luego, los defectos de carácter del individuo que se perciben como falta de voluntad, pasiones tiránicas o antinaturales, creencias rígidas y falsas, deshonestidad; se infieren de conocidos informes sobre, por ejemplo, perturbaciones mentales, reclusiones, adicciones a las drogas, alcoholismo, homosexualidad, desempleo, intentos de suicidio y conductas políticas extremistas. Por último, existen los estigmas de raza, nación y religión, susceptibles de ser transmitidos por herencia y contaminar por igual a todos los miembros de una familia (Goffman, 2006, p. 14).

De esta manera, los estigmas marginan a quienes los poseen y los someten a duras prácticas de discriminación. Para diferenciar a quienes no poseen un estigma de quienes sí lo poseen, Goffman (2006) utiliza el término de los normales; por ende, un estigmatizado es lo mismo que un anormal. En el ámbito carcelario, se encuentran todo tipo de estigmas, relacionados con conductas reprochables, prácticas inaceptables, marcas corporales y aspectos culturales. Como veremos más adelante, muchos de estos estigmas también pueden extrapolarse a las familias de los internos, afectando de manera negativa diferentes aspectos de su vida (social, laboral, económico, etc.). De la información obtenida en campo se identificaron los siguientes aspectos asociados a la categoría estigmatización (tabla 25).

Tabla 25. Aspectos asociados a la categoría estigmatización

\begin{tabular}{|l|l|}
\hline \multicolumn{1}{|c|}{ Categoría } & \multicolumn{1}{c|}{ Aspectos asociados } \\
\hline \multirow{4}{*}{ Estigmatización } & Consecuencias para la familia. \\
\cline { 2 - 2 } & Actitud de la sociedad. \\
\cline { 2 - 2 } & Actitud de la familia. \\
\cline { 2 - 2 } & Homogeneización. \\
\cline { 2 - 2 } & Desconocimiento de la problemática social. \\
\hline
\end{tabular}

Fuente: elaboración propia.

\section{Consecuencias para la familia}

En cuanto a las consecuencias para la familia, en lo que se refiere a la estigmatización, la mayoría de AMPL afirman que muchos de sus familiares han 
perdido el trabajo u oportunidades laborales, que son víctimas de matoneo en el colegio y que reciben afrentas por el hecho de tener un familiar en prisión: "Mi hijo está en undécimo, ya terminaba este año y no volvió al colegio militar porque los compañeritos le decían 'qué va hermano... si usted tiene a su mamá en una cárcel”" (grupo focal de mujeres, Reclusión de Mujeres de Medellín, julio de 2013); de acuerdo con estos testimonios, el estigma es más fuerte en las mujeres que en los hombres, y pesa también más en sus familias. Las consecuencias de transferir estos estigmas a la familia son innumerables y, según los investigadores, estas acentúan problemáticas sociales y perpetúan círculos de pobreza.

\section{Actitud de la sociedad y de la familia}

La actitud de la sociedad, según los participantes, es extremadamente negativa; muchos reconocen la presencia de estigmas o etiquetas como "mata bruja" o "inepto social"; se afirma que el hecho de haber estado en prisión es algo que marca para toda la vida y limita las posibilidades de existencia, pues las oportunidades para reestablecer una vida social, laboral o económica son prácticamente inexistentes. En ocasiones, la actitud de la familia frente al AMPL también es negativa y, aunque no es el común de los casos, algunos internos afirman que sus familias se sienten avergonzadas de ellos, los niegan, los ocultan y los abandonan emocionalmente.

\section{Homogeneización}

Ligado al anterior aspecto, aparece el concepto de homogenización o generalización del AMPL; en este caso, independientemente de la historia de vida del sujeto, el delito cometido o las condiciones que lo llevaron a estar en prisión es tratado y concebido de la misma manera por la sociedad: como un delincuente y una amenaza: "Se nos estigmatiza y se nos generaliza como si todos fuéramos iguales, entonces nos califican como lo peor, como si todos fuéramos lo peor" (grupo focal, EPMSC Cali, julio de 2013); esta situación resulta ser bastante incómoda para la mayoría de los internos, quienes re- 
currentemente demuestran su inconformidad y desacuerdo; recalcan la individualidad de cada persona y las características particulares en cada caso.

\section{Desconocimiento de la problemática social}

Un aspecto que resulta muy interesante y que aparece en la información recabada en campo es el reconocimiento de que la estigmatización del AMPL puede obedecer al desconocimiento de la problemática social, pues se señala y se juzga sin analizar los contextos, las realidades, las coyunturas o las necesidades; al respecto, se afirma que "la reingeniería se debe dar en conjunto con la sociedad, el hecho de que se cometa un delito, no quiere decir que uno no se pueda reintegrar a la sociedad, es ahí donde la sociedad debe entender que es un problema social, producto de la desigualdad" (grupo focal, EPMSC Cali, julio de 2013).

\section{Expectativas de vida}

La categoría denominada expectativas de vida es definida, en este estudio, como lo que esperan hacer, tener o ser los AMPL en los años que les restan de vida. En este punto, se identificaron 12 subcategorías asociadas (tabla 26)

Tabla 26. Aspectos asociados a la categoría expectativas de vida

\begin{tabular}{|l|l|}
\hline \multicolumn{1}{|c|}{ Categoría } & \multicolumn{1}{c|}{ Aspectos asociados } \\
\hline \multirow{5}{*}{ Expectativas de vida } & Pensión. \\
\cline { 2 - 2 } & Trabajo. \\
\cline { 2 - 2 } & Segunda oportunidad de la sociedad. \\
\cline { 2 - 2 } & Familia. \\
\cline { 2 - 2 } & Libertad. \\
\cline { 2 - 2 } & Espiritualidad. \\
\cline { 2 - 2 } & Trabajo comunitario. \\
\cline { 2 - 2 } & Sociabilidad. \\
\hline
\end{tabular}




\begin{tabular}{|l|l|}
\hline \multicolumn{1}{|c|}{ Categoría } & \multicolumn{1}{c|}{ Aspectos asociados } \\
\hline \multirow{4}{*}{ Expectativas de vida } & Aplicar lo aprendido en prisión. \\
\cline { 2 - 2 } & No salir. \\
\cline { 2 - 2 } & Cambiar. \\
\cline { 2 - 2 } & Asistencia del Estado. \\
\cline { 2 - 2 } & Muerte. \\
\hline
\end{tabular}

Fuente: elaboración propia.

\section{Pensión}

Aunque la mayoría de las respuestas se concentran en los aspectos de trabajo y familia, es importante mencionar, también, las demás opiniones al respecto. Por ejemplo, una sola persona manifestó su interés por salir a disfrutar de su pensión, lo cual llama poderosamente la atención, tratándose de un AM que, al menos, en teoría debería tener acceso a este componente de la seguridad social. El hecho de que nadie más mencione este derecho se puede deber a que no todos pueden ejercerlo, bien sea porque siempre han estado en el ámbito de la informalidad, porque desde la cárcel no es posible seguir trabajando ni cotizando o, simplemente, porque se priorizan otros aspectos.

\section{Trabajo}

El trabajo, en cambio, se consolida como la expectativa de vida más mencionada; la mayoría de los participantes afirman querer seguir trabajando, retomar las actividades que realizaban antes del ingreso a la prisión, aportarle económicamente a la familia y conseguir el sustento para seguir viviendo: "Yo sí verdaderamente quiero salir de acá e irme a mi trabajito, porque andar con los hijos ya poco... ellos tienen su obligación y todo para que llegue uno a molestar. Yo lo que quiero es seguir trabajando hasta que sea capaz, hasta ya lo último" (grupo focal, EPMSC Bucaramanga, julio de 2013). Esta frase es muy ilustrativa pues muestra, por un lado, la necesidad de los AM de seguir trabajando para sobrevivir; por otro, el alejamiento de 
la familia y el peso de haber estado ausente, y, por último, el imaginario negativo de que los AM son un estorbo. Esta intención de seguir trabajando también es compatible con algunas sociedades antiguas, en las que la edad era un factor determinante de retiro, solo en el sentido en que no permitía la productividad. $\mathrm{Al}$ respecto:

Si bien se consideraba viejo a quien rebasaba bastante la edad normal de morirse, no se les daba un trato especial mientras fueran productivos. No había jubilación ni retiro, desde luego. Era el cuerpo lo que se retiraba. No había en cierto modo, una vejez social, sino solo una vejez biológica que tenía repercusiones sociales. (Alba, 1992, p. 18)

Así pues, el AMPL considera que está en capacidad física y mental para seguir trabajando y ubica este aspecto de su vida dentro de sus expectativas más importantes. Muchos de los participantes afirman haber trabajado toda su vida y no saber hacer otra cosa, por lo que es su única opción.

\section{Segunda oportunidad de la sociedad}

Resulta muy interesante encontrar una expectativa de vida que hace referencia a una segunda oportunidad de la sociedad; esta oportunidad se solicita en términos tanto de la edad como del delito: "Lo ven a uno viejo y creen que uno no puede salir, pero todavía nosotros somos útiles como para la sociedad, como para nosotros mismos, entonces que den esa oportunidad... que porque estamos viejos... pero no, nosotros tenemos ganas todavía, nos sentimos con fuerzas para empujar, entonces esperamos que nos den esa oportunidad" (grupo focal, Complejo Penitenciario y Carcelario de Ibagué, junio de 2013).

En diferentes referencias, se hace mención a una segunda oportunidad también para aludir a la posibilidad de cumplir una pena alternativa a la prisión, por lo general se solicita la prisión domiciliaria, el brazalete electrónico o la libertad condicional, abogando a los supuestos de la baja peligrosidad que representa un AM para la sociedad y la resocialización que viene implícita con muchos años de privación de la libertad y tratamiento. 


\section{Familia}

La familia es la expectativa más nombrada por los AMP; muchos añoran el calor del hogar, otros quieren salir para retomar las responsabilidades que abandonaron por el hecho de ingresar a prisión, muchos quieren recuperar el tiempo perdido, conocer familiares que no han visto nunca y otros desean cumplir una labor preventiva con sus familias, a través de sus testimonios e historias de vida: "Quiero llevarle, enseñarle a mis nietos y nietas todo lo que he aprendido, decirles que esta no es una vida adecuada" (grupo focal, EPMSC Bucaramanga, julio de 2013). Se reitera que la familia está presente en todos los ámbitos del AMPL; en la mayoría de los casos, esta se consolida como añoranza, apoyo, prioridad, culpabilidad, angustia o ausencia, todo depende del escenario y, por supuesto, de las variables que afectan cada caso en particular.

\section{Libertad}

Junto con la familia y el trabajo, la libertad es la expectativa de vida por excelencia; de hecho, ninguna de las dos es posible sin la libertad: "Yo creo que el principal sueño de todos es salir de acá" (grupo focal, Complejo Carcelario y Penitenciario Metropolitano de Bogotá, julio de 2013). La libertad es, pues, el prerrequisito para el cumplimiento de cualquier expectativa planteada; sin ella, todo es un sueño y una vana ilusión.

\section{Espiritualidad}

La espiritualidad se consolida como respuesta a muchos de los retos planteados por la prisión; es común, entonces, encontrar discursos que hacen referencia a varias religiones o dioses o a diferentes prácticas espirituales; muchos internos afirman haber encontrado a Dios en la prisión, por lo que dedican mucho tiempo a la oración y la predicación: "Yo creo que lo que debo llevar afuera es lo que aprendí acá, llevar la palabra de Dios, mostrar lo grande y maravilloso de su obra, eso le aportaría yo a la sociedad, el mensaje de Dios" (grupo focal, EPMSC Cali, julio de 2013). Así, encontramos 
una relación entre esta categoría y las expectativas de vida, por un lado, $y$, por el otro, con las redes de apoyo institucional que comprenden, en su mayoría, organizaciones y grupos de carácter religioso.

\section{Trabajo comunitario}

Varios internos afirman que al salir de prisión, quisieran realizar una especie de trabajo comunitario dirigido en ocasiones a PPL, pues son conscientes del apoyo y la compañía que requiere esta población, al haber sido parte de esta. Algunos participantes afirman que actualmente hay personas que realizan esta labor; quienes después de haber recuperado su libertad, realizan visitas y ejercen prácticas solidarias con las personas que siguen en prisión. Este aspecto es muy importante pues se cruza con la categoría denominada red de apoyo. Otros participantes afirman que quieren formar una institución de prevención o continuar con trabajos de tipo social que realizaban antes de perder su libertad.

\section{Sociabilidad}

En pocos casos se menciona el interés por recuperar la sociabilidad; es decir, compartir espacios y reuniones con amigos. Se menciona esta subcategoría porque emerge de la información recolectada, aunque no es una respuesta muy recurrente dentro de los participantes.

\section{Aplicar lo aprendido en la prisión}

Es muy recurrente, en cambio, encontrar dentro de las expectativas de los AMPL querer aplicar lo aprendido en la prisión, una vez obtengan su libertad. La mayoría de los participantes valoran mucho los conocimientos que adquieren en el área de educación y en los talleres; por ello, es muy común encontrar en las respuestas, sobre todo de las mujeres, un interés por generar emprendimientos y microempresas asociados a las labores que se desarrollan en la prisión: "A mí me gustaría poder salir y tener un cacharrito pa' vender pulseras y las cosas que he aprendido aquî" (grupo focal de mujeres, Complejo 
Carcelario y Penitenciario de Jamundí, julio de 2013). Este aspecto está relacionado con un hallazgo importante en materia de tratamiento que se abordará con mayor profundidad posteriormente, y que hace referencia a las oportunidades de aprendizaje fuera y dentro de la prisión, pues muchos de los participantes afirman que no sabían leer y escribir antes de ingresar a la prisión, y que fue allí donde aprendieron y, además, obtuvieron otros conocimientos a los que no habrían podido acceder fuera de la cárcel.

\section{No querer salir}

Este aspecto también se puede relacionar con lo manifestado por algunos pocos participantes, quienes afirman que no quieren salir de la prisión porque no cuentan con ninguna posibilidad de supervivencia afuera ni con nadie que los esté esperando: "Yo salgo y dónde voy a almorzar, dónde voy a vivir... ya con la edad que tengo, imagínese, yo salgo de ochenta y pico de años, tengo 72, me faltan 12 años todavía y salgo, ipara dónde salgo?, mejor evito eso" (grupo focal, EPMSC Medellín, julio de 2013).

\section{Muerte y cambio}

En este sentido, también se encontraron respuestas referentes a la muerte como única expectativa, como lo único a lo que se puede aspirar. Estos testimonios evidencian otra de las categorías que emerge recurrentemente de la información recolectada: la problemática social. Otra expectativa es cambiar, es decir, dejar la delincuencia, los vicios y las prácticas que los llevaron a estar en prisión.

\section{Imaginario social del delincuente}

La categoría denominada imaginario social del delincuente se define como la representación o las representaciones que, según los internos, tiene la sociedad de las personas que han cometido un delito o que han estado en una prisión. Se identificaron cuatro aspectos relacionados que, cabe anotar, tienen una connotación negativa (tabla 27). 
Tabla 27. Aspectos asociados a la categoría imaginario social del delincuente

\begin{tabular}{|l|l|}
\hline \multicolumn{1}{|c|}{ Categoría } & \multicolumn{1}{c|}{ Aspectos asociados } \\
\hline \multirow{3}{*}{$\begin{array}{l}\text { Imaginario social del } \\
\text { delincuente }\end{array}$} & No aptitud para vivir en sociedad. \\
\cline { 2 - 2 } & Amenaza. \\
\cline { 2 - 2 } & Desprecio. \\
\cline { 2 - 2 } & Homogeneización. \\
\hline
\end{tabular}

Fuente: elaboración propia.

\section{No aptitud para vivir en sociedad}

Los AMPL afirman que son considerados no aptos para vivir en sociedad; este aspecto se vincula estrechamente con la categoría estigmatización, pues apunta a homogeneizar a las PPL, independientemente de los móviles que llevaron a la comisión del delito, la historia de vida, las coyunturas y los contextos: "De pronto no todo el mundo delinque, pero no estamos ajenos de caer en esto... pero generalizan con el único hecho de que el que cae en la cárcel no es apto para la sociedad" (grupo focal, Complejo penitenciario y Carcelario de Ibagué, junio de 2013).

\section{Amenaza}

En ese sentido, también es recurrente generalizar el hecho de que las PPL representan una amenaza para el resto de la sociedad; es decir, para los individuos "normales". La pena, entonces, sigue cumpliendo una doble finalidad: por un lado, castiga al delincuente, y, por otro, lo somete a un tratamiento que lo hará mejor persona, que le permitirá vivir en sociedad, reduciendo o anulando su peligrosidad.

\section{Desprecio y homogeneización}

Como sujetos peligrosos y no aptos para vivir en comunidad, los privados de la libertad inspiran desprecio y son considerados como la escoria de la sociedad; todos son iguales, todos son delincuentes; hay, pues, un fuerte 
componente de homogeneización hacia el infractor. Frente a esta posición de la sociedad, los AMPL afirman que hay una gran inconciencia del común de la gente, que no se detiene a analizar las circunstancias y realidades que influyen, y enfatizan, además, en que todos sin excepción somos potenciales delincuentes.

\section{Red de apoyo}

La categoría denominada red de apoyo es definida, en este estudio, como el conjunto de instituciones, personas, grupos o instancias que brindan aportes materiales, emocionales o espirituales a las PPL, y que se consolidan como soporte y garante de necesidades. La familia, por supuesto, en la mayoría de los casos, representa el componente más fuerte de la red de apoyo de los AMPL, aunque también representa muchas otras cosas, por ello se analiza como categoría independiente. A la red de apoyo de los internos se relacionan los aspectos que se exponen en la tabla 28.

Tabla 28. Aspectos asociados a la categoría red de apoyo

\begin{tabular}{|l|l|}
\hline \multicolumn{1}{|c|}{ Categoría } & \multicolumn{1}{c|}{ Aspectos asociados } \\
\hline \multirow{4}{*}{ Red de apoyo } & Familia. \\
\cline { 2 - 2 } & Amigos. \\
\cline { 2 - 2 } & Acceso. \\
\cline { 2 - 2 } & Solidaridad. \\
\cline { 2 - 2 } & Estrategias al interior del penal. \\
\cline { 2 - 2 } & Convenios interinstitucionales. \\
\cline { 2 - 2 } & Eventos especiales. \\
\hline
\end{tabular}

Fuente: elaboración propia

\section{Familia}

Como se mencionó anteriormente, la familia se consolida como la base fundamental de la red de apoyo; de hecho, en la mayoría de los casos solo se 
cuenta con el apoyo de la familia para la solución de necesidades materiales y emocionales. Hay una valoración muy positiva por parte de los internos en lo que se refiere a la familia; sin embargo, también en ocasiones, se habla de abandono o desentendimiento. Algunos internos afirman que prefieren mantener a la familia alejada del ámbito penitenciario; por ello, solicitan a sus allegados no realizar visitas o comunicarse con ellos: "A mí no me gusta que mi familia, que mis hijos vengan, por la humillación que pasan afuera, las filas... yo les digo que vengan cada mes si pueden, pero no me gusta lo que pasan afuera" (grupo focal, EPMSC Cali, julio de 2013).

\section{Amigos}

Con respecto a los amigos, muchos internos aseguran que mantienen las relaciones con los amigos que tenían antes de ingresar a prisión; otros, por el contrario, denuncian un abandono de su parte, afirman que los amigos no existen en realidad, que las relaciones están mediadas por intereses y que las personas cambian por el tema de la prisión: "En la calle yo tenía amigos con los que viajaba, compartía... amigos entre comillas, porque caí acá y desaparecieron" (grupo focal, EPMSC Bucaramanga, julio de 2013). Esto se reafirma al observar lo encontrado en el total de la población, donde el mayor porcentaje de ese apoyo viene de la familia, en un $84 \%$, y solo el $1 \%$ se reconoce en los amigos (figura 27 ).

\section{Acceso}

Sin embargo, el abandono no solo responde a la decisión personal de los amigos, sino también a las dificultades de acceso que impone la prisión, en ese sentido se menciona la lejanía entre el EPC y el lugar de origen, las complicaciones de ingreso para las visitas y el límite de personas que puede recibir un interno en cada visita. 
Figura 27. Personas que brindan apoyo al adulto mayor privado de derechos

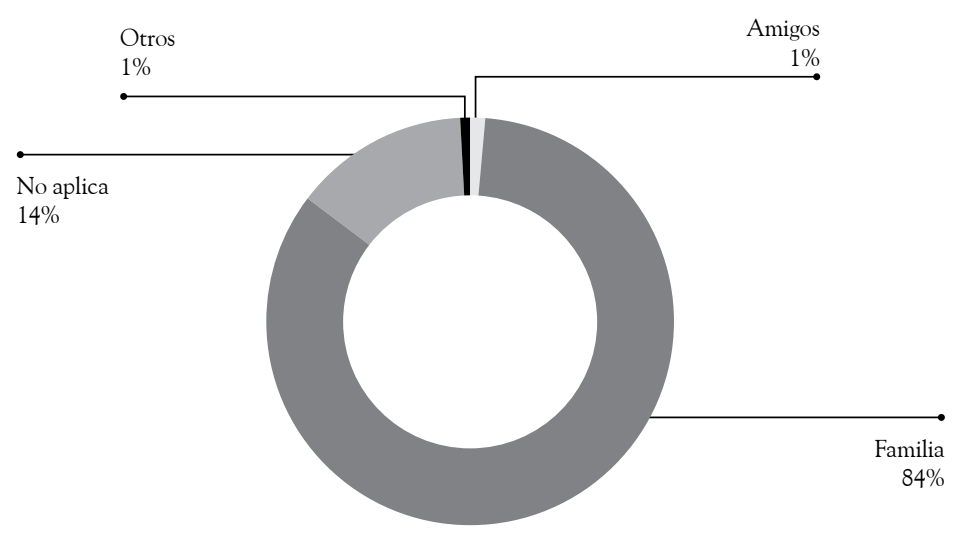

Fuente: Sisipec Web, censo condiciones excepcionales, 31 de julio de 2013. Cálculos de los autores.

\section{Solidaridad}

Los AMPL afirman que en ocasiones hay manifestaciones de solidaridad en el interior del penal y que es posible encontrar amigos en prisión; sin embargo, esta no es la constante, pues el ambiente de la prisión se torna hostil. Las buenas relaciones y el buen trato entre internos son más comunes en pabellones que albergan únicamente AM, así lo afirman los protagonistas. En este sentido, se considera vital mencionar la experiencia del pabellón de AMPL del EPMSC Cali (ERE), en el que se evidencian prácticas de autogestión y organización que han resultado muy funcionales y que permiten el fortalecimiento de la red de apoyo entre internos: "Todos aquí todos somos amigos, somos como una familia, aquí todos nos tratamos bien" (grupo focal, EPMSC Cali, julio de 2013).

\section{Estrategias en el interior del pena}

Las realidades vividas en prisión hacen que los internos desarrollen nuevas formas de comunicarse, de apoyarse y de sobrevivir, que se han denominado estrategias en el interior del penal. De esta manera, se fortalecen grupos, se generan identidades y se construyen códigos de comunicación que retan y superan las barreras del espacio y de la rutina. Un ejemplo muy interesante 
de esta situación es un lenguaje que se ha venido desarrollando en las cárceles que tienen pabellones tanto femeninos como masculinos, que consiste en comunicarse a través de símbolos realizados con las manos o incluso con implementos como toallas o telas. Los internos y el personal de guardia denominan a esta práctica "chateo", y a través de ella se relacionan hombres y mujeres a distancias muy largas y con toda clase de obstáculos. Al indagar en esta forma de comunicación, se encontró un interesante imaginario vinculado a los AMPL, quienes afirman que esas son cosas de muchachos y que ellos ya no están para enamorarse ni para aprender el sistema. "Ellos (los muchachos) crearon un lenguaje de señas, le dicen el e-mail" (grupo focal, Complejo Penitenciario y Carcelario de Ibagué, junio de 2013).

\section{Convenios interinstitucionales}

Los convenios interinstitucionales se consideran un aspecto fundamental de la red de apoyo, pues a través de ellos se subsanan algunas de las necesidades de los internos. Así, cada establecimiento gestiona convenios con universidades, ONG o entidades regionales, que prestan servicios de terapia ocupacional, fisioterapia, preescolar, psicología y capacitación, entre otros. No obstante, al indagar por las instituciones que hacen presencia en las cárceles, los internos solo reconocen las entidades de carácter religioso, que están presentes en todos los EPC. Al respecto, en las visitas realizadas a los diferentes EPC, se demuestra una presencia constante de diferentes iglesias y grupos religiosos, que se vincula directamente a la categoría espiritualidad que será abordada posteriormente.

\section{Eventos especiales}

Si bien no se consolidan como un componente fundamental de la red de apoyo, la celebración de fechas especiales en los establecimientos es muy importante para los internos, pues se rompe la rutina y se genera bienestar. Las fechas y eventos mencionados por los AMPL son la Virgen de las Mercedes, el Día de la Madre y la Navidad. Estas actividades concretas están 
vinculadas a otras tradiciones del ámbito carcelario, como los reinados o campeonatos, que se organizan por patios.

\section{Solidaridad}

Esta categoría es definida en nuestro caso como la presencia de unión y colaboración entre internos de un EPC, bien sea de manera permanente o coyuntural. De este modo, se identifican los siguientes 5 aspectos asociados (tabla 29).

Tabla 29. Aspectos asociados a la categoría solidaridad

\begin{tabular}{|l|l|}
\hline \multicolumn{1}{|c|}{ Categoría } & \multicolumn{1}{c|}{ Aspectos asociados } \\
\hline \multirow{4}{*}{ Solidaridad } & Apoyo. \\
\cline { 2 - 2 } & Autogestión. \\
\cline { 2 - 2 } & Espacios físicos. \\
\cline { 2 - 2 } & Capacitación. \\
\cline { 2 - 2 } & Oferta de servicios. \\
\hline
\end{tabular}

Fuente: elaboración propia.

\section{Apoyo}

La solidaridad inmediatamente se asocia al apoyo. Varios de los participantes afirman haber recibido o brindado manifestaciones o gestos de colaboración en el interior del penal, que se refieren sobre todo a buen trato y compañerismo. Es importante recalcar que no todos los AMPL hablan de solidaridad y que es más común encontrar referencia al concepto en los testimonios obtenidos en EPC, que cuentan con pabellones exclusivos para AM. El siguiente es un ejemplo de ello, que se encontró en el pabellón Años Dorados de la cárcel de mujeres de Jamundí: "Aquí la que sabe le enseña a la que no sabe..., una no tiene y la otra le da, así es con los útiles de aseo, con las cosas personales" (grupo focal de mujeres, Complejo Carcelario y Penitenciario de Jamundí, julio de 2013). Así pues, el enfoque diferencial por grupo etario favorece la convivencia y la colaboración entre internos. 


\section{Autogestión}

Igualmente, en este tipo de pabellones se identificaron algunas prácticas de autogestión que van enfocadas al bienestar de los internos. Así, en el pabellón de AMPL de EPMSC Cali, hay clases permanentes en diferentes materias que son impartidas por los mismos internos; asimismo, hay una oferta permanente de actividades lúdicas y manuales, hay ciertas normas que se consensan y se respetan e incluso se habla de un "plan padrino" que consiste en adquirir bienes y útiles personales y de aseo para los que no tienen la posibilidad de adquirirlos.

Desde luego, hay muchos gestos de solidaridad, incluso aquí tenemos un programa de padrinos, donde los que tienen más comodidad apadrinan a los que no tienen nada para comprar sus cosas de aseo, que antes lo hacía el INPEC, pero que debido a los problemas económicos que tiene (o no se sabe por qué) ya no dan nada. Entonces esa es la forma de ayudar a esas personas que no tienen nada, a través de ese apadrinamiento y que se ha comentado aquí con los mismos internos. Es una iniciativa de nosotros. (Grupo focal, EPMSC Cali, julio de 2013)

\section{Espacios físicos}

Los espacios físicos son determinantes para que la solidaridad sea posible en el ámbito penitenciario. Los pabellones exclusivos para AMPL manejan unas rutinas diferentes a las de los demás pabellones; en algunos casos, las celdas están abiertas y se puede ingresar y salir de ellas cuando se desee. Allí la convivencia es más sencilla, no son muy ruidosos y el consumo de sustancias psicoactivas es menor o inexistente. Por ello, los internos consideran estos pabellones como espacios realmente privilegiados, algunos incluso afirman que por sus características parecen más un hogar geriátrico que una prisión. En cualquier caso, el AMPL está sujeto a las características propias de una institución total. 
Una institución total puede definirse como un lugar de residencia y trabajo, donde un gran número de individuos en igual situación, aislados de la sociedad por un periodo apreciable de tiempo, comparten en su encierro una rutina diaria, administrada formalmente. Las cárceles sirven como ejemplo notorio, pero ha de advertirse que el mismo carácter intrínseco de prisión tienen otras instituciones, cuyos miembros no ha quebrantado ninguna ley. (Goffman, 2001, p. 13)

Junto a las cárceles encontramos entonces los internados y asilos de cualquier índole, que impliquen el aislamiento, la imposición de una normativa particular y el control del tiempo de los internos. El tema de las instituciones totalizantes, así definidas por Goffman (2001), es fundamental en este estudio, pues se consolidan como respuesta a muchas de las condiciones presentadas por nuestra población objeto. Por un lado, esta población enfrenta las vicisitudes de su edad, que muchas veces implica el cese de actividades económicas, el deterioro físico, que acarrea enfermedades y situaciones crónicas que pueden generar discapacidad. Es decir, la sociedad ha ofrecido históricamente pocas alternativas frente a las conductas o condiciones llamadas "anormales", que se restringen al encierro, el exilio o el exterminio. Se impone la institución totalizante como remedio a la discapacidad, la enfermedad, la ancianidad y el delito, condiciones que están presentes en mayor o menor grado en la población que nos ocupa.

\section{Capacitación}

Dentro de las manifestaciones de solidaridad en el interior del penal, se menciona la capacitación que muchos de los internos imparten a sus compañeros. De esta manera, se enseña a leer, a escribir, a realizar operaciones matemáticas, diversas materias y oficios.

A las que sabemos trabajar por ejemplo los químicos, para hacer el límpido, los ambientadores, la crema de manos, el champú, que nos den la oportunidad de enseñarle a las compañeras que lo quisieran aprender, porque yo eso lo propuse cuando estaba en el Buen Pastor y me dijeron 
que lo iban a estudiar, pero todavía estoy esperando la respuesta. (Grupo focal de mujeres, Complejo Carcelario y Penitenciario de Jamundí, julio de 2013)

En este testimonio particular, se menciona la iniciativa de una de las internas por compartir sus conocimientos en un área específica, que de ser tenida en cuenta podría resolver necesidades ocupacionales, laborales y de redención de las internas.

\section{Oferta de servicios}

En esta misma línea, algunos internos afirman ofrecer servicios en campos específicos, muchos de ellos tienen conocimientos en el área de la salud, por lo que realizan consultas médicas, recetan medicamentos y dan consejos sobre buenas prácticas; otros son verdaderos guías espirituales, que comparten la palabra y el testimonio con los internos interesados; hay también abogados que elaboran derechos de petición y memoriales. Así, no solo se comparten conocimientos, sino que estos se ponen al servicio de los compañeros que los requieren.

\section{Asistencia social}

Esta categoría se define en el presente estudio como la cantidad y el tipo de servicios que reciben los AMPL por parte de instituciones públicas, privadas u organizaciones civiles. Es muy importante mencionar que la categoría se declaró prácticamente desierta, ya que los internos en general no reconocen ningún tipo de asistencia que llegue a las cárceles; por el contrario, denuncian abandono, desinterés y olvido. Este hecho fue contrastado en campo, pues en todas las visitas realizadas solo fue posible identificar instituciones de carácter religioso que prestan sus servicios y que se mantienen constantes en todos los EPC. Efectivamente, se asocian solo 2 aspectos a esta categoría (tabla 30). 
Tabla 30. Aspectos asociados a la categoría asistencia social

\begin{tabular}{|c|l|}
\hline \multicolumn{1}{|c|}{ Categoría } & \multicolumn{1}{|c|}{ Aspectos asociados } \\
\hline \multirow{2}{*}{ Asistencia social } & Asistencia religiosa. \\
\cline { 2 - 2 } & Caridad. \\
\hline
\end{tabular}

Fuente: elaboración propia.

La presencia de las iglesias e instituciones religiosas es permanente e incluso hay días específicos de visita para cada religión. La caridad en cambio se vive de manera esporádica: "Sí, claro, por ejemplo en una fecha determinada viene una señora y trae pasabocas" (grupo focal, establecimiento EC Bogotá, La Modelo, mayo de 2013). Por lo demás, toda la atención que requieren los internos recae sobre la familia y por supuesto sobre el EPC.

\section{Aprendizajes en prisión}

En esta categoría se definen la experiencia, los conocimientos, las prácticas y los comportamientos adquiridos en prisión. La mayoría de las veces los AMPL hacen referencia a lo que han aprendido en las áreas educativa y laboral, pero también se encuentran referencias a aspectos de carácter espiritual y moral. Se asocian a la categoría 5 aspectos (tabla 31).

Tabla 31. Aspectos asociados a la categoría aprendizajes en prisión

\begin{tabular}{|l|l|}
\hline \multicolumn{1}{|c|}{ Categoría } & \multicolumn{1}{c|}{ Aspectos asociados } \\
\hline \multirow{4}{*}{ Aprendizajes en prisión } & Solidaridad. \\
\cline { 2 - 2 } & Tratamiento. \\
\cline { 2 - 2 } & Reflexión. \\
\cline { 2 - 2 } & Resocialización. \\
\cline { 2 - 2 } & Valorar. \\
\hline
\end{tabular}

Fuente: elaboración propia. 


\section{Solidaridad y tratamiento}

La estancia en prisión genera solidaridad, como se documentó anteriormente. Para algunos internos, esta solidaridad se consolida como aprendizaje, pues no es fácil conformar lazos solidarios en un espacio tan agresivo como el de la prisión. El tratamiento penitenciario que reciben los internos es valorado muy positivamente, y en ese sentido se asocia inmediatamente con los aprendizajes, con aquellos conocimientos y oficios que no se conocían antes de prisión. De allí que el tratamiento también se consolide como "expectativa de vida", toda vez que permite al individuo desempeñarse en áreas o tareas a las que antes no tenía acceso.

\section{Reflexión y resocialización}

Los aprendizajes también se asocian a la reflexión y la espiritualidad, los AMPL afirman llegar a conocerse mejor en prisión, acercarse más a Dios y a los seres queridos, pensar en el significado de la vida y ser conscientes de los propios errores, lo que conlleva un cambio interior. Este cambio, por supuesto, se asocia a la resocialización, y así, en ocasiones, el cumplimiento de la pena en prisión permite la corrección de conductas indeseadas o inapropiadas; por tanto, genera individuos aptos para vivir en sociedad. Sin embargo, esta resocialización no se adjudica al tratamiento penitenciario, sino a la decisión personal de cambio que surge como resultado de largas jornadas de reflexión y conocimiento de sí mismo.

\section{Valorar}

En ese sentido, también es frecuente escuchar entre los participantes que en prisión se aprende a valorar todo lo que se tenía afuera: la comida, la familia, los amigos, la libertad y el tiempo. "He aprendido a conocer más a la gente, a tratar, a ayudar, a ser solidario y he aprendido también de la gente, es una experiencia enriquecedora" (grupo focal, EPMSC Cali, julio de 2013). 


\section{Aspectos sociales de los delitos sexuales}

Esta categoría resulta fundamental para nuestro estudio pues representa la doble estigmatización de la que se hablaba anteriormente, que consolida al AMPL como un individuo dos veces "anormal", en razón de su edad y del delito. El imaginario que circunda al AM que comete un delito o al que se le imputa un delito es el delito sexual, de allí que tanto en el ámbito penitenciario como en otros espacios se afirme que "todo viejo es violo". Se identifican tres aspectos relacionados a esta categoría: estigmatización, justicia y falsa imputación.

Tabla 32. Aspectos asociados a la categoría aspectos sociales de los delitos sexuales

\begin{tabular}{|l|l|}
\hline \multicolumn{1}{|c|}{ Categoría } & \multicolumn{1}{c|}{ Aspectos asociados } \\
\hline \multirow{2}{*}{$\begin{array}{l}\text { Aspectos sociales de los } \\
\text { delitos sexuales }\end{array}$} & Estigmatización. \\
\cline { 2 - 2 } & Justicia. \\
\cline { 2 - 2 } & Falsa imputación. \\
\hline
\end{tabular}

Fuente: elaboración propia.

\section{Estigmatización}

En cuanto a la estigmatización, se afirma que "muchas personas creen que uno está en la cárcel es por violación de menores y eso no es así. Aquí los jóvenes le dicen a uno violo y no todos estamos aquí por eso, la mayoría de la juventud y la misma guardia creen que uno está aquí por eso" (grupo focal, Complejo Carcelario y Penitenciario de Jamundí, julio de 2013). Así, independientemente del caso y sin conocimiento de las situaciones particulares, se imputa en general al AMPL un delito de tipo sexual.

\section{Justicia y falsa imputación}

Algunos internos refirieron el tema de justicia, por considerar que la ley de delitos sexuales es poco clara y tiene un espectro tan amplio que cata- 
loga como delito algunos comportamientos o actitudes que no lo son. Esta disyuntiva es acorde con el tercer aspecto identificado, la falsa imputación, pues la mayoría de los AMPL a quienes se les imputan delitos sexuales afirman no haber cometido el delito y, por el contrario, suelen hablar de montajes o engaños. "Están condenando arbitraria y corruptamente a gente de la tercera edad que no ha cometido ninguna falta y la juzgan y la meten a esta cárcel por primera vez. Yo por ejemplo vengo de una familia muy decente, muy humilde y muy respetuosa y mire lo que me está pasando ahorita por las malas lenguas de una mujer" (grupo focal, Complejo Carcelario y Penitenciario de Bogotá, julio de 2013).

La negación de este tipo de delitos es común en diferentes EPC y se mantiene también en diferentes países. En España, por ejemplo, de acuerdo con los resultados de una investigación sobre delitos de tipo sexual, se afirma que: "Aproximadamente el $56 \%$ de las personas que cometen delitos sexuales niega totalmente la autoría de los hechos. Su tendencia es el de atribuirlo a montajes o a que ellas querían y después se vengaron" (Castro et al., 2009, p. 44).

Por otro lado, los AMPL suelen restar importancia a los delitos sexuales, afirmando que hay otros delitos realmente graves que son condenados de manera más ligera y con penas más amables. Es decir, no hay un reconocimiento del delito, bien sea porque el acto no es considerado inadecuado o porque se niega su comisión, o se culpa tanto a las instancias de justicia como a las víctimas, proclamando inocencia y reclamando un trato justo. Otro factor fundamental en este punto es el género, toda vez que los delitos sexuales son cometidos en su mayoría por hombres. Al respecto, de acuerdo con datos oficiales (Inpec, 2013), en el 99\% de estos casos, se encuentra sindicado o condenado un hombre (tabla 33).

\section{Espiritualidad}

Esta categoría se define como toda práctica de tipo religioso o autorreflexivo de los AMPL, adquirida en ocasiones en prisión o fortalecida allí. Así, es muy recurrente encontrar en los discursos de los participantes referencias a 
Tabla 33. Principales delitos sexuales por género

\begin{tabular}{|l|c|c|c|c|}
\hline \multirow{2}{*}{ Delito } & \multicolumn{2}{c|}{ Hombres } & \multicolumn{2}{c|}{ Mujeres } \\
\cline { 2 - 5 } & Sindicados & Condenados & Sindicadas & Condenadas \\
\hline Actos sexuales con menor de 14 años & 2053 & 3133 & 24 & 25 \\
\hline $\begin{array}{l}\text { Acceso carnal abusivo con menor } \\
\text { de 14 años }\end{array}$ & 1476 & 2446 & 21 & 17 \\
\hline Acceso carnal violento & 743 & 2107 & 9 & 7 \\
\hline
\end{tabular}

Fuente: elaboración propia basada en datos del Inpec (2013).

dioses, a las religiones o a diferentes convicciones espirituales. Se asocian a esta categoría los aspectos que se dan a conocer en la tabla 34.

Tabla 34. Aspectos asociados a la categoría espiritualidad

\begin{tabular}{|l|l|}
\hline \multicolumn{1}{|c|}{ Categoría } & \multicolumn{1}{c|}{ Aspectos asociados } \\
\hline \multirow{4}{*}{ Espiritualidad } & Cotidianidad. \\
\cline { 2 - 2 } & Apoyo. \\
\cline { 2 - 2 } & Expectativa de vida. \\
\cline { 2 - 2 } & Arrepentimiento. \\
\cline { 2 - 2 } & Resocialización. \\
\cline { 2 - 2 } & Importancia. \\
\hline
\end{tabular}

Fuente: elaboración propia.

$\mathrm{Al}$ indagar por las rutinas propias de prisión, muchos AMPL afirman que como parte de su cotidianidad oran, rezan y estudian la palabra de Dios; algunos encuentran su único apoyo en Dios, a quien consideran su único amigo, su padre, su esperanza y su felicidad. Otros participantes afirman que su expectativa de vida está dirigida a predicar la palabra de Dios y pregonar su ejemplo; otros pocos reconocen sentir arrepentimiento y buscar consuelo y perdón en Dios. Muchos adjudican su resocialización al acercamiento que han tenido a Dios, más que al tratamiento que han recibido por parte del Inpec, e igualmente afirman que Dios es lo más importante de su vida.

La espiritualidad se asocia a la categoría de aprendizaje en prisión, "es una cosa muy fuerte porque uno no está acostumbrado, y mucho menos a 
la edad de uno, a una cárcel; son cosas de la vida, que da uno un paso mal, pero yo en medio de ese conflicto y todas esas cosas me acerqué a mi dios, que ha sido el que me dio toda la fortaleza para seguir adelante y que me ha ayudado a construir una familia aquí en la cárcel" (grupo focal, EPMSC Acacias, mayo de 2013). Asimismo, la espiritualidad se relaciona con la categoría familia, pues también esta se consolida como bastión principal de apoyo; con la categoría expectativa de vida, referenciada anteriormente, y con la categoría asistencia social, pues, como se mencionó en el apartado correspondiente, prácticamente la única asistencia social que reciben los AMPL está vinculada a organizaciones o instituciones de carácter religioso.

\section{Familia}

Esta categoría se define como el grupo de personas con algún grado de consanguinidad con la persona privada de la libertad. Es una de las categorías más importantes, pues todos los AMPL hacen referencia a esta, en diferentes momentos de la conversación. Se asocian a ella los siguientes aspectos (tabla 35).

Tabla 35. Aspectos asociados a la categoría familia

\begin{tabular}{|l|l|}
\hline \multicolumn{1}{|c|}{ Categoría } & \multicolumn{1}{|c|}{ Aspectos asociados } \\
\hline \multirow{5}{*}{ Familia } & Desgaste. \\
\cline { 2 - 2 } & Abandono. \\
\cline { 2 - 2 } & Experiencia. \\
\cline { 2 - 2 } & Maltrato en el EPC. \\
\cline { 2 - 2 } & Apoyo. \\
\hline & Lejanía. \\
\cline { 2 - 2 } & Muerte. \\
\hline & Problemas psicológicos. \\
\hline & Destrucción. \\
\hline & Problemas legales. \\
\hline
\end{tabular}




\begin{tabular}{|l|l|}
\hline \multicolumn{1}{|c|}{ Categoría } & \multicolumn{1}{c|}{ Aspectos asociados } \\
\hline \multirow{4}{*}{ Familia } & Ausencia. \\
\cline { 2 - 2 } & Necesidades económicas. \\
\cline { 2 - 2 } & Dependencia. \\
\cline { 2 - 2 } & Ocultamiento. \\
\hline
\end{tabular}

Fuente: elaboración propia.

\section{Desgaste y abandono}

Algunos participantes afirman que aunque inicialmente contaban con el apoyo de sus familias, con el tiempo se ha venido sufriendo un proceso de desgaste; es decir, las visitas, las llamadas telefónicas y la correspondencia ya no son tan frecuentes: "el contacto familiar, yo no sé si es por estar acá, y eso lo he comentado con algunos amigos, las familias con el correr del tiempo no sé si es que se cansan, o si es por temor o por vergüenza que se van alejando, eso no es como al principio..., las familias se van alejando" (grupo focal, Complejo Carcelario y Penitenciario Metropolitano de Cúcuta, julio de 2013). Este fenómeno está estrechamente ligado a un proceso de abandono que, sin embargo, se presenta desde el principio en algunos casos. Muchos internos excusan a su familia al indicar que no tienen tiempo y dinero, que tienen muchas otras obligaciones y que por estos motivos no pueden estar pendientes de ellos.

\section{Experiencia}

Algunos AMPL afirman que sus casos particulares y su experiencia personal servirán de ejemplo para que en el futuro ningún miembro de sus familias tenga que pasar por una cárcel; "esto es experiencia, sirve uno de ejemplo para que los nietos no caigan en esto" (grupo focal EPMSC Cali, julio de 2013). 


\section{Maltrato en el EPC}

Algunos de los participantes hacen referencia al maltrato que reciben sus familiares en prisión; así, es común escuchar quejas frente a los acontecimientos que ocurren los días de visita, que ellos califican como humillaciones, gritos y brusquedad.

\section{Apoyo}

La mayoría de los participantes afirman encontrar apoyo en sus familias, y son estas las que sin duda sustentan la vida de sus familiares en prisión. En este punto, es importante hacer una diferenciación de género, pues aunque la mayoría de los hombres afirman haberse acercado más a sus seres queridos, las mujeres manifiestan mucha preocupación por no estar afuera, respondiendo por sus hijos y nietos, que en muchas ocasiones son menores de edad. Al respecto, se encuentra que: "La mayoría de mujeres, que suelen vivir en estrecha relación con su núcleo familiar, al ingresar a la prisión son abandonadas por sus parientes, lo que genera mayor angustia, tanto por la situación de abandono, como por la ausencia de su entorno, en el que desempeñaban un rol central" (Briceño-Donn, 2006, p. 18).

\section{Lejanía}

La lejanía es considerada como una de las mayores dificultades para la conservación y el cuidado de las relaciones familiares. Muchos AMPL atribuyen a la misma la ruptura o el debilitamiento de los lazos familiares. En el caso particular de las mujeres del Complejo Penitenciario y Carcelario de Jamundí, se encontró que la mayoría provienen de Bogotá y que hace muchos años que no pueden ver a sus hijos o que han perdido contacto con ellos: "nosotras todas venimos de Bogotá..., ella nunca ha tenido visitas". Al respecto, las internas son conscientes de que están privadas de la libertad y que están cumpliendo una pena, pero también reconocen que "no por el hecho de estar encerradas, tenemos que estar lejos de nuestras familias" (grupo focal de mujeres, Complejo Carcelario y Penitenciario de 
Jamundí, julio de 2013). Este aspecto es muy importante, pues la privación de la libertad, como respuesta a la infracción de la ley, limita o entorpece el goce efectivo de otros derechos que no deberían estar asociados a la pena, en este caso, el derecho a la familia.

Esta situación de lejanía con respecto a la familia dificulta por supuesto las visitas y se complejiza con la escasez de recursos económicos, manifestada por muchos de los participantes. Por este motivo, muchos de ellos solicitan un traslado a otro establecimiento más cercano a su lugar de origen o al lugar en el que habitan sus familias, donde no estén aislados de los suyos, pues se declaran muy solos y en ocasiones manifiestan no conocer a algunos de sus hijos o nietos. Al respecto:

Cuando el acceso a los establecimientos de detención y penitenciarios se hace extremadamente difícil u oneroso para los familiares, al punto de imposibilitar el contacto regular, se afecta inevitablemente el derecho de ambas partes a mantener relaciones familiares. Por lo que, dependiendo de las particularidades del caso este hecho podría constituir una violación al derecho a la protección de familia, y eventualmente de otros derechos, como el derecho a la integridad personal o al debido proceso. (Comisión Interamericana de Derechos Humanos, 2011, p. 223)

\section{Muerte y problemas psicológicos}

Algunos de los participantes mencionan la muerte al evocar a sus familias, pues han perdido a muchos de sus seres queridos estando en prisión, y manifiestan no haber podido despedirse de ellos o verlos por última vez. Al respecto, en algunos EPC se presenta la posibilidad de dar un último adiós a los seres queridos, mediante un trámite que permite el ingreso del féretro a las instalaciones: "sí, así sean 30 minutos se los traen, se los permiten ver, ellas lo único que tienen que hacer, cuando se enteran que su familiar falleció, es una solicitud ante dirección y que digan a qué hora van a traer al ser querido" (grupo focal de mujeres, Coped, Pedregral de Medellín, julio de 2013). Las muertes que se referencian son principalmente las del padre o la madre, aunque también se habla de hermanos e, incluso, de hijos. Por 
otro lado, algunos AMPL afirman que miembros de sus familias han tenido que enfrentar problemas psicológicos derivados de su privación de la libertad: "sí, a uno de mis hijos le entró una depresión por el hecho de estar yo en las condiciones que estaba, no salía..., y él murió..., se dejó llevar por la depresión" (grupo focal de mujeres, Complejo Carcelario y Penitenciario de Jamundí, julio de 2013).

\section{Destrucción y problemas legales}

En muchos casos, la privación de la libertad se equipara a la destrucción de la familia y es demoledora tanto para el privado, como para los demás miembros del hogar: "se está perdiendo un núcleo familiar, los afectados no somos nosotros solos, toda nuestra familia se está afectando" (grupo focal, Complejo Penitenciario y Carcelario de Ibagué, junio de 2013). Incluso, en ocasiones se afirma en los grupos focales que algunos miembros del grupo familiar comienzan a tener problemas legales, al involucrarse en venganzas o retaliaciones, para con quienes llevaron a su familiar a prisión o al incurrir en nuevos delitos, como escapatoria a su situación.

\section{Ausencia}

La ausencia del privado de la libertad en su hogar es difícil de abordar, pues en ocasiones este representaba un rol esencial en su familia, bien sea moral o económico, lo que genera cambios abruptos en las dinámicas cotidianas. Por otro lado, en algunos casos se trata de ausencias permanentes e incomprensibles; esto sucede principalmente con los nuevos miembros de la familia que pueden no conocer en persona a su familiar privado de la libertad, pero que saben de su existencia como algo etéreo y difuso.

\section{Necesidades económicas}

Las necesidades económicas de la familia son casi una constante en los AMPL. La mayoría manifiesta no tener recursos suficientes para suplir sus necesidades básicas, lo que dificulta la cohesión familiar: "para venir aquí 
necesitan plata, por eso mejor nos comunicamos por teléfono" (grupo focal, Complejo Carcelario y Penitenciario de Jamundí, julio de 2013).

La mayoría de las veces, el privado de la libertad constituía un aporte fundamental para la familia en términos económicos, de allí que se manifieste preocupación por el presente y futuro de las familias al no poder aportar desde prisión. Efectivamente, el ingreso de un miembro de la familia a prisión implica en muchas oportunidades una disminución en el recurso económico, pues es una persona menos que trabaja y devenga.

\section{Dependencia}

Este tema de las necesidades económicas está entonces estrechamente ligado a la dependencia, pues el sustento de muchas de las familias estaba a cargo del privado de la libertad. Este aspecto es bastante llamativo, pues aunque se trata de AM, muchos afirman ser los directamente responsables de sus hijos y de sus nietos. "En el caso mío, yo soy madre cabeza de familia, mi hijo menor tiene 18 años y está solo porque está apenas estudiando y si yo no hago algo para pagarle sus estudios no va poder estudiar y está solo en la casa enfermo, no come y nadie está pendiente de él" (grupo focal, Reclusión de Mujeres de Bogotá, julio de 2013). La dependencia entonces no solo es de tipo económico, sino también afectiva y moral.

\section{Ocultamiento}

Respecto al ocultamiento, algunos AMPL afirman que muchos de sus familiares desconocen su paradero y situación actual, ellos prefieren mentir al respecto e inventar una realidad paralela: "estamos cansados de esperarte, ¿cuándo es que vas a llegar? Muy pronto, mi bebé, muy pronto..., ella cree que estoy de trabajo, ella no sabe que estoy aquî" (grupo focal, EPMSC Medellín, julio de 2013).

La familia, como una de las categorías principales del estudio, está estrechamente vinculada a la categoría de expectativa de vida, pues es casi una constante que el sueño de todo AMPL sea retornar al hogar, recuperar el tiempo perdido con sus seres queridos y pasar sus últimos días con ellos; 
así como a la categoría red de apoyo, pues como se ilustró anteriormente, es en la familia donde se encuentra el sustento moral, espiritual y económico. También está vinculada a la categoría estigmatización, pues los significados otorgados al delincuente se hacen extensivos para los miembros de su hogar, y a la categoría significado otorgado a prisión, ya que para muchos la prisión significa el fin y la destrucción de la familia.

\section{Significado otorgado a prisión}

La categoría denominada significado otorgado a prisión está definida por las implicaciones y efectos que trae la prisión a la vida de los individuos. Se identificaron seis aspectos asociados a esta categoría (tabla 36).

Tabla 36. Aspectos asociados a la categoría significado otorgado a prisión

\begin{tabular}{|l|l|}
\hline \multicolumn{1}{|c|}{ Categoría } & \multicolumn{1}{c|}{ Aspectos asociados } \\
\hline \multirow{4}{*}{$\begin{array}{l}\text { Significado otorgado a } \\
\text { prisión }\end{array}$} & Pérdida de tiempo. \\
\cline { 2 - 2 } & Hostilidad. \\
\cline { 2 - 2 } & Supervivencia. \\
\cline { 2 - 2 } & Oportunidad. \\
\cline { 2 - 2 } & Abandono. \\
\cline { 2 - 2 } & Muerte. \\
\hline
\end{tabular}

Fuente: elaboración propia.

Muchos de los participantes, lejos de reconocer las bondades de la resocialización, afirman que la prisión es una pérdida de tiempo y que no acarrea nada positivo en sus vidas; por otro lado, algunos afirman que en prisión han encontrado un ambiente hostil con el que no estaban familiarizados y que, por tanto, ha sido muy difícil de adaptar a sus vidas. Otros reconocen que la prisión representa una segunda oportunidad, al permitir espacios de reflexión, arrepentimiento, aprendizaje, experiencia y resocialización: "yo no lo tomo como un castigo, sino como una nueva oportunidad que me da la vida para salir adelante" (grupo focal EPMSC Cali, julio de 
2013). Esta posición no es la más común y son más frecuentes las respuestas que vinculan la prisión al abandono y al olvido: "no tenemos un cariño ni nada, es plena soledad" (grupo focal, Complejo Penitenciario y Carcelario de Ibagué, junio de 2013). Igualmente, en algunos casos la prisión se equipara con la muerte, pues acaba con las expectativas e ilusiones: "apenas me condenaron yo sentí que el corazón me falló, iba yo a respirar y no podía, me puse lívido, me fui de lado, y la misma secretaria del juez fue y me trajo agua. Ya fue cuando salí al patio, cuando me asignaron celda, que dije: a partir de hoy estoy muerto y me metí en la cabeza que había muerto para todo el mundo, para la familia y eso..." (grupo focal, Complejo Penitenciario y Carcelario de Ibagué, junio de 2013).

\section{Condiciones económicas}

La tercera condición tiene que ver con el bienestar económico, que es analizado con la disponibilidad de ingresos con la cual cuentan los AMPL, o la asignación que tienen para su atención. Se percibe que estando fuera o dentro de un EPC las condiciones económicas de los AM en general no son las mejores, principalmente porque tienen limitaciones para su autocuidado y tendrían una dependencia económica que, junto con el deterioro que sufre su cuerpo, les impediría en ocasiones la movilidad o el mantenerse activos en el mundo laboral, producto del proceso de envejecimiento.

Sin embargo, esta situación es contraria a lo que dejan ver las cifras de participación en el mercado laboral, que registra la dinámica del empleo, el desempleo y subempleo, donde se refleja que los AM de 60 años se mantienen laboralmente activos, principalmente en las áreas rurales, donde las coberturas en seguridad social son más bajas (Ministerio de Salud y Protección Social, 2008). De acuerdo con la tasa de ocupación, que es el indicador porcentual entre la población ocupada y el número de personas que integran la población en edad de trabajar, las personas mayores de 60 años se ubican con tasas del 51,3\% para hombres y $21,7 \%$ para mujeres, teniendo tasas de desempleo bajas: $6 \%$ para los hombres y $4,8 \%$ para las mujeres (DANE, 2012). Esto refleja que la población mayor de 60 años 
en Colombia se mantiene laboralmente activa, aunque no quiere decir que implique remuneración económica, debido a que los ingresos de estas personas caen proporcionalmente con la edad, y en la mayoría el Sistema General de Pensiones no los cubre. Según la Encuesta de Calidad de Vida (DANE, 2012), la cobertura pensional alcanza al 21,8\% de estas personas en las zonas urbanas y al $5 \%$ en las zonas rurales, donde generalmente no existe una fuente de ingresos fija.

Esa es la situación general externa, pero iqué ocurre cuando un AM es privado de su libertad? Básicamente lo que se encontró en los EPC es una dependencia casi absoluta de esta población, que si tenía algún ingreso por fuera de la cárcel, en el interior desaparece y entra a depender del apoyo económico que le dé principalmente la familia (figura 28).

Figura 28. Tipo de apoyo que recibe el adulto mayor privado de libertad

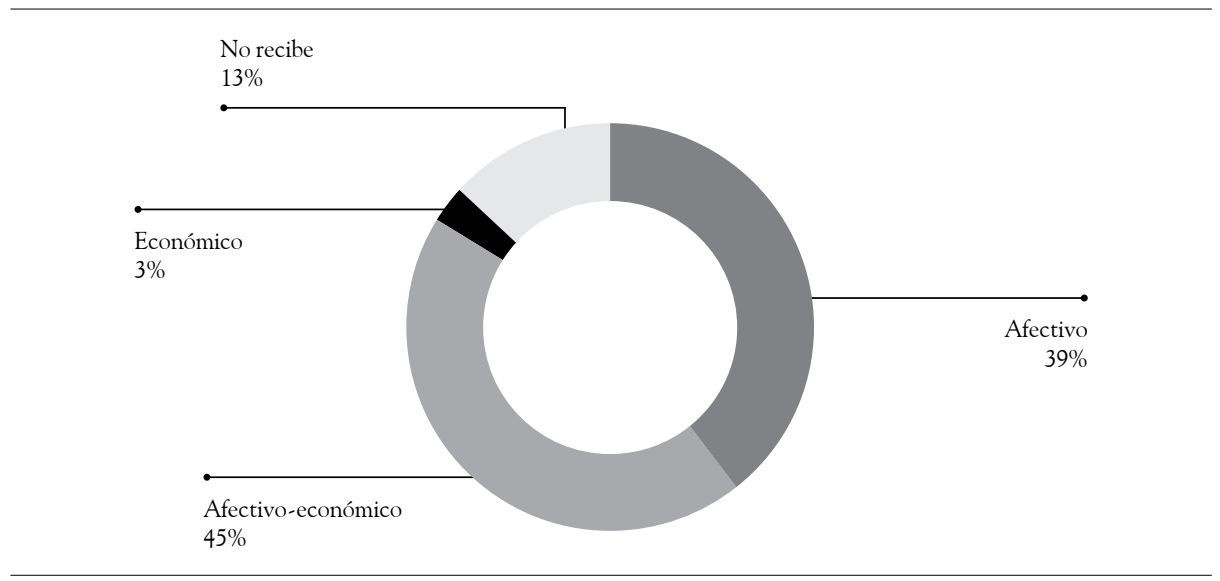

Fuente: Sisipec Web, censo condiciones excepcionales, 31 de julio de 2013. Cálculos de los autores.

En ese contexto, acorde con la realidad que se presenta por fuera de los EPC, donde la principal fuente de ingresos para los AM son los aportes familiares, se indagó sobre el presupuesto que les es asignado a los AMPL como parte de los grupos de condiciones excepcionales en el Inpec. Allí se evidenció que de acuerdo con el crecimiento que se ha tenido de esta población, la asignación presupuestal también se incrementa (figura 29). 
Figura 29. Presupuesto asignado a población en condiciones excepcionales y adultos mayores privados de la libertad 2009-2013

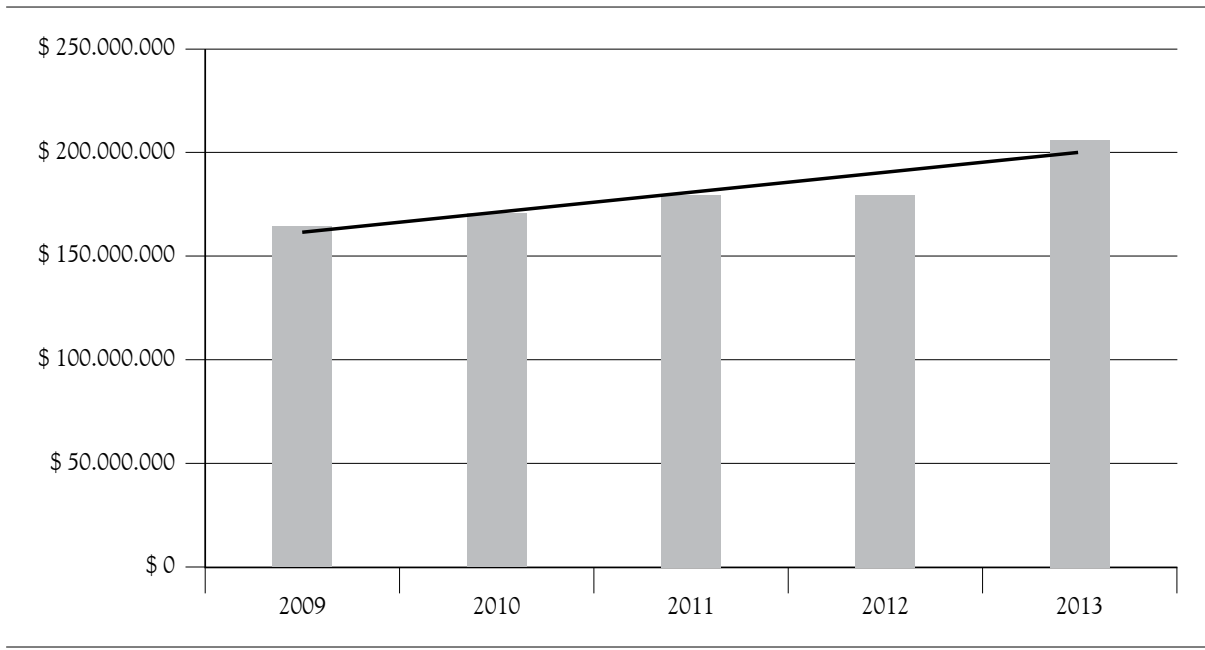

Fuente: Plan de Compras del Inpec para cada vigencia, Sisipec Web, censo condiciones excepcionales, 31 de julio de 2013. Cálculos de los autores.

En los últimos 5 años el incremento en la asignación presupuestal para atender la población en condiciones excepcionales (PCE) aumentó; sin embargo, al revisar cuánto le corresponde de esa asignación a los AMPL y qué porcentaje pertenece al total de esa población, se encontró que los resultados son un poco menos alentadores, debido a que les corresponde una asignación según el tamaño de la misma población frente al general distribuido para el total de la población (figura 30).

De acuerdo con la asignación presupuestal, se puede inferir que a los AMPL mayores de 60 años en 2013 -que correspondían al 16,85\% del total de este tipo de población- les fueron asignados ese año cerca de \$35.000.000 para la atención en programas que se organizan en los EPC. En consecuencia, cada AMPL tuvo una asignación presupuestal de $\$ 20.284$ durante todo el año 2013, para que el EPC donde se encontraba recluido le diera la atención en los programas establecidos. El resto de los recursos que requiere la población fueron conseguidos por la red de apoyo disponible. 
Figura 30. Presupuesto asignado para adultos mayores privados de la libertad vs. presupuesto para la población en condiciones excepcionales

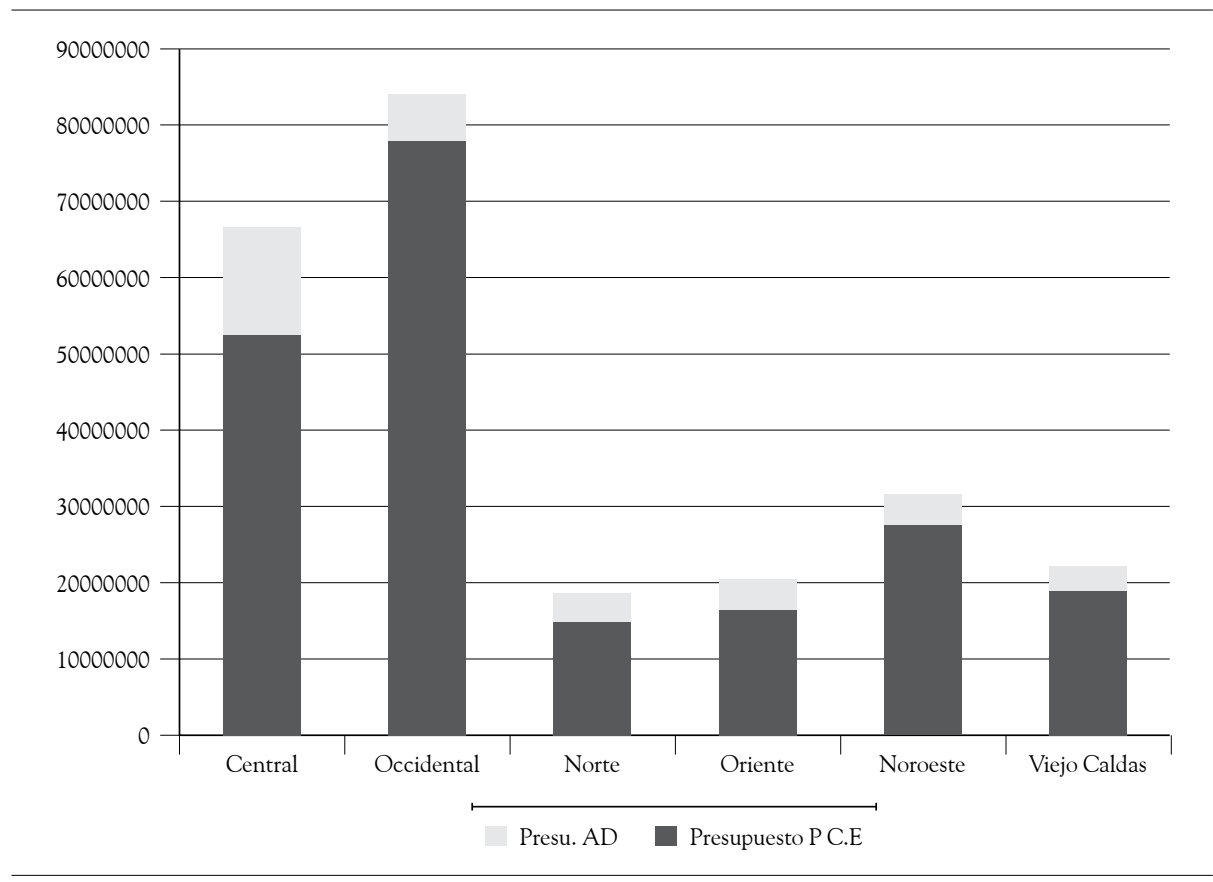

Fuente: Plan de Compras del Inpec para cada vigencia, 31 de julio de 2013. Cálculos de los autores.

La evidente escasez de recursos para atender al total de la población carcelaria del país no es ajena al limitado presupuesto para atender a los AMPL. Es notable la intención, el profesionalismo y las ganas de los funcionarios del Inpec por atender al total de la población AMPL; sin embargo, una cosa es lo que se desea y otra lo que se puede hacer con los recursos que se tienen. El propio personal de la Subdirección de Atención Psicosocial, de la Dirección de Atención y Tratamiento del Inpec es consciente de ello al manifestar lo siguiente:

[...] aún no se ha trabajado con el tema de la red de apoyo familiar del interno adulto mayor a la hora de recuperar la libertad, no hay estructuración del plan ocupacional que responda a las características propias de la población de tercera edad, no se cuenta con los espacios ni la infraestructura adecuada para ubicar a esta población (por ejemplo, celdas acondicionadas). No hay personal suficiente ni adecuado para 
atender esta población, como terapeutas ocupacionales, fisioterapeutas, gerontólogos, entre otros; los profesionales que hay en su mayoría psicólogos y trabajadores sociales atienden a toda la población en general y no hay un servicio especializado para esta población. De otra parte, se está empezando un trabajo en esta dirección para establecer políticas de atención a la población de tercera edad que se ajusten a las necesidades reales del contexto. Se han realizado algunos contactos, pero es una tarea que está empezando.

Esto hace pensar que en los EPC los funcionarios que laboran allí sienten una frustración profesional, al saber que se puede hacer más, pero los recursos y la sobrepoblación no se los permite.

\section{Condiciones jurídicas}

Finalmente, la cuarta condición reúne aquellos factores que determinan los aspectos legales a los que se enfrenta esta población en la actualidad, y se observan las principales adecuaciones típicas por las cuales los AMPL se encuentran recluidos en los EPC, dentro de las que se destacan los delitos contra la libertad, la integridad y la formación sexual, contemplados en el título IV, capítulo I del CP, como acceso carnal violento, acto sexual violento, acceso carnal o acto sexual en persona puesta en incapacidad de resistir. Asimismo, los relacionados en el capítulo II de los actos sexuales abusivos: acceso carnal abusivo con menor de catorce años, actos sexuales con menor de catorce años, acceso carnal o acto sexual abusivo con incapacidad de resistir y acoso sexual. A pesar de darse un alto porcentaje de privaciones de la libertad, como se dijo, por esta clase de conductas punibles, se reportan otras contra la vida e integridad personal, la libertad individual y otras garantías, el patrimonio económico, la administración pública, entre otras.

Sin embargo, se evidenció en el trabajo de campo que un gran porcentaje de los AMPL no tienen claridad acerca del tipo penal en el que incurrieron, en el caso de delitos sexuales, por ejemplo, algunos asocian acceso carnal con otras infracciones descritas en el mismo título, circunstancia que 
resta claridad a la pena dado que al no precisar cuál fue realmente el delito que se cometió, no se identifican los derechos transgredidos.

Hasta que cae uno, me da dolor que uno tenga que pagar ocho años por eso, bueno ya casi me voy, pero digo: yo por qué tengo que vivir esta situación, porque le hace falta a uno mucha información del mismo Gobierno, de decirle a la mujer que no se meta con este... a uno de hombre también. Es de decirle a uno que el acceso carnal da 60 años como dice la difunta que en paz descanse, doña Gilma, uno llega al patio y lo señalan que uno es un violo, entonces el otro señor está por un secuestro..., a ese no le dicen nada. (Grupo focal EPC de Cúcuta, julio de 2013)

Con alguna frecuencia los AMPL manifiestan ser "víctimas" de componendas, falsedades y arbitrariedades que generaron su estancia en la cárcel:

Yo trabajaba en la casa y llegó una muchacha que me decía que por qué no le regalaba 1000 pesos, yo se los di y entonces en eso ella llegó a la casa y fue un vecino y llamó a la Policía. Yo tenía la puerta abierta, yo no estoy haciendo nada...ella entró a tomar agua, entonces llamaron y llegó un bus..., a mí me dejaron. A los dos meses estaba la familia en Bogotá y llegó la Fiscalía, me buscaron por la mañana y yo estaba trabajando y llegaron por la tarde y me dijeron que estaba preso. Resulta que la abuela de la china..., me tienen por manoseo, me dieron 13 años y seis meses, esa no la debo. (Grupo focal EPC de Cúcuta, julio de 2013)

Al observar el tipo de defensa que tienen los AMPL se encontró que en su gran mayoría son asistidos jurídicamente por defensores de oficio, hoy públicos, en más de un $92 \%$ de los casos, tanto en mujeres como en hombres. Esto resulta entendible ante la imposibilidad económica que la gran mayoría padece, con el acoso de las multas exageradas, impagables, que por demás no tienen ningún sentido en relación con la pobreza e insolvencia de la gran mayoría de los condenados; las afugias de sus seres queridos cuando todavía se cuenta con ellos o las propias en el interior del establecimiento, donde nada se produce, nada se cosecha (figura 31). 
Figura 31. Asistencia jurídica que reciben los adultos mayores privados de la libertad

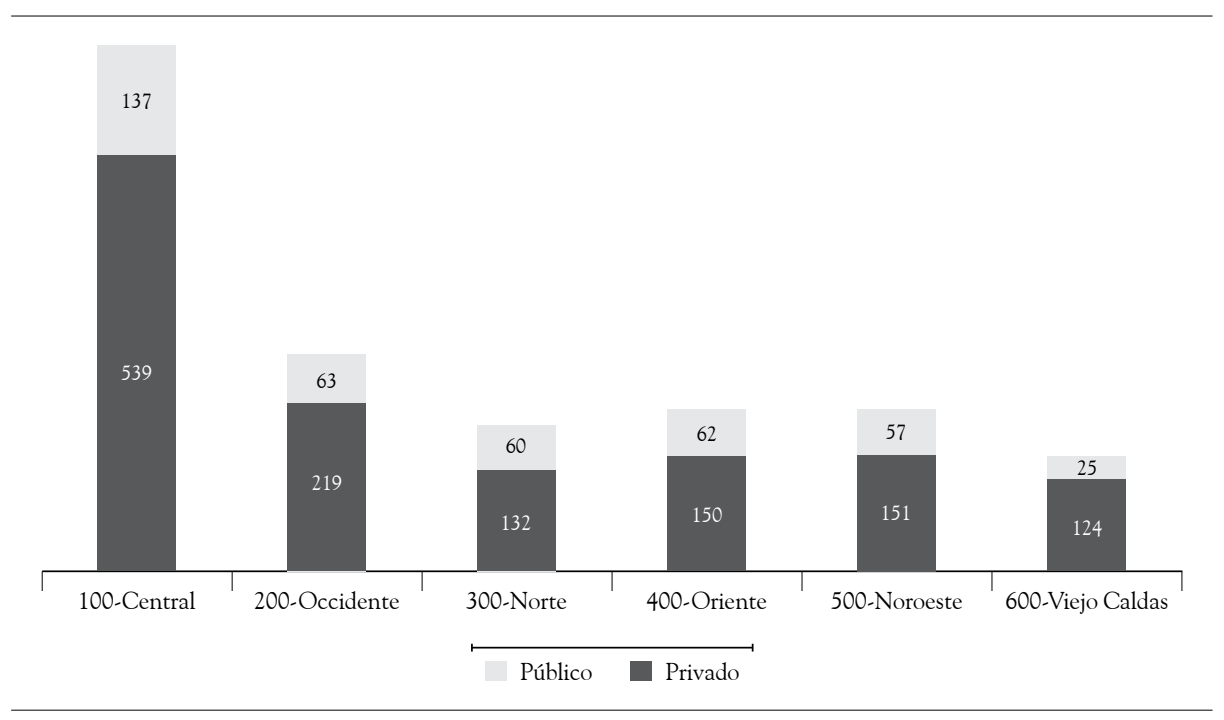

Fuente: Sisipec Web, censo condiciones excepcionales, 31 de julio de 2013. Cálculos de los autores.

Junto con ello, muchas veces son los propios operadores judiciales quienes los irrespetan, los ofenden y los maltratan. El juez tiene mucho poder de interpretación, la aplicación de la ley debería ser más estricta, más concreta. iQue el juez cumpla la ley! Conforme a lo expresado, el operador de justicia no está dando aplicación a principios como el del in dubio pro reo, el favor rei, el pro homine, este último reconocido en la Convención Americana sobre Derechos Humanos en su artículo 39. Igualmente, se observó que en los EPC visitados la mayoría de las personas internas AMPL están condenadas y, en una menor proporción, se encuentran sindicadas, imputadas y acusadas (figura 32).

Los AMPL consideran que la acumulación de penas no se hace en forma correcta, situación que les prolonga aún más su estancia en prisión, mutando en ocasiones a una cadena perpetua. Insisten en que las penas son demasiado extensas, exageradas, inexplicables por no tener nada de proporcionales, ni de racionales. La libertad condicional o el brazalete no llegan nunca y la domiciliaria es casi que una utopía. Por alta que haya sido la condena, estiman que debería tener algún grado de flexibilidad, considerando el buen comportamiento personal que se tenga dentro del reclusorio. 
Figura 32. Situación jurídica de los adultos mayores privados de la libertad

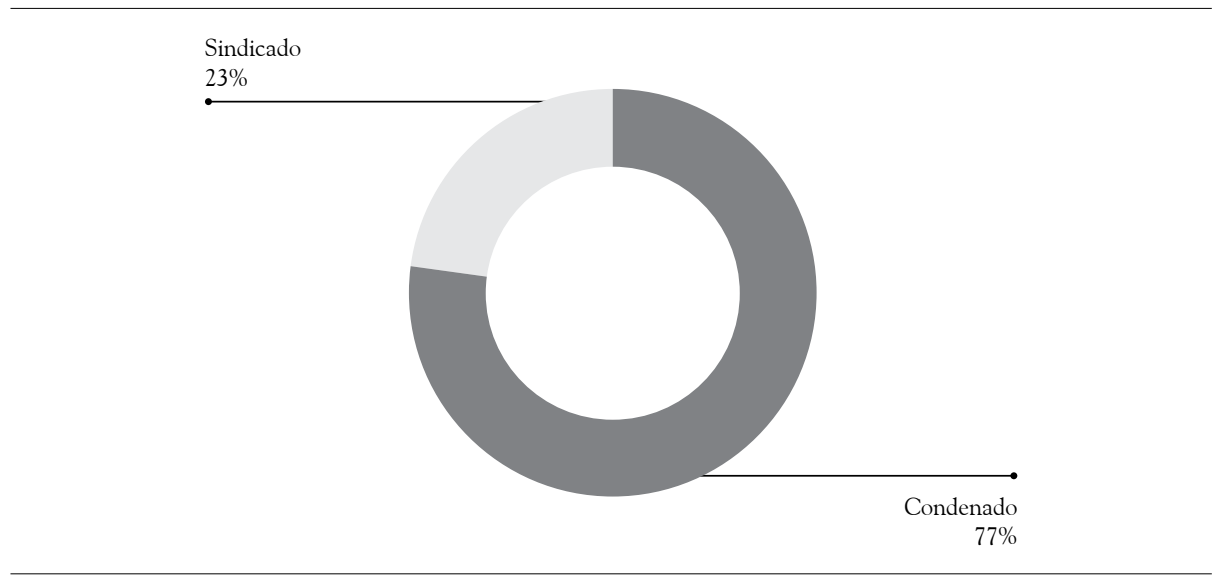

Fuente: Sisipec Web, censo condiciones excepcionales, 31 de julio de 2013. Cálculos de los autores.

Los permisos se perciben por los AMPL como un premio cuando ya se ha cumplido cierta parte de la pena y se ha tenido buen comportamiento, de manera que si en esas condiciones no se dan, dicha negativa se ve como una afrenta, como una respuesta arbitraria. Igualmente, quienes han trasegado varios EPC del país no se explican por qué el trato diferente en relación con los permisos, siendo que la ley es una sola, máxime cuando consideran que el permiso es el único mecanismo establecido que en algo ayuda al recluso a preparase para la libertad, para volver a la sociedad.

Gran parte desea obtener permisos, porque perciben que no son "un peligro para la sociedad"; por el contrario, los AMPL se consideran como personas pacíficas, no conflictivas, sin vicios, que no delinquen en el interior de los EPC, donde se dan hurtos, lesiones y hasta homicidios. Manifiestan por ello el rechazo en su gran mayoría a ser mezclados con otros reclusos de menor edad, porque consideran que estos son portadores de estas malas prácticas, además de ser algunos ruidosos, agresivos e intolerantes. Sin dejar de mencionar el comportamiento sexualmente escandaloso e inapropiado por parte de miembros de las comunidades LGBTI, lo cual aumenta su estado de vulnerabilidad. Se dice que: 
La vulnerabilidad coloca a quien la padece en una situación de desventaja en el ejercicio pleno de sus derechos y libertades [...] esta circunstancia viola los derechos de los miembros más débiles de la sociedad y los margina, razón por la cual el Estado tiene la responsabilidad de proteger a estas personas, quienes frecuentemente desconocen cuáles son sus derechos, ignoran los medios para hacerlos valer y carecen de los recursos necesarios para acudir ante los sistemas de justicia. (Arriagada Peñailillo, 2006)

No obstante lo anterior, los AM no tienen claro cuáles son sus derechos, no saben cómo ejercerlos y demandarlos, condición que revela su vulnerabilidad y que impide la exigencia de un trato diferencial, en el ámbito de la privación de la libertad. Salvo en algunos casos en los que se separan de los demás reclusos, no hay ningún tipo de diferencia respecto al AM por parte del legislador, del juez o de quien ejecuta la pena. Igualmente, la mayoría de los AMPL desconocen que existan leyes especiales para el AM, y tienen claro que se rebaja o se descuenta pena con trabajo o estudio, pero manifiestan que las certificaciones no son fáciles, por lo que en ocasiones se pierde el tiempo redimido. "En la cárcel se roban los descuentos" (grupo Focal, EPMSC ERE Cúcuta, julio de 2013). El trabajo no es remunerado, solo excepcionalmente. Algunos de los participantes manifiestan que se les han vulnerado sus derechos, y los que mayoritariamente señalan son acceso a la justicia, debido proceso, defensa, familia, salud, trabajo, educación y resocialización.

\section{Acceso a la justicia (artículo $29 \mathrm{CN}$ )}

Principalmente por no tener recursos económicos, se considera que la ley sigue siendo un "perro que solo muerde a los de ruana", que el preacuerdo es una trampa, un engaño; se aceptan responsabilidades para obtener alguna rebaja muchas veces sin haber cometido el delito, como penas excesivas, falsos positivos judiciales. Los trámites para el reconocimiento de la rebaja son muy demorados y engorrosos. 


\section{Debido proceso (artículo $29 \mathrm{CN}$ )}

Se sienten engañados con los preacuerdos y la aceptación de cargos a los cuales accedieron buscando una pronta libertad o rebaja significativa, aún en eventos de franca inocencia bajo el entendido de que por su situación social y económica no se les haría justicia. Hay quienes consideran que la justicia no investiga, que el juez está cargado de prejuicios, aspecto que quita objetividad e imparcialidad, que frente a ciertos señalamientos como los relacionados con conductas sexuales no hay nada que hacer, puesto que basta la denuncia para ser condenados. Esta situación se agrava cuando la persona ha sido juzgada y condenada en contumacia.

\section{Defensa (artículos 29 y $34 \mathrm{CN}$ )}

Ausencia o falta de defensa no solamente en relación con la defensa técnica, por cuanto informan que es muy poco o nada lo que hace el defensor por ellos; incluso hay quienes manifiestan que son condenados por sus propios abogados, cuando les sugieren o los convencen de llegar a un preacuerdo o aceptación de cargos. En lo que toca a la defensa material, señalan que el juez no los dejó hablar, que ni el juez ni el abogado los dejó defenderse. La acumulación de penas no se hace correctamente y esto degenera en verdaderas cadenas perpetuas.

\section{Familia (artículo $44 \mathrm{CN}$ )}

La reclusión alejada de la familia hace que esta se pierda en dos sentidos: para el recluso cuando es marginado del grupo familiar o cuando menores, ancianos o personas con discapacidad se ven afectados con la privación de la libertad de quien veía por ellos. De ahí que la Corte Constitucional ponga límites a la privación de la libertad como medida cautelar, condición que se deben replicar para la condena, de subsistir dichas circunstancias al momento de proferirse el fallo o ejecutarse, salvo en los eventos contemplados en el artículo 27 de la Ley 1142 de 2007, que adicionó el artículo 314 del CPP. En estos artículos, de ninguna manera procede la domiciliaria. La familia, 
sin embargo, sigue siendo el soporte de muchas PPL para seguir adelante, lo mismo que la esperanza de recuperar algún día la libertad perdida.

\section{Salud (artículo $44 \mathrm{CN}$ )}

A pesar de que se trata de una población bastante necesitada, no cuenta con una asistencia médica y farmacológica: "uno también ve esas colas de esos pobres viejitos para ir a recoger una medicina, eso es abandono, uno ve morir al viejito con la tutela en el bolsillo y nada, no lo atendieron" (grupo focal, Coiba Ibagué, junio de 2013). La mayoría de la veces la alimentación que se suministra no es la apropiada para enfrentar sus problemas de salud y sus condiciones se agravan por el hacinamiento, causante de epidemias y generador de espacios no adecuados para las personas de edad avanzada. Estos reclamos realizados en los grupos focales, frente a la atención y la calidad de la salud, contrastan con los estándares internacionales, como se observa en el apartado denominado "Caracterización de los adultos mayores privados de la libertad". Así pues, la percepción que tienen los AMPL de la atención en salud es negativa, lo cual es bastante delicado considerando que este grupo representa un riesgo mayor de adquirir problemas de salud, que se suman a la condición de hacinamiento en la que se encuentran.

\section{Trabajo (artículo $25 \mathrm{CN}$ )}

Ese derecho y esa obligación no están prohibidos o excluidos en los centros carcelarios y penitenciarios; por el contrario, es allí donde la ocupación debe ser plena para todos los reclusos, considerando que el trabajo es un medio para alcanzar la resocialización del Código Penitenciario y Carcelario de Colombia (Ley 65 de 1993, artículo 10), mientras que el ocio sigue siendo causa de todos los vicios.

\section{Educación (artículos 44 y $67 \mathrm{CN}$ )}

El Inpec no cuenta con los recursos necesarios para tal fin, en 2007 apenas se le destinaba a dicho rubro el 1,6\% de su presupuesto, sin que haya evidencia 
del mejor aprovechamiento de estos recursos (Serge Jiménez, 2007). Situación que bien se refleja en la realidad, por cuanto son los propios reclusos los que manifiestan su frustración total frente a la resocialización: "la cárcel no resocializa a nadie, solo se aprenden mañas", "la cárcel no enseña nada bueno, un oficio, un arte, una manera de ganarse la vida honradamente" (grupo focal, Coiba Ibagué, junio de 2013). De esta manera, ven la estancia en la cárcel como una pérdida de tiempo, un abandono llevado al extremo, pues se consideran tratados como animales, únicamente comiendo y durmiendo en las peores condiciones, de allí que igualmente vean las penas a las que son sometidos como muy altas y absurdas desde todo punto de vista.

\section{Resocialización}

Así no esté expresamente consagrado, protuberantemente vulnerado resulta este derecho del penado dentro del SPCC, que hace de esa sola posibilidad una meta muy difícil de alcanzar. Por otro lado, se puede establecer que los AMPL solo reconocen el delito cuando aceptan sus culpas e indican haber infringido la ley, afectando derechos ajenos con su comportamiento. Sin embargo, no tienen precisa su conducta delictuosa, quienes han cometido el delito no entienden la tipificación que se les adjudicó, y existe entonces una clara justificación en la inoperancia del sistema judicial. Así las cosas, como las crueles penas de los siglos pasados, como el suplicio de la rueda o descuartizar o cortar a hachazos los miembros del cuerpo, la prisión no ha logrado disminuir la criminalidad, por lo que cada delito es ya por el solo hecho de existir una prueba en contra de la eficacia que estas políticas de prevención general persiguen mediante el incremento de las penas. 


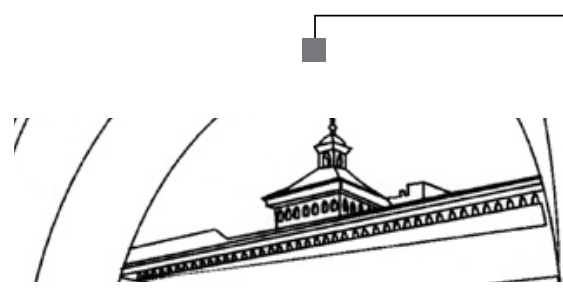




\section{Capacidad criminal}


El análisis propuesto para este apartado toma como referencia la información recabada de los internos que participaron en los grupos focales y busca poner en contexto las percepciones acerca de las razones por las cuales los adultos mayores cometen delitos, motivos para la reincidencia y la función del tratamiento penitenciario tanto en estos dos tópicos como en la convivencia diaria.

En Colombia se ha convertido en un hábito legislativo reformar el CP y sus afines, como el Código de Procedimiento Penal y el propio Código Penitenciario, bajo el prurito de atajar la criminalidad y la delincuencia. Estas reformas han ampliado el tiempo de condena de la mayoría de los delitos, han penalizado nuevas conductas y también han reducido beneficios. Esta política del Estado parece haber arrojado un creciente hacinamiento en las cárceles (Inpec, 2013). A juzgar por esta maximización del régimen punitivo, pareciese que el Estado colombiano no tuviese más instrumentos para solucionar los problemas de conflictividad social y económica (Barreto \& Sneider, 2009).

Encontrar respuestas que permitan comprender las actuaciones de las personas que cometen delitos es una constante en el campo de la investigación y prevenir conductas a futuro, una de las metas. Una prueba de ello es la normatividad que contempla la resocialización de los infractores de la ley penal mediante actividades de tratamiento, como es el caso del Código Penitenciario y Carcelario (Congreso de Colombia, 1993). Lograr este objetivo contempla la necesidad de conocer aspectos personales, sociales, familiares o institucionales de los infractores, para proponer acciones de resocialización cercanas a las realidades de los internos.

Como el segmento de la población carcelaria que motivó esta investigación son los AM, se procede a realizar un análisis de la capacidad criminal en internos que participaron en grupos focales realizados en diferentes EPC del país, con indagaciones acerca de las razones por los cuales cometen delitos y reinciden, y las alternativas de tratamiento penitenciario que ayudarían a prevenir la reincidencia en los AMPL. Los resultados se exponen a continuación. 


\section{Razones por las cuales los adultos mayores cometen delitos}

En las participaciones se observa que los AMPL mencionaron ejemplos o situaciones con las que explicaron su estadía en la cárcel, pero no la acción delictiva. En este sentido, el delito se presentaría como una oportunidad, como una única salida que liberaría de culpa a los condenados. Señalan aspectos personales relacionados con el uso y abuso del alcohol: "nadie está libre de que le pase y, isabe qué es lo que da más odio hoy en día?, que por el alcoholismo este aquí, donde yo no hubiera estado borracho no estuviera aquî" (grupo focal, EPMSC Bucaramanga, julio de 2013). Una de las participaciones generalizó al consumo de alcohol como la principal causa de la comisión de los delitos en AMPL: "por el alcoholismo es que la mayoría está aquî" (grupo focal, EPMSC Bucaramanga, julio de 2013). Para estos internos las situaciones que enmarcan el consumo de alcohol son las que desencadenaron las consecuencias jurídicas que actualmente enfrentan. También se hicieron referencias a los delitos efectivos o potenciales, que pueden estar relacionados con las diferentes etapas del proceso de las sustancias psicoactivas: producción, distribución, cambio y consumo.

El tema de la droga es una constante en varios de los discursos de los AMPL. Muchos de ellos han estado involucrados en esta problemática como consumidores, distribuidores, transportadores o fabricantes, o tienen algún miembro de la familia vinculado a estas actividades. También afirmaron que los delitos están aumentando con el paso del tiempo, debido a que la juventud tiene muchos problemas de uso y abuso de sustancias psicoactivas lícitas e ilícitas. Otros manifestaron que en sus casas se guardaba la droga, pero que ellos no tenían nada que ver con el asunto. Finalmente, hubo quienes afirmaron que la distribución y el transporte de drogas representaron una oportunidad para generar ingresos y garantizar la supervivencia. En otro caso, se evidencia cómo en las estructuras delictivas relacionadas con el narcotráfico la corrupción facilita el ejercicio de la comercialización y estimula la persecución al consumidor: "me veían ahí consumiendo drogas y encontraban al vendedor y a ese no lo cogían porque les daba plata a los policías y entonces por cumplir con la misión recogían cualquier 'chirrete', 
iy tenga!, yo estaba ahí, y me decían que yo traía más de lo que tenía. Ellos se aprovechan de esa situación para cargarse a la gente, solo por ser viciosos" (grupo focal EPMSC Cali, julio de 2013).

Esta participación ilustra un panorama en el que aparece el poder corruptor del dinero para exculpar a quien comete un delito, inculpando a quien padece una enfermedad como la adicción. De todo esto, se puede concluir que la droga y todos los procesos y efectos asociados a esta son determinantes para el abordaje del delito y reflejan una aguda problemática social que ha sido nombrada y reconocida por muchos de los AMPL, en varios de los temas que se abordaron en los grupos focales.

Otro de los tópicos se refiere a la teoría del autocontrol, en la que para explicar el delito, se muestra que en los individuos el autocontrol no puede observarse directamente aunque sí en sus manifestaciones y consecuencias (Serrano, 2011). En este sentido, algunos participantes declararon situaciones en las que se puede inferir que está presente ese factor: "resulta que me tocó matar a un señor porque no le fie un corte de cabello, era un ladrón, y yo le dije muchas veces que no lo podía peluquear, que yo tenía que pagar arriendo" (grupo focal, EPMSC Acacias, julio de 2013). En este relato se pueden observar efectos del bajo autocontrol. Un desequilibrio entre lo que el interno menciona como causa y la consecuencia que trajo tanto para la víctima como para el victimario. Otra participación se relacionó con esta característica: "Llegó el caso de estar tantos años sufriendo y luchando que salí por ahí a buscar unos materiales para mi trabajo, y por casualidad nos encontramos de frente y cuando ellos se me lanzaron de frente a pelear por lo mío tuve que matar a uno y bueno, el otro se salvó de milagro" (grupo focal, EPMSC Bucaramanga, julio de 2013). En estos casos se proponen situaciones en las que más que, explicar el delito, se justifica la ocurrencia como algo inevitable.

Los participantes expusieron una serie de explicaciones por las cuales los AM cometen delitos. Entre estas se identificó una gran cantidad de pensamientos que los libera de responsabilidad de la acción delictiva, proponiéndola como una conducta justificable. "Yo creo que sicológicamente todos tenemos el ego y desde que nacimos lo hemos estado alimentando negativamente y entonces nosotros de tercera edad tenemos ese ego hasta 
que muramos y eso lo obliga a uno a hacer cosas por costumbre" (grupo focal, EPMSC Bucaramanga, julio de 2013). En esta afirmación se explica el delito por una entidad que el participante denomina "ego", que es afirmado negativamente a través del tiempo y es el que determina la conducta. Otro interno manifestó que

[...] en ese sentido, se explicaría por qué hay dos cosas en la vida, una que se llama sino y otra que es el destino, ustedes entienden eso mejor que yo. El sino es lo que debe sucederse que está para sucederse, que se sucede aceptando, y el destino ya se lo forma uno, se lo hace se lo construye, y tal vez el sino nos traicionó en la primera oportunidad, pasó lo que tenía que suceder y sucedió. (Grupo focal, EPMSC Bucaramanga, julio de 2013)

En la anterior afirmación el motivo del delito se atribuye a una traición del sino y este es inapelable. Mientras que el destino se asoció con la decisión propia y esta no la relacionó con lo sucedido. Otras participaciones invirtieron el rol del AMPL, poniéndolo en el lugar de víctima de otras personas o situaciones, asociando el motivo de encarcelamiento con características de ingenuidad asociadas con la niñez: "el adulto mayor es muy fácil de convencer, igual que un niño. Uno tiene mucha sensibilidad y de pronto queda uno involucrado en cosas que no deben ser" o "por engaño, uno hace cosas que no debe" (grupo focal, EPMSC ERE Cali, julio de 2013). En estas afirmaciones continúa la tendencia a observar la responsabilidad del delito como algo ajeno a sí mismo.

Aportes realizados por los AMPL se centraron en minimizar las razones para la comisión del delito, y se llegó incluso a exculparlos mediante generalizaciones: "cualquier persona puede cometer un delito" (grupo focal, EPMS ERE Medellín, julio de 2013). Al parecer en esta ocasión existió el deseo de evitar la rotulación del AMPL como delincuente. Se observó también la propensión a homologar el acto delictivo con errores cotidianos: "aunque los que no han cometido ningún delito han cometido errores, quién no comete un error" (grupo focal, EPMS ERE Medellín, julio de 2013) o "todos cometemos errores sea de una u otra manera, pero cometemos errores y 
los cometemos una vez en la vida" (grupo focal, EPC Cojam, Jamundí, julio de 2013).

Una de las teorías que soportan el origen de la delincuencia está asociada a los procesos de aprendizaje y socialización de la conducta delictiva mediante la cual se llega a afirmar que todas las personas pueden delinquir y todo depende de la interacción del sujeto con las instituciones que forman su sociedad (Eduforma, 2012). En relación con esta postura, se manifestaron aseveraciones respecto a que en todas las esferas se presentan conductas delictivas, tanto en el ámbito público como en el privado, la diferencia es la forma como se tratan los delincuentes de "cuello blanco", respecto a los delincuentes de "overol".

Pero más allá de la reducción a la desigualdad en el trato, se puede vincular la historia familiar como formadora o no de la comisión del delito: "Pues que nadie está a salvo de cometer delitos, pero muchas veces el delito de uno no es que lo cometa uno, sino que la misma familia de uno se busca sus problemas. Pero no es porque verdaderamente uno lo haya cometido" (grupo focal, EPMS ERE Bucaramanga, julio de 2013). Por otra parte, se hace necesario mencionar prácticas familiares en las que existe tendencia a validar el quebrantamiento de la norma o de la ley; "hay personas que son muy desadaptadas, pero por qué, por malos padres, por la crianza" (grupo focal, EPMSC Medellín, julio de 2013), y como producto de la exposición a estas conductas, la percepción del delito se normaliza. Complementario a esto, los AMPL también explican la comisión de delitos a causa de la influencia del grupo social; en este sentido, las malas amistades, las costumbres y buscar obtener un estatus delictivo originan y preservan la conducta criminal.

Desde las explicaciones que se pretenden dar a las causas del delito entre los AMPL, la mayoría se centran en que se cometió el delito por necesidad: "en este caso, en la mayoría de las cárceles o centros se ve mucho el que llega por hurto, por la necesidad" (grupo focal, Coiba, Ibagué, julio de 2013). A esta condición está asociado el delito de hurto y las justificaciones giran en torno a ayudar a sus hijos, en especial las mujeres; además, en esta etapa de la vida se incluyen otras personas dentro del núcleo familiar para mantener que son los nietos: "un hijo pidiendo comida y uno no poder llegar a la casa y decir: no tengo para la leche de mi hijo, mi señora está 
aguantando hambre. Esa persona si no delinque a lo mejor se prostituye por las necesidades" (grupo focal, EPMSC Acacias, julio de 2013). Estas situaciones ponen de manifiesto una tensión entre las aspiraciones que los internos participantes tienen con respecto de las necesidades y las pocas oportunidades que observan para satisfacerlas. En ese sentido, Durkheim (citado en Soria \& Sáiz, 2006) afirma que en caso de que las primeras (aspiraciones) no puedan realizarse mediante oportunidades legítimas, se emplearán para ello métodos no convencionales. Otra de las justificaciones al delito es el consumo de sustancias psicoactivas: "el señor por consumir su vicio entonces comete ese delito que es lo que más se ve en las cárceles" (grupo focal, Coiba Ibagué, julio de 2013). En esta etapa aún se mantiene tal práctica y la dependencia a las diferentes sustancias conlleva nuevamente a que el delito de hurto sea el utilizado para adquirir la droga.

Dentro de este apartado resulta interesante analizar el rol dentro de la conducta delictiva; una proporción de AMPL dentro de la narración de los hechos materia de sanción esgrimen historias que pueden ser calificadas como increíbles si se aplican principios lógicos para su interpretación y comprensión: "Yo me dejé convencer de un tipo naturista que sembraba unas pepas y salió marihuana, y me las dio para que se las vendiera y las tenía en la casa como planta medicinal" (grupo focal, EPMS ERE Bucaramanga, julio de 2013). Las coincidencias presentadas en los testimonios están en el papel de víctima, exponiendo a manera de insinuaciones la ingenuidad o carencia de conocimientos como las razones para la comisión del delito.

También existen tendencias a observar a los AM como personas con menor capacidad para delinquir o reincidir aunque las carencias económicas, limitaciones al mercado laboral y las condiciones de vida son de un elevado nivel de riesgo (Williams et al., 2012), y es una realidad que sean utilizadas por la facilidad que esta percepción ofrece para desviar posibles sospechas. Las limitaciones físicas conducen a desempeñar acciones que no tengan implicación de esfuerzo, con prácticas generalmente asociadas a delitos por estupefacientes, especialmente el porte, el microtráfico o la receptación.

El fenómeno de la comisión de delitos sexuales por parte de AM es el más generalizado. Según datos del Inpec, a la fecha del 31 de julio de 2013, el 47,58 \% de los AMPL están por este delito. Seguido se encuentra el tráfico 
de estupefacientes con un 14,42\% y homicidio con el 13,55\%. Dentro del trabajo de campo, un hecho presentado es la negación del delito sexual ante personas externas, pero también por su integridad en el interior de la cárcel. Sin embargo, otras personas condenadas por este mismo delito sí lo manifestaron abiertamente; lo que llama la atención es escuchar la justificación del delito: "Yo no me siento orgulloso de que me hayan condenado por ese delito, pero tampoco me avergüenzo porque lo mío fue con una mujer que estaba viviendo con una señora, llegó la hija y vio las buenas condiciones..., entonces la muchacha vio las condiciones y empezó a metérseme, y las tentaciones de uno... iLa carne es jodida!" (grupo focal, Cocuc Cúcuta, julio de 2013). Se desplaza la culpabilidad a la víctima indicando insinuación y preparación del delito por parte de esta con el fin de conseguir algo, pero también se presenta a la víctima como un estímulo imposible de controlar. Así, la consumación del delito es justificada, como algo ocasional o de oportunidad.

Desde los factores sociales, los AMPL en sus narraciones hacen mayor énfasis en la falta de oportunidades laborales como fuente del delito; en este orden, existen dos planos que lo sustentan: la edad como limitación o impedimento para la consecución de un trabajo "porque a una de 40 años en adelante no le dan trabajo en ninguna parte, entonces uno se pone a hacer cosas que uno no cree llegar hasta aquî" (grupo focal, Coped Medellín, julio de 2013) y la ignorancia vista como ausencia de algún conocimiento. Muchos afirman haber delinquido por desconocimiento o por no tener herramientas para discernir entre lo que está bien y lo que no.

En este punto, vale la pena mencionar que algunos AMPL afirman no saber leer y escribir o no haber recibido educación alguna al momento de la comisión del delito y de la captura; por lo tanto, se recalca la importancia que se otorga a los conocimientos adquiridos en los programas de tratamiento penitenciario, reiterando que de no ser por estos programas no habría otras oportunidades de acceder a la educación. "El adulto mayor, por lo general, en el caso principal mío comete errores, los he cometido y de pronto los esté cometiendo, pero es por falta de estudio" (grupo focal, EC Bogotá, julio de 2013). Existen condiciones sociales de desigualdad, pobreza y vulneración que también fueron consideradas por los AMPL: 
Antes violaron mis normas, mis derechos y por eso me encarcelaron, uno como persona debe mirar y definir a qué capa social pertenece y se une con ella..., con la presión que viene de hace mucho tiempo de la violencia y eso, entonces no lo dejan a uno, uno ve que al compañero lo mataron, que al otro también, entonces necesariamente uno se ve presionado y le toca coger otro camino para seguir luchando, porque es mejor morir de pie que vivir toda la vida arrodillado. (Grupo focal, Complejo Penitenciario y Carcelario de Ibagué, junio de 2013).

Otros testimonios en este mismo sentido apuntan a un choque contra las estructuras del Estado, que convierte a los individuos en amenazas para la sociedad y el orden establecido. Como se ha notado, la "necesidad" es según los participantes la principal causa del delito y en torno a un cúmulo de necesidad se hicieron alusiones a la familia, los niños, la enfermedad, el hambre y la falta de trabajo. En efecto, muchos testimonios evidencian las precarias condiciones de vida y la suma de muchas vulnerabilidades, que en ocasiones desembocan en la comisión del delito como alternativa de supervivencia; sin embargo, existen estudios como los de Cohen y Felson (citados en Garrido et al., 2001), que les permite afirmar que la mejora de las condiciones de vida de la gente en términos de eliminación de pobreza, aumento de la escolarización y del empleo no tiene relación directa con la disminución de la delincuencia.

Como se observó, en la mayoría de los casos, los AMPL afirman ser inocentes, haber sido mal condenados, culpan al sistema de justicia y a sus diferentes actores, es decir, no reconocen el delito, no entienden la pena o esta última no es aceptada por considerarse injusta. Muy pocos reconocen haber delinquido, muy pocos se muestran arrepentidos, muy pocos reconocen el daño que pudieron ocasionarle a terceros y solo un mínimo reconoce la funcionalidad de la prisión. Como consecuencia de la negación del delito, se imputa la privación de la libertad al sistema de justicia. Desde esta perspectiva, no hay un delito como tal, pero sí se imprime un castigo; por lo tanto, no hay causas del delito, sino de la pérdida de libertad, que en muchas ocasiones se atribuyen a la mala administración de la justicia, la corrupción y ejercicios de poder en los cuales ellos son las víctimas. 
Sin dejar de lado lo anterior, es necesario visibilizar que también resultan afectados por dos fenómenos sociales actuales del país, el desplazamiento: "soy una persona desplazada y tenía seis hijos, entre ellos yo tenía cuatro menores, al papá lo mató la guerrilla, yo no tenía otra alternativa” (grupo focal, Cojam Jamundí, julio de 2013) y la desigualdad social: "yo diría que las condiciones varían de acuerdo con la condición social, uno por la desigualdad, la pobreza y el otro por la situación que vivimos, el vicio, entre las dos hay delincuentes" (grupo focal, Coiba Ibagué, julio de 2013). El primero está presente principalmente en las mujeres y el segundo es manifestado más por los hombres. En este orden de ideas, la génesis del delito en AMPL también es producto de consecuencias sociales de otros delitos, como el conflicto armado y la corrupción, que deben ser estudiados en profundidad y de manera específica desde la perspectiva de género, orden social y delito.

\section{Razones para la reincidencia}

Maximizar el uso del régimen punitivo demanda crecientes recursos públicos, sin que se obtengan resultados claros sobre el beneficio que esta política tiene a corto, mediano y largo plazo para la sociedad. No es claro que las cárceles produzcan reinserción social a quienes las habitan sin importar el tiempo que dure el encarcelamiento, toda vez que en Colombia la reincidencia de reclusos condenados es creciente y el endurecimiento de las penas ha sido una política deliberada. Según datos del Inpec, se registra un incremento de 1771 reclusos reincidentes, al pasar de 9244 en diciembre de 2003 a 11015 en abril de 2008 (Barreto \& Sneider, 2009). La reincidencia se refiere a la repetición de un acto delictivo por parte del delincuente, hace parte de su comportamiento y alude a los estudios del delito y la criminología, como un elemento de la interacción social (Ossa López, 2012). En términos generales, se tiene como un agravante en el proceso penal, conforme a lo manifestado por la Corte Constitucional en sentencia C-077/2006 al referirse al artículo $55 \mathrm{del} \mathrm{CP}$. Aunque cosa diferente hubiese expresado la Corte Suprema de Justicia en el radicado 26149 del 18-05/2008. 
$\mathrm{Al}$ señalar el término como referencia a una persona que es objeto de una intervención judicial penal (pena) por reincidir (Unodc, 2012), y teniendo en cuenta que constituye un obstáculo para acceder a los beneficios sustitutivos de la pena privativa de la libertad, de la suspensión condicional de la ejecución de la pena (artículo 63 CP) y la prisión domiciliaria (artículo $38 \mathrm{CP}$ ), la reincidencia se convierte en un factor determinante para evaluar la efectividad del tratamiento penitenciario ofrecido a los internos. En este sentido, se indagaron en los participantes las razones por las cuales los AMPL vuelven a cometer delitos, y se encontró que están correlacionadas con las explicaciones de por qué se cometen delitos, en especial por la falta de oportunidades y la necesidad.

En relación con este cuestionamiento, los AMPL se centraron en dos focos principales: factores personales y factores sociales. En el primer factor indican los participantes que la reincidencia está condicionada a la edad, es decir, que observan con mayor probabilidad que las personas jóvenes vuelvan a cometer un delito y que las personas AM por su condición ya no lo hacen: "yo creo que reincide más la gente joven, por edad, por la falta de experiencia” o "ya no. Nosotras no. Las jóvenes" (grupo focal, RM Bogotá, julio de 2013). También se hace alusión al consumo de alcohol y otras drogas como posible detonante de actos delictivos, luego de haber estado condenado en prisión: "yo pienso en el tal ladrón, porque un muchacho de esos vive de eso y para sostener su vicio, si no consigue dinero van a volver a robar" (grupo focal, EPMSC ERE Bucaramanga, julio de 2013).

De igual manera, incluyen la oportunidad como factor de elección del delito: "la mayoría de nosotros no tenemos esa educación; si uno teniendo familia, papá y mamá, comete esos errores..., hacemos lo de Judas, nos bañamos las manos y decimos que no lo volvemos a hacer, pero si vemos la oportunidad..." (grupo focal, Cocuc Cúcuta, julio de 2013). Se puede entender que para estos participantes la reincidencia se presentará una vez se dé la confluencia entre ellos, las víctimas y la ausencia de eficaces protectores, nombrados por Cohen y Felson (citados en Garrido et al., 2001).

Dentro de los factores sociales se menciona de forma particular que la atribución es relacionada con el locus de control externo, definido como la tendencia del individuo a percibir su conducta como menos controlable 
porque las causas no dependen de sí (Azzollini \& Bail Pupko, 2012). En esta medida, sugieren la reincidencia como producto de la falta de acceso a la educación: "acá en Colombia le quitan el fuero a todo, a mi edad, nosotros no tuvimos la oportunidad de estudiar" (grupo focal, Cocuc Cúcuta, julio de 2013), por historia de vida o idiosincrasia: "bueno, un concepto personal, parte de la misma idiosincrasia, el papá de uno le dice que uno es una bestia..., esa manera de ellos pensar se la educaron a uno, uno puede llegar a donde no debe para salir a la realidad de la vida" (grupo focal, Cocuc Cúcuta, julio de 2013). Sin desconocer lo anterior, se hace necesario mencionar que aparecieron razones para la reincidencia asociadas a condiciones sociales evidentes en la realidad del país, como son las problemáticas de los conflictos armados internos, falta de vivienda y de educación, de las cuales señalan como responsable al Gobierno y el Estado.

Al fenómeno de la reincidencia le son adjudicadas causas disímiles por parte de los aMPL, especialmente centradas en la falta de oportunidades y el acoso de las necesidades. Solo un participante retomó la reincidencia como un fracaso en la resocialización: "yo creo que hay una parte virtual y la otra real, en la virtualidad de pronto informes de agencias y así para aparentar, pero a mí me parece que hay casos de gente que lleva cinco, seis y siete entradas, entonces el trato no se ha realizado para atacar el problema estructural" (grupo focal, EPMSC Bucaramanga, julio de 2013). Este discernimiento aborda el fracaso de un tratamiento penitenciario anterior y por ser la única afirmación relacionada con este aspecto como posible causa de la reincidencia pone de manifiesto que para la mayoría o no existe el tratamiento o no se percibe con los objetivos con los cuales ha sido postulado, tanto en ley como en la normatividad penitenciaria, con lo cual se confirma que las dificultades de acceso a educación, trabajo, salud física o mental truncan la inserción social y aumentan las probabilidades de reincidencia penal (Bravo \& Castrillón, 2010).

Más allá de quedarse en el bucle de si la cárcel mejora a las personas o las destruye, es necesario pensar en tratamientos diferentes para los primodelincuentes y para los reincidentes, por cuanto en los comportamientos delictivos de unos y otros se implican interacciones, pensamientos, elecciones, emociones, recompensas, rasgos y perfiles de personalidad, aprendizajes 
y socializaciones, creencias, actitudes, atribuciones, expectativas (Redondo $\&$ Pueyo, 2007), que exigen ampliar los marcos desde los cuales se analizan las necesidades de los internos, como esta en la que se observa la incertidumbre y la importancia del sistema familiar para lograr una reinserción exitosa: "que uno tenga certeza de que al salir no va a reincidir porque eso depende del sistema de vida que ha tenido, de la forma como vaya a salir, de si la familia está presente. Porque aquí "hay gente que tiene familia y no les permiten la entrada a la casa, hablo de muchas personas", "no, no, no aquí a la casa no venga” (grupo focal EPMSC Medellín, julio de 2013). Contrastar esta información obtenida de primera mano con los protagonistas, con la que se encuentra en las pautas, los procedimientos y las directrices del Inpec, deja la sensación de que las necesidades de los internos -contrario de ser incluidas mediante recolección de información estructurada, como resultado de investigaciones promovidas por las diversas subdirecciones del Inpec- parecen ser inferidas en relación con la experiencia de los profesionales que se encuentran a cargo de impartirlas desde un nivel central.

\section{Tratamiento penitenciario}

El tratamiento penitenciario en Colombia se define como:

[...] el conjunto de mecanismos de construcción grupal e individual, tendientes a influir en la condición de las personas, mediante el aprovechamiento del tiempo de condena como oportunidades, para que puedan construir y llevar a cabo su propio proyecto de vida, de manera tal que logren competencias para integrarse a la comunidad como seres creativos, productivos, autogestionarios, una vez recuperen su libertad. (Inpec, 2005)

Dichas estrategias se desarrollan mediante estudio, trabajo y enseñanza. Como se puede observar, con el tratamiento penitenciario se busca lograr cambios en las personas, sin definir particularidades por tener en 
cuenta de acuerdo con las características de los diversos grupos que forman la población privada de la libertad. Entre estos se encuentran los AMPL.

Estas acciones se han organizado teniendo en cuenta los principios del sistema progresivo, en una metodología denominada Plan de Acción y Sistema de Oportunidades (PASO), concebida como herramienta para organizar y articular cada uno de los mencionados componentes y fases de seguridad en el Tratamiento Penitenciario y la Atención Integral, en beneficio del interno(a) y su proceso de reinserción de manera progresiva (Universidad Nacional de Colombia, Inpec, 2008). Con esto se encontró que los AM condenados en su mayoría están en fase de alta seguridad. El porcentaje correspondiente a quienes aún no se encuentran clasificados en fase de seguridad y los que están en fase de observación, diagnóstico y clasificación suman un $48 \%$ de la población; es decir, casi la mitad de los AM condenados en Colombia no han iniciado su tratamiento penitenciario.

Figura 33. Población adulta mayor privada de la libertad por fase de tratamiento

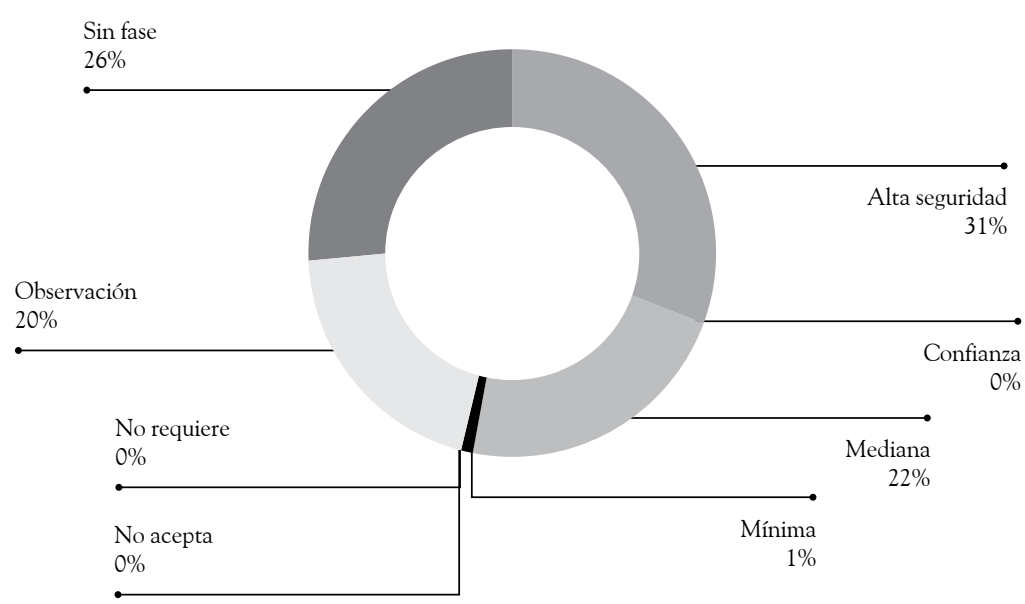

Fuente: Sisipec Web, 31 de julio de 2013. Cálculos de los autores.

Partiendo de la premisa que rige el tratamiento penitenciario, se encontraron percepciones que los AMPL tienen al respecto, máxime cuando han sido considerados como población en condiciones excepcionales (Subdirección de Reinserción Social Inpec, 2012), y aun cuando los participantes no estén relacionados con el término. La mayoría de participantes en los 
grupos focales no conocen qué es una población excepcional o no están relacionados con el término. Algunos de ellos lo asocian a la población LGBTI o a los pueblos indígenas, otros reconocen que se trata de poblaciones que tienen una especial protección de la ley, que se encuentran en riesgo o que requieren un tratamiento especial "excepcionales, como los indígenas", "los campesinos", "los que no tienen abogado", "los gais, los de la tercera edad" (grupo focal, EC Bogotá, julio de 2013). La precepción está asociada a la pertenencia a grupos minoritarios o con características diferenciales marcadas frente a la población en general. En el ámbito carcelario, se reconoce, por algunos de los participantes, que los AM hacen parte de las poblaciones excepcionales y que por tanto deben recibir un tratamiento diferente al de los demás internos. Dentro de los aspectos que se mencionan, asociados a este tipo de tratamiento, los más comunes son un patio exclusivo, una alimentación acorde a la edad, la posibilidad de una metodología de estudio especial que reconozca las condiciones físicas y mentales propias de los AM y la prioridad de atención en salud.

Los AMPL participantes asocian el tratamiento al estudio o capacitación formal y no formal, que reciben en el EPC, y uno de los que tiene acceso a este le otorga calificación positiva, manifestando agradecimiento por las cosas aprendidas en prisión. Se mencionan entonces las clases, las manualidades, los talleres y los oficios, haciendo referencia constante al aprovechamiento del tiempo y a la utilidad que se le dará a estos nuevos conocimientos, una vez se recupere la libertad. "Para mí es muy bueno porque cuando yo era pequeña mi mamá no pudo darme estudio, pero en la cárcel terminé mi primaria. No pude estudiar bachiller por cuestiones de salud, entonces no pude seguir con mi bachillerato..., quería seguir estudiando, pero no pude" (grupo focal de mujeres, Complejo Carcelario y Penitenciario de Jamundí, julio de 2013).

Se identificó la carencia de competencias lectoras y escritoras de los AMPL y la falta de oportunidades para acceder a capacitaciones o formación en su juventud. Esto puede incidir en que identifique el tratamiento con la formación y se afirme que la prisión trae algunos aprendizajes. Sin embargo, no se valora la capacidad resocializadora del tratamiento, sino la oportunidad que representa para redimir pena o la diferencia que ofrece frente 
a una vida anterior de privaciones. $\mathrm{Al}$ respecto, incluso se hacen bromas: "No, de haber sabido que iba a aprender tantas cosas, habría entrado antes ja, ja, ja," (grupo focal, EPMSC Bucaramanga, julio de 2013).

Las constantes menciones de ocupación en lo educativo y lo laboral cuando hacen alusión al tratamiento penitenciario visualizan la brecha existente entre la definición que se expuso por parte del Inpec y lo que los AMPL perciben de este: "Porque yo manejo los hilos, pero aprendí con eso a entretenerlos, pero aquí no hay alguien que diga: vengan muchachos hagamos esto, hagamos lo otro. No hay nada. Y si comienzan un proceso, vienen dos o tres días y no vuelven" (grupo focal EC Bogotá, julio de 2013). Conexo aparece el uso del término "resocialización" para referirse a la participación en actividades, mas no a un proceso que implica cambios personales:

[...] aquí no se resocializa a nadie, aquí se viene a aprender más mañas, que sí, que yo sé que salgo, no eso es mentira porque si por ejemplo yo soy un exportador aquí hay muchas personas. Aquí por ejemplo me dicen: vea se va a ganar $\$ 30.000 .000$ o $\$ 20.000 .000$ y yo en este momento con la situación que salgo, yo no me pongo a pensar tanto en la cárcel que me devuelvan porque necesito la plata, entonces aquí no hay resocialización. (Grupo focal, EPMSC Acacias, julio de 2013)

En este sentido, el tratamiento se ha convertido en un conjunto de actividades para entretener a los presos (Gil, 2010). En algunos casos las actividades resultan inexistentes, al tiempo que la redención de pena se certifica como efectiva, hecho que desdibuja aún más la orientación que debería tener el tratamiento penitenciario: "Sí, pero eso es simbólico porque nosotros eso no lo hacemos", "únicamente dice trabajo, nos llega una planilla que dice trabajo tanto tiempo, pero en realidad no se ve como trabajo" (grupo focal, EPMSC Acacias, julio de 2013).

Al indagar sobre el tipo de tratamiento que se recibe en prisión, la mayoría de AMPL afirmaron no recibir un tratamiento de tipo diferencial; por el contrario, enfatizaron en que el tratamiento es el mismo para todos y que no se adapta a las condiciones particulares de un AM. Lo que más se reclama en este sentido es un espacio exclusivo para AM, pues se afirma 
que los pabellones compartidos con otras poblaciones son extremadamente agresivos y facilitan la vulneración de esta población. "Allá se consume mucho vicio, hay muchos problemas y todo eso a uno ya le molesta por la edad, uno requiere más tranquilidad, más sosiego" (grupo focal, EPMSC Cali, julio de 2013). Algunos de los AMPL dicen haber sido víctimas de ataques, robos o malos tratos por parte de otros internos, que no respetan su edad ni su condición.

Así pues, pocos participantes tienen una valoración positiva del tratamiento penitenciario que reciben, afirmando que efectivamente está orientado a la resocialización o reconociendo que cualquier tipo de ocupación es necesaria en prisión, para pasar el tiempo y no desesperar. En general los participantes tienen una valoración negativa y no reconocen que el tratamiento pueda servir para la resocialización; por el contrario, afirman que la prisión es una verdadera "universidad del delito".

¡No sirve! Aquí el tratamiento que la cárcel le da al preso no resocializa a nadie; aquí de pronto el que no requiera resocialización se mantenga firme y no siga incurriendo, ni especializándose, pero las cárceles colombianas son una especialización del delito. Muchas personas que realmente no son delincuentes y por cualquier circunstancia caen a la cárcel se convierten en verdaderos delincuentes. Aquí no hay resocialización. (Grupo focal, EPMSC Cali, julio de 2013).

En consecuencia, pocos AMPL reconocen un cambio interno como resultado de su estancia en prisión y este no es atribuido al tratamiento, sino a largas jornadas de reflexión, a un enfrentamiento consigo mismos y a la superación de las adversidades y sinsabores propios del ámbito penitenciario.

El aspecto de tratamiento diferencial es entendido por los AMPL como un derecho al que pueden y deben acceder, por su condición de AM: "tienen que darnos un trato especial porque somos adultos mayores. En la cárcel no es lo mismo que nos vayan a tirar revueltos con los muchachos de $20 \mathrm{o}$ 25 , que nos pueden agredir y uno no puede defenderse igual" (grupo focal, Complejo Carcelario y Penitenciario de Jamundí, julio de 2013). Se reitera así que la solicitud primordial de los internos es un patio especial, aislado 
de otras poblaciones frente a las que se sienten amenazados o que manejan una escala de valores diferente a las suyas.

Las solicitudes muy puntuales de los internos se ubican perfectamente en el marco de los enfoques diferenciales, reconocidos y estipulados por la Ley 65 de 1993, en su artículo 3 A: "El principio de enfoque diferencial reconoce que hay poblaciones con características particulares en razón de su edad, género, orientación sexual y situación de discapacidad. Por tal razón, las medidas penitenciarias contenidas en la presente ley, contarán con dicho enfoque" (Congreso de Colombia, 1993).

Hablar de enfoques diferenciales en prisión inmediatamente remite a pensar en espacios adecuados para las necesidades específicas de las distintas poblaciones. Este razonamiento se fortalece aún más al tratarse de poblaciones de AM, de personas en condición de discapacidad o de personas con enfermedades crónicas, pues sus determinantes físicos y las limitaciones a la movilidad sin duda exigen un entorno amigable, que facilite su vida. De esta manera, los espacios deberían estar dotados de rampas, preferiblemente no tener escaleras, tener corredores amplios y garantizar tramos cortos entre los lugares donde se desarrolla la vida cotidiana (la celda, el baño, el patio, el comedor). Sin embargo, no se ha llegado a un consenso sobre la importancia de generar espacios especiales para estas poblaciones o adecuar todos los EPC con estas características. Lo cierto es que en la actualidad no hay espacios especiales en los EPC existentes y tampoco están dotados para facilitar la movilidad.

Un hecho que parecería obvio, en términos médicos, sociales y económicos, como la creación de establecimientos especiales para estas poblaciones, no lo es tanto para quienes toman las decisiones en materia penitenciaria. De esta manera, no hay una normativa internacional que recomiende los establecimientos especiales y tampoco hay muchos países que los estén implementando. Colombia no es la excepción y así los AMPL comparten su estadía en prisión con todos los demás reclusos, con algunas excepciones, como el pabellón de AM de EPMSC Cali (ERE), en el que sin duda se presentan dinámicas interesantes de autogestión y se evidencian prácticas en materia de calidad de vida acordes con la población. Este establecimiento puede presentarse como ejemplo claro de tratamiento diferencial a la 
población de AMPL: "Yo siento que aquí en este patio se viven cosas muy diferentes a otros patios, que están en hacinamiento y donde no duermen bien; nosotros aquí estamos viviendo una vida mejor. No hay hacinamiento, no hay encierro, aquí no se consume droga, no se pierden las cosas, no hay delincuencia" (grupo focal EPMSC Cali, julio de 2013).

Es pertinente en este punto precisar la diferencia existente entre el trato y el tratamiento, definiendo el trato como la forma de configurar las relaciones entre el interno y la guardia, y entre el interno y los demás internos. Al respecto, la mayoría de AM reconocen un buen trato por parte de la guardia, que se ve favorecido en los casos en los que se cuenta con un patio especial para ellos, dado que (como lo reconoce el personal de guardia) los AM no representan un gran riesgo para la seguridad, por lo que las relaciones con ellos tienden a disminuir la tensión: "Como le digo hay muchos..., pues digamos en ese tema de los guardianes, el personal de seguridad, para los que vivimos en este patio el trato es normal, dentro de lo normal" (grupo focal, Coiba Ibagué, julio de 2013).

Igualmente, las relaciones entre el interno y los demás internos son mucho más cordiales y llevaderas en estos espacios especiales aun en condiciones de hacinamiento, que cuando no se cuenta con ellos: "Pero desde que yo estoy aquí en este patio..., en este patio hay buena convivencia, relativamente. De pronto por ahí hay disgustos pero pasajeros, pero no pasan a mayores" (grupo focal, Coiba Ibagué, julio de 2013).

Cuando no se cuenta con un patio especial, la guardia mantiene un trato igual con todos los internos, sin consideraciones con el AM; de esta manera, se somete a todos a las mismas requisas y a las mismas rutinas:

Sí porque muchas veces en una requisa la verdad lo miran a uno mal, lo empujan $[\ldots]$ pero muchas veces el mismo trabajo que hacemos cuando hacen esas rascadas en los patios cuando se llevan las matas que hacemos, se llevan los cinturones que hacemos, entran los muchachos bachilleres y ellos llegan con orden del teniente y nos recogen todo se lo llevan y lo botan por allá y eso desaparece, no tenemos derecho a tener una pantaloneta para ponérnosla porque tiene que ser de tal color. (Grupo focal, EPMSC Acacias, julio de 2013) 
Lo anterior, sumado a la relación con los otros internos, complejiza la convivencia del AMPL, pues se manifiestan abusos precisos como el robo de objetos personales: "Uno sale pa' allá abajo con miedo porque a los viejos nos atracan, nos hacen de todo" (grupo focal, Complejo Carcelario y Penitenciario de Bogotá, julio de 2013), las agresiones físicas y verbales y el uso y abuso de sustancias psicoactivas, que se atribuyen mayormente a los internos más jóvenes.

Hay mucho consumo de vicio, la pelea, la riña y los jóvenes no son todos los que pelean, o que lo insultan y lo quieren agredir, pero sí hay uno que otro que lo trata por lo menos de agredir. Por ahí está el grupo de oración y lo tratan a uno de viejos hijue... no sé qué. Hay un trato verbal que ofende, pero como uno no puede ponerse a pelear con ellos porque pierde uno por la edad, porque ellos lo pueden herir a uno. (Grupo focal, Cocuc Cúcuta, julio de 2012)

En el tema de alimentación, se evidenció que hay una dieta especial para las personas hipertensas, que no necesariamente pertenecen al grupo de AM; por lo demás, las dietas son las mismas y también los demás aspectos. Como conclusiones se puede proponer el hecho de que los internos afirmen haber encontrado en la prisión oportunidades que no encontraron afuera. Se plantea una reflexión sobre la finalidad del tratamiento penitenciario, que por supuesto no es garantizar derechos que debieron ser garantizados afuera. Que la prisión tenga este significado para los AMPL permite en primer lugar cuestionar el rol del Estado como garante y como castigador. En segundo lugar, ofrece la posibilidad de analizar las ventajas de delinquir, sobre las posibilidades de no hacerlo en ciertos medios; finalmente, hablar de las bondades de estar en prisión por las ventajas que ofrece la satisfacción de necesidades básicas por parte de las instituciones carcelarias.

Las condiciones físicas de los AMPL son unas de las principales razones por la cuales se puede presentar la disminución en el riesgo de reincidencia, pero tanto la capacidad intelectual como las características individuales y condiciones sociales son cercanas a los factores de riesgo que favorecen las posibilidades de reincidencia en actos delictivos. 
Como variable del tratamiento penitenciario surgió el concepto de tratamiento diferencial, que hace referencia a las formas de discriminación de las que pueden ser víctimas los grupos minoritarios o poblaciones excepcionales y además busca brindar una atención acorde a los requerimientos de dichas poblaciones. Efectivamente, las rutinas en los pabellones destinados específicamente para AMPL son más flexibles: las celdas suelen estar abiertas, no hay un horario estricto para levantarse ni para acostarse y hay más posibilidad de movilidad. Esto puede responder a que no se percibe en los AMPL una amenaza latente, de hecho, los guardias hacen referencia a que allí nunca ocurre nada y hacen bromas relativas a la "peligrosidad" de los internos que allí se alojan, incluso se refieren a ellos como "perros viejos".

La ausencia de intervenciones diseñadas para las problemáticas psicosociales manifestadas por los AMPL y de personal capacitado en la atención de estas personas pone de manifiesto la tendencia de los EPC y del Inpec en general a implementar acciones que distan de la realidad cotidiana, lo cual dificulta el hecho de que un AMPL pueda experimentar adherencia en un proceso de tratamiento, ya que una persona no puede ni debería adecuarse a lo que otros consideran conveniente para ella (Saenz, 2007). Al respecto, se encontró un estudio en el que se evidenció que los AMPL en promedio experimentaron más adherencia al tratamiento específico y un menor número de violaciones de libertad condicional que los adultos jóvenes, durante un seguimiento que se les hizo durante seis meses (Canada et al., 2013), que apoyan la necesidad de implementar acciones de tratamiento diferencial de acuerdo con las necesidades percibidas por los participantes y las que son producto de investigaciones estructuradas. 


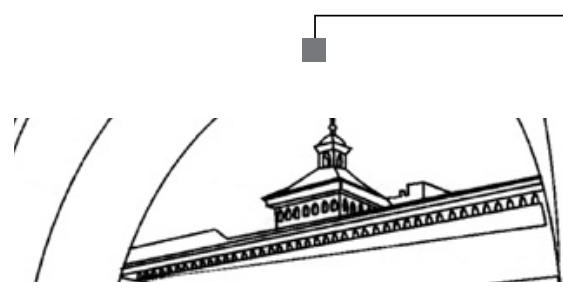




\section{Política criminal con enfoque diferencial en relación con el adulto mayor}


El CP establece en el artículo 3 que la pena debe responder a los principios de necesidad, proporcionalidad y razonabilidad, principios que no se cumplen, considerando lo excesivos que resultan; la falta de seguimiento y control a estos, amén de la imposibilidad que se tiene de brindar un tratamiento adecuado con la situación particularizada de los reclusos, que como se ha indicado carecen en su gran mayoría de condiciones dignas durante el periodo de internamiento. Otro tanto ocurre con las funciones de la pena a las que alude el artículo 4 del mismo estatuto: prevención general, retribución justa, prevención especial y protección al condenado.

De manera que a la luz del ordenamiento jurídico, la pena a la que se somete un ciudadano debería ser objeto de consideración por parte de quien se encarga de velar por su cumplimiento y las condiciones con las cuales esta se paga, especialmente por el juez de ejecución de penas, operador que tendría que contar con una serie de instrumentos legales, plenamente establecidos a fin de poder evaluar los resultados del "tratamiento" recibido por el recluso.

Independientemente de que la ley sea general, en materia penal la ejecución de la sanción para los AM debería estar ceñida no solamente a los controles y los seguimientos que se reclaman, sino estrictamente apegada a los postulados del derecho humanitario y constitucional, considerando, como se ha venido pregonando y reiterando, su condición de vulnerabilidad manifiesta, condición que se acrecienta en los AMPL por el impacto que produce la sanción y la mayor dificultad de esta población a la prisionización. Estos son efectos bien distintos a aquellos que se suscitan en otras personas que no comparten ese estado permanente de vulnerabilidad, bien sea porque la persona ha sido condena como AM, o porque a través del proceso de envejecimiento dentro de la prisión ha adquirido dicha categoría, sin que se pueda deslindar en este último caso del trato especial, por cuanto la condición para dicho trato deviene de una condición intrínseca del sujeto.

De allí que si existe ese trato especial para otras personas reconocidas en condición de manifiesta vulnerabilidad, como es el caso de los menores, no resulta proporcional y lógico que ello no se dé en relación con los AM, diferenciación que rompe con el principio de igualdad entre desiguales; aspecto que genera discriminación y falta de integración normativa. Se trata 
entonces de crear condiciones especiales de internamiento para los AMPL cuando estas resulten necesarias, proporcionales y razonables, y mecanismos alternativos a la prisión intramural. Al indagar por las penas alternativas, los participantes enfatizaron en la prisión domiciliaria, en el brazalete electrónico, y en unos casos muy interesantes se planteaba la posibilidad de realizar trabajos comunitarios o trabajar como sujetos de prevención frente al delito, partiendo de su propio testimonio y experiencia en los EPC.

En cuanto a lo primero, si la reclusión resulta necesaria, el establecimiento debería cumplir con condiciones físicas apropiadas para los AM. Con respecto a lo segundo, las penas alternativas, que exista la posibilidad de dosificar el quantum de la pena impuesta frente al deterioro físico o mental, condiciones más benignas para acceder a la prisión domiciliaria, al igual que a los subrogados penales y beneficios genéricos, como términos más reducidos, tratamiento penitenciario combinado, que parte se cumpla en el domicilio personal o laboral, y parte intramural, trabajo social cuando se esté en capacidad de realizarlo y descuentos mayores por el tiempo redimido, por ejemplo. A continuación, se considerarán los aspectos mencionados anteriormente, independientemente de cómo hayan sido tratados por el Código Penitenciario Carcelario.

Ley 1709 de 2014, nuevo código penitenciario (Diario Oficial 49039, lunes 20 de enero de 2014), "Por medio de la cual se reforman algunos artículos de la Ley 65 de 1993, de la Ley 599 de 2000, de la Ley 55 de 1985 y se dictan otras disposiciones". Aunque lastimosamente esta ley no alude en concreto o directamente al AM, ni mucho menos constituye la creación de establecimientos o pabellones destinados a su reclusorio, y a pesar de que no resulta ser la panacea para todos los problemas que aquejan nuestro SPCC, pareciera que constituye un avance en la línea de asegurar un trato más humano, más digno para aquellos que hoy se hallan privados de la libertad o que pueden llegar a estarlo, además de impulsar con su vigencia una política criminal más estable, sensata y equilibrada con nuestra realidad. Su buena y exitosa aplicación dependerá de la voluntad política, léase recursos necesarios que se destinen a tal fin, como en buena parte lo prevé en sus artículos 10, 97 y 98. 
Procurando realizar un recorrido ordenado por su articulado, dado que la expedición y aplicación de esta nueva ley tendrá que ver con todas las PPL, incluidos los AM, encontramos como aspectos relevantes los que se dan a conocer a continuación.

Artículo 1: "Toda persona es libre. Nadie puede ser sometido a prisión o arresto, ni detenido sino en virtud de mandamiento escrito de autoridad judicial competente, con las formalidades legales y por motivo previamente definido en la ley". La refrendación del principio de legalidad frente a cualquier escenario donde se pueda afectar la libertad constituye una garantía fundamental para los ciudadanos, no interesa cuántas veces se reitere ello en una democracia, en un Estado social de derecho. Nunca serán demasiadas las veces de los llamados que se hagan para preservar los derechos fundamentales de aquellos que se encuentran privados de la libertad.

Se asume tímidamente el enfoque diferencial cuando se reconoce que hay poblaciones con características particulares en razón de su edad, género, religión, identidad de género, orientación sexual, raza, etnia, situación de discapacidad, etc. (artículo 2).

Se busca hacer claridad sobre las penas y medidas de seguridad, siendo modalidades de la primera como penas privativas de la libertad para imputables, la prisión intramural o domiciliaria y el arresto, esta última sustitutiva de la multa en establecimientos especiales (artículo 3).

A pesar de que el artículo 5 de la Ley 65 de 1993 ya consagraba el respeto a la dignidad humana, y como es sabido dicho precepto no se cumplió, una vez más se entroniza por lo menos teóricamente el respeto a la dignidad humana: "En los establecimientos de reclusión prevalecerá el respeto a la dignidad humana, a las garantías constitucionales y a los Derechos Humanos universalmente reconocidos. Se prohíbe toda forma de violencia síquica, física o moral" (Congreso de Colombia, 2014, artículo 4). Su vulneración no podrá justificarse en la carencia de recursos (artículo 4). Será este mandato, sin lugar a dudas, uno de los principales retos que tiene la reforma, puesto que no tiene justificación de ninguna clase el estado actual de varios de los EPC que funcionan en el país y que ya reportan tragedias muy graves como la registrada en Barranquilla. Colombia bajo ningún 
pretexto puede prolongar las condiciones que caracterizan en la actualidad la privación de la libertad.

El Consejo Superior de la Judicatura garantizará la presencia de por los menos un juez de ejecución de penas y medidas de seguridad en los EPC que así lo requieran (artículo 5). Ya era hora de que dichos funcionarios se ubicaran adecuadamente, para que al fin puedan cumplir ágil y oportunamente con sus obligaciones, como operadores de justicia, evacuando solicitudes sobre libertad definitiva por pena cumplida, libertad condicional y reconocimiento de redenciones de pena, entre otros. Resulta coherente que los EPC del orden nacional estén a cargo del Inpec (artículo 8), incluso como se ha sugerido en otras oportunidades su competencia debería abarcar todas las entidades y dependencias que alberguen PPL, cualquiera que sea su situación jurídica.

También la Ley 65 en su artículo 20 clasificaba los establecimientos de reclusión; sin embargo, esta reforma la reitera y la recompone así: 1) cárceles de detención preventiva; 2) cárceles penitenciarias; 3) centro de arraigo transitorio; 4) establecimientos para inimputables; 5) penitenciarias y cárceles de alta seguridad; 6) cárceles y prisiones para mujeres; 7) cárceles y penitenciarias para miembros de la fuerza pública; 8) colonias agrícolas; 9) casas para detención preventiva y cumplimiento de penas para conductas culposas; 10) demás centros de reclusión. Las clasificaciones resultan en ocasiones convenientes, necesarias y hasta deseables, siempre que no se afecten principios fundantes como el de la dignidad y la igualdad, dado que a través de ellas se puede incurrir en privilegios y desafueros como ha ocurrido a lo largo de nuestra historia patria, los cuales conllevan necesariamente discriminaciones y desventajas para otros.

Cárcel para la detención y cumplimiento de pena por conductas punibles culposas cometidas en accidente de tránsito o en ejercicio de toda profesión u oficio; centros de arraigo transitorio; establecimientos de reclusión para inimputables por trastorno mental permanente o transitorio con base patológica y personas con trastorno mental sobreviniente (artículos $14,15$ y 16$)$.

Dicha reforma sustituye algunos lineamientos del CP en lo que tiene que ver con prisión domiciliaria, suspensión de la ejecución de la pena y 
libertad condicional, y se permite incluso que la ejecución de la pena se complete en el lugar de residencia cuando se haya cumplido la mitad de esta, siempre y cuando concurran los presupuestos contemplados en los numerales 2 y 3 del artículo 38 del CP, así como la exclusión de cualquier clase de beneficio y subrogado, cuando la persona haya sido condena por delito doloso dentro de los cinco años anteriores, esto conforme a los artículos 22 a 28, 29, 30 y 32. Normas donde se centra lo más importante de la política criminal que se pretende implementar, considerando que lo penitenciario y lo carcelario hacen parte de aquella; sin embargo, pareciera que los aspectos penitenciario y carcelario para los efectos se superpusieran a lo sustancial, a las directrices de un orden normativo, moldeado en un estatuto punitivo integral, así su praxis, la pena, lo trascienda, pues es desde el CP desde donde se deben trazar los lineamientos generales del ius puniendi, y en consecuencia donde se deben consignar las pautas más importantes de la política criminal, todo aquello que tiene que ver no solamente con los comportamientos delictivos, inicio de la criminalización, sino la respuesta institucional manifestada a través de las penas, considerando sus aspectos cuantitativos y cualitativos.

Indiscutiblemente resulta práctico y necesario aprovechar los recursos tecnológicos, cuando se establecen las audiencias virtuales (artículo 33), siempre y cuando no se afecte el debido proceso y se conculque derecho de defensa.

El parágrafo del artículo 37 insiste una vez más en la dignidad, cuando plantea que: "En los establecimientos de reclusión prevalecerá el respeto a la dignidad humana, a las garantías constitucionales y a los Derechos $\mathrm{Hu}$ manos universalmente reconocidos. Se prohíbe toda forma de violencia síquica, física o moral". "Parágrafo. Todos los establecimientos carcelarios y penitenciarios contarán con las condiciones de infraestructura adecuadas para la reclusión de la población en condiciones de discapacidad, teniendo en cuenta el artículo $5^{\circ}$ numerales 2, 8, 10, el artículo 14 de la Ley 1618 de 2013".

Se busca corregir el déficit de jueces de ejecución de penas cuando se prevé la creación de los despachos que resulten necesarios para asegurar la celeridad o pronta decisión a las peticiones hechas por los reclusos 
(artículo 42); a su vez, se destaca la importancia que tiene el sistema de información de Sistematización Integral del Sistema Penitenciario y Carcelario (Sisipec) como fuente principal de información de las autoridades penitenciarias, carcelarias y judiciales de las PPL y que se encuentren por cuenta del SPCC (artículo 43).

La provisión de alimentos estará a cargo de la Unidad de Servicios Penitenciarios y Carcelarios (Uspec), y se posibilita por orden del médico el cambio del régimen alimentario, de conformidad con el artículo 48. Quizás se logre respetar y efectivizar, lo cual supondrá una reglamentación muy estricta por parte del Inpec, todo lo relativo a trabajo, a la redención de pena por estudio, enseñanza y, lo más importante, el derecho a esa redención, conforme lo establecen los artículos 55 y ss., 60, 61 y 64, respectivamente.

Se reitera en forma expresa el derecho a la salud, sin lugar a dudas uno de los más vulnerados a las PPL y en especial a los AM, y se crea el Fondo Nacional de Salud de las PPL, como una cuenta especial de la nación, con independencia patrimonial, contable y estadística, sin personería jurídica. Este fondo estará constituido por recursos del presupuesto general de la nación (artículos 65 y 66); así como la asistencia médica de internos con especiales afecciones de salud (artículo 67).

El artículo 72, que modifica el 111 de la Ley 65 de 1993, señala lo relativo a las comunicaciones del privado de la libertad con el núcleo social y familiar. Los artículos 73 y 74 regulan lo relativo a vistas, incluyendo las de menores.

La reforma igualmente se pronuncia sobre los permisos excepcionales (artículo 85); asistencia jurídica (artículo 89); modifica igualmente la composición del Consejo Superior de Política Criminal (artículo 91), al igual que la Comisión de Seguimiento a las Condiciones de Reclusión del SPCC (artículo 93); también se alude a las condiciones de reclusión y resocialización para miembros de pueblos indígenas, de comunidades afrocolombianas, raizales y palanqueras, así como de grupos Rom, facultando al presidente para que en el término de seis meses regule todo lo relativo a la privación de la libertad de estos grupos (artículo 96). Este último aspecto ha debido ser mayormente considerado, puesto que si bien se ha querido connotar el tratamiento diferencial, existen prioridades como el caso de los AMPL. 
El artículo 99 modifica el artículo 89 de la Ley 599/2000 (CP), en lo relativo a la prescripción de la sanción penal. Compromiso igualmente importante se asume con el tema de la resocialización y la reintegración social, cuando el artículo 102 determina lo siguiente:

Programa de Resocialización y Reintegración Social, dentro de los seis (6) meses siguientes a la publicación de la presente ley, el Ministerio de Justicia y del Derecho, el Instituto Nacional Penitenciario y Carcelario (Inpec), el Ministerio de Educación Nacional, el Ministerio de Salud y de la Protección Social, el Ministerio de Trabajo, el Ministerio de Cultura, el SENA y la Unidad de Servicios Penitenciarios y Carcelarios (Uspec) elaborarán un programa de resocialización y reintegración social que deberá implementarse y ejecutarse en todos los establecimientos carcelarios y penitenciarios del país. Dicho programa incluirá componentes de bienestar social del interno, educación, deporte y cultura, emprenderismo y trabajo con enfoque diferencial. 


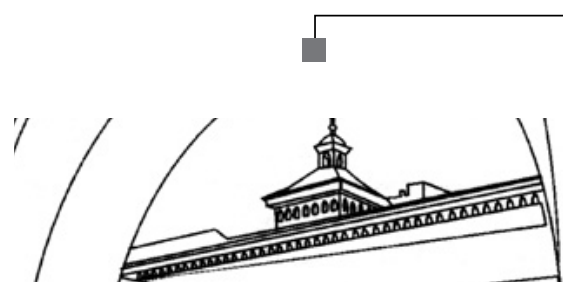




\section{Conclusiones y recomendaciones}




\section{Trato}

Definitivamente el AM en Colombia requiere recobrar su valía, un lugar que le permita coexistir con distintas generaciones sin ser segregado, dándole cabida en una sociedad incluyente para todas las edades. Lo anterior supone tener acceso a la salud y a una forma de vida saludable, a participar en el desarrollo económico de sus comunidades con beneficio propio, a un entorno social favorable. Los AM deben compartir la suerte de otros grupos en condición de vulnerabilidad u opresión, como es el caso de mujeres, niños, indígenas, personas con discapacidad, migrantes, refugiados, personas en situación de extrema pobreza, etc., para el reconocimiento de sus derechos específicos o particulares. Trato diferencial que debe asegurar una Convención Internacional de las Personas Mayores.

Como grupo etario, el AM requiere de la construcción de una legislación que asuma su realidad y haga clara, explícita y efectiva la garantía estricta de sus derechos, los cuales se pervierten aún más dentro de los EPC, donde no existen pabellones o espacios especializados para los AMPL. La experiencia mostró que también se pueden generar dinámicas de autogestión y solidaridad entre internos que comparten, en razón de su edad, necesidades, sentimientos y concepciones de la vida.

Deben incluirse perspectivas de diversas disciplinas para el diseño de nuevos establecimientos y la modificación o adecuación de los ya existentes, con el fin de generar espacios donde realmente se tengan en cuenta las necesidades y las posibilidades de esta población. Así, los espacios deben contar con rampas, corredores amplios, barandas en casos especiales y tramos cortos entre celdas, baños, comedor y patio, lugares en los que transcurre la vida cotidiana. Igualmente, se debe garantizar el acceso a ayudas técnicas en caso de presentarse alguna discapacidad, como bastones, caminadores, sillas de ruedas, audífonos, etc.

En ese sentido, se debe contar con establecimientos o pabellones exclusivamente destinados al AM, diseñados y construidos con una distribución geográfica adecuada, que además permitan su clasificación por comportamientos delictuales. En Colombia no se cuenta con espacios tan especializados, pero hay pocos establecimientos que han implementado pa- 
bellones exclusivos para adultos mayores, lo cual ha demostrado resultados muy positivos en cuanto a convivencia, tratamiento y trato.

Así, los EPC que cuentan con pabellones especiales para AM presentan una dinámica diferente a los que carecen de ellos. Sin embargo, estos pabellones son escasos por la situación de hacinamiento presente en todo el país. Este hecho es lamentable, pues la percepción es que con pabellones exclusivos para los AMPL se logra dignificar a esta población, reconociendo su situación de vulnerabilidad frente al resto de los internos. Mientras no se aminore la situación de hacinamiento que se presenta en el país y que posiblemente llegará a cifras del $60 \%$, pensar en pabellones exclusivos, sobre todo en la población masculina, es casi una utopía.

Por otro lado, la persona mayor debe ser considerada como sujeto activo especial de delito, no para vestirlo con un ropaje de impunidad o presumirlo inimputable, aunque en ocasiones pueda llegar a serlo, sino como sujeto personal y socialmente merecedor de un trato especial, de un acompañamiento exclusivo, de una tratamiento diferente que le permita como sujeto de derechos alcanzar la rehabilitación y la socialización, que supone justifica la pena, así se encuentre en las postrimerías de su existencia, por cuanto sigue siendo persona y poseedor de sueños y esperanzas.

En casos de deterioro físico o mental, es decir, cuando la condición de salud no es compatible con la vida en prisión, se sugiere el traslado de estos AM a casas geriátricas o instituciones psiquiátricas, aplicando también el otorgamiento de prisión domiciliaria. Así pues, al igual que el adolescente infractor, resultaría necesario darle al infractor AM un trato especial, dado que la respuesta institucional que se da en relación con la investigación, el juzgamiento y la sanción no contempla tratos diferenciales de mayor envergadura, como se puede corroborar a través de las distintas instituciones procesales.

Por último, la dignidad es una categoría transversal a la atención en salud, así como a la no discriminación e igualdad. Se puede afirmar única y exclusivamente bajo el contexto de la presente investigación que el trato no digno de la PPL está relacionado con una falencia en el enfoque diferencial. 


\section{Política penitenciaria para el adulto mayor privado de la libertad}

El ya limitado presupuesto se difumina al ser asignado en general para los grupos en condiciones excepcionales, sin tener en cuenta que entre este conglomerado existen subgrupos que tienen necesidades específicas, como el caso de los AMPL. Por esta razón, se recomienda realizar la asignación de recursos acorde a los programas diseñados y desarrollados según las características de cada población.

No se encuentran funcionarios profesionales especializados en AM que desde sus respectivas disciplinas o especialidades actúen como asesores, tanto en la planeación como en la ejecución de los programas específicos para los AMPL. Por este motivo, se propone la vinculación de personal especializado en el manejo de AM, pues el conocimiento que ofrecen los profesionales en gerontología o geriatría (tomadas a manera de ejemplo) puede orientar con mayor precisión las acciones por emprender con aquellos internos cuyas necesidades requieren atención especial.

En los planes de formación para los funcionarios del Inpec no se contemplan temas de AMPL como ejes de aprendizaje específicos, por cuanto no se considera una especialidad por aprender. Por esa razón, se deben incluir en los componentes temáticos de la formación del Cuerpo de Custodia y Vigilancia en la Escuela Penitenciaria capacitaciones en el manejo de esta población, sus necesidades específicas para el trato, tratamiento, atención médica y estrategias que pueden guiar algunas maneras adecuadas de acompañamiento en los procesos laborales, de formación y demás que se desarrollen durante su estadía en prisión. Estos procesos formativos deben hacerse extensivos al resto del personal de los establecimientos. Una segunda recomendación en ese sentido es llevar a cabo jornadas con los funcionarios que ya se encuentran en los establecimientos.

El hacinamiento actual unido a las condiciones precarias de atención en salud, alojamiento, alimentación, asesoría jurídica, atención y tratamiento penitenciario es la exigencia más clara de la necesidad de dar cumplimiento real a la normatividad nacional e internacional, y los efectos directos deben observarse inicialmente en el cumplimiento de las exigencias 
de higiene, adecuación al clima, particularmente en lo que concierne al volumen de aire, superficie mínima, alumbrado, calefacción y ventilación, entre otros. No se invita a que tengan privilegios para los AMPL, pero sí a que las estrategias que se implementen para atenderlos faciliten la infraestructura, la cual debe adaptarse a sus condiciones particulares.

Como lo menciona la División de Población de la Cepal (Celade, 2001): "Los Adultos Mayores, al igual que cualquier persona, puede mantener y desarrollar actividades sociales determinada por tres factores o variables: Condiciones de salud, situación económica y apoyo social recibido. Así, la edad por sí sola no debería impedir el desarrollo social, exceptuando que por circunstancias puntuales las variables mencionadas presenten un deterioro". Esta debería ser la premisa para la realización de programas, más aún cuando organismos como la Organización Panamericana de la Salud (OPS) plantean objetivos que deberían aplicar los países al promover la formulación de leyes, dirigidos a la atención de los AM en todos los componentes de la vida, pero asegurando que los planes y los programas cuenten con presupuestos para poderlos ejecutar (OPS, 2012). Para este organismo, "el desarrollo de conductas personales y ambientales saludables durante todo el ciclo de vida hasta llegar a un envejecimiento sano y activo, la prevención y manejo de enfermedades crónicas y otros padecimientos relacionados con la edad, así como el fortalecimiento y desarrollo de servicios de salud de calidad" deberían ser la prioridad de los países (OPS, 2012).

Colombia parecía haber dado prioridad a este temática al incorporar una Política Nacional de Envejecimiento y Vejez (2007-2019), donde diversos autores que se encuentran involucrados han realizado diversos análisis al respecto (Ministerio de Protección Social, 2007). Sin embargo, a la fecha se mantiene como una versión preliminar para análisis de involucrados en la gestión de la política, a pesar de que se había previsto que sería aprobada antes de finalizar el 2010. 


\section{Política criminal}

Todo tiene un tiempo y un límite en este mundo y en Colombia no se contemplan mecanismos que abrevien la reclusión del AM, aun con el amplio margen de configuración normativa con el que cuenta el aparato judicial, como manifestación de su competencia para fijar las políticas criminales del Estado. Sería importante reflexionar sobre la posibilidad de colocar límite máximo de edad para estar en un EPC, así como hay un límite mínimo para entrar, y se sugiere que se utilice para ese máximo el indicador de esperanza de vida en Colombia. Los AMPL que se encuentren por encima de ese límite deberán estar fuera del EPC, bien sea en un tipo diferente de reclusión o internamiento en unidades geriátricas urbanas o rurales, como existen para los menores; otorgar la libertad condicional por razón de la edad, aplicación de la condena de ejecución condicional considerando que no existe necesidad de ejecución de la pena por la mayor edad del condenado, dependiendo del comportamiento atribuido, prisión domiciliaria, indulto, libertad con control de mecanismos telemáticos. Estos ajustes tendrían como fin preservar la dignidad de la persona recluida, evitando que sus últimos días los pase en prisión o llegue a morir en ella, máxime cuando el AMPL tenga pronosticada una enfermedad grave o una muerte cierta e inminente.

\section{Atención y tratamiento}

La situación del interno no culmina con la imposición de la pena, sino que adicionalmente requiere del tratamiento pertinente para su resocialización, por lo que en primera instancia debe concientizarse sobre los derechos que vulneró, así como los derechos que le asisten al momento de empezar a purgar la pena y durante el tiempo que esta dure. Se pudo establecer que los AMPL carecen de una información apropiada al respecto, así como de la forma de acceder a beneficios. Los que conocen estos datos ha sido gracias a la información suministrada por otros internos o instituciones.

Se encontró relación entre los periodos de internamiento y diferentes niveles de afectación psicológica y cognitiva en los AMPL que participaron 
en la aplicación de instrumentos. Esto abre un abanico de necesidades en cuanto a intervenciones de manera diferencial con este grupo etario. No obstante, se hace necesario conocer a profundidad y en el total de la población de AMPL los cambios que se presentan a nivel psicológico, cognitivo y comportamental, en relación con los periodos considerados durante este estudio (internamiento inicial, intermedio, prolongado), para ofrecer actividades ocupacionales, educativas o de enseñanza acordes con lo dinámico del desarrollo humano, máxime cuando se enfrentan a situaciones límites como la privación de la libertad.

Las limitaciones físicas que imponen los deterioros de la edad no parecen afectar las capacidades intelectuales de los AMPL participantes, lo que muestra que la capacidad criminal en términos de planeación o adaptación para la comisión de actos delictivos se encuentra en el mismo nivel de un delincuente más joven. Por esto, los programas con AMPL deben definir claramente cuáles de las acciones corresponden a la prevención de la reincidencia y cuáles forman parte de aquellas que buscan disminuir los efectos negativos que vengan con la prisionización. Un punto de partida es llevar a cabo estudios con muestras representativas en las que se analicen y caractericen funciones cognitivas y condiciones psicológicas, a efecto de establecer una línea de base que indique la real disminución, el incremento o la incapacidad para el crimen, la peligrosidad y el pronóstico de reincidencia.

\section{Condiciones jurídicas}

Desde hace varios años Colombia ha implementado el inflacionismo penal, y a través del sistema penal acusatorio ha permitido la violación flagrante y vergonzosa de los derechos de las personas que ingresan a este. Un proceso penal, en vez de ser un asunto para la búsqueda de la verdad y la sanción oportuna o efectiva del delito, se ha convertido en un canje de inocencia por "mejores probabilidades de salir rápido". Un trueque de preacuerdos y silencios en los que el profesional del derecho no hace saber al cliente la razón o la naturaleza jurídica del delito ni la sanción que amerita, por cuanto este no es consciente del delito que se le imputa o los derechos que 
tiene. En el peor de los casos, termina justificando su comportamiento delictuoso, pues la sensación de pérdida de autoridad que acompaña estos procesos es reforzada con algunos jueces que han permitido la corrupción en los estrados. Profesionales del derecho han negociado con la verdad o la libertad y entes acusadores que se han ensañado en sus posturas sin aceptar errores cometidos.

¿Qué se puede derivar de un Estado en el que la autoridad no se respeta porque se ha perdido su razón de ser, unos organismos de defensa de los derechos que no lo hacen y una ley inaplicada o en ocasiones absurda? No es necesario un estudio científico para determinar que lo que hoy sucede es indiscutiblemente un efecto acumulativo de lo acontecido desde periodos atrás. En Colombia se castiga al inocente como al culpable y este último no se resocializa porque en este Estado la ley es burlada por quienes deberían defenderla, así como por los que la conocen y han aprendido a obstruirla; en medio de estas realidades, procura abrirse paso una verdad a gritos: "es tan justo castigar al delincuente como absolver al inocente".

Esa condición de incapacidad de los penados para demandar respeto, garantía y cumplimiento de derechos se acentúa en la mayoría de EPC, tanto por la falta de asesores legales privados o públicos como por ausencia de la Procuraduría. Ellos deben hacer el seguimiento a las penas que se están cumpliendo, a fin de solicitar las libertades o beneficios que se causen oportunamente. Contrario a esto, pareciera que se ha dado una trasmutación de la función de la prisión como estamento de resocialización a un sitio donde solo se recuerda la pena y se olvida al hombre que la habita y la sufre.

En este contexto, los AMPL son considerados como parte de un grupo vulnerable, por el hecho de ser una población sujeta a especial protección constitucional. Teniendo en cuenta que el Estado es el directo responsable de su protección, los convenios internacionales contienen unos derechos específicos en relación con la privación de la libertad de esta población. El Estado tiene la obligación de tratar a la población carcelaria en general de manera justa y digna bajo un esquema de igualdad, así como garantizar sus derechos ya que está aportando al proceso de reintegración de esta a la comunidad (Castro et al., 2010, pp. 19-288). El desafío del siglo XXI es mantener sistemas penitenciarios que se caractericen por la dignidad, efi- 
ciencia y respeto por los derechos fundamentales, por esta razón resulta de mayor importancia el diseño de nuevos modelos que propendan hacia la restructuración de la legislación en este sentido. Ejemplo de esto puede ser la implementación de normatividad especializada para AM y AMPL; aspecto que puede hacer posible el acceso efectivo a la justicia y asistencia jurídica que permita la concreción en el marco de sus derechos, a rebajas de pena, permisos, sustitución de la prisión intramural, libertad condicional, libertad definitiva, la salud, el trabajo, la familia, la educación y la resocialización.

\section{Condiciones de vida del adulto mayor privado de la libertad}

La privación de la libertad del AM, previa constatación de su caracterización, debe ser excepcional en un EPC donde se le respete su dignidad, que se ha de traducir en condiciones físicas aptas para su internamiento y servicios básicos en materia de salud, alimentación y ocupación. Sobre este último aspecto, sería necesario contar con una mayor disponibilidad de datos estructurados sobre la información de conocimientos y experiencias de los AMPL. Se debe potencializar el uso de las TIC para contar con datos que faciliten la toma de decisiones del sistema.

En aras de mejorar las condiciones de vida de los AMPL, pueden abordarse dos alternativas complementarias. La primera, que el tema se asuma de forma centralizada para generar así políticas institucionales que señalen parámetros generales a todos los EPC del país para el manejo de los grupos con condiciones excepcionales. La otra alternativa es permitir que desde cada uno de los EPC y de acuerdo con las condiciones locales de ubicación se genere una dinámica propia, estructurando programas de acción que atiendan a los AMPL, desde la lógica regional con el apoyo de recursos del orden nacional, departamental y municipal, considerando que cada EPC tiene particularidades y dinámicas que difieren en su interior y que involucran el entorno que los rodea. 


\section{Pospena}

Como ocurre con los pospenados en general, tampoco el AM cuenta con un programa de apoyo que facilite su inserción en la sociedad, una vez cumplida la pena. Considerando la condición del AM que fue ampliamente desarrollada en el texto, se considera fundamental implementar estrategias dirigidas al AM pospenado, como el acompañamiento de un grupo interdisciplinar de apoyo, la inclusión de estos sujetos a centros de vida; en los casos en los que no se cuenta con apoyo familiar o de otro tipo, identificar las instituciones que trabajan en este campo para consolidar una red de acogida y brindar alternativas de reubicación laboral. 


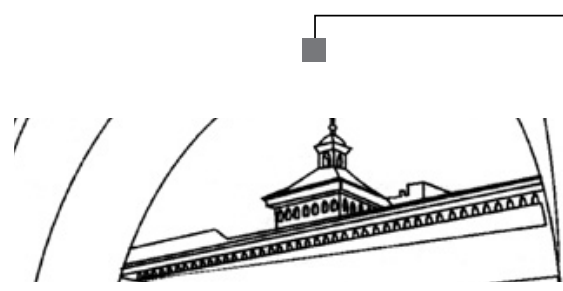




\section{Referencias}


Abaunza, C. I., Mendoza, M., Bustos, P., Enríquez, K. \& Paredes, G. (2011). Desarrollo del sistema penitenciario y carcelario colombiano entre 1995 y 2010, en el marco de las políticas de Estado a partir de las sentencias de la Corte Constitucional. Bogotá: Universidad del Rosario.

Abregú, T. L. (2009). Evolution of analogical reasoning in children: Follow-up from six to eleven years old. Avances en Psicología Latinoamericana, 27(1), 97-110.

Alba, V. (1992). Historia de la vejez. Barcelona: Laertes.

Álvarez, M., Mendoza, V., Rodríguez, M., Parra, S. \& Corzo, L. (2008). Semillas de cristal. Jóvenes y Sistema Penal para Adolescentes. (Ley 1098/2006): Alcance y diagnóstico de su primer año de funcionamiento. Colombia: Fundación Antonio Restrepo Barco.

Arango, V. \& Ruiz, I. (2001). Diagnóstico de los adultos mayores de Colombia. Población colombiana adulta mayor y subpoblaciones específicas. Colombia: Fundación Saldarriaga. Concha.

Arango, V. \& Ruiz, I. (2008). Secretaría de Planeación, Alcaldía de Bogotá. Recuperado el 24 de agosto de 2013 de http:/www.sdp.gov.co/portal/page/ portal/PortalSDP/SeguimientoPoliticas/Politicas\%20Poblacionales/ Envejecimiento\%20y\%20Vejez/Documentaci\%F2n/A31ACF931BA329B4E040080A6C0A5D1C

Arenas-Monsalve, G. (2007). El derecho colombiano de la seguridad social. Bogotá: Legis.

Arriagada Peñailillo, W. (2006). Red Latinoamericana de Gerontología. Recuperado el 4 de abril de 2013 de http://www.gerontologia.org/portal/archivosUpload/Derechos_Humanos_y_Politicas_de_Proteccion_Social_del_ Adulto_Mayor.pdf

Arrow, K. (1972). Models of job discimination. En A. Pascal, Racial discrimation in economic life. Lexington, Mass: Lexington Books.

Baltes, P. \& Strunder, U. (1996). Interactive minds: Lifes-pan perspectives on the social foundation of cognition. New York: Cambridge University Press.

Banco Mundial. (2013). El Banco Mundial. Recuperado el 19 de septiembre de 2013 de http://datos.bancomundial.org/indicador/SP.DYN.LE00.IN

Barreto, N. L. \& Sneider, R. (2009). Una mirada a la impunidad en el marco del Sistema Penal Oral Acusatorio en Colombia. Bogotá: Milla LTDA. 
Becerra, S., Torres, G. \& Ruiz, J. I. (2008). Longitudinal and comparative studie of psychosocial adaptation to prision environment. Anuario de Psicología Jurídica, 18, 61-72.

Becker, G. (1957). The economics of discrimination. Chicago: University of Chicago Press.

Berger, K. S. \& Thompson, R. A. (2009). Psicología del desarrollo. Adultez y vejez. Madrid: Editorial Médica Panamericana S. A.

Bergmann, B. R. (1974). Occupational segregation, wage and profits when employers discriminate by race and sex. Eastern Economic Journal, 1, 103-110.

Blau, F., Ferber, M. \& Winkler, A. (1998). The economist of women, men and work. New York: Prentice Hall.

Bliss, C. (1996). El estilo de vida y el estándar de vida. En A. Sen \& M. Nussbaum, La calidad de vida (pp. 534-557). México: Fondo de Cultura Económica. Bonilla, C., Hurtado, C. J. \& Jaramillo, C. (2009). La investigación: aproximaciones a la construcción del conocimiento científico. Bogotá: Alfaomega Colombia.

Bravo, A. \& Castrillón, M. D. (2010). Vulnerabilidad en sujetos en situación de prisión domiciliaria en el Distrito Federal, Brasil. Psicología desde el Caribe, $15,108-127$.

Briceño-Donn, M. (2006). Mujeres y prisión en Colombia: análisis desde una perspectiva de derechos humanos y género. Bogotá: Fondo de Desarrollo de las Naciones Unidas para la Mujer (Unifem).

Canada, K., Engstrom, M. \& Jang, E. (2013). Psychosocial and reincarceration risks among older adults in mental health courts. American Journal of Geriatric Psychiatry, 22(8), 845-849.

Casas, A., Cortés, D. \& Gamboa, L. F. (2001). Desarrollo, bienestar y comparaciones interpersonales. En F. D. Rosario, Borrador de Investigación n. ${ }^{\circ} 14$. Bogotá: Centro Editorial Rosarista.

Castro, Á., Cillero, M., \& Mera, J. (2010). Derechos fundamentales de los privados de la libertad. Guía práctica con los estándares internacionales en la materia. Santiago de Chile: Universidad Diego Portales.

Castro, M. E., López-Castedo, A. \& Sueiro, E. (junio de 2009). Sintomatología asociada a agresores sexuales en prisión. Anales de psicología, 25 (1), 44-51.

Centro Latinoamericano y Caribeño de Demografía (Celade). (2001). Acercamiento conceptual a la situación del adulto mayor en América Latina. En P. Araníbar, Serie Población y Desarrollo (vol. 21, p. 70). Santiago de Chile: Publicación de las Naciones Unidas. 
Centro Latinamericano y Caribeño de Demografía (Celade). (2010). Separata. Boletín de envejecimiento. En Cepal, El envejecimiento y las personas de edad. Indicadores para América Latina y el Caribe (p. 4). New York: Naciones Unidas.

Christie, N. (1984). Los límites del dolor. México D. F:: Fondo de Cultura Económica.

Ciprián-Carvajal, C. M. (2011). Principio de progresividad en la pensión de vejez del régimen de prima media. Bogotá: Universidad Libre. Facultad de Derecho.

Comisión Económica para América Latina (Cepal). (2009). Envejecimiento, derechos humanos y políticas públicas. Santiago de Chile: autor.

Comisión Económica para América Latina y el Caribe (Cepal). (junio de 2011). En S. Huenchuan (Ed.), Los derechos de las personas mayores. Recuperado en septiembre de 2013 de http://www.cepal.org/celade/envejecimiento/

Comisión Interamericana de Derechos Humanos. (2011). Informe sobre los derechos humanos de las personas privadas de la libertad en las Américas. Organización de Estados Americanos.

Conferencia Internacional Americana. (1948). Declaración americana de los derechos y deberes del hombre. Bogotá: autor.

Congreso de Colombia. (25 de septiembre de 1975). Ley 29 de 1975, por la cual se faculta al Gobierno Nacional para establecer la protección a la ancianidad y se crea el Fondo Nacional de la Ancianidad desprotegida. Diario Oficial n. ${ }^{\circ} 34.420$.

Congreso de Colombia. (23 de septiembre de 1986). Ley 48 de 1986, por la cual se autoriza la emisión de una estampilla proconstrucción, dotación y funcionamiento de los centros de bienestar del anciano, se establece su destinación y se dictan otras disposiciones. Diario Oficial n. 37.644 .

Congreso de Colombia. (22 de enero de 1991). Ley 12 de 1991, por medio de la cual se aprueba la Convención sobre los Derechos Del Niño adoptada por la Asamblea General de las Naciones Unidas el 20 de noviembre de 1989.

Congreso de Colombia. (19 de agosto de 1993). secretariasenado.gov.co. Recuperado el 11 de diciembre de 2013 de http://www.secretariasenado.gov. co/senado/basedoc/ley/1993/ley_0065_1993.html

Congreso de Colombia. (27 de noviembre de 2008). Ley 1251 de 2008, por la cual se dictan normas tendientes a procurar la protección, promoción y defensa de los derechos de los adultos mayores. 
Congreso de Colombia. (2009). Ley 1276 de 2009, a través de la cual se modifica la Ley 687 del 15 de agosto de 2001 y se establecen nuevos criterios de atención integral del adulto mayor en los centros vida.

Congreso de Colombia. (20 de enero de 2014). Ley 1709 de 2014, por la que se reforman algunos artículos de la Ley 65 de 1993, de la Ley 599 de 2000, de la Ley 55 de 1985 y se dictan otras disposiciones

Consejo de Estado. (24 de junio de 1998). Sala de Lo Contencioso Administrativo, Sección Tercera. Consejero ponente: Ricardo Hoyos Duque, Bogotá, D. C. Radicación número: 10.530. Actor: Mirelda Acosta Vásquez y otras. Demandado: nación-Ministerio de Defensa.

Consejo de Estado 2002. (24 de junio de 1998). Sala de lo Contencioso Administrativo, Sección Tercera, Bogotá, D. C. Consejero ponente: Ricardo Hoyos Duque. Radicación número: 10530. Actor: Mirelda Acosta Vásquez y otras. Demandado: nación-Ministerio de Defensa.

Consejo de Estado. (2002). Sentencia del 27 de noviembre de 2002. Exp. 13760. Consejo de Estado. (23 de abril de 2008). Sala de lo Contencioso Administrativo, Sección Tercera, Bogotá, D. C. Consejero ponente: Mauricio Fajardo Gómez

Corte Constitucional. (1992). Sentencia T-596.

Corte Constitucional. (1998). Sentencia T-153.

Corte Constitucional. (2002). Sentencia C-491.

Corte Constitucional. (2010). Sentencia T-138.

Corte Constitucional. (2011). Sentencia T-559.

Cristófalo, V. J. (1991). Special focus on the biology aging. New York: Springer Publishing Company.

Defensoría del Pueblo de la República de Colombia. (s. f.). Observatorio de justicia constitucional-Defensoría del Pueblo de Colombia-protección constitucional y derechos fundamentales de las personas mayores. Recuperado el 25 de marzo de 2013 de http://www.defensoria.org.co/ojc/pdf.php/4

Departamento Administrativo Nacional de Estadística (DANE). (21 de noviembre de 2012). Boletín de Prensa-Género 2011. Recuperado el 27 de enero de 2014 de http://www.dane.gov.co/files/investigaciones/boletines/especiales/genero/bol_genero_2011.pdf

Derogatis, L. (2002). SCL-90-R Manual. Madrid: TEA Ediciones.

Destéfano, M. (2012). Pensamiento y lenguaje en el marco de la ciencia cognitiva. Revista Argentina de Ciencias del Comportamiento, 4(1), 56-67. 
Dixon, A. R., McFall, P., Witehead, B. \& Dolcos, S. (2013). Cognitive development in adulthood and aging. En W. I., M. J., E. A., \& L. R., Handbook of psychology (vol. 6, pp. 418-474). New Jersey: John Wiley \& Sons, Inc.

Dixon, R., Small, B., MacDonald, S. \& McArdle, J. (2012). Yes, memory declines with aging-but when, how, and why? En N. Naveh-Benjamin \& N. O., Memory and aging. New York: Psychology Press.

Dueñas, O. (2011). Derechos humanos y políticas públicas para el adulto mayor: situación en Colombia y referencias iberoamericanas Colombia, España, Ecuador, Cuba, Costa Rica, Uruguay. Bogotá: Universidad del Rosario.

Eduforma. (2012). Recuperado el 14 de septiembre de 2013 de www.mad.es

El Tiempo. (9 de septiembre de 2013). Recuperado el 20 de septiembre de 2013 de http://www.eltiempo.com/Multimedia/galeria_fotos/justicia/GALERIAFOTOS-WEB-PLANTILLA_GALERIA_FOTOS-12586021. html

Ericsson, K. A. \& Hastie, R. (1994). Contemporary approaches to the study of Thinking and Problem Solving. En R. J. Sternberg, Thinking and Problem Solving (pp. 37-80). New York: Academic Press.

Escamilla, J. C. C. (2004). Algunas reflexiones con respecto a la relación entre el principio de solidaridad constitucional y los delitos de omisión. Universitas, 108, 603-625.

Etchepareborda, M. \& Abad-Mas, L. (2005). Working memory in basic learning processes. Neurol, 40 (1), 79-83.

Ferralloli, L. (1997). Derecho y razón, teoría del garantismo penal. España: Trotta Ltda.

Flores, L. J. \& Ostrosky, S. F. (2008). Neuropsicología de lóbulos frontales, funciones ejecutivas y conducta humana. Revista Neuropsicología, Neuropsiquiatría y Neurociencias, 22(2), 47-58.

Foucault, M. (2000). Los anormales. Buenos Aires: Fondo de Cultura Económica. Gainzo Vicente, F. N. (2009). Geroinfo. Publicación de Gerontología y Geriatría. Recuperado el 4 de abril de 2013 de http:/www.sld.cu/galerias/pdf/sitios/ gericuba/jubilacion_fermin_nivardo_.pdf

Gamboa, L. F., Cortés, D. \& González, J. (2000). Consideraciones analíticas sobre el estándar de vida. Revista de Economía, $3(2)$.

Garrido, V., Stangeland, P. \& Redondo, S. (2001). Principios de criminología. Valencia: Tirant lo Blanch. 
Gasca Mata, E., Fonseca Hernández, C. \& Contreras Landgrave, G. (2012). Derechos humanos en personas de la tercera edad, desde una perspectiva de género. Revista Digital Universitaria, 13(3).

Gil, C. F. (2010). La acción pedagógica en las prisiones. Posibilidades y límites. Revista Española de Pedagogía, 25, 49-64.

Goffman, E. (2001). Internados. Ensayos sobre la situación social de los enfermos mentales. Buenos Aires: Amorrortu Editores.

Goffman, E. (2006). Estigma, la identidad deteriorada. Buenos Aires: Amorrortu Editores.

Herlitz, A. \& Rehnman, J. (2008). Sex differences in episodic memory. Current Directions in Psychological Science (Wiley-Blackwell), 17(1), 52-56.

Huenchuan, S. (2010). Envejecimiento y género: acercamiento a la situación de las mujeres mayores en América Latina y las recomendaciones internacionales en el tema. En Nieve-Unfpa, Envejecimiento, género y políticas públicas. Coloquio Regional de Expertos. Montevideo: Lucida Ediciones.

Ibáñez, J.-E. R. (1979). Perspectiva sociológica de la vejez. REIS, 7, 77-97.

Instituto Nacional Penitenciario y Carcelario (Inpec). (23 de noviembre de 2005).

Resolución 7302 de 2005. Recuperado el 16 de diciembre de 2013 de http://www.google.com.co/url?sa $=\mathrm{t} \& \mathrm{rct}=\mathrm{j} \& \mathrm{q}=$ \&esrc $=\mathrm{s} \& \operatorname{source}=\mathrm{w}$ eb\&cd =1\&ved=0CCkQFjAA\&url=http\%3A\%2F\%2Fwww.inpec. gov.co\%2Fportal\%2Fpage\%2Fportal\%2FInpec\%2FServiciosDeInfor macionAlCiudadano\%2FConvocatorias\%2FRESOLUCI\%25D3N\% 25207302\%2520DE\%25202005.doc\&ei=KOzOUoq

Instituto Nacional Penitenciario y Carcelario (Inpec). (2012). Pautas Programas Grupo Desarrollo Humano (p. 31). Recuperado el 6 de marzo de 2013 de http://www.inpec.gov.co/portal/page/portal/Inpec/SeccionDerechosHumanosResocializacion/ReinsercionSocial/PROGRAMASGDESARROLLOHUMANO.pdf

Instituto Nacional Penitenciario y Carcelario (Inpec). (2013a). Informe estadístico de julio de 2013. Recuperado de http:/www.inpec.gov.co/portal/page/ portal/Inpec/Institucion/Estad\%EDsticas/Informes\%20y\%20Boletines\%20Estad\%EDsticos

Instituto Nacional Penitenciario y Carcelario (Inpec). (26 de julio de 2013b). Informe estadístico de julio de 2013. Recuperado el 3 de septiembre de 2013 de http://www.inpec.gov.co/portal/page/portal/Inpec/Institucion/ Estad\%EDsticas/Informes\%20y\%20Boletines\%20Estad\%EDsticos 
Instituto Nacional Penitenciario y Carcelario (Inpec). (16 de enero de 2014). Informe estadístico de diciembre. Recuperado el 24 de enero de 2014 de http://www.inpec.gov.co/portal/page/portal/Inpec/Institucion/ Estad\%EDsticas/Informes\%20y\%20Boletines\%20Estad\%EDsticos

Instituto Nacional Penitenciario y Carcelario (Inpec) \& Ministerio del Interior y de Justicia. (24 de octubre de 2011). Caracterización y perfilación criminológica y penitenciaria de la población condenada y privada de la libertad en los establecimientos de reclusión del INPEC y propuesta para el direccionamiento del tratamiento penitenciario en Colombia. Recuperado el 5 de abril de 2013 de http://www.inpec.gov.co/portal/pls/portal/!PORTAL. wwpob_page.show?_docname $=2893094 . \mathrm{PDF}$

Jakobs, G. (1995). Derecho Penal parte general, fundamentos y teoría de la imputación. Madrid: Marcial Pons.

La Vanguardia. (2013). Abadia Aljarafe. Nuestro mundo. Recuperado el 19 de marzo de 2013 de http://ooche813.blogspot.com/2011/01/roban-parair-la-carcel-y-huir-de-una.html

Limón, L. M. (2005). Formación de conceptos y cambio conceptual. En C. F. Gabucio, Psicología del pensamiento (pp. 52-90). Barcelona: Editorial UOC.

Londoño, P. O. \& Chaparro, B. P. (2011). Condiciones de hábitat y percepción de los estados de salud. Conceptos categoriales emergentes. Hacia la Promoción de la Salud, 16(2), 13-31.

López, P. A., Calero, M. D. \& Navarro, G. H. (2013). Predicción del deterioro cognitivo en ancianos mediante el análisis del rendimiento en fluidez verbal y atención sostenida. Revista Neurol, 56, 1-7.

Lopuzzo, N. (1 de junio de 2002). Espacio logopédico. Recuperado el 23 de septiembre de 2013 de http://www.espaciologopedico.com/articulos/articulos2. php?Id_articulo $=215$

Mandela, N. (2010). El largo camino hacia la libertad. Madrid: Aguilar.

Marshall, F. R. (1974). The economics of racial discrimation: A survey. Journal of Economic Literature, 12.

Martínez, M., Morgante, M. \& Remorini, C. (2008). ¿Por qué los viejos? Reflexiones desde una etnografía de la vejez. Revista Argentina de Sociología, 6(10), 69-90.

Ministerio de Salud y Protección Social. (2008). Diagnóstico preliminar sobre personas mayores, dependencia y servicios sociales en Colombia. Recuperado el 27 de enero de 2014 de http://www.minsalud.gov.co/proteccionso- 
cial/Documents/Situacion\%20Actual\%20de\%20las\%20Personas\%20 adultas\%20mayores.pdf

Ministerio del Interior del Gobierno de España, Secretaría General de Instituciones Penitenciarias. (s. f.). Análisis de la ancianidad en el medio penitenciario. Recuperado el 24 de abril de 2013 de http://www.interior.gob.es/ file/53/53011/53011.pdf

Mojica, C. A., Sáenz, D. A. \& Rey-Anacona, C. A. (2009). Riesgo suicida, desesperanza y depresión en internos de un establecimiento carcelario colombiano. Revista Colombiana de Psiquiatría, 38(4), 681-692.

Mora, M., Villalobos, D., Araya, G. \& Ozols, A. (2004). Perspectiva subjetiva de la calidad de vida del adulto mayor, diferencias ligadas al género y a la práctica de la actividad físico recreativa. Revista MHSalud®. Recuperado el 15 de agosto de 2013 de http://www.lubrano.com/glosario/index.html Moreno, J. (2004). Mayores y calidad de vida. Portularia, 4, 187-198.

Moulin, C., Naveh-Benjamín, M. \& Souchay, C. (2010). Episodic memory and healthy aging. Applied Cognitive Psichology, 1196-1198.

Oficina del Alto Comisionado de las Naciones Unidas para los Derechos Humanos (OACDH). (1996). Recuperado el 24 de septiembre de 2013 de http:// www2.ohchr.org/spanish/law/tortura.htm

Oficina del Alto Comisionado de las Naciones Unidas para los Derechos Humanos (OACDH) (1996-2012). Reglas mínimas para el tratamiento de los reclusos. Recuperado el 24 de septiembre de 2013 de http://www2.ohchr.org/ spanish/law/reclusos.htm

Oficina del Alto Comisionado de las Naciones Unidas para los Derechos Humanos (OACDH). (2002). Compilación de Instrumentos Internacionales (3ํㅡㄹ ed.). Bogotá: Nuevas Ediciones Limitada.

Olmos, C. Y. (2009). Análisis de la ancianidad en el medio penitenciario. Madrid: Ministerio del Interior.

Organización de las Naciones Unidas (ONU). (1976). Pacto Internacional de los Derechos Civiles y Políticos. Autor.

Organización de las Naciones Unidas (ONU). (1991). Principios de las Naciones Unidas en favor de las personas de edad. ONU.

Organización de las Naciones Unidas (ONU), Comisión Económica para América Latina y el Caribe (Cepal), United Nations Population Fund (Unfpa) \& Agencia Sueca de Desarrollo Internacional (ASDI). (2011). Los derechos de las personas mayores. ONU. 
Organización de los Estados Americanos (OEA). (1 de enero de 2013). Recuperado el 23 de septiembre de 2013 de http://www.oas.org/dsp/observatorio/ database/indicatorsdetails.aspx?lang $=$ es\&indicator $=53$

Organización Mundial de la Salud (OMS). (s. f.). Informe mundial sobre la discapacidad. Recuperado el 23 de enero de 2014 de http://www.who.int/ disabilities/world_report/2011/es/

Ortiz, A. J. \& Castro, S. M. (2009). The psychological well-being of the elderly and their relation with self-esteem and self-efficiency. Nursing contribution. Ciencia y Enfermería, XV, 25-91.

Ossa López, M. F. (2012). Recuperado el 6 de septiembre de 2013 de http://www. unaula.edu.co/sistes/default/files/APROXIMACIONES\%20CONCEPTUALES.pc

Ostrosky, S. F., Ardila, A. \& Rosselli, M. (2010). Neuropsi, evaluación neuropsicológica breve en español. México D. F.: Manual Moderno.

Park, D. \& Reuter-Lorenz, P. (2009). The adaptive brain: Aging and neurocognitive scaffolding. Annual Review of Psychology, 60, 173-196.

Pérez Ortiz, L. (1997). Las necesidades de las personas mayores. Vejez, economía y sociedad. Madrid, España: Inserso.

Phelps, E. (septiembre de 1973). The statistical theory of racism and sexism. American Economic Review, 4, 659-661.

Portellano, J. A. (2005). Introducción a la neuropsicología. Madrid: McGraw-Hill, Interamericana de España, S. A. U.

Profamilia. (julio de 2010). Encuesta nacional de demografía y salud. Recuperado el 24 de agosto de 2013 de http://www.profamilia.org.co/encuestas/ Profamilia/Profamilia/images/stories/PDF-capitulos/Capitulo-17.pdf

Pulido, C. F., Rodríguez, L. J., \& Colorado, M. M. (2009). Factores sociodemográficos asociados con los sintomas depresivos en una muestra de mujeres recluidas en dos prisiones de México. Revista Panamericana de Salud Pública, 26(3), 209.

Rawls, J. (s. f.). Teoría de la justicia. México: Lito Ediciones Olimpia.

Real Academia Española (RAE). (2001). Diccionario de la Lengua Española. Madrid, España: Espasa Libros, S. L. U.

Real Academia Española (RAE). (4 de abril de 2013). Recuperado el 19 de marzo de 2013 de http://lema.rae.es/drae/?val=concepccion

Redondo, I. S. \& Pueyo, A. A. (2007). La psicología de la delincuencia. Papeles del Psicólogo, 28(3). 147-156. 
Revista Semana. (1 de febrero de 2014). La "bomba” carcelaria explotó. Recuperado el 6 de febrero de 2014 de http:/www.semana.com/nacion/articulo/ crisis-carcelaria-una-bomba-de-tiempo-que-exploto/375789-3

Robison, J. (1965). The economics of imperfect competition. New York: Martin's Press.

Rodríguez-Ibañez, J. E. (1979). Perspectiva sociológica de la vejez. Revista Española de Investigaciones Sociológicas (REIS), 7, 77-97.

Rodríguez Zepeda, J. (2006). Un marco teórico para la discriminación. México D. F.: Consejo Nacional para Prevenir la Discriminación.

Roxin, C. (2000). Política criminal y sistema del derecho penal. Buenos Aires: Hammurabi.

Ruiz, J. I. (2007). Síntomas psicológicos, clima emocional, cultura y factores psicosociales en el medio penitenciario. Revista Latinoamericana de Psicología, 39(3), 547-561.

Ruiz-Orjuela, W. (2010). Responsabilidad del Estado y sus regímenes. Bogotá: Ecoe Ediciones.

Saenz, R. M. (2007). El discurso resocializador. Hacia una nueva propuesta para el sistema penitenciario. Revista Ciencias Sociales, 115, 125-136.

Sánchez, G. I. \& Pérez, M. V. (abril de 2008). El funcionamiento cognitivo en la vejez: atención y percepción en el adulto mayor. Revista Cubana de Medicina General Integral, 24(2), 0-0.

Serge Jiménez, C. H. (2007). La cultura jurídica externa, cómplice de la falla en la resocialización del condenado. Jornada de Derecho Penal, Santa Marta, Colombia.

Schumpeter, J. (1994). Historia del análisis económico. Madrid: Ariel.

Seabright, P. (1996). El pluralismo y el estándar de vida. En A. Sen \& M. Nussbaum, La calidad de vida (pp. 504-524). México: Fondo de Cultura Económica.

Sebastián, L. D. (2000). De la esclavitud a los derechos humanos. Barcelona: Ariel. Sen, A. (1998). The concept of development. Handbook of Development Economics, $1,15$.

Senado de la República de Colombia. (24 de julio de 2000). Código Penal. Diario oficial número 44.097.

Sentencia del Tribunal Constitucional. (Sección tercera, 24 de junio de 1998). Sentencia, EXP. 10530.

Sentencia, EXP. 16186 (Sección Tercera 23 de abril de 2008).

Sentencia T-138, 138 (2010). 
Serrano, M. A. (2011). El problema de las contingencias en la teoría del autocontrol. Madrid: Dykinson.

Subdirección de Reinserción Social-Instituto Nacional Penitenciario y Carcelario (Inpec). (2012). Pautas Programas Grupo de Desarrollo Humano. Bogotá: autor.

Thurow, L. C. (1975). Generating inequality. New York: Basic Books.

United Nations, Department of Economic and Social Affairs, Population Division. (2013). World population prospects: The 2012 revision, key findings and advance tables. Recuperado el 12 de febrero de 2014 de http://esa.un.org/ wpp/Documentation/pdf/WPP2012_\%20KEY\%20FINDINGS.pdf

Universidad Libre. (s. f.). La tercera edad un sujeto de derechos. Recuperado el 2013 de http://www.unilibrebaq.edu.co/unilibrebaq-test/pdhulbq/html/capitulo3.html

Universidad Nacional de Colombia-Instituto Nacional Penitenciario y Carcelario (Inpec). (diciembre de 2008). Recuperado el 17 de diciembre de 2013 de http://extension.upbbga.edu.co/web2/pagina2/archivos/DIAGNOSTICO.pdf

Velásquez, E. D. (2009). Reflexiones epistemológicas para una sociología de la discapacidad. Intersticios. Revista Sociológica de Pensamiento Crítico, $3(2), 85-99$.

Verdejo, G. A. \& Bechara, A. (2010). Neuropsicología de las funciones ejecutivas. Psichothema, 22(2), 227-235.

Williams, B., Goodwin, J. S., Baillargeon, J., Ahalt, C. \& Walter, L. C. (2012). Addressing the aging crisis in U.S. criminal justice health care. Journal of the American Geriatrics Society, 60(6), 1150-1156. 


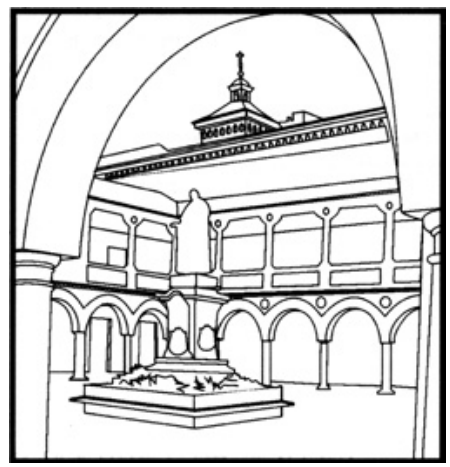

Este libro fue compuesto en caracteres Goudy Old Style 12

Fue impreso sobre papel bond de 70 gramos y encuadernado con método Hot Melt

Bogotá, Colombia

Octubre de 2014 